\title{
Retaining the knowledge of older experts in an organisational context and the role of ICT
}

By

Carmel Joe

A thesis submitted to

Victoria University of Wellington

in fulfilment of the requirements for the degree of

Doctor of Philosophy in Information Systems

VICTORIA UNIVERSITY OF WELLINGTON

2010 



\section{Abstract}

The oldest members of the post-World War 2 baby boomer generation — born between 1945 and 1963 - are soon nearing retirement, reducing or reviewing the extent of their participation in the workforce in the future. This has significant implications, especially for organisations relying on knowledge workers' expertise and experience, as within this cohort resides knowledge that is valuable to organisations. In New Zealand, the problem is twofold. First, Generation X — born between 1964 and 1981 — is numerically only $75 \%$ of the size of the baby boomer cohort. The workforce as a whole is predicted to grow at a slower rate after 2016 than it has between 1991 and 2006. Second, organisations will lose valuable knowledge if they do not act to remedy the potential impacts of this demographic phenomenon. The research topic is relevant at a time when few organisations have given serious consideration to the loss of expertise.

There is extensive literature on the baby boomer generation, and on the information and communications technologies that exist to support knowledge-related activities such as capture and storage, facilitating access, and sharing and dissemination. However, less specific information was found on the infrastructure or processes for successfully retaining the knowledge of older experts. Do organisations know who the experts are and how their expertise may be retained? This action research study using qualitative methods explores how two organisations define the types of knowledge they will lose when experts leave. An in-depth study of one organisation's infrastructure and processes for retaining the knowledge of a specific expert in a key business setting, reveals that his expertise was valued but less understood.

The study identified similarities between some characteristics of the expert's expertise and elements of wisdom. The findings are presented with reference to an existing research framework pertaining to wisdom as a type of expert knowledge. The framework was adaptable as a representation of the older expert's knowledge, and could also be related to the organisation's knowledge retention process. The study's contribution is a model that integrates knowledge retention with the knowledge framework of an older expert. This research study complements a rise in practitioner efforts to address knowledge loss concerns overseas — by extending our understanding of the nature of the knowledge that organisations value, how this knowledge can be retained, and how ICT can support the knowledge retention imperative. 


\section{Acknowledgements}

Completing my $\mathrm{PhD}$ has been one of my life's biggest goals and greatest challenges. It has not been achieved by my efforts alone - many professionals, experts, colleagues, family and friends have accompanied me on this journey.

Thank you to Professor Pak Yoong for your indefatigable support and encouragement and for your creative ideas and enthusiasm for my research topic. Dr Brian Harmer, I am grateful for your logical, sense-making approach and for challenging me in different ways in the quest for quality. I acknowledge the support of staff from the School of Information Management, who were always positive and available to give help.

None of this would have been possible without the belief that mine was a topic worthy of study, and without the commitment of the study sponsors and numerous participants, who remain anonymous. You welcomed me and helped me to understand important and sometimes complex aspects of your organisations, and read numerous draft reports and chapters. Thanks for giving your time and your opinions so generously despite the demands of your busy roles. Your openness, honesty and candid approaches led me to a finer appreciation of your organisations' cultures.

My fellow travellers provided much help along the way. Members of the PhD learning group shared ideas and provided encouragement: Pak, Allan, Janet, Jocelyn, Julie, Kate, Maria and Silke. Sally, Lanthom and Nishanie: thanks for your company and support as we lived through our various challenges and milestones. My clients, colleagues and friends put up with my absences and multi-tasking during my part-time years — thanks for your polite inquiries about progress and for keeping me connected. Thanks to Sparky and Tinks for your companionship.

To my husband Steve: I am especially grateful for your patience, perseverance and for taking care of things when I needed time and space. Thanks for your encouragement every day, the companionship in the years we studied together and for the commitment to life-long learning.

\section{Dedication}

This thesis is dedicated to my late parents Norman and Deborah, for their encouragement and sacrifices from the beginning. 


\section{Table of contents}

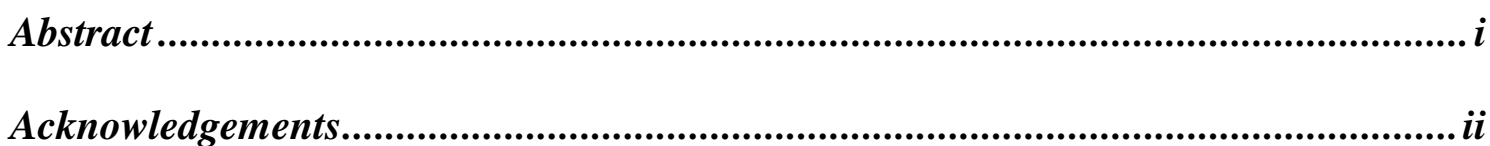

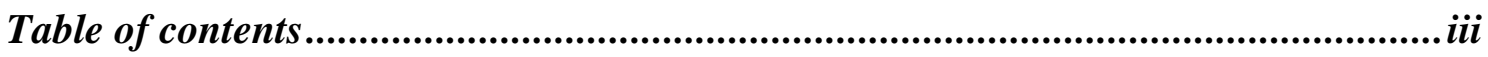

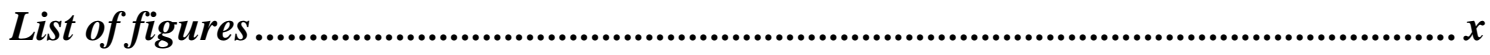

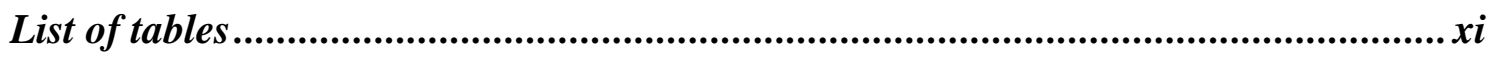

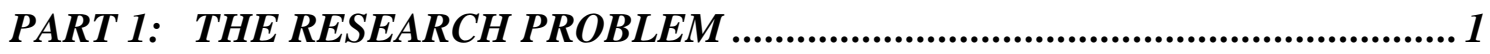

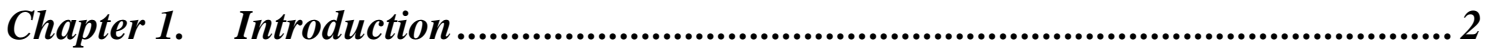

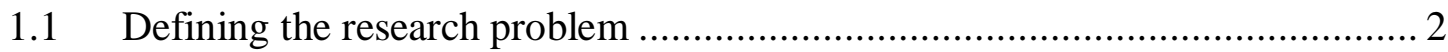

1.2 The research topic and research questions ............................................ 4

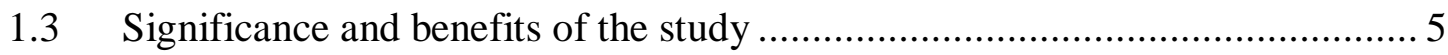

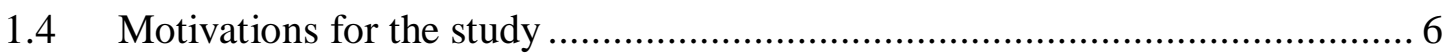

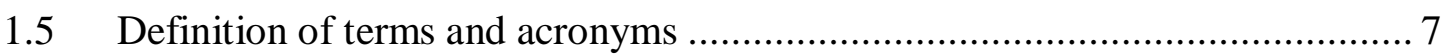

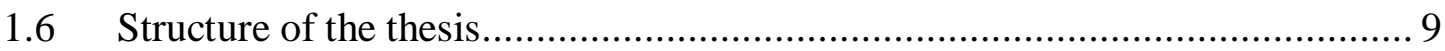

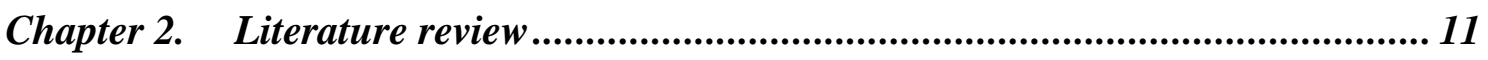

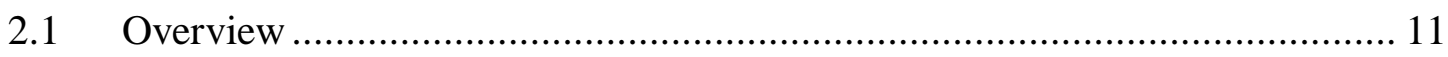

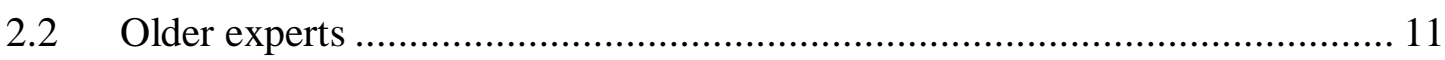

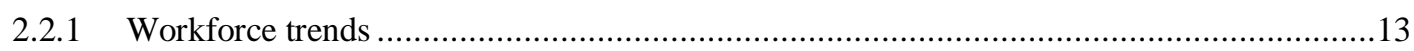

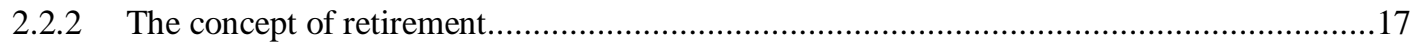

2.2.3 The experience and knowledge of older experts ........................................................18

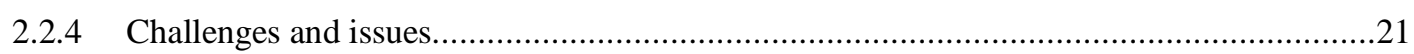

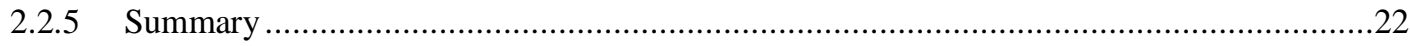

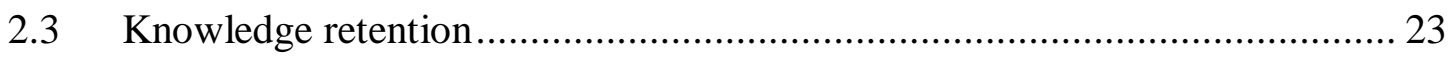

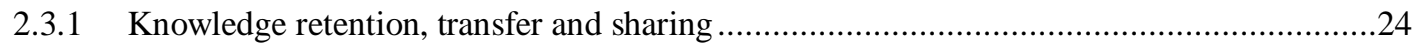

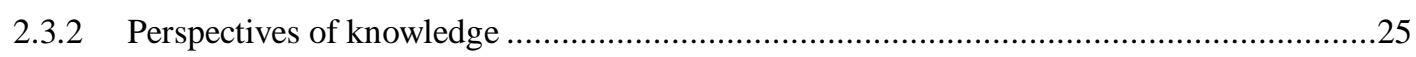

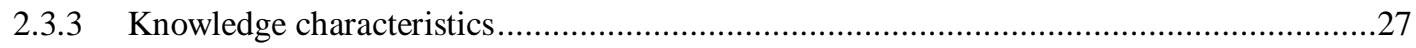

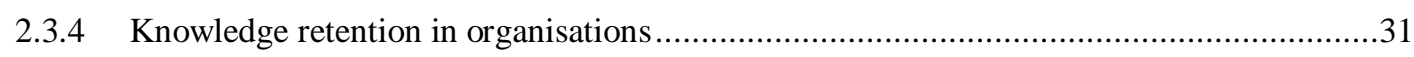

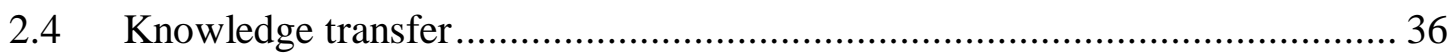

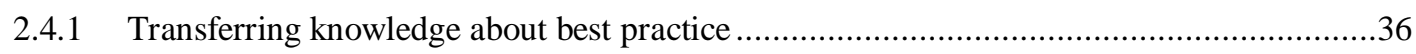

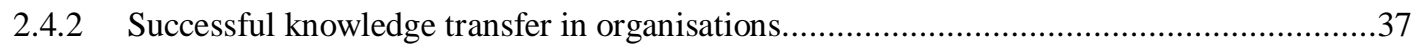

2.4.3 Inhibitors, issues and challenges in knowledge transfer ................................................ 
2.5 Retaining expertise from older experts .............................................. 45

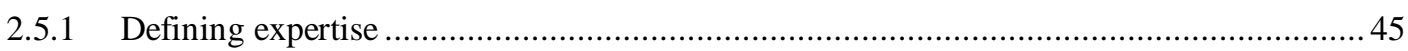

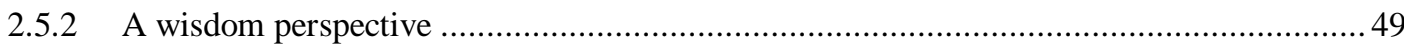

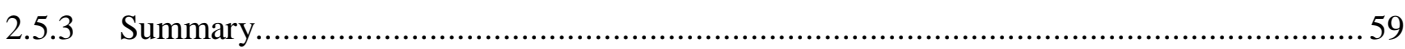

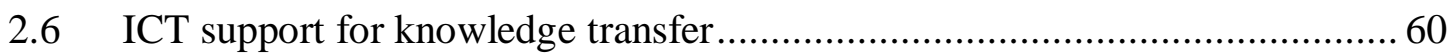

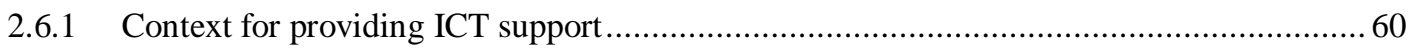

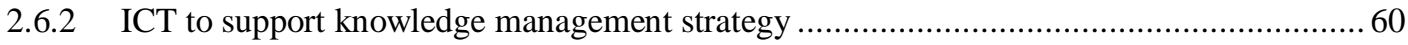

2.6.3 ICT to support knowledge transfer objectives and activities........................................... 61

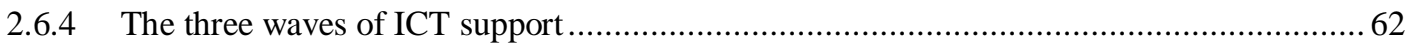

2.6.5 Types of information systems that support knowledge transfer .........................................67

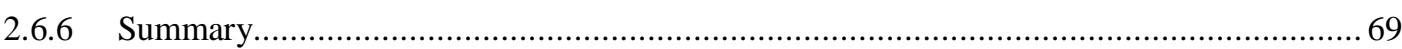

2.7 Gaps in knowledge addressed by research question ..................................69

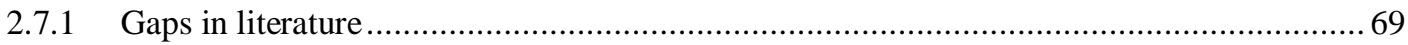

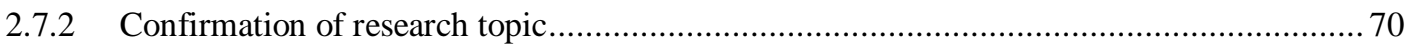

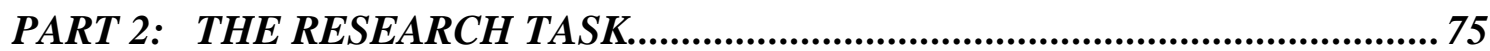

Chapter 3. Research methodology ................................................................. 76

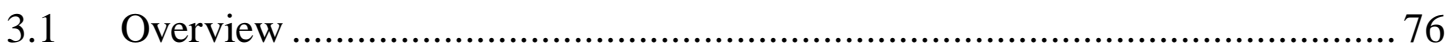

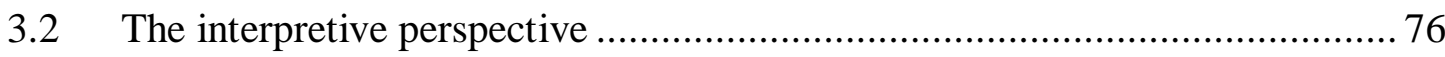

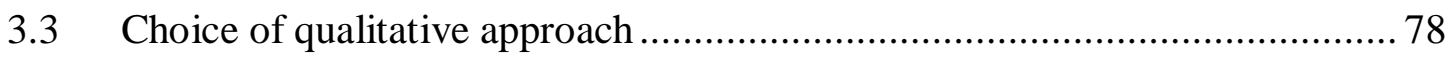

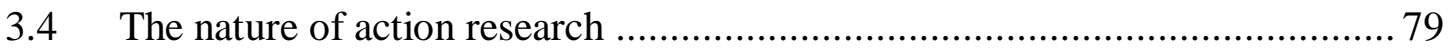

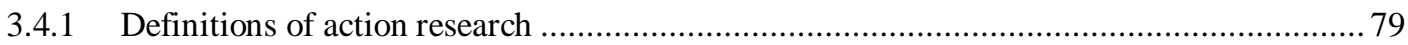

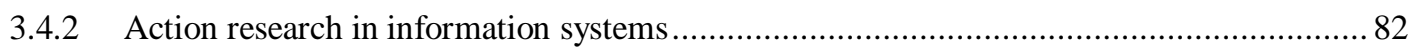

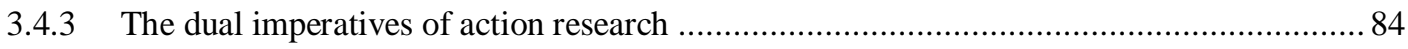

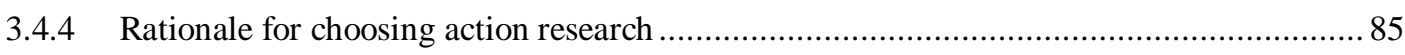

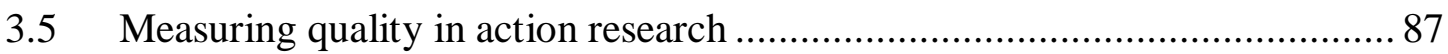

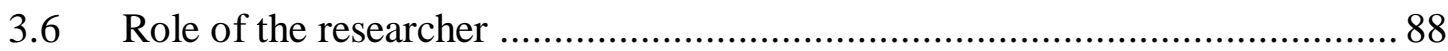

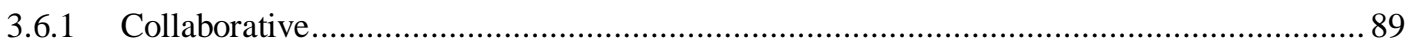

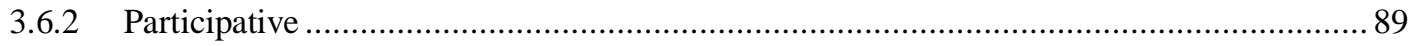

3.6.3 Researcher skills and competencies.......................................................................... 90

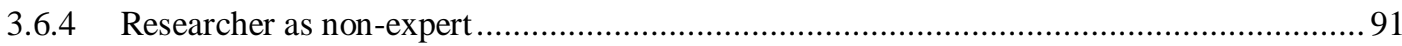

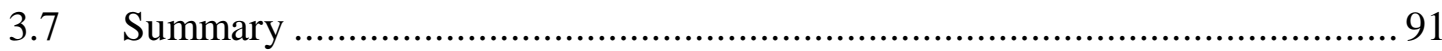

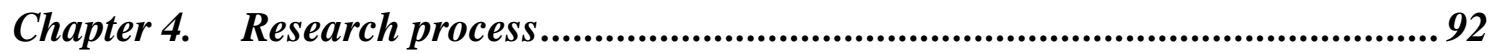

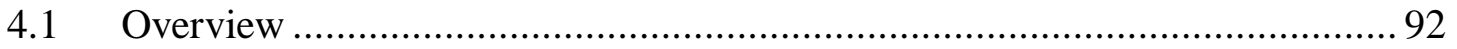




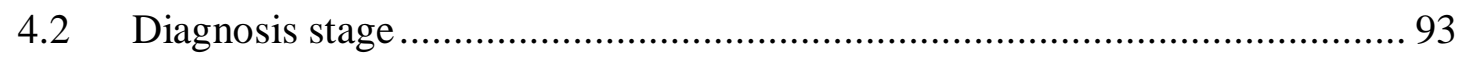

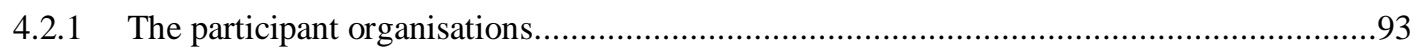

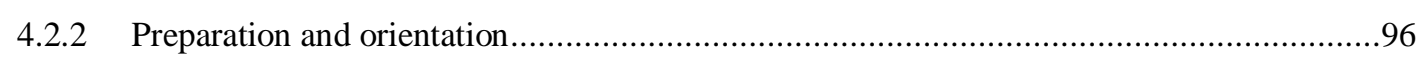

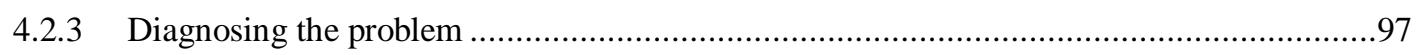

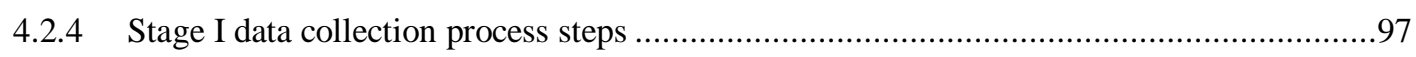

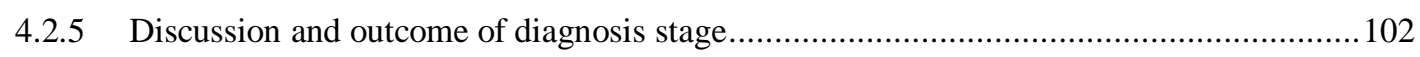

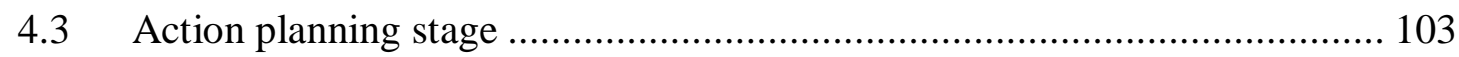

4.3.1 Organisation A — knowledge management programme................................................103

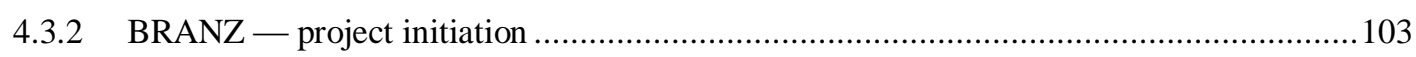

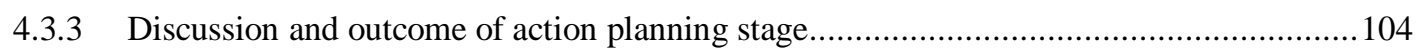

4.4 Implementation — action taking stage ............................................... 106

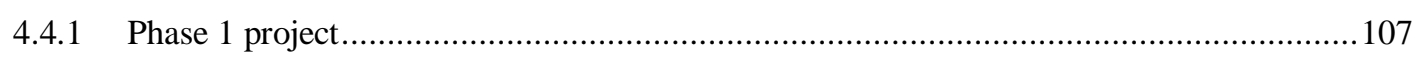

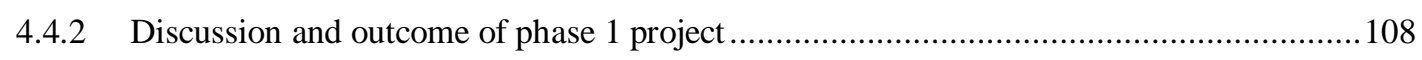

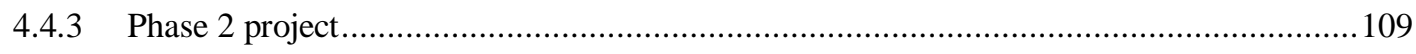

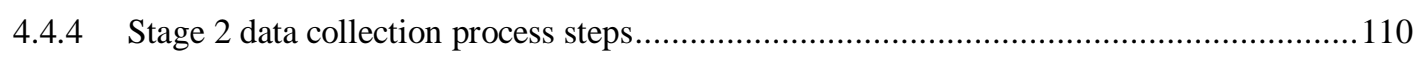

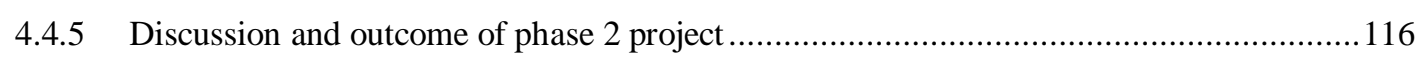

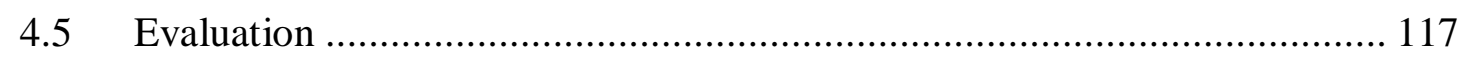

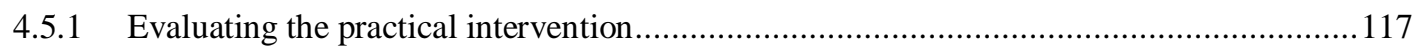

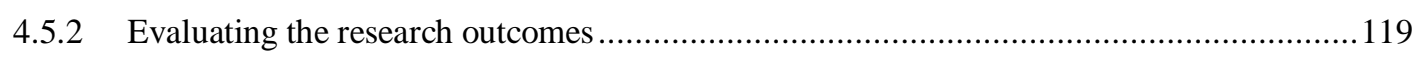

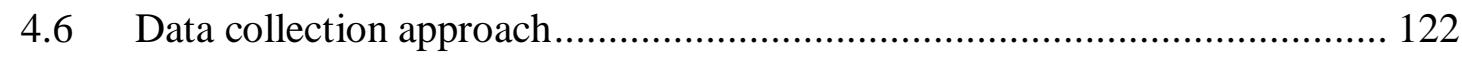

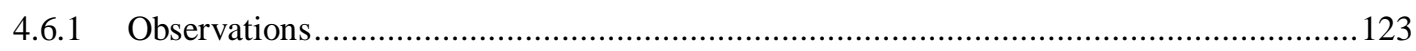

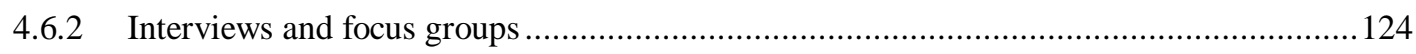

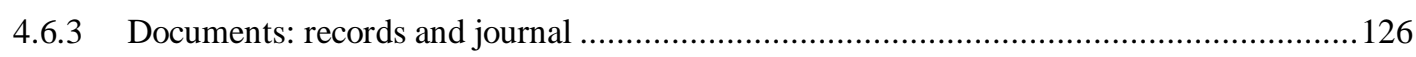

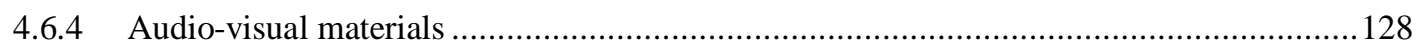

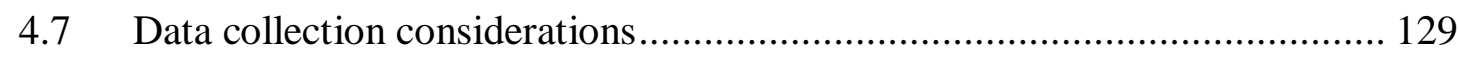

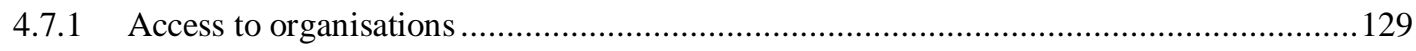

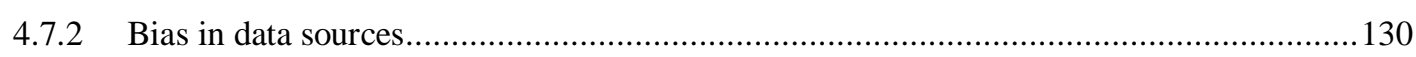

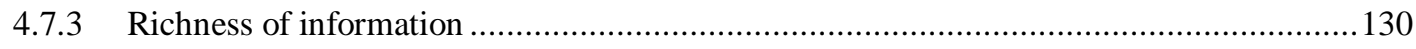

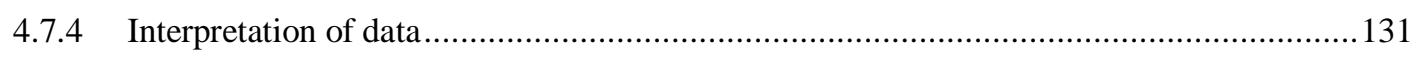

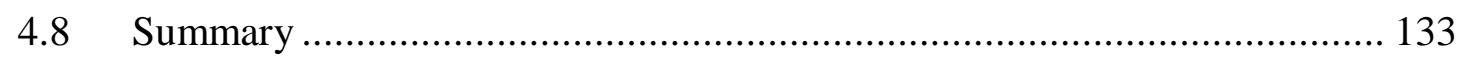

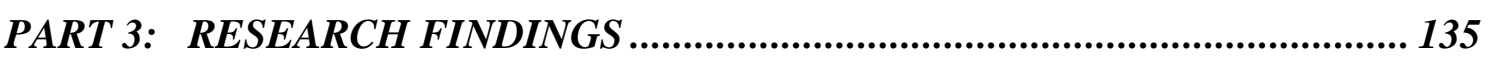

Chapter 5. Organisational aspects of valuable knowledge .................................. 136

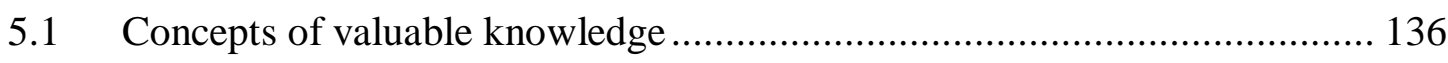

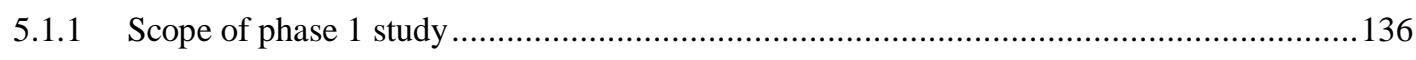

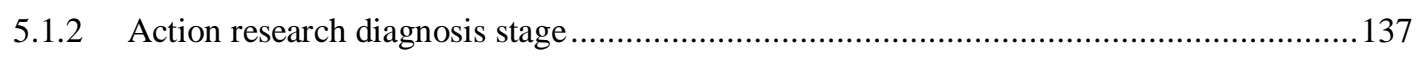

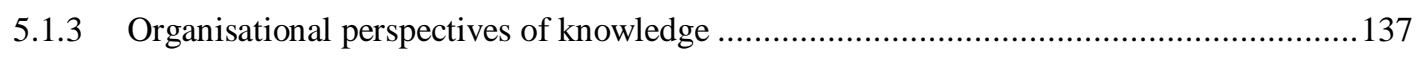


5.2 Subject matter expertise and experience ............................................... 138

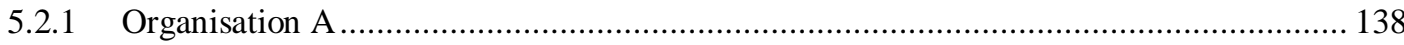

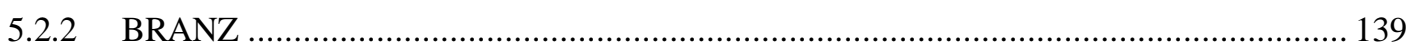

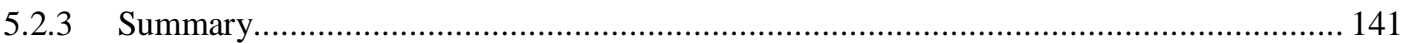

5.3 Knowledge of relationships and social networks ..................................... 142

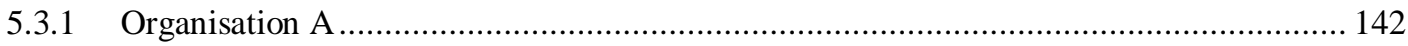

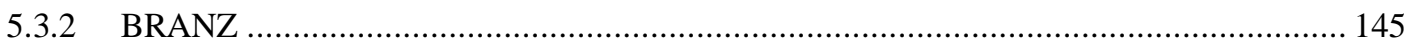

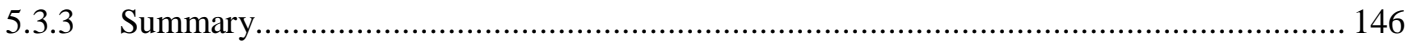

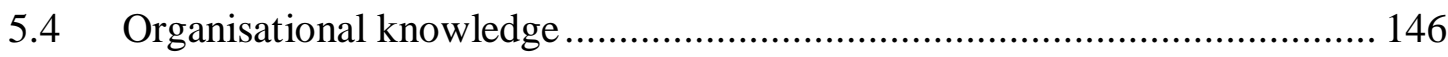

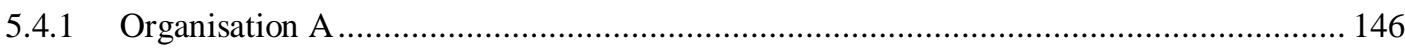

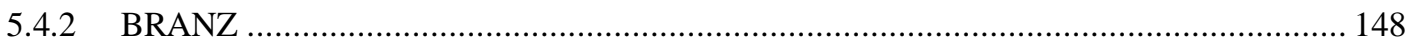

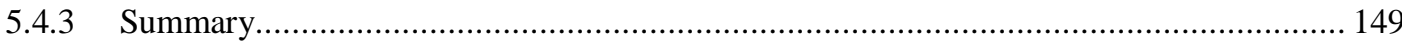

5.5 Knowledge of business systems and processes .................................... 149

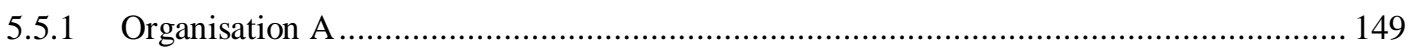

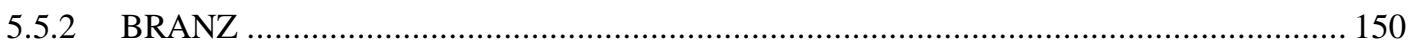

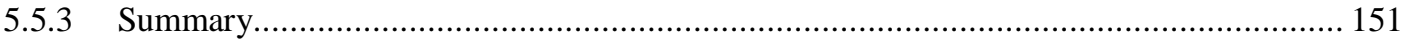

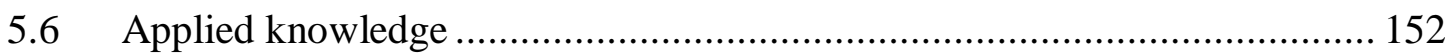

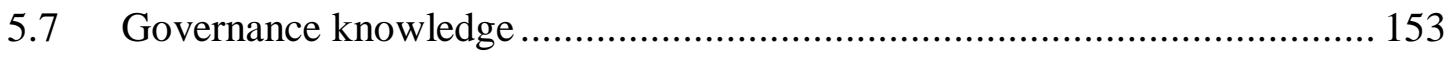

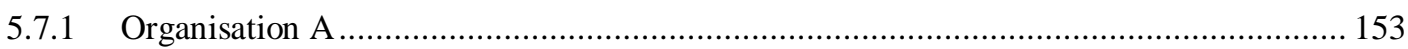

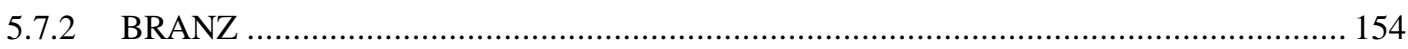

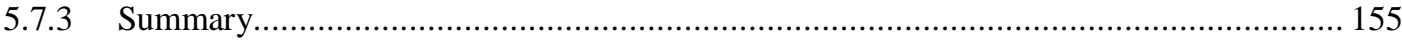

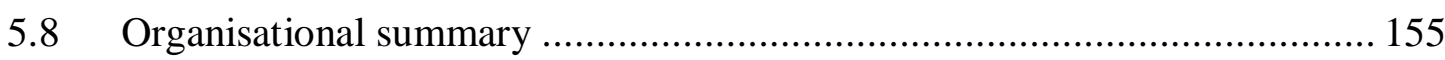

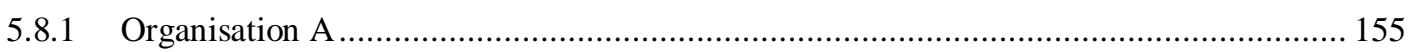

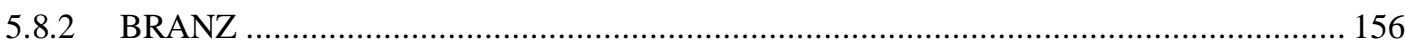

Chapter 6. The valuable knowledge of older experts ........................................ 157

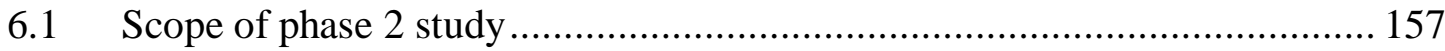

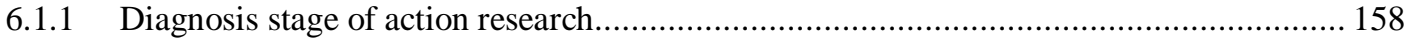

6.2 The nature of older workers' expertise at BRANZ .................................. 159

6.2.1 Unique combination of excellent skills and vast experience.......................................... 160

6.2.2 Wide networks, long standing relationships — reputations ......................................... 162

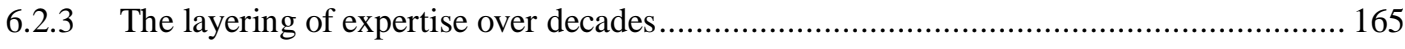

6.2.4 High levels of efficiency and effectiveness................................................................ 167

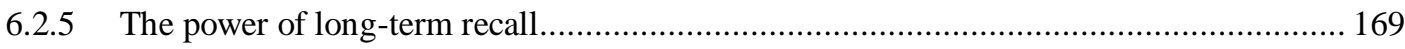

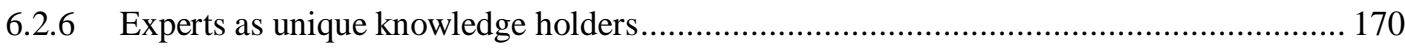

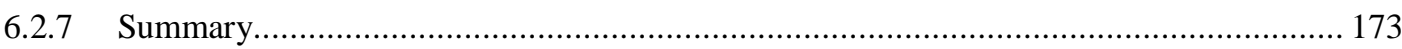




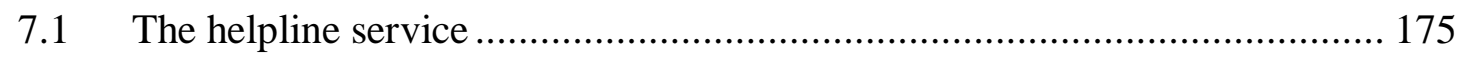

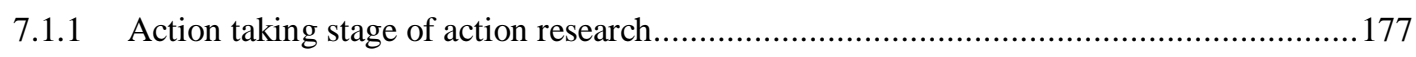

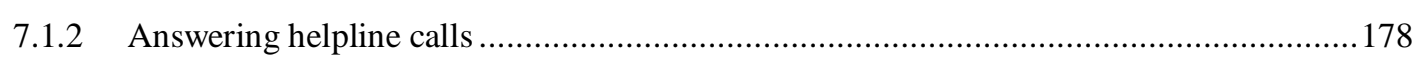

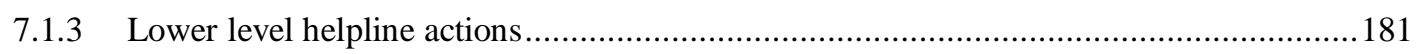

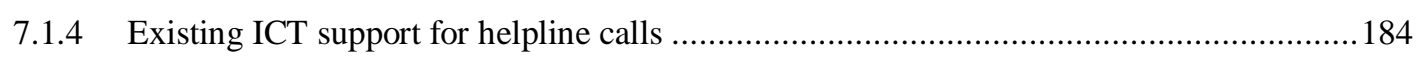

7.2 Retaining knowledge through the use of ICT …................................... 187

7.2.1 Capturing and retaining new knowledge on innovative practice .....................................190

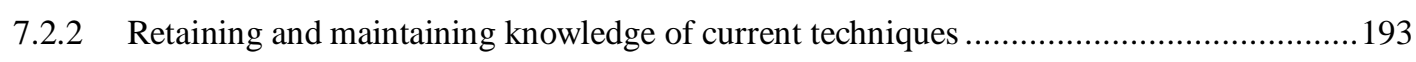

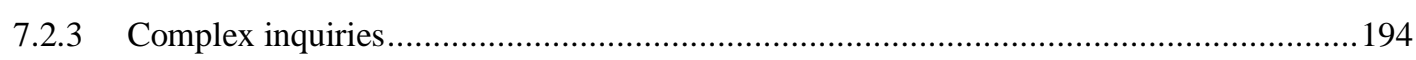

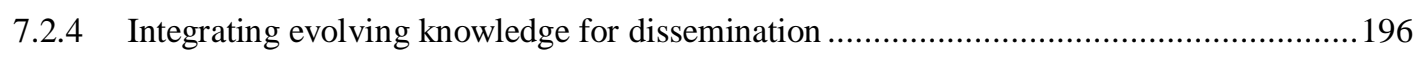

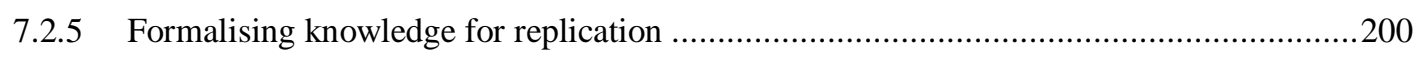

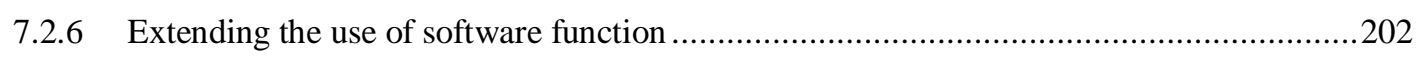

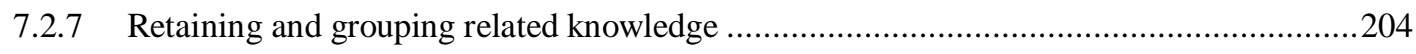

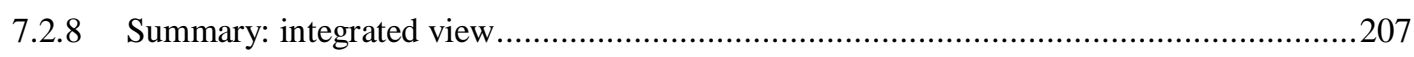

Chapter 8. An older expert's knowledge use and retention ................................. 209

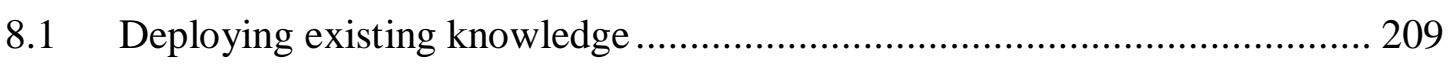

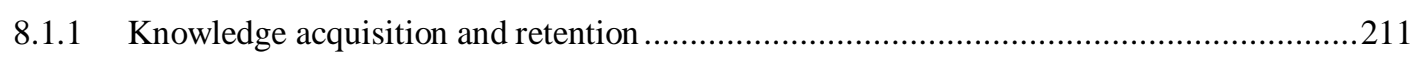

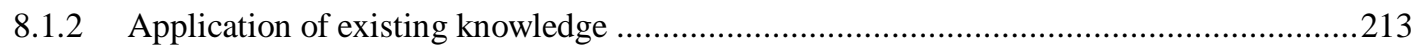

8.2 Refining and retaining knowledge ................................................. 215

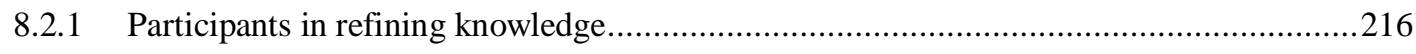

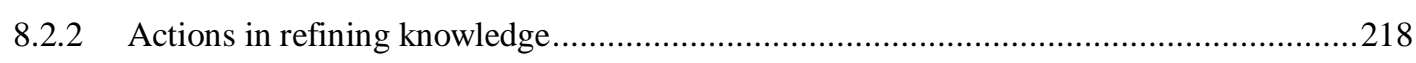

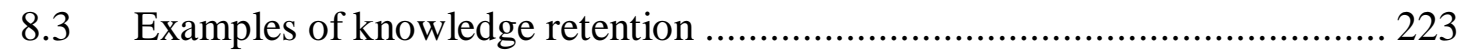

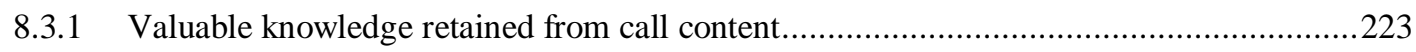

8.3.2 Valuable knowledge retained from helpline process........................................................22

8.4 Applications and benefits of retaining knowledge ................................ 227

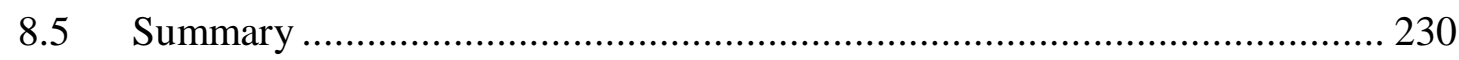

PART 4: DISCUSSION \& CONCLUSIONS ................................................... 231

Chapter 9. Action research — limitations and benefits ....................................... 232

9.1 Limitations of action research and some mitigations ............................. 232

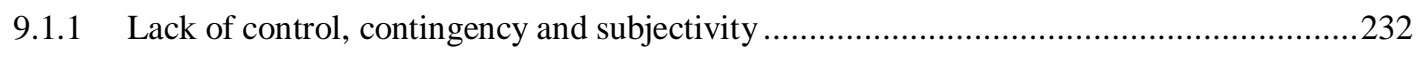

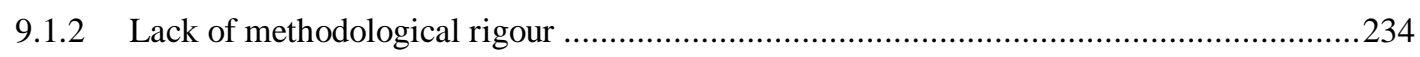

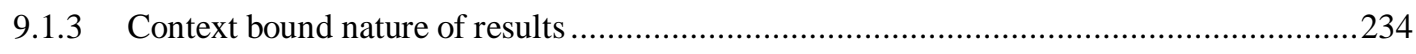

9.1.4 Indistinguishable from consulting - Rapoport's "role dilemma".....................................2. 235

9.2 Matters of credibility, validity and trustworthiness ................................ 236 


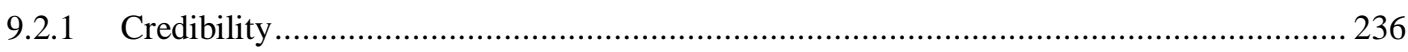

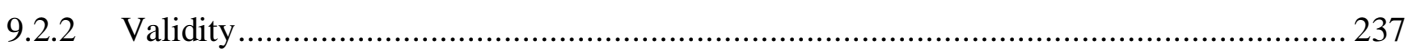

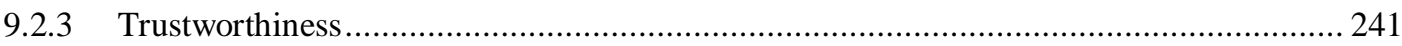

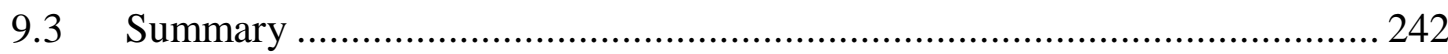

Chapter 10. A wisdom-related knowledge framework .....................................243

10.1 Baltes \& Staudinger's research framework......................................... 243

10.1.1 Discussion of Baltes and Staudinger's framework .......................................... 245

10.1.2 Appropriateness of framework of wisdom-related knowledge ................................ 246

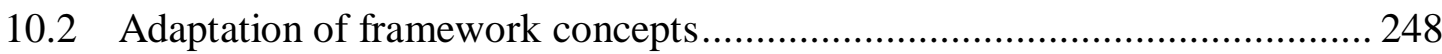

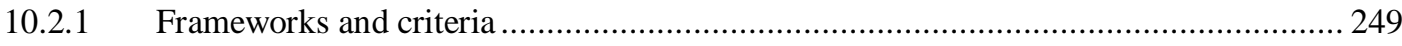

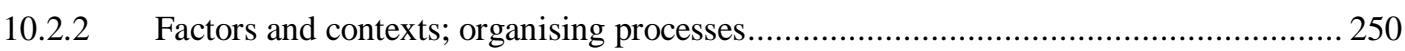

10.2.3 Knowledge framework of individual expert ..................................................... 250

10.3 Knowledge framework and helpline expertise ...................................... 252

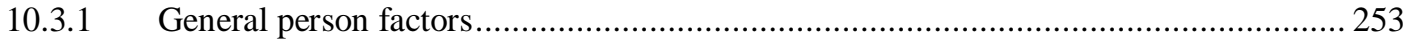

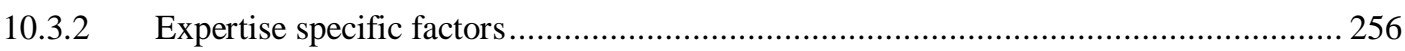

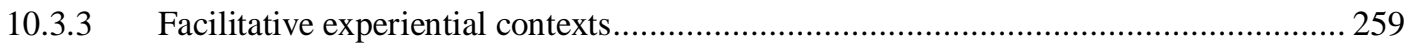

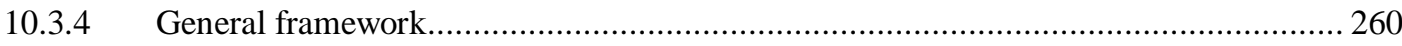

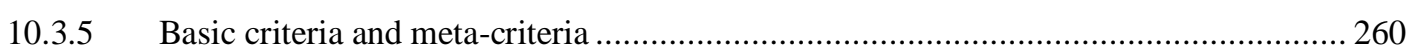

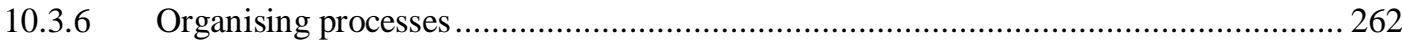

10.3.7 Taxonomy of an older expert's knowledge .................................................. 265

10.4 Integrated model of expertise and knowledge retention ........................... 266

10.4.1 Step 1 - identify a need to provide knowledge ................................................... 268

10.4.2 Step 2 - coordinate parties to provide or retain knowledge ................................ 269

10.4.3 Step 3 - conduct discussions on knowledge retention ........................................... 269

10.4.4 Step 4 - agree solution and actions ....................................................... 270

10.4.5 Step 5 - take actions to retain knowledge .................................................. 271

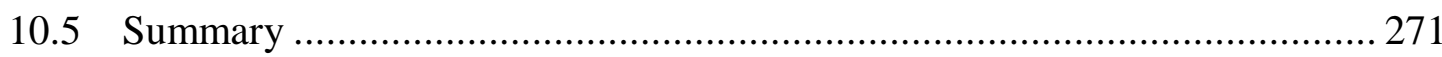

Chapter 11. Implications, limitations and conclusions ..................................2273

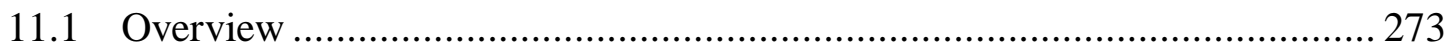

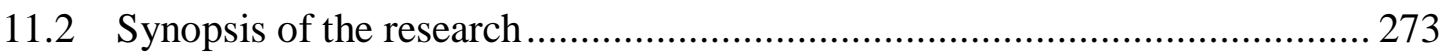

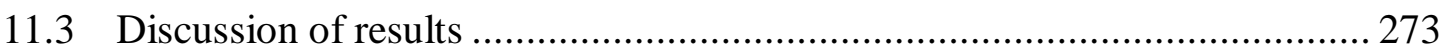

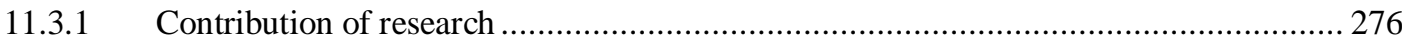

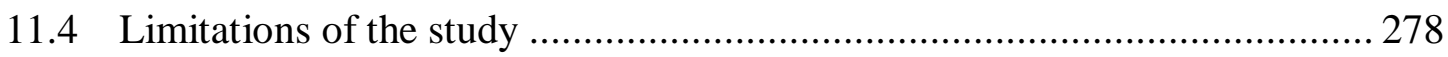

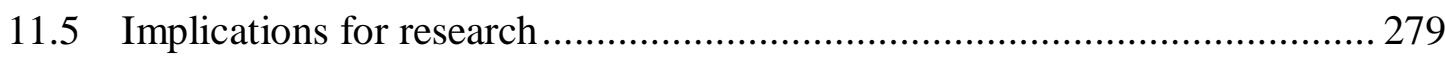




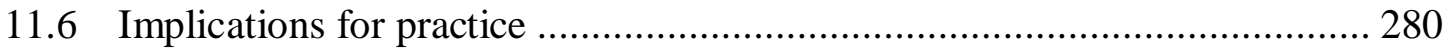

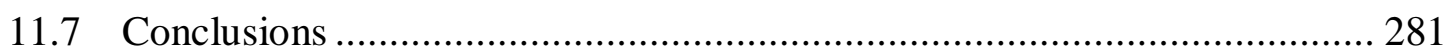

Appendix A: Information sheet and consent form .......................................... 285

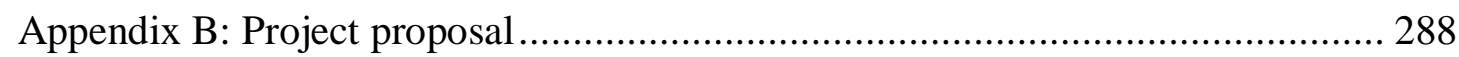

Appendix C: Table of contents for project terms of reference .............................. 291

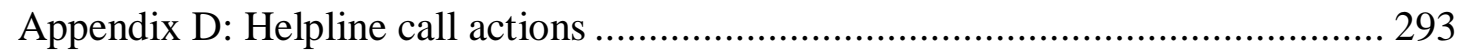

Appendix E: Expertise and using ICT for knowledge retention ........................... 298

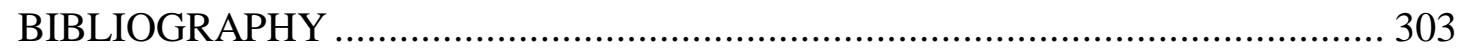




\section{List of figures}

Figure 2-1: Research framework (Baltes \& Staudinger, 2000, p3). ..........................53

Figure 3-1: The cyclical process of action research (Susman \& Evered, 1978) .......... 81

Figure 3-2: Dual imperatives of action research (McKay \& Marshall, 2001, p. 4)...... 85

Figure 4-1: Data collection and analysis stage 1 - the nature of knowledge .................98

Figure 4-2: Helpline knowledge retention project schedule - phase 1 ..................... 107

Figure 4-3: Schedule for developing helpline web site prototype ........................... 110

Figure 4-4: Data collection \& analysis stage 2 - knowledge retention in the helpline 112

Figure 7-1: The new adviser at work on the helpline ....................................... 176

Figure 7-2: Sample of helpline resource material.................................................. 176

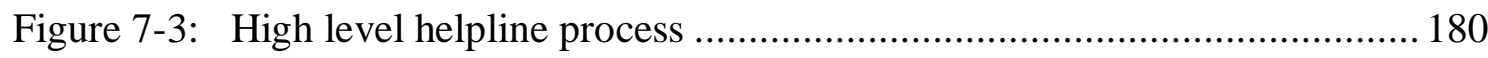

Figure 7-4: Call analysis logic diagram: seeking and using formal documentation ... 183

Figure 7-5: Use of ICT in answering helpline calls ............................................. 186

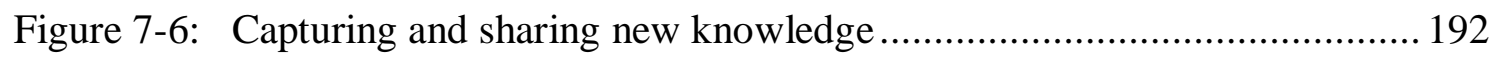

Figure 7-7: Maintaining knowledge of current techniques ................................... 195

Figure 7-8: Capturing and integrating evolving knowledge.................................. 199

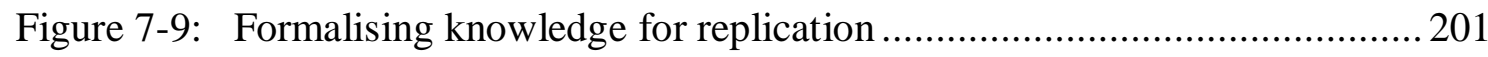

Figure 7-10: Extending use of software for knowledge retention ........................... 203

Figure 7-11: Retaining and linking grouped knowledge....................................206

Figure 7-12: Integrated process view: using ICT for knowledge retention ...............208

Figure 8-1: The older expert's actions in refining knowledge for retention ..............219

Figure 10-1: Research framework (Baltes \& Staudinger, 2000, p3) ........................ 244

Figure 10-2: Knowledge framework of individual expert (adapted, Baltes \&

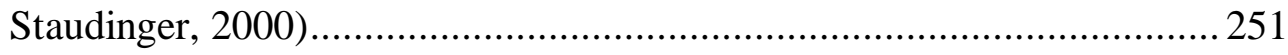

Figure 10-3: Example of general person factors - at process step 2 ...................... 254

Figure 10-4: Signposting as an example of helpline work management ...................264

Figure 10-5 Taxonomy of an older expert's knowledge ........................................265

Figure 10-6: Integrated model - knowledge retention and expertise factors .............267 


\section{List of tables}

Table 1-1: Definition of terms and acronyms in this thesis ................................... 8

Table 2-1: Knowledge conversion modes, Nonaka \& Konno (1995). ....................... 28

Table 2-2: Knowledge creating spaces, Nonaka and Konno (1998). ........................ 32

Table 2-3: Stages of best practice knowledge transfer (Szulanski, 1996) .................. 37

Table 2-4: Implicit \& explicit theories of wisdom summarised from Baltes \&

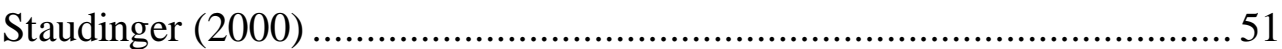

Table 2-5: Wisdom as a three-dimensional personality characteristic (Ardelt, 2004) . 54

Table 2-6: Descriptions of wisdom summarised from a sample of literature .............. 55

Table 2-7: Characteristics and capabilities of individuals possessing wisdom-related

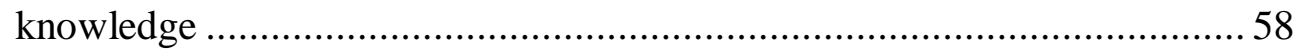

Table 2-8: Examples of knowledge retention initiatives and ICT support forms ........ 68

Table 3-1: Key contributions to action research (Avison, et al., 1999) ...................... 83

Table 3-2: Researcher competencies for action research (Mumford. 2001) ................ 90

Table 4-1: Interview types (Duffy, Ferguson and Watson, 2004, p. 68) ................... 124

Table 7-1: Lower level helpline actions and process steps. .................................. 182

Table 7-2: Examples of using ICT for knowledge retention on the helpline ............. 189

Table 8-1: How existing knowledge was captured and retained ............................ 212

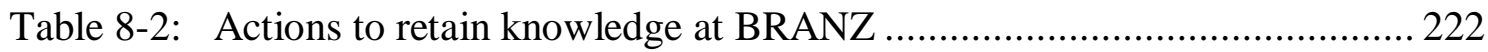

Table 8-3: Contributions of knowledge retention from older expert (adapted from

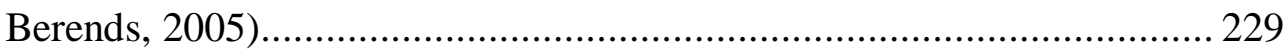

Table 9-1: Characteristics of quality in action research (Reason, 2006) ................... 240

Table 9-2: Dimensions of authenticity (Coghlan, 2008, p. 360) ............................. 241 



\section{PART 1: THE RESEARCH PROBLEM}

The first part of this thesis consists of two chapters.

I define the research problem in Chapter 1 before introducing the research topic and questions. The significance and motivations of the study are discussed next, and this is followed by a definition of terms used in the thesis.

A review of relevant literature is presented in Chapter 2. The literature on older experts includes the topics of workforce trends, the concept of retirement and the knowledge assets that reside in older experts. Next, I discuss the relevant literature on knowledge retention and the topic of how expertise may be retained from older experts, followed by the role of ICT in supporting knowledge transfer.

Lastly, I discuss the gaps I have identified in the extant literature and confirm my research topic in the context of the literature. 


\section{Chapter 1. Introduction}

\subsection{Defining the research problem}

The baby boomers are beginning to reach retirement age. As they leave the workforce, they are taking with them knowledge that no one else has. The loss of this knowledge has the potential to be a business problem. The challenge to organisations is to find ways to identify, access and retain this knowledge.

In introducing the context for my study, I present three relevant factors I identified.

The first factor is that a growing proportion of the work force is made up of older workers. This phenomenon is apparent in New Zealand where the study took place. This condition reflects the situation elsewhere in the developed western world. A large proportion of these older workers is made up of members of the post-World War II baby boom generation, born between 1945 and 1963. The oldest members of this generation are approaching retirement, or are likely to reduce their working hours within the next decade. The New Zealand Department of Labour (2006) predicted that by 2051, $45 \%$ of the working age population will be over age 45 . In the shorter term, $25 \%$ of the New Zealand workforce is predicted to be over 55 years of age by 2020 (New Zealand Department of Labour, 2009).

New Zealand's labour force participation rate of $60 \%$ for workers between the ages of 55 and 64 compares well with a participation rate of $40 \%$ in Australia, 59\% in the US and $65 \%$ in Scandinavia (New Zealand Department of Labour, 2007; IBM Business Consulting Services, 2004 p. 499). The subsequent generation, however, is only about $75 \%$ of the size of New Zealand's baby boomer cohort. While the labour force grew by 500,000 between 1991 and 2006, the rate of growth is predicted to slow after 2016 to about 15,000 workers per annum (New Zealand Department of Labour, 2009). Few employers have given serious consideration to the composition of the workforce (Albrecht, 2001; Davey, 2008).

The second factor is that there is a growing realisation that within the baby boom generation and the generation that precedes it, there are some workers with valuable knowledge, experience and expertise that will be lost if organisations do not act to retain such assets. Baby boomers are currently the largest sector of the working population - 
they are also the segment where a significant amount of institutional knowledge resides. There may be some workforce challenges as the available pool of workers diminishes significantly after the baby boom generation. Organisations may need strategies for retaining as many knowledgeable older workers as possible, as well as for retaining the knowledge of those who leave the workforce.

All too often, the extent of organisations' commitment to retaining knowledge from older workers extends no further than the exit interview before they leave (Patton, 2006), or attempts to recapture required knowledge after employees have retired or been retrenched (Becerra-Fernandez \& Sabherwal, 2005; Hammer, 2002). Employers need to address the threat of losing institutional knowledge, given the increasing reliance on mid- and late-career workers to meet skills demands.

In organisations that regard knowledge as a valuable organisational resource, the generation and transfer of knowledge is widely recognised as a significant organisational capability and is regarded as being a source of long-term competitive advantage (Alavi \& Leidner, 2001; Connell, Klein, Loebbecke, \& Powell, 2001; Leonard \& Swap, 2005). Davenport and Prusak (1998) advise that organisations must keep track of knowledge, "because knowledge assets are difficult to buy in a market".

The third factor is the role of ICT (information and communications technologies). ICT has been used to capture explicit knowledge, employing the likes of databases, electronic document and content management systems and knowledge bases (Hammer, Leonard, \& Davenport, 2004; Hylko, 2005; Lesser, 2006). There has also been some focus on tools to identify experts and facilitate the sharing of their tacit knowledge (Hansen, Nohria, \& Tiernay, 1999; Stenmark, 2001) via web and other mobile channels. The pervasive nature of the World Wide Web enables myriad social technologies and an “architecture of participation" (Gordon, 2006).

It is important to include the role of ICT in the study of knowledge retention, because it is a crucial tool in knowledge management. It can provide quickly and systematically, the means by which knowledge can be captured and stored before older experts leave the organisation. In many cases, organisations have already made significant investments in ICT to manage knowledge as an organisational asset. Such investments may be leveraged at minimal cost. ICT may also be deeply embedded in a business process to the extent that technology is an integral element of the process. 
Little information was found, however, on the role of ICT in retaining the knowledge of older experts, despite its role as a vital tool in knowledge management. Therefore, there is a research gap in the use of ICT in retaining the knowledge of older experts.

Reviewing the literature on the expertise of older workers (Ebrahimi, Saives, \& Holford, 2008; Leonard \& Swap, 2005; Parise, Cross, \& Davenport, 2006), the nature of expertise (Didierjean \& Gobet, 2008; Ericsson \& Ward, 2007; Lesser, 2006; Williams, Ward, Ward, \& Smeeton, 2008) and studies of wisdom (Ardelt, 2004; Baltes \& Kunzmann, 2004; Baltes \& Staudinger, 2000; Hammer, 2002; Rowley \& Slack, 2009) led me to the recognition that to some extent, older experts' knowledge in the organisational context must include wisdom-related elements. There was therefore an opportunity to build upon the work of these researchers, particularly with the wisdom framework of Baltes and Staudinger. Existing literature on infrastructure and processes for retaining the knowledge of older experts indicates that it is a relatively new area, based largely upon practitioner experiences (England \& Herrera, 2005; Gross, Hanes, \& Ayres, 2001; Hylko, 2005; Lesser, 2006). There is therefore a research gap and an opportunity to contribute to this topic domain. I was interested in understanding what types of knowledge organisations categorise as being valuable and specifically at risk of being lost when an older expert left the organisation. Following this, I wanted to study the knowledge of an older expert in action, together with the existing processes an expert used or could use to retain knowledge, including ICT. Subsequently, this has enabled me to propose an emergent theoretical framework that represents the components of an older expert's knowledge and knowledge retention behaviour.

This study therefore addresses a research gap in the combined areas of older experts' knowledge, knowledge retention processes, and the use of ICT. The study is limited to, and concerned specifically with, the knowledge of experts. I do not assume that all knowledge residing in older workers is valuable or at risk of being lost. Similarly, I recognise that valuable knowledge and significant levels of expertise also reside in younger members of the workforce.

\subsection{The research topic and research questions}

Organisations often embark on significant initiatives and investments in knowledge management, including ICT, without reference to the concept of knowledge as an organisational asset. My research objective was to discover how an organisation 
described the types of knowledge that it considered as being valuable. This would provide me some context for finding within the organisation an example of an older expert with valuable knowledge. Having an opportunity to observe such an expert in action would enable me to study the existing processes for retaining some of this knowledge, and to discover how ICT was, or could be, used to support such processes in an organisational context.

When studying knowledge types and the means of their retention, the unit of analysis is the organisation. When studying the knowledge retained by older experts, the unit of analysis is the individual.

The main research topic is:

Retaining the knowledge of older experts in an organisational context and the role of ICT

The research topic was addressed by answering three questions:

1. What types of knowledge does an organisation risk losing when older experts leave?

2. What processes does an organisation use to retain the knowledge of older experts?

3. How can ICT support the knowledge retention process for the identified knowledge source(s) and recipients?

This study aims to develop or evolve a framework to illustrate the nature of an older experts' knowledge and the knowledge retention actions associated with preventing the loss of that knowledge in the organisation.

The study uses an action research approach with the intent of solving a business problem while extending theoretical knowledge.

\subsection{Significance and benefits of the study}

There is a recent and growing awareness that valuable knowledge resides within workers in the baby boom generation and the preceding one, and that this knowledge will be lost. The research questions are therefore relevant to practitioners and 
researchers interested in the topic of knowledge retention. Practitioners' and consultants' efforts to remedy the problem of knowledge loss from older experts feature in the literature, although deeper information about much of this work is proprietary due to commercial considerations. At the outset of the study, I did not find much literature that addressed the coalescing subject domains of older workers, the loss of valuable knowledge assets and the opportunities for ICT to support knowledge retention. This study is therefore a response to the recognition that the intersecting area of these subject domains presents rich opportunities for research.

Many organisations have embarked on significant knowledge management or retention initiatives and investments without having a framework for understanding what types of knowledge are valuable in their organisational context. The potential for losing older experts may mean that organisations want to address the strategic (philosophical and conceptual) question of what knowledge actually means in that organisation. This contrasts with the tactical stance of embarking directly on ICT implementations, and sheds light on the organisation's embedded assumptions about knowledge.

Organisations could then identify and confirm the elements of experts' individual knowledge that need to be retained.

In addressing the meaning of knowledge in an organisational context, as well as studying an older expert in action, this study sought to contribute to recent interest, both practitioner and academic, on wisdom theory in an organisational context (Hammer, 2002; Rooney, 2006; Rowley \& Slack, 2009). The research output from the study was an emergent theoretical model of knowledge retention and expertise factors.

\subsection{Motivations for the study}

In my early career I spent over a decade in government service in several policy and advisory roles concerned with various aspects of retirement. I dealt with individuals, employers and groups in different facets of planning and saving for a more financially secure retirement. My work with older employees included matters such as transitioning from full-time to part-time work, and understanding benefits and entitlements. It often struck me that some of these older workers had developed deep knowledge and experience, judging by the roles they had held over their decades-long careers — and that they still had much to offer. I wondered if they held valuable knowledge that might not be visible to their organisations. 
During the 1990s, I saw many organisations restructure their businesses, right-size their workforces, and declare many experienced staff or their roles as being redundant. Later, a small number of these employees would be rehired temporarily to fill a knowledge gap in their areas of expertise, as organisations realised in hindsight that they had not understood their employees' actual skills and experience. In some cases however, staff who had left the organisation were no longer available when needed.

Subsequently, I have worked in ICT-related and general project roles. My work is sponsored and overseen by senior executives, who are in most cases over the age of 50, that is, older workers with expertise. They have an awareness of knowledge loss issues in the case of experts of any age, but the pressures of conducting business as usual inhibits any focused effort to retain knowledge. Some executives are also becoming aware that the issue could be intensified with the impending retirement or reduced participation of baby boomers in the workforce. The organisations that participated in my study acknowledged that while ICT is part of the toolset in addressing the problem of knowledge loss, it would be useful to better understand the nature of valuable knowledge within the organisation.

Together, these threads contributed the motivation for my study. Several other factors compelled me to action as I discovered that my personal curiosity was reflected in others. First, I detected a growing interest from the time of my initial discussions with potential participants. Second, at that time the literature in my area of interest was sparse. Finally, there would also be practitioner interest in the topic, particularly in terms of practical frameworks or tools.

\subsection{Definition of terms and acronyms}

Table 1-1 (p. 8) defines some terms and acronyms used in this thesis.

\begin{tabular}{|l|l|}
\hline Term & Meaning \\
\hline AARP & $\begin{array}{l}\text { American Association of Retired Persons (also known as the } \\
\text { Association for the Advancement of Retired Persons), an association } \\
\text { of people to promote the welfare of senior citizens. }\end{array}$ \\
\hline baby boomers & $\begin{array}{l}\text { This term defines members of the generation born during an increase } \\
\text { in births, starting immediately after World War II. Depending on } \\
\text { various sources, members of this group were born between 1945 and } \\
1963 \text { (to 1965). }\end{array}$ \\
\hline cohort & $\begin{array}{l}\text { A generational group as defined in demographics, statistics, or market } \\
\text { research. }\end{array}$ \\
\hline
\end{tabular}




\begin{tabular}{|c|c|}
\hline Term & Meaning \\
\hline deep smarts & $\begin{array}{l}\text { "...a potent form of expertise based on first hand life experiences, } \\
\text { providing insights drawn from tacit knowledge, and shaped by beliefs } \\
\text { and forces. Deep smarts are as close as we get to wisdom." (Leonard } \\
\text { and Swap, 2005, p. 2). }\end{array}$ \\
\hline $\begin{array}{l}\text { dependency } \\
\text { ratio }\end{array}$ & $\begin{array}{l}\text { A measure, often used by economists and demographers, showing the } \\
\text { number of dependents (aged 0-14 and over the age of } 65 \text { ) to the total } \\
\text { population (aged 15-64). Also referred to as the "total dependency } \\
\text { ratio". Calculated by: } \\
=\frac{\text { Number of Dependents }}{\text { Population (Ages } 15-64)} \times 100 \%\end{array}$ \\
\hline Generation X & $\begin{array}{l}\text { The generation following the post-World War II baby boom, } \\
\text { especially people born in the United States and Canada from the early } \\
\text { 1960s to the late 1970s. }\end{array}$ \\
\hline ICT & $\begin{array}{l}\text { Information and communications technology, meaning technology } \\
\text { that is used to handle information and aid communication. ICT is } \\
\text { relevant to this study as a means of supporting knowledge retention. }\end{array}$ \\
\hline $\begin{array}{l}\text { knowledge } \\
\text { retention }\end{array}$ & $\begin{array}{l}\text { The strategic concept of knowledge retention appears in more recent } \\
\text { literature, such as de Long and Davenport (2003). There are elements } \\
\text { of reinterpreting and integrating knowledge to make it explicit } \\
\text { (McKay \& Marshall, 2005) and capturing it a repository (Argote, } \\
\text { McEvily, \& Reagans, 2003). }\end{array}$ \\
\hline $\begin{array}{l}\text { know } \\
\text { transf }\end{array}$ & $\begin{array}{l}\text { Much literature implies a unidirectional transfer of knowledge } \\
\text { (Tempest, 2003), involving a knowledge source and destination. } \\
\text { Knowledge is held by individuals, groups or organisations, and is } \\
\text { physically passed to other such entities, or into systems and } \\
\text { processes. Knowledge transfer may be defined as "the practical } \\
\text { problem of recognizing, capturing, distilling, managing, and } \\
\text { distributing key organizational knowledge. It also covers ensuring } \\
\text { availability of this knowledge to those that come after" (Hewitt, 2008, } \\
\text { p. 3). }\end{array}$ \\
\hline $\begin{array}{l}\text { knowledge } \\
\text { workers }\end{array}$ & $\begin{array}{l}\text { This term was coined by Peter Drucker in } 1959 \text { to describe workers } \\
\text { who work mainly with information, or who create and use knowledge } \\
\text { in the workplace, that is "someone who knows more about his or her } \\
\text { job than anyone else in the organisation" (Hammer, Leonard and } \\
\text { Davenport, 2004, p. 14) }\end{array}$ \\
\hline older worker & $\begin{array}{l}\text { There various views in the literature on what constitutes an older } \\
\text { worker, and this depends on the perspective being taken. In the } \\
\text { demographic literature, it is often the over } 60 \text { age group; in work } \\
\text { place and retirement-related discussions, workers generally become } \\
\text { entitled to pensions at age } 65 \text {. In an employment equality setting, it } \\
\text { may be anyone over age } 45 \text {. In the context of this research study, my } \\
\text { use of the term "older worker" applies to anyone over age } 45 \text {. } \\
\text { For the purposes of this study and the research it describes, the older } \\
\text { workers who are of interest are more experienced knowledge workers } \\
\text { with expertise that is of value to their organisation. }\end{array}$ \\
\hline Third Age & $\begin{array}{l}\text { A term used in gerontology, the Third Age starts at around } 60 \text { years } \\
\text { of age, and "Fourth Age commences when half the original 'birth } \\
\text { cohort' is no longer alive" (Baltes, 2003; p. 15) }\end{array}$ \\
\hline
\end{tabular}

Table 1-1: Definition of terms and acronyms in this thesis 


\subsection{Structure of the thesis}

This thesis is structured in four parts.

Part 1 consists of two chapters introducing the research topic and setting the scene for the research by reviewing the relevant extant literature.

I introduced my research in Chapter 1, with a definition of the problem, followed by a description of the topic and a statement of the research questions. The study's significance and benefits were discussed next, and the motivations for the study were explained. Finally, the terms and acronyms used in the study were listed.

The literature review outlines current research on older workers and workforce trends, explores the concept of retirement, and considers the knowledge assets of older workers. Perspectives and characteristics of knowledge, and relevant factors and models for knowledge transfer are also reviewed. Relevant to the discussion on knowledge are the concepts of expertise and wisdom. The nature of ICT support for knowledge transfer is represented as three waves. Finally, a summary shows how the research question addresses gaps in the literature (Chapter 2).

Part 2 of the thesis details my research methodology and process in two chapters.

I present my perspective and approaches in terms of methodology, outlining the rationale for choosing action research as the research method. Next I discuss how quality may be measured in action research, then I describe my role as the researcher, and the roles of the study's participants (Chapter 3).

The design of the research process is informed by the nature of action research inquiry. I outline the approach I adopted for each action research stage of the study, and describe the collection and analysis process, and the outcome of the stage (Chapter 4).

Part 3 of the thesis presents the findings of the study (Chapters 5-8).

I discuss findings on the organisational aspects of valuable knowledge (Chapter 5). This leads to my findings on the valuable knowledge of the older expert and in particular, the identification of attributes of expertise (Chapter 6). Next, the focus turns to an older expert's knowledge retention actions in the setting of an industry advisory helpline service (Chapters 7 and 8). 
Part 4 of the thesis develops a theoretical framework emerging from the study (Chapters 9 and 10), and outlines some of the study's limitations, implications and conclusions (Chapter 11).

I discuss some limitiations of action research and their mitigations (Chapter 9). I then introduce an existing wisdom-related knowledge framework, relate it to the findings from the study of the older expert. Resulting from this step, I propose a combined framework of expertise and knowledge retention, drawing together the main findings of the study (Chapter 10). The thesis closes with a discussion of the limitations, implications and conclusions of the study (Chapter 11). 


\section{Chapter 2. Literature review}

\subsection{Overview}

The research topic covers three relevant subject domains in literature. The first is the subject of older experts and the knowledge they possess. The second subject concerns the knowledge retention processes that may assist organisations in preventing the loss of older experts' knowledge. The third subject is the role of ICT in supporting knowledge retention in organisations. The literature pertaining to each of these subject domains therefore merits review.

The ageing of the labour force is explored in Section 2.2. The concept of retirement has also changed over the last few decades, and is therefore a significant factor to consider, together with the knowledge assets of older workers and the value of this knowledge. Other challenges and issues such as the negative perceptions of older workers, and the need to transition to retirement through part-time work, are reviewed briefly.

Next, I address the subject of knowledge retention in Section 2.3, including the perspectives and characteristics of knowledge and some knowledge retention approaches. The requirements for knowledge transfer are addressed in Section 2.4, as well as the inhibiting factors, issues and challenges involved.

The nature of knowledge retention from older experts is then reviewed in Section 2.5. The review addresses the types of knowledge that older experts possess, the processes by which this knowledge is retained, and how an expert may be distinguished in terms of the knowledge they possess. The nature of knowledge and expertise in relation to wisdom is explored. There are various ways in which information systems may support knowledge transfer and these are reviewed in Section 2.6.

Finally, I address the gaps in research, and confirm the appropriateness of the research topic and the research questions in Section 2.7.

\subsection{Older experts}

The focus of this study is older experts who possess experience and specialist knowledge that should be retained because it is valuable to their organisations. For the purposes of the study, the term "older worker" refers to people who are aged 45 and 
over (McPherson, 2008). A fuller definition is set out in Section 1.5. This includes workers who are members of the baby boom generation, and members of older cohorts. Organisations may retain the expertise that these workers possess, through initiatives that encourage older experts to remain in the workforce. Organisations may also facilitate the retention of that expertise as a resource. Thus, within the context of this study, all references to older workers in the context of knowledge retention or transfer relate to experts who possess valuable knowledge that organisations need to retain.

There will be a significant reduction in the workforce as baby boomers retire. In the US, there are an estimated 78 million baby boomers, now aged between 44 and 61 . The estimated size of the demographic group known as Generation X, aged 28 to 43, is 44 million (Bell, 2001). In New Zealand, it is expected that there will be a slowing in the growth of the labour force (Stephenson \& Scobie, 2002), down from 1.5 per cent a year in the late 1990s, to 0.1 per cent in the year 2019 (Department of Statistics, 2003). A negative growth rate is expected from 2020 (Institute of Policy Studies, 2008).

The demographic trend presents a two-fold problem. First, organisations are faced with the problems such as the loss of knowledge, skills and personnel, and they may not yet have effective solutions or approaches for addressing them (Ashworth, 2006; Hall, 2008; Ham, 2009; Shapinker, 2000). "Employers have to realise that there is a crisis developing, and they must find ways to attract qualified workers as the pool of new workers gets smaller" (Albrecht, 2001, p. 62). Despite growing awareness of the ageing workforce, many New Zealand employers still lack policies or any sense of urgency (McPherson, 2008; Mercer, 2008; Strack, Baier, \& Fahlander, 2008). Organisations will need to explore ways of retaining knowledge and personnel with a range of ages, skills and experience in the workforce. For example, US government agencies are legally required "to develop strategic workforce plans identifying their current employees' skills and capabilities and the agency's future needs" (Liebowitz, 2004, p. 421).

Second, for several reasons, older workers do not necessarily want to move from fulltime work to full retirement as was traditionally the case. They may have accumulated insufficient funds for retirement (Cairns, 2009; Connolly, 2000; Mercer, 2008; Morrall, 2008; The Times, 2010); they may be seeking a balance between work and life, with the opportunity to continue sharing their knowledge, and may still want the challenge associated with working (Bell, 2001). Organisations need to put processes in place to manage the retention of knowledge in the organisation when experienced workers retire, 
enabling older experts to transfer their skills, knowledge and experience as a corporate asset (Hammer, 2002; Morrall, 2008).

\subsubsection{Workforce trends}

\section{Growing proportion of older workers}

In the western world, the baby boom generation is numerically dominant, due to its increasing longevity, the relatively smaller size of the following generation, and decreased fertility rates (Schetagne, 2001). For example, Canadians over 65 years of age comprised $10 \%$ of the population in 1956, but an increase to $20 \%$ is expected by 2026 . Different approaches may be applied in response to the growth in the proportion of older workers, the contraction of the workforce and the recognition that older workers may have valuable experience and knowledge (Armstrong-Stassen \& Schlosser, 2008; Hammer, 2002; Morrall, 2008; Schetagne, 2001). Greater flexibility in terms of redesigning roles, varying working hours and increasing leave arrangements may assist workers who wish to work longer and transition to retirement - and employers wishing to avoid an exodus of older workers with expertise (McPherson, 2008; Mercer, 2008). Morrall (2008) lists other factors such as the ability to take extended leave while preserving one's job, work remotely, have interesting and challenging work that makes a difference, and to be valued and be less stressed.

\section{Contraction of the workforce}

Workforce contraction is defined as a transitional demographic effect, resulting in large numbers of workers retiring, and influenced by other factors such as workforce participation rates, net migration effect and economic factors (New Zealand Department of Labour, 2007). The rate of growth of the labour force is predicted to halve after 2016 (New Zealand Department of Labour, 2009). The proportion of the New Zealand labour force aged 55 and over is expected to increase from $18 \%$ in 2007, to $20 \%$ in 2012 (Mercer, 2008). The New Zealand Department of Labour (2009) predicts that by 2020, $25 \%$ of the working age population will be over age 55 . Both the youth labour force (under age 25) and the middle working ages (25-44 years) will number $11 \%$ less than 1996 levels, the base year for New Zealand's labour force projections.

In New Zealand, $60 \%$ of people between the ages of 55 and 64 participate in the labour force, compared with $40 \%$ in Australia, $59 \%$ in the US and $65 \%$ in Scandinavia (IBM Business Consulting Services, 2004). New Zealand's relatively high labour force 
participation rate is due to reasons such as the removal of a compulsory retirement age, increased life expectancy, better health, technology that reduces the manual nature of work, skills shortages, and aspects of the pensions system (New Zealand Department of Labour, 2007; Dunstan \& Thomson, 2006). Mercer notes that "many countries in the world economy are anticipating a drought of workers as the Baby Boomers retire" (Mercer, 2008). Information on New Zealand's dependency ratio for the number of people aged over 65 per number per 100 people aged 15-64, shows that over time, there will be a smaller number of working age population to support the number of retirees (Dunstan \& Thomson, 2006; New Zealand Treasury, 2002).

Because of increasing financial pressure, older workers often are not in a position to move directly into retirement, while others are not interested in a long period of retirement (McPherson, 2008; Morrall, 2008; The Times, 2010), wishing to reinvent themselves (Dychtwald \& Forsberg, 2001). Employers may be competing not with other employers, but with lifestyle changes that baby boomers find desirable (Mercer, 2008). There is also a growth in alternatives to permanent full-time roles, such as part-time, temporary and seasonal work (New Zealand Department of Labour, 2009; Schetagne, 2001). Self-employment may appeal for financial or lifestyle reasons (New Zealand Department of Labour, 2009). Having been through redundancies during the corporate restructuring of the 1980s and 1990s (Znidarsic \& Dimovski, 2010), during which "employers ... responded to cyclical downturns by disproportionately thinning the ranks of their older employees" (Robson, 2001), older workers may also be comfortable with change and actively seek it. Thus, increasing numbers of older people are seeking work and retraining to take on new roles. In the Cornell Retirement and Well-being Study, $44 \%$ of retirees studied have been in paid work following retirement, with the most popular reason being to work to stay active (Cairns, 2009; Gardyn, 2000). The AARP Public Policy Institute (2004) noted that $25 \%$ of people over age 55 were employed part-time and $4.7 \%$ held multiple jobs during that year. In New Zealand, the number of people over age 50 who are in work has more than doubled between 1991 and 2005 (New Zealand Department of Labour, 2007).

\section{Workforce planning}

Organisations need to adopt more strategic approaches for managing their workforces, recognising that a longer planning horizon is appropriate (Strack, et al., 2008). Acknowledging this, organisations are rehiring older workers or offering transitional 
arrangements to delay their full retirement. One advantage of this approach is that existing older workers embody a known quantity in terms of their skills, reliability and reliability (Albrecht, 2001; Davey, 2007; McPherson, 2008). A study by the Equal Employment Opportunities Trust shows that employers saw them as valuable employees, noting that "their reliability, good work ethic, maturity, experience, expertise, institutional knowledge, stability, loyalty and their ability to mentor younger workers were all mentioned" (McPherson, 2008, p. 4).

In fact, it is noted that older workers, as a cohort, are better-educated than 10 to 20 years ago, due partly to increasing rates of technology adoption (Besl \& Kale, 1996; Schetagne, 2001). Schetagne's study notes that the positive views of older workers include a wide range of qualities related to their adaptability and capacity for work. The United States' most recent economic shift has been from a manufacturing-based economy to a new order where the key resource is knowledge rather than labour, raw materials or capital (Drucker, 1994; Purcell, 2000). The OECD’s 1996 report estimated that more than half of the gross domestic product (GDP) of developed economies was knowledge-based and knowledge workers account for 8 out of 10 new jobs (Husted \& Michailova, 2002). This signals an increase in demand for highly educated workers.

Retaining knowledgeable older workers will be critical to workforce participation (New Zealand Department of Labour, 2009; Mercer, 2008). New Zealand has adapted to significant demographic changes before, but the change from a growing workforce towards a diminishing one is a new phenomenon. Although the fall in the number of workers may be offset by greater productivity per worker, the reality is that older workers will also have other requirements such as greater flexibility for part-time work, and responsibilities for caring for elderly relatives.

The US and other Western nations are ill prepared for ageing and an aged society. In the US and Canada, the bulk of the baby boomers is yet to retire, and to some extent, there is time to plan for an older workforce and an ageing population. With further economic growth expected in New Zealand, the labour market will tighten, and employers will find that they need to attract and compete for older workers, focusing some attention on the rewards that they seek (Equal Employment Opportunities Trust, 2008; McPherson, 2008; Mercer, 2008; D. Salisbury, 2001). Governments and individuals need to start planning now, to cope with social changes and changes in lifestyle for older people. A failure to plan for retirement will lead to the decline of people over 65 years of age. 
Where workers generate earnings beyond the age of 65 , this makes a significant difference to their economic independence.

\section{Motivations of older workers}

Older people are seeking to work longer for several reasons. First, life expectancy has increased and the rate of disability for older people is declining (Wellner, 2002), so that they are physically in a better position to continue working than any past generation. Second, literature on the New Zealand situation indicates that older workers may need to continue working if they often have inadequate financial resources to retire (Cairns, 2009; McPherson, 2008; Mercer, 2008). Two-thirds of older baby boomers have inadequate finances to retire, and the qualification age for Social Security in the US increases to age 67 for those born after 1960. This means that there is an income gap necessitating the extension of working life beyond accepted retirement age. Finally, increased life expectancy and better health mean that people who retire may become bored with retirement activities and seek to return to the workforce. They need to feel needed and valued, and to be intellectually challenged and remain mentally active (Gardyn, 2000; Joyce, 2006a).

As skills become scarcer, organisations will need to retain or seek older workers to meet the shortage. A challenge that will face employers will be the need to get young and older workers to team together in a productive and harmonious environment (Challenger, 2000; Schetagne, 2001). A future trend may be for entrepreneurial older people to team up with technology savvy younger people to develop new products and services, combining the skills and experience of older workers with the technical knowhow of recent graduates. Older managers, chief executives and senior staff will be in demand for their reliability and experience, with organisations recognising their track record and the lower requirement for training, through more attractive remuneration.

Due to the sheer force of their numbers, whether baby boomers decide to remain in the workforce longer than previous generations of workers, or to retire earlier, there will be significant implications for labour markets and workforce planning (Purcell, 2000). 


\subsubsection{The concept of retirement}

\section{Retirement trends}

A gerontologist notes that we are entering the fourth era of retirement (Dychtwald \& Forsberg, 2001). Dychtwald states that the first era lasted till the early twentieth century and involved people working all their lives, moving to less strenuous jobs with advancing age. The second era began in the 1920s and lasted until the 1970s, introducing social security, which served as both a safety net and a means of removing older adults from the workforce. The 1970s saw the start of the third era of retirement, when leaving the workforce was a sign of success. There was an expectation of 20-30 years of retirement, funded by a combination of government and employer-based superannuation, supplemented by personal savings (Dychtwald \& Forsberg, 2001).

The fourth era of retirement is characterised by the realisation that retirees may lack sufficient funds, or become bored with their retirement activities. The re-definition of the term "retirement" therefore has its basis partly in the fact that life expectancy has increased over the last 20 years, so that at age 65 , we have a life expectancy of 18 years (Dychtwald \& Forsberg, 2001). Purcell's (2000) comparative analysis of life expectancy at average retirement age in four countries shows that between 1970 and 1995, there have been significant increases in life expectancy. For men, there was an increase from 11-13 years (in 1970) to 16-17 years (in 1995); for women, the increase was from 15-16 years (in 1965) to 21 -22 years (in 1995). Schetagne's (2001) focus groups with people in their early years of retirement identified a "not really retired" attitude, hopes to return to work for financial reasons, and that some attendees were reorienting their careers rather than retiring.

Purcell (2000) notes that the term "retirement" is most commonly defined with reference to two characteristics: "non-participation in the paid labour force and receipt of income from pensions, Social Security, and other retirement plans." (p19). However, between these two extremes are a range of scenarios, for example receiving a careerbased pension (military, law enforcement) while working to supplement a pension.

\section{Phased retirement}

There has, in recent years, been an increasing trend for retired workers to return to work following a period of retirement (Albrecht, 2001). Studies in the US indicate that $80 \%$ of the baby boomers intend to work at least on a part-time basis (Albrecht, 2001; Bolch, 
2000). Thus, while the baby boomers reach retirement age and Generation $X$ represent a smaller cohort, older workers may be willing and able to continue working beyond what was considered the traditional age of retirement. Gendell's (1998) study retirement age trends in US, Germany, Japan and Sweden noted that Japan's older workers have a remarkable high workforce participation rate because the widespread practice of rehiring workers once they have retired from their career jobs. This has, in Japan's particular case, been in response to labour scarcity and increasing life expectancy. The traditional concept of retirement as a single event involving the total cessation of employment is becoming an out-dated concept (Rappaport, 2001).

Phased retirement can be seen as a staged or gradual transition from full-time work to full retirement (Equal Employment Opportunities Trust, 2008; Liebowitz, 2004; Purcell, 2000) and the intermediate steps may involve working part-time, job-sharing, or on some other form of reduced working schedule, and may involve a change in employment status, such as moving from being an employee to self-employment or contracting, or switching from permanent to temporary employment. The concept of phased retirement is more prevalent in education and government, particularly where older workers possess technical skills, hold positions that are difficult to fill, or have valuable knowledge and strong business relationships with an organisation's key clients (Hirschman, 2001). Thus retirement is seen as the start of a new phase of life, rather than an end to employment (Gardyn, 2000).

\subsubsection{The experience and knowledge of older experts}

\section{Older experts' experience}

Older experts can be resilient and adaptable workers, with much life experience to complement their expertise (Bell, 2001; Equal Employment Opportunities Trust, 2008; Platt, 2001). Although some economies may have a stockpile of formal education in their labour markets, this is not the only factor in productivity, and skills and experience are needed to supplement education. Older experts can possess sound experience in all areas of business, have positive work ethics, and fill employers' needs for staff who can work flexible hours (Joyce, 2006a). Baby boomers represent the largest sector of the population - within this sector resides a significant amount of knowledge that is valuable as an organisational asset. When older experts leave the workforce, they can tend to leave skills gaps, taking with them significant experience and critical knowledge 
essential to the smooth management of organisations, affecting a range of industries (Hammer, 2002; Hylko, 2006; Liebowitz, 2004; Schetagne, 2001).

Older experts need to have ways of transferring their knowledge and sharing their experience. They may have capabilities to advise other workers, while having a flexible working arrangement such as working part-time, phasing into retirement or acting as a project team consultants (Liebowitz, 2004). From an organisational perspective, older workers may have expertise that is not entirely visible and is therefore lost to the organisation when they leave. "Human capital designating the valuable knowledge incorporated within individuals is, contrary to other forms of capital, appropriable by the individual who is also its carrier" (Ebrahimi, et al., 2008, p. 125).

\section{Retaining knowledge from older experts}

All too often, the extent of organisations' commitment to retaining expertise from older workers extends no further than the exit interview prior to their leaving (Liebowitz, 2010; Patton, 2006), or attempts to recapture required knowledge after employees have retired or their roles made redundant (Becerra-Fernandez \& Sabherwal, 2005; Hammer, 2002; Liebowitz, 2004). In western developed countries, employers need to address the threat of losing different types of knowledge, given the increasing reliance on mid- and late-career workers to meet skills demands. For example, the proportion of the New Zealand workforce aged between 45 and 64 years is expected to increase from $35 \%$ in 2001, to $45 \%$ by 2051 (NZ Department of Labour, 2006). In the US, 33\% of the labour force was over 45 years of age in 1998 (American Public Power Association, 2003). This percentage was expected to increase to $50 \%$ in 2010 (Kanfer \& Ackerman, 2004). By 2015, 20\% of the workforce would be over 55 years of age (AARP, 2004). This ageing of the population is reflected in the age structure of organisations (Streb, Voelpel, \& Leibold, 2008). Baby boomers have valuable knowledge that their younger colleagues do not possess, or have not yet developed (Hewitt, 2008).

It is therefore important for employers to implement processes for retaining and embedding the knowledge that older workers possess that is of value to their organisations. This includes knowledge of how technology, business processes and systems have evolved in the organisation, as well as qualities and irregularities of those systems, and knowledge about the organisation's work planning, markets and customer relationships (G. P. Huber, 2001; Rappaport, 2001; Slagter, 2007; Streb, et al., 2008). Older experts may also hold valuable knowledge of key industry players and resources, 
and tacit knowledge about company culture, politics and norms. Another important component of organisational knowledge is represented in the range of experience that such experts develop over time. This includes elements of corporate memory, such as the planning and decisions that led to the current organisational form; awareness of the organisation's past successes and failures, and why certain tactics or approaches are more effective than others. Most institutional knowledge is tacit in nature, therefore it is not documented or easily expressed; its existence may not be known; and it may have been built up over many years and through a web of relationships (Lahaie, 2005; Lesser, 2006; Liebowitz, 2010).

In specific areas, older experts may have unique skills that are no longer learned. For example, a transitional problem is that there is a severe shortage of skills and workers experienced in legacy applications skills such as mainframe applications programming (Goodridge \& McGee, 2002; Hewitt, 2008; Hilson, 2001). These skills may no longer be taught and younger workers are not interested in learning them, preferring new technologies such as web-based design and development. However, new applications often require interfaces to legacy systems. Skills in legacy systems are therefore required for as long as customers have no compelling reason to migrate from such platforms. Older workers may also have expertise in how to deal with technology failures (Hilsen \& Ennals, 2005).

There are many examples of organisations, such as NASA, Rolls Royce, Monsanto, Delta Airlines and Northrop Grumman, that lost knowledge following the departure of experts through redundancy. Such organisations realised that they were unaware of the lost knowledge until after the event and discovered that it was not easy to access and recapture that expertise (Becerra-Fernandez \& Sabherwal, 2005; De Long, 2004; De Long \& Mann, 2003; Parise, et al., 2006; Patton, 2006). Older experts have substantial knowledge about complex technical systems and integrated work processes (APPA, 2003; Carruthers, 2005; Hylko, 2006; Morrall, 2008; Stoutamire, 2006). Due to the impact of information technology over the last two decades, there is an organisational reliance on complex types of knowledge that did not previously exist (De Long \& Mann, 2003; Foos, Schum, \& Rothenberg, 2006; Stoutamire, 2006).

Older experts tend to have well-developed communication skills, knowledge, a sense of loyalty and good work ethics (Albrecht, 2001; Bell, 2001; Bolch, 2000; Equal Employment Opportunities Trust, 2008; Sternberg, 2003; Wellner, 2002) and are 
creative (Dychtwald \& Forsberg, 2001; Sternberg, 2003; Wellner, 2002). According to Bell, changes in the work environment, such as new ownership models in real estate, changes in industry structure and the use of technology, favour workers with maturity and experience. A study of human resource consultants by the American Association of Retired Persons (AARP) indicated that older experts are valued for their knowledge, experience, good work ethics, reliability, solid performance and that they respond well in a crisis. Intuition, judgement and knowledge, both tacit and explicit are indicative of deep smarts that may form the basis of organisational viability (Leonard, 2005; Leonard $\&$ Swap, 2005). These types of knowledge, skills and experience may not be recognised until those who possess it have left the organisation. This is partly because there is no particular correlation between the holders of such knowledge and those who hold formal power in organisations.

\subsubsection{Challenges and issues}

A major area of challenge for older experts is in the need to break down other people's negative perceptions of their attitudes to work and preventing discrimination in many forms (Equal Employment Opportunities Trust, 2008; Stam, 2009). These perceptions may include the view that they are less productive than younger people, that they will not be in the workforce for long, therefore are uneconomical to train, and that they are not as healthy or vital as younger workers (Albrecht, 2001; Ebrahimi, et al., 2008; Kaye $\&$ Cohen, 2008). Older experts who are still interested in promotions may be overlooked if they are not seen as having current skills or being as ambitious as younger workers (Wellner, 2002).

Older workers in general tend to be seen as being set in their ways and therefore harder to train or retrain, there is a perception that they lack ICT skills. At a time when management wants to reduce personnel costs, older workers may be seen to be expensive resources, and they are seen as being less able to deal with stress, or with current management methods and technology (Bell, 2001). Younger workers, by contrast, may be seen as being better educated and able to work harder and be more flexible (Bolch, 2000; Connolly, 2000).

Older experts want realistic alternatives to retiring abruptly, such as working full time to a certain point, then leaving the workforce completely. In light of the knowledge and skills gap caused by an ageing workforce (Liebowitz, 2004; Stam, 2009), there may be room to negotiate aspects such as the roles, location, timing and the number of hours 
that older experts work (De Long, 2007). Where employers are not proactive in offering employees alternative arrangements through formal schemes, they are managing their own transition to retirement by seeking bridging jobs and essentially taking responsibility for their own career management (Rappaport, 2001).

The rate of retirement per annum from the New Zealand workforce is gradually increasing, from an average of $1.2 \%$ of the workforce between 2001 and 2006, to an estimated average of 1.6 per annum from 2006 and 2011. The estimated average for the period 2011 to 2016 is 2.2\% per annum (New Zealand Department of Labour, 2010). This pattern of an increasing rate of retirement has a couple of implications for knowledge retention initiatives in terms of timing. The first implication is that organisations need time to plan initiatives and establish the culture, support and infrastructure for successful knowledge transfer (Davenport \& Prusak, 1998). The second implication is that organisations need to plan and allow for sufficient time before older workers who represent the knowledge source actually leave. This raises the issue that companies need to identify the types of knowledge that should be retained, and distinguish which older workers represent the source of this knowledge. Not all workers possess relevant knowledge, or other qualities such as experience, wisdom or intelligence by virtue of age alone (Baltes \& Staudinger, 2000; Leonard \& Swap, 2005).

\subsubsection{Summary}

There is an impending reduction in the rate of growth of the workforce with the ageing of the baby boom generation and a shortage of younger workers (Joe \& Yoong, 2006; Stam, 2009). Information on the specific types of knowledge that older workers possess has been gleaned from the literature on management, workforce trends, demography and retirement. However, it is not clear whether, or the extent to which, older workers' expert knowledge is distinct from that of younger workers. This study therefore aims to provide more insight into older experts.

Society and organisations need to rethink negative perceptions of older workers in general - older experts and their expertise are at risk of being lost from organisations. There are dual challenges in preventing the loss of expertise: first, in retaining such experts where they wish to delay their departure from the workforce, and second, in having appropriate initiatives to retain their specialist knowledge before they leave. 


\subsection{Knowledge retention}

In light of the ageing population and the knowledge that resides within older experts of the baby boom generation, a major challenge for organisations is the retention of this knowledge. In addressing knowledge retention challenges, organisations are concerned with "how best to capture and leverage knowledge to create value as well as preserve the institutional knowledge base" (Liebowitz, 2010, p. 87). The role of knowledge in the organisation influences how organisations retain knowledge. Action to retain knowledge may be taken at an organisational level through strategic initiatives aimed at the problem of knowledge loss associated with older workers' departure (Bresnen, Edelman, Newell, \& Swan, 2003; De Long, 2004). A wide range of processes and solutions are described in this literature (American Public Power Association, 2003).

Different models for knowledge retention exist, and these involve the retention of both explicit and tacit knowledge held by older experts. Explicit knowledge may be structured into a firm's intellectual capital. Tacit knowledge, however, is personal, inferred, subjective, based upon experience and practice, and "important in understanding organizational routines" (McAdam, Mason, \& McCrory, 2007, p. 43), is shared and made explicit through socialisation, demonstrations and stories.

The literature on factors for successful knowledge transfer is reviewed, and some commonalities are identified. I briefly discuss knowledge retention, knowledge transfer and knowledge sharing. In understanding knowledge retention, the dimensions or characteristics of knowledge are pertinent, for example tacit and explicit knowledge are retained or transferred differently, and the strength of the ties between the knowledge holder and recipient also influence the method of transfer. Next, the perspectives and characteristics of knowledge are addressed, followed by a discussion of knowledge retention in organisations.

For the purposes of this study, I adopt the stance that tacit knowledge may not usually be transferred directly from the expert, as knowledge holder, to the knowledge recipient. Tacit knowledge needs to be converted to an explicit form, through methods such as shared experience, practical demonstrations and other means of socialisation. Once made explicit, this knowledge may then be documented and retained by organisations. 


\subsubsection{Knowledge retention, transfer and sharing}

A review of the literature on knowledge management reveals that authors often use the terms "knowledge retention", "knowledge transfer" and "knowledge sharing" interchangeably. For clarity, it is appropriate to distinguish between these related concepts and describe how they have been used in this thesis.

Knowledge retention is a strategic concept relating to organisations' efforts to preserve knowledge which is at risk of being lost. An example of this is the retention of knowledge from older experts who are approaching retirement and whose knowledge may then become inaccessible as an organisational asset. Retention is important from an organisational perspective, while the word transfer often relates to the actions of the individual: "How do we ensure retention of knowledge in the organization when experienced workers retire, and enable older workers to transfer their skills, knowledge and experience as a corporate asset?” (Hewitt, 2008).

Knowledge retention processes can be closely related to the knowledge life cycle, which consists of several stages. The stages are described similarly by various authors: knowledge acquisition, refinement, storage and retrieval, distribution and presentation (M. Zack, 1999a); creation, acquisition, expansion and innovation (Chen, Shang, Harris, $\&$ Chen, 2007); create, preserve and disseminate (M. Salisbury, 2009); and acquisition, modelling, reuse and maintenance (Millard, Tao, Doody, Woukeu, \& Davis, 2006).

Taking Zack's (1999) description, the first stage, acquisition, involves creating knowledge or acquiring it from sources such as employees. The second stage, refinement, includes indexing, sorting, abstracting, standardising and recategorising knowledge so that it can ultimately be made available for reuse. The third stage, storage and retrieval, involves entering knowledge into a repository. The fourth stage,

distribution, involves putting mechanisms into place for making content accessible. The fifth and final stage, presentation, includes selecting, arranging and integrating knowledge for use. Knowledge retention is therefore related to the knowledge life cycle, in that it involves activities such as identifying valuable knowledge, selecting methods and technologies for capturing or recording it, transferring knowledge, then converting it into products or formats for presentation and reuse. The successful execution of each step of the cycle enables organisations to leverage knowledge as an asset (Freeze \& Kulkarni, 2008). 
Knowledge transfer is a subset of the knowledge retention activities. Transfer relates to the practical, focused efforts in physically passing knowledge from a knowledge holder to a knowledge seeker, or to a repository from which transferred knowledge can be accessed. Knowledge transfer may occur between individuals or at the group or team level (Davenport \& Prusak, 1998; Gammelgaard \& Ritter, 2005; Szulanski, 2000). Thus the term knowledge transfer may refer to a flow of knowledge (Alavi \& Leidner, 2001)The transfer of knowledge to a system involves the creation or acquisition stage of the knowledge life cycle. Once knowledge has been transferred, it may move to the next stage of the knowledge life cycle and undergo refinement by the recipient, for reuse. Knowledge transfer is a lower level concept than knowledge retention, and much of the literature implies a uni-directional flow of knowledge from the knowledge source to the knowledge seeker or system (Tempest, 2003).

Knowledge sharing is the exchange of knowledge between or among individuals (McAdam, et al., 2007) and groups (Osterloh \& Frey, 2000; Riege \& Zulpo, 2007). The knowledge that is shared may be explicit, such as through extending to different groups of users access to knowledge resources like knowledge management systems. Communities of practice (CoP) and special interest groups (SIG) also facilitate mutual sharing of tacit knowledge among members, often across organisational boundaries, and participation tends to be voluntary and informal (Snyder, Wenger, \& Briggs, 2003). Knowledge sharing may be a broader concept than knowledge transfer, as "sharing encompasses more than only the transfer of descriptions containing justified factual information. ... many knowledge sharing episodes contribute to the creation of knowledge..." (Berends, 2005, p. 104)

\subsubsection{Perspectives of knowledge}

Knowledge and its management hold an important role in the modern economy (Abbasi, Moncef, \& Hollman, 2009; Calo, 2008; Davenport \& Prusak, 1998; B. Huber, 1999; McAdam, et al., 2007). The role of knowledge in an organisation's activities, and the way in which an organisation uses knowledge, influence its approach and methods for managing knowledge. Knowledge creation and retention is widely recognised as a significant organisational capability and is regarded as representing a source of longterm competitive advantage (Alavi \& Leidner, 2001; Connell, et al., 2001; Gammelgaard \& Ritter, 2005; Leonard \& Swap, 2005). 
Knowledge is primarily managed through strategies such as the acquisition and retention of knowledge workers, and the establishment of infrastructure such as the use of computer-based knowledge management systems (England \& Herrera, 2005; Hammer, et al., 2004; G. P. Huber, 2001; IBM Business Consulting Services, 2004). As older experts retire, their knowledge will be lost to organisations that do not act to retain it by capturing it within information technologies or facilitating its transfer to other employees (APPA, 2003; Ashworth, 2006; Basiulis, 2009; Casher \& Lesser, 2003; Slagter, 2007).

Organisations employ a combination of two distinct strategies for knowledge management (Gammelgaard \& Ritter, 2005; Hansen, et al., 1999). A codification strategy involves capturing and structuring knowledge by means of ICT and is appropriate where organisations view certain types of knowledge as being separate from the individuals who possess it, or where they need to retain knowledge from knowledge holders. A strategy of personalisation relies on personal interaction and socialisation for the purposes of knowledge sharing, focusing on channelling expertise to the place where the knowledge is required.

There is much literature that describes and distinguishes between explicit and tacit knowledge and the different ways in which they may be retained or transferred. Further dichotomies exist in the literature as to whether tacit knowledge may be converted or made explicit, for the purposes of transfer (McAdam, et al., 2007; Nonaka \& Konno, 1998; Nonaka \& Toyama, 2005; Polanyi, 1967; Stenmark, 2001). Knowledge is embedded in an organisation's culture, policies and procedures, systems and documents, as well as in individual employees (Alavi \& Leidner, 2001; Argote, et al., 2003; Davenport \& Prusak, 1998). This knowledge may be explicit, in which case it is conscious, articulated, documented and communicated, often referred to as "knowing about", and reside with individuals or groups. Tacit knowledge is described as automatic, related to actions and experience, and referred to as "knowing how". It is idiosyncratic and difficult to articulate or share (McAdam, et al., 2007). Tacit knowledge is "possessed in the mind of individuals: it is personalised information (which may or may not be new, unique, useful or accurate) related to facts, procedures, concepts, interpretations, ideas, observations and judgements." (Alavi \& Leidner, 2001). Personal relationships, participation, and the building of team spirit foster its exchange. Tacit knowledge is marketable only if it is encapsulated in goods or services (Osterloh $\&$ Frey, 2000). 
The distinction between individual and organisational knowledge also relates to the tacit and explicit dimensions. Alavi and Leidner cite Stein and Zwass (1995, p85) in observing that storing and retrieving knowledge are part of managing the organisational memory, "the means by which knowledge from the past, experience and events influence present organisational activities." An organisation's semantic memory is articulated and documented - episodic memory relates to context-specific, situated knowledge.

\subsubsection{Knowledge characteristics}

\section{Tacit and explicit dimensions of knowledge}

"It is argued that knowledge is a form of human capital which is owned by knowledge workers. It includes all the intellectual abilities and knowledge possessed by employees, as well as their capacity to learn and acquire more knowledge" (Abbasi, et al., 2009, p. 366). Ebrahimi (2008) goes further in onserving that the knowledge of older experts is largely tacit and that it is "embedded in their 'memory' and their knowledge of the professional environment, and in their relational knowledge instituted in networks of contacts" (Ebrahimi, et al., 2008, p. 136). As much as $90 \%$ of knowledge within organisations may be tacit (Wah, 1999), but the value of tacit knowledge and the processes for its transfer are poorly understood (Foos, et al., 2006).

In terms of the importance of tacit knowledge within organisations, Grant (1996; cited in McAdam et al., 2007), states that it is the most strategic organisational resource. Tacit knowledge is also required for organisations to apply and exploit their explicit knowledge (Brown \& Duguid, 1998; Wah, 1999). McAdam (2007) proposes a working definition of tacit knowledge, drawn from a review of some of the literature: "Tacit knowledge - knowledge-in-practice developed from direct experience and action; highly pragmatic and situation specific; subconsciously understood and applied; difficult to articulate; usually shared through interactive conversation and shared experience" (McAdam, et al., 2007, p. 46).

Relevant to the subject of knowledge transfer is the distinction between explicit knowledge and tacit knowledge, first made by Polanyi, who noted that only a small part of our knowledge is explicit, in that "we know more than we can tell" (Polanyi, 1967, p. 4). Individuals acquire and store tacit knowledge and it cannot be transferred or traded as a separate entity (Leonard, 2005), yet it informs all of our actions. While explicit 
knowledge consists of words and symbols, tacit knowledge is invisible and difficult to measure. Leadership, a positive organisational culture, trust and rewards are all factors that encourage the sharing of tacit knowledge (McAdam, et al., 2007).

Older experts are said to possess much accumulated tacit knowledge, which is a strategic resource at risk of being lost when they leave the organisation. "It is not a matter of making that expertise explicit and capturing it in software, but of enabling junior workers to gain access to tacit knowledge through dialogue" (Hilsen \& Ennals, 2005 , p. 554). The conversion of tacit knowledge into explicit knowledge involves one person's tacit knowledge being amplified and recorded in the form of routines. The knowledge conversion modes are explained in Table 2-1 (p. 28).

\begin{tabular}{|l|l|}
\hline Conversion mode & \multicolumn{1}{|l|}{ Description } \\
\hline Socialisation & $\begin{array}{l}\text { Individuals share tacit knowledge mainly by learning by } \\
\text { doing. }\end{array}$ \\
\hline Externalisation & $\begin{array}{l}\text { Parts of tacit knowledge are translated into explicit supported } \\
\text { narratives, visuals and analogies. }\end{array}$ \\
\hline Combination & $\begin{array}{l}\text { Different explicit knowledge is bundled together for example } \\
\text { the exchange of documents, computerised communications or } \\
\text { formal training serve to enrich and systemise the explicit } \\
\text { knowledge base. }\end{array}$ \\
\hline Internalisation & $\begin{array}{l}\text { Knowledge converted into rules of action and practice } \\
\text { becomes routines and part of the firm's organisational } \\
\text { memory }\end{array}$ \\
\hline
\end{tabular}

Table 2-1: Knowledge conversion modes, Nonaka \& Konno (1995).

Assuming the presence of goodwill, Nonaka subsequently summarises the effect of converting tacit knowledge to explicit knowledge: "through this process of tacit and explicit knowledge conversion, subjective values are synthesized into more objective, socially shared knowledge" (Nonaka \& Toyama, 2005, p. 423). Zack (1999) echoes this with his assertion that tacit knowledge that is made explicit and shared eventually becomes core knowledge in the future.

Some of the knowledge that needs to be transferred from an expert to another employee can be embedded "not only in documents or repositories but also in organizational routines, processes, practices and norms" (Davenport \& Prusak, 1998, p. 5) and may therefore not easily lend itself to being located and shared (Gammelgaard \& Ritter, 2005). Tacit knowledge may also include knowledge about a company's politics, norms and culture (Hewitt, 2008). Osterloh and Frey (2000) discuss knowledge-based production teams where knowledge is embedded in an organisational unit and cannot be 
made explicit by reverse engineering or by capture in expert systems. They cite the example of Benetton's superior fashion design, which is integrated with garment knowledge, market knowledge and manufacturing expertise. Other reasons for the inability to share knowledge between organisational units could be that competition between profit centres hinders goodwill required for the retention of tacit knowledge, or that compensation is based on a unit's profitability.

Tacit knowledge may remain tacit for several reasons. It may be inefficient to convert it to explicit, formalised knowledge due to the cost or the lack of incentives to do so. It is difficult to articulate knowledge that is largely personal, since it exists within mental models, in the form of intuition, beliefs and perceptions that are so deeply embedded in the individual or their role that they are unaware that they possess it. Even if such knowledge could be articulated, it may not be meaningful once encoded, or it may not be useable in a different context (McAdam, et al., 2007). Technology is thought to be a barrier (Connell, Klein, \& Powell, 2003) as there are few successful knowledge sharing technologies. Motivation and language are also inhibitors insofar as there is no guarantee that knowledge can be internalised once transferred to a recipient. Successful transfer is also reliant on knowledge being articulated in a form that enables the transfer to happen, for example the knowledge recipient understands the knowledge in context (Gammelgaard \& Ritter, 2005; Szulanski, 2000). There are difficulties with internalising and externalising knowledge in that some tacit knowledge cannot be coded. Facilitating the generation of knowledge in the recipient could be a more effective way of getting knowledge where it is needed.

The literature reveals conceptually different views on the nature of tacit knowledge. Some scholars state that tacit and explicit knowledge are two separate types, and that tacit knowledge needs to be converted to explicit knowledge for it to be transferred (Chilton \& Bloodgood, 2008; Nonaka \& Konno, 1998; Nonaka \& Toyama, 2005; Osterloh \& Frey, 2000). A different perspective, as described by Polanyi (1966) is that someone who possesses tacit knowledge needs to become aware of that knowledge before they can find a way to express it explicitly and therefore share it with others. Sharing is most effectively achieved through experience, such as interacting in a practical way with an expert within the context of a business process, where the expert is able to provide feedback (McAdam, et al., 2007). 
There is a related matter regarding the desirability of making tacit knowledge explicit, assuming this is possible. First, the nature of tacit knowledge makes it resistant to efforts to convert it to explicit knowledge, and implies different approaches for sharing, as discussed above. McAdam, Mason and McCrory's analysis of literature on tacit knowledge revealed sub-types or epitomes of tacit knowledge that assist our understanding of its diversity. The epitomes include intuition, skills, insight, know-how, beliefs, mental models and practical intelligence (McAdam, et al., 2007, p. 52). These epitomes convey that tacit knowledge is personal, experiential, situated and contextual, with the implication that they would be challenging to make explicit. Second, tacit knowledge provides greater competitive advantage as it is difficult to imitate and is socially complex. Where an organisation's tacit knowledge is strategically important, and forms the foundation of a firm's competitiveness, there is therefore an argument against codification since codified knowledge is easily acquired by competitors - for this reason, tacit knowledge should remain embedded in a product or service (Chilton $\&$ Bloodgood, 2008; Gammelgaard \& Ritter, 2005; Grover \& Davenport, 2001). Last, McAdam (2007) notes that attempts to convert and codify tacit knowledge in knowledge management systems may be interpreted as increasing managers' power over knowledge workers. Therefore, organisational focus should be directed more towards valuing and sharing tacit knowledge, and less on converting it (Chilton \& Bloodgood, 2008; Gammelgaard \& Ritter, 2005; M. H. Zack, 1999).

\section{Alternative views}

Alavi and Leidner (2001) express the view that to focus on the relative value of tacit knowledge compared with explicit knowledge misses the point, and that one way technology can be leveraged is to strengthen the weak ties in organisations. Weak ties "cover distant, infrequent relationships between individuals" (Gammelgaard \& Ritter, 2005, p. 135). Examples of these types of technologies would be databases, expert directories, collaborative software for on-line discussions, and web sites that support communities of practice and encourage participation and collaborative work. Such tools support knowledge retention by increasing the breadth of knowledge sharing.

Other knowledge classifications include looking at different dimensions of knowledge. Declarative knowledge is "know about" or explicit knowledge, procedural is tacit or "know how" and "know who" which is developed through experience (Abbasi, et al., 2009) causal is to "know why", conditional is "know when", and relational is "know 
with". A pragmatic approach would be to define types of knowledge that are useful to organisations, and use these taxonomies to inform the design of knowledge retention processes and knowledge management systems.

Other dimensions of knowledge include those drawn by Matusik and Hill (1998) as cited by Connell et al (2003). Individual versus collective knowledge distinguishes between knowledge held by persons and that held by groups or organisations. Private and public knowledge distinguishes between knowledge held within the boundaries of the firm, and that available in the public domain. Component knowledge is about processes, business areas or parts of an organisation's operations, while architectural knowledge (more valuable) provides a holistic view of the organisation for example its operations, objectives and performance.

\subsubsection{Knowledge retention in organisations}

With the increasing pace of organisational change, knowledge may be current only for a short time, and organisations need to enable faster organisational and personal learning through more effective knowledge retention methods (Bockman \& Sirotnik, 2008; Gammelgaard \& Ritter, 2005; Wiig, 2001). “Today's rapid changes make it vital that employees, regardless of specific occupation or expertise, must remain current in their knowledge and skills" (Bockman \& Sirotnik, 2008, pp. 130-131). Operational knowledge, that is, knowledge about business processes, needs to be captured effectively when employees depart, so that organisations do not lose large amounts of knowledge, but are able to turn it into what Wiig refers to as structured intellectual capital (p 159), for the benefit of the organisation. Tacit knowledge which may not be made explicit or transferred to another person, needs to be re-created through guided experience (Leonard, 2005). "Practice lays a foundation to share tacit knowledge (socialization) through shared experience" (Nonaka \& Toyama, 2005).

Knowledge management projects and knowledge systems both have an important role in supporting knowledge retention in organisations. Davenport and Prusak (1998) observe that knowledge management projects appear to have one of three aims. First, projects may have the objective of making knowledge and the role of knowledge visible to the organisation. Second, they may develop a knowledge intensive culture and promote knowledge sharing. Finally, they may build a knowledge infrastructure in the form of systems, the connection of people, and the provision of space, time and tools that aid collaboration. Therefore, such projects provide an infrastructure for knowledge 
retention and may, in the course of making knowledge visible, also raise awareness of the location of valuable knowledge that needs to be retained.

Adopting a view of organisations as knowledge systems, Nonaka and Konno (1998) posit that organisations need to create their "ba", which they define as a common place or space for creating knowledge. There are 4 types of ba facilitating knowledge creation, as described in Table 2-2 (p. 32).

\begin{tabular}{|l|l|}
\hline $\begin{array}{l}\text { Space for creating } \\
\text { knowledge }\end{array}$ & Description \\
\hline Originating ba & $\begin{array}{l}\text { Socialising mode: a common place for individuals to share } \\
\text { experiences in the same place and time }\end{array}$ \\
\hline Interacting ba & $\begin{array}{l}\text { Externalising mode: place where tacit knowledge is } \\
\text { converted to explicit knowledge, then shared through } \\
\text { dialogue and collaboration }\end{array}$ \\
\hline Cyber ba & $\begin{array}{l}\text { Combining mode: a virtual space for interacting and sharing } \\
\text { knowledge }\end{array}$ \\
\hline Exercising ba & $\begin{array}{l}\text { Internalising mode: a place to convert explicit to tacit, } \\
\text { continuous space for individual learning }\end{array}$ \\
\hline
\end{tabular}

Table 2-2: Knowledge creating spaces, Nonaka and Konno (1998).

Knowledge that is created in the spaces of originating ba, interacting ba and cyber ba may initially be created and shared informally, but may also lead to that knowledge being retained in the form of knowledge products for wider use in the organisation.

\section{Knowledge retention approaches}

Various organisations have documented approaches for addressing the workforce issue, and include knowledge retention in the scope of this broader issue. For example, the American Public Power Association (APPA, 2003) describes an approach that involves:

1. tracking relevant workforce statistics

2. making retirement projections

3. educating stakeholders and political leaders about the issue

4. implementing workforce and succession planning

5. capturing undocumented knowledge and facilitating its transfer from older to younger workers

6. recruiting and developing younger workers

7. considering rehiring selected retirees

8. slowing the departure of older workers who are retiring

9. creating a supportive workplace that promotes diversity 
The Electrical Power Research Institute describes a generic process for capturing tacit knowledge through making it explicit, which involves initially defining the process and methods to prevent loss of knowledge, and then capturing undocumented knowledge from identified experts (EPRI, 2006). Sites that are willing to test the process and methods are identified, and training workshops are held for personnel who are to manage the process including knowledge elicitation. Once the process is finalised and the plan implemented, the organisation packages the knowledge product for future reuse. Lesser's (2006) cross-industry analysis stresses the importance of being proactive, and developing a plan that includes diagnosing the problem - analysing the organisation's workforce characteristics, determining critical skills and experience, identifying solution options - then developing a plan to address this workforce issue.

A generic process for facilitating knowledge retention in response to the loss of older workers who have valuable, critical and unique knowledge may involve identifying critical experts and expertise, defining knowledge retention initiatives, outcomes and knowledge products, eliciting and recording the knowledge (or implementing the technology for facilitating the and sharing of tacit knowledge), verifying the knowledge and making it available for reuse.

The first step, assuming an organisation recognises that it needs to plan for the loss of knowledge associated with the retirement of older workers, would be the identification of experts whose knowledge needs to be retained or documented, whose details need to be captured for future contact, or who may be available to work in the future (Hammer, 2002; Gross, Hanes and Ayres, 2002; APPA, 2003; Hylko, 2005; and IBM 2005). Specific responses to loss of knowledge depend on a few factors. Timing is critical, as the time available determines how long an organisation has for capturing explicit knowledge or facilitating the sharing of tacit knowledge. Loss of knowledge may be immediate, for example personnel leaving suddenly through retrenchment, or progressive, as baby boomers retire over the next decade (De Long and Mann, 2003). With the sudden departure of personnel, such knowledge is likely to be irretrievable due to the lack of motivation (Slagter, 2007). The type of knowledge being lost is relevant, in that explicit knowledge can be captured, but tacit knowledge implies direct, frequent interaction between expert and knowledge recipient to be effective (Leonard \& Sensiper, 1998; Leonard \& Swap, 2005). In particular, knowledge that is both critical and unique needs to be addressed as a priority. 
Second, the organisation needs to decide what types of initiatives it will implement to most effectively support knowledge retention. For the sake of efficiency, existing initiatives, tools and processes may be used or updated. Examples are recruiting and retention policies (Joyce, 2006b), training schemes, mentoring arrangements, communities of practice and knowledge coaches (Hammer, 2002; Leonard \& Sensiper, 1998). It is important to allocate sufficient time for effective knowledge transfer at a practical level, especially where training a new appointee is concerned. This may be addressed through the retiree spending reduced hours in their organisational role or in a position of less responsibility, so that knowledge transfer can take place and the new appointee can be supported through medium-term activities such as planning and budget cycles (Lahaie, 2004).

Third, knowledgeable employees who are approaching retirement are encouraged to record their knowledge, or make their knowledge available for capture. Various processes and technologies exist to capture explicit knowledge and to support the sharing of tacit knowledge. These include creating a company-wide database of retired workers (Hewitt, 2008), using storytelling techniques to capture lessons learned (De Long, 2007), and using the critical decision method to elicit valuable knowledge on significant incidents, simulations, scenarios, and concept mapping (Hylko, 2005). In each case, there is an agreed knowledge product or outcome..

Last, the knowledge that is captured needs to be evaluated and made available for reuse. The newly captured knowledge may be made available as an updated database, and knowledge products produced from the elicitation process may be made available as manuals (Hylko, 2005). Media such as video may be made available in DVD format, or published on company intranets, bandwidth permitting. Where organisations need knowledge to be dynamic rather than static and to short circuit the traditional publishing cycle they may choose to capture and make knowledge knowledge available on a wiki web site. This provides the advantages of “....alternative and fast pathways to get at expertise and use community intelligence to bring new ideas to the forefront" (Gordon, 2006, p.26).

Stenmark's (2001) and Crowder et al's (2002) studies of the introduction of a recommender system shows how ICT can provide support for sharing tacit knowledge. Instead of focusing on systems to aid documentation of explicit knowledge, ICT can be used to help find useful people. 
Berend's (2005) framework for knowledge sharing may be a meaningful perspective from which to consider knowledge retention from older experts. The framework was developed from a study of industrial researchers' actions in sharing knowledge in the course of problem-solving. His framework addresses the content and contributions or value of knowledge that is shared, areas in which there had been little research. Based on his analysis of researchers' recorded dialogue, he identified five categories of knowledge sharing moves, which are defined as the basic unit of knowledge sharing. The categories are descriptions, suggestions, evaluations, questions and actions.

The first category, descriptions, could be of technologies, research results or characteristics of materials. A description is a an explanation of an idea, a theory or a process that exists in reality. The second category, suggestions, differs from descriptions, as suggestions include valid and invalid ideas. Suggestions may not necessarily lead to further exploratory actions, as a person making a suggestion may not necessarily expect it to be followed up. A suggestion may also be in the form of a warning that recommends someone against taking a specific action. The third category, evaluations, relates to concurrence or disagreement with previous moves. Researchers are often occupied with evaluating options, assessing the suitability of solutions and giving reasons for their choices. The fourth category, questions, includes an individual seeking information they need for their own purposes, or asking someone for clarification so they can better understand the problem. The fifth and final category is actions, which have meaning in a context or environment such as a laboratory or office, and involve objects such as files, data or publications. There may be non-linguistic aspects involved, such as when two researchers are sharing tacit knowledge through observing an experiment or completing a calculation together.

The knowledge sharing moves described above affect or contribute to work practices, in this case, problem-solving. First, a knowledge sharing move may contribute directly to solving a problem. Second, it may help a researcher to formulate the research problem more clearly. Third, it may be activating, causing a researcher to take a particular action. Fourth, it may yield background information that can be used in problem-solving, or be useful at a later date. Last, it may lead to the development of knowledge about others, for example, their problems, their knowledge or some aspect of their work. Such knowledge is useful in future interactions. 
Berends' framework focuses on the contribution or effect of knowledge sharing in relation to the work practice of solving problems. It is therefore relevant in my research, which is set in the context of a problem solving business process. The research topic also acknowledges the value of knowledge that needs to be retained, so Berends' concept of the contributions of knowledge is directly relevant.

\subsection{Knowledge transfer}

There are different frameworks for organisations to encourage groups and individuals to transfer or share knowledge as part of the organisational culture. Encouraging effective knowledge-sharing behaviour requires collaboration and support in a non-political environment, such as voluntary learning communities, knowledge networks or communities of practice (Gongla \& Rizzuto, 2001). Membership of these communities can continue after an employee has left an organisation, and such ongoing links can enable the retiree to remain contactable for mentoring where this is appropriate. These communities provide an environment and motivation for knowledge sharing and may decrease the level of institutional knowledge that is lost on retirement or resignation.

Another perspective of knowledge transfer is Gupta and Govindarajan's (2000) model, as described by (Alavi \& Leidner, 2001, p. 120). The five elements of knowledge transfer, or knowledge flows, are the perceived value of the source unit's knowledge, the motivational disposition of the source to share knowledge, the existence and richness of transmission channels, the motivational disposition of the receiving unit to acquire knowledge from the source, and the absorptive capacity of the receiving unit to acquire, assimilate and use knowledge. Alavi and Leidner note that most of the literature focuses on transfer channels. ICT support for knowledge transfer has mainly been for impersonal and informal transfer, for example discussion databases. Formal and impersonal means are also supported by knowledge maps and corporate directories.

\subsubsection{Transferring knowledge about best practice}

Szulanski's (1996) model for knowledge transfer in the domain of best practices involves 4 stages for knowledge transfer projects, as described in Table 2-3 (p. 37). Szulanski's model has similarities with O'Dell and Grayson's (1999) four-step change process for transferring knowledge. First, the organisation plans, assesses and prepares for the transfer. Second, it designs the transfer project, and third, the transfer is 
implemented. Last, the process is complete, with the transition and scale-up to full use of the knowledge.

\begin{tabular}{|l|l|}
\hline Project stage & $\begin{array}{l}\text { Description } \\
\text { Initiation }\end{array}$ \\
$\begin{array}{l}\text { Identify the knowledge need, and the knowledge to meet the } \\
\text { need } \\
\text { Collect and evaluate information to confirm the feasibility of } \\
\text { the transfer }\end{array}$ \\
\hline Implementation & $\begin{array}{l}\text { Set up transfer-specific social ties between the knowledge } \\
\text { Source and the recipient } \\
\text { Adapt the best practices to be transferred to suit the needs of } \\
\text { the recipient, pre-empt problems }\end{array}$ \\
\hline Ramp-up & $\begin{array}{l}\text { Recipient starts using transferred knowledge } \\
\text { Resolve unexpected problems that cause the objectives of the } \\
\text { transfer not to be met }\end{array}$ \\
\hline Integration & $\begin{array}{l}\text { Recipient gets satisfactory results from using the transferred } \\
\text { knowledge } \\
\text { New practices lose their novelty and are accepted as part of the } \\
\text { organisational routines }\end{array}$ \\
\hline
\end{tabular}

Table 2-3: Stages of best practice knowledge transfer (Szulanski, 1996)

\subsubsection{Successful knowledge transfer in organisations}

In a knowledge-based economy, the effective use of knowledge, regardless of the age of its provider, is a major factor in achieving competitive advantage and increasing performance (Abbasi, et al., 2009; Calo, 2008; Gammelgaard \& Ritter, 2005). O’Dell \& Grayson (1998) cite examples of improvements such as increased revenues, increased capacity, financial and time savings and increased profitability that result from the transfer of benchmarking-related knowledge in firms. Michael Hammer argues that the concept of improving knowledge worker productivity misses the point, due to the inability to define meaningful measures, and that a more appropriate goal is to "get more out of the entire organisation" (Hammer, et al., 2004).

Organisations need to share knowledge, between individuals and across business units, to avoid redundancy in knowledge production, although knowledge production and creation can be embedded in some organisations' culture (Husted \& Michailova, 2002) and form a fundamental part of some organisations' business models, for example creative industries such as advertising tend to have values related to originating rather than reusing knowledge (Davenport \& Prusak, 1998).

In some organisations, it is sufficient for management to provide incentives, goals and technology for knowledge transfer among employees and across business units, while in 
others, there may exist a hostile environment, where knowledge-sharing depends on management first addressing this hostility and building trust (Husted \& Michailova, 2002; Szulanski, Cappetta, \& Jensen, 2004).

Transferring and sharing knowledge are both essentially people-related activities that require an environment of goodwill and trust, clear objectives that are consistent with organisational strategies, appropriate rewards and demonstrated senior management support at an organisational level (Husted \& Michailova, 2002; O’Dell \& Grayson, 1999; Zarraga \& Bonache, 2003). Noting that in recent years, knowledge management has turned its focus from technology and back to the human dimensions, Leonard reminds us that "we still love stories and learning in communities; ... want to establish trust before conveying information; we still crave experience-based, proven and practical knowledge" (Hammer, et al., 2004).

A distinction must be made between individually held knowledge and knowledge that resides within an organisation, because in the context of this study, personally held expert knowledge examined in two ways. First, the expert shared with knowledge with other individuals in his organisation and industry. Second, some of his expert knowledge was retained in a variety of ways so it could be made available as organisational knowledge.

According to O'Dell and Grayson (1999) there are three enablers for successful knowledge transfer, once the strategic value proposition for knowledge transfer has been formulated. The first enabler, a culture conducive to knowledge sharing, is the most important factor, as it is potent and difficult to alter. It is a function of the past, "it's the set of underlying beliefs that, while never exactly articulated, are always there to colour the perception of actions and communications." (p12). Learning and sharing knowledge are social activities. Connections have to be made between people who wish to share their knowledge. The sharing of tacit knowledge is largely informal and collaborative. Davenport and Prusak (p88) refer to the need to "hire smart people and let them talk to one another", for knowledge to be transferred effectively.

Actions to facilitate knowledge transfer depend on whether the culture promotes sharing or hoarding of knowledge (Husted \& Michailova, 2002). People and culture are the keys, as learning and the sharing of tacit knowledge are social activities. Also, in the case of best practices, these are complex, rich and embedded in context. On this basis, 
O'Dell and Grayson conclude that knowledge transfer works best in healthy, sophisticated firms with team-based cultures that are accustomed to change initiatives.

Alongside a knowledge sharing culture, tools may assist the transfer of expertise, through collaboration. This leads to the second enabler, in the form of information and communications technologies (ICT), whose distributed nature supports collaboration, and may also assist in reducing costs and improving the efficiency of business processes. It can also result in too much information, however, leaving overloaded workers in a position where they cannot make sense of their environment (Gammelgaard \& Ritter, 2005). Other negative impacts include having technology inappropriate to the type of knowledge being transferred. In developing a knowledge retrieval matrix, Gammelgaard and Ritter (2005) state that different types of technologies are appropriate for different knowledge strategies in an organisation. For example, databases are suited to highly codified knowledge with little personalisation, such as standards and procedures, corporate documents and reports. By contrast, software to support virtual communities of practice could support codified knowledge that is also personalised, for example via a web site or portal. A related concept is that the sharing of tacit knowledge requires less technology and more time spent with the expert as the knowledge holder (Hewitt, 2008; B. Huber, 1999; McAdam, et al., 2007).

The third enabler is a knowledge infrastructure to facilitate change. Organisations may establish knowledge management services and networks to assist with the transfer process. Organisations must "put in place structures, processes and supporting information technology systems that provide a knowledge management architecture" (Hewitt, 2008). Initiatives such as communities of practice and knowledge networks may form part of the knowledge sharing infrastructure, with older experts continuing to use them following retirement. Other options may include self-directed facilities such as libraries, web sites and databases.

O'Dell and Grayson (1999) note, however, that measurement methods do not currently address the knowledge transfer effort itself, but focus on the success of projects or business processes that are dependent on the transfer of best practices. While external knowledge management initiatives may be measured by increased revenue or cost avoidance, it is difficult to quantify the successful sharing of tacit knowledge.

In the case of person-to-person knowledge transfer, Connell, Klein and Powell (2003) cite from Simonin (1999) several factors that assist the transfer. Collaborative know- 
how and learning capacity are required. There is a focus on tacit knowledge and training. The duration of the alliance of knowledge source and recipient is a relevant factor, as is the transfer of knowledgeable personnel. Knowledge is generated through know-why transfer, through the use of explanations and models. In the course of the transfer, it is necessary to address the assumptions about contextuality, and consider how the knowledge that is transferred can be embodied in equipment and tools.

Successful knowledge transfer stems from organisational clarity on the strategic value proposition for the business (Hammer, et al., 2004; O’Dell \& Grayson, 1999). This sets direction and influences an organisation's decisions on the types of knowledge it needs to acquire, develop, retain and use. It is also likely to determine the organisation's methods for transferring knowledge, in that "knowledge management and transfer are best linked to the competitive strategy that wins you the best advantage in your marketplace" (Hewitt, 2008; O’Dell \& Grayson, 1999). Another perspective involves the belief that knowledge management should enable organisations to take effective action (Connell, et al., 2003). Adopting an action-orientated perspective implies a focus on capturing and integrating knowledge, and this perspective also treats knowledge as a systemic property of the organisational system to which it belongs.

Specific types of motivation are required for the successful sharing of tacit knowledge, according to Osterloh and Frey, 2000, who have applied the social psychology theory of interaction between intrinsic and extrinsic motivation to organisational theory. With extrinsic motivation, an individual's needs are satisfied indirectly, for example through remuneration. Intrinsic motivation is voluntary and is said to exist when performing the activity (knowledge transfer) provides reward in itself. Firms rely on intrinsic motivation, as it is a pre-requisite for tasks that require creativity.

The motivational disposition of the knowledge holder is one of the elements of knowledge transfer cited by Alavi and Leidner (from Gupta and Govindarajan, 2000). For this reason, organisations need to be aware of the motivations and of older experts if they want to facilitate the transfer of their expertise to other staff. Lord and Farrington's (2006) study of age-related differences in the motivation of knowledge workers indicates that older workers are motivated by independence and job satisfaction. They remain in the workforce not necessarily because they aim for promotion, but because they enjoy their work and have pride in it (Lord \& Farrington, 2006). These are all positive factors that may be leveraged for the successful transfer of knowledge from 
older experts. Hewitt advises that "organizations need to put incentives in place for more mature workers - the most important being to offer them a choice. Not all wish to retire as soon as possible" (Hewitt, 2008).

This leads to another observation from Hewitt (2008). She notes that although it is selfevident that a knowledge transfer initiative requires a knowledge recipient, the recipient must have a need for professional development, and they must also value the expertise they receive, particularly as the expert may not be in a more senior role. Other factors include the perceived value of the knowledge holder's expertise, the existence and richness of the transmission channels, the motivational disposition of the knowledge recipient, and the recipient's absorptive capacity to acquire, assimilate and use the knowledge (Gupta \& Govindarajan, 2000). It is the application of the knowledge, rather than the possession of it that is the source of competitive advantage, and Alavi and Leidner cite Grant's (1996) three mechanisms for integrating knowledge. The first mechanism exists in the form of directives that consist of rules, standards and procedures. The second mechanism comprises organisational routines such as task performance and co-ordination, and process specifications, which may be developed or enhanced as part of integrating new knowledge. The third mechanism involves selfcontained teams that may be formed to solve problems involving elements of uncertainty or complexity, for example a task force or project team.

\subsubsection{Inhibitors, issues and challenges in knowledge transfer}

Organisations seeking to retain valuable knowledge from older workers need to acknowledge that inhibiting factors exist, and should not assume that these individuals are motivated to participate in initiatives to transfer knowledge. There are various reasons for not wanting to transfer knowledge (Hylko, 2005). An individual may regard knowledge as their intellectual property, and there may be intentions to use it for commercial reasons following retirement. Sharing knowledge involves goodwill in giving up possession of unique knowledge - this may cause an expert to feel disposable or feel that their professional standing has been diminished. One of the characteristics of knowledge transfer, however, is that the original knowledge holder can still use the knowledge that has been shared (Abbasi, et al., 2009). Transferring knowledge may not be a priority, especially if it is not a part of the expert's job and no time has been allocated to this activity (Hammer, 2002; Leonard \& Sensiper, 1998). There may be concerns that the knowledge, once captured or handed over, does not get 
used - the effort in transferring the knowledge may be viewed as a waste of time. Finally, the expert may not have a positive relationship with the organisation and therefore not want to participate in knowledge transfer (Hylko, 2005). A worker may view possession of knowledge as ensuring employment tenure; therefore they may believe that once the knowledge has been shared, they may lose their job (De Long, 2007; Slagter, 2007). Embittered retirees or employees who have lost their jobs through retrenchment are a non-trivial problem.

An APEX survey of public servants, however, presents a contrasting perspective in that, monetary factors aside, $55 \%$ of older executives responding to the survey indicated that they would extend their careers if given opportunities to assist with public service transitions, such as mentoring, initiatives to preserve corporate memory and transfer of their knowledge (Hammer, 2002).

Older workers who have expert knowledge may be willing to participate in knowledge transfer if they view it as an honour to be recognised as an expert, consider they have an obligation to share knowledge because of the benefits they have received during their careers, or because it is the right thing to do. Older experts are not always aware of what knowledge may be valuable or not so useful to an organisation (Joe \& Yoong, 2006). If managers ask experts to share their knowledge in certain areas, allocate the time for this process to occur, and both parties treat it as being part of the job, this may engender a positive attitude to knowledge transfer (Hanes, undated).

Gammelgaard and Ritter (2005) note three characteristics of the knowledge itself that act as barriers to knowledge transfer. The first problem is that knowledge may be fragmented: dispersed throughout the organisation or localised. Actions to overcome this issue can then lead the second problem of knowledge overload, for example in repositories that are seldom used. De-contextualisation of knowledge is noted as the third problem - knowledge transfer is unsuccessful because the recipient cannot use it successfully, due to cultural or technical reasons.

Relative absorptive capacity is also a factor in knowledge transfer. Lane and Lubatkin's (1998) study of inter-organisational knowledge transfer found that, for the knowledge recipient to understand the knowledge that has been passed on, they must have some existing knowledge as a pre-requisite or foundation for the new knowledge. This context enables the recipient to evaluate the new knowledge for its operations. Also, some of the source's knowledge needs to be diverse to allow the recipient to use the 
new knowledge in a creative manner. If there was some degree of similarity between the two firms' knowledge processing systems and norms, measured through the firms' compensation structures, this also provided an appropriate driver for the transfer. The study also found that where the source and recipient organisations were members of similar research communities, this led to successful transfers.

Organisations also face other issues and challenges relating to knowledge transfer. Huber (1999; cited in Alavi and Leidner 2001) suggests that organisations also have weak systems for locating and retrieving knowledge that resides in them. The ability to locate knowledge can therefore be an inhibitor to effective knowledge transfer (Connell, et al., 2001; Gammelgaard \& Ritter, 2005; Joe \& Yoong, 2006; Teece, 2001) and this challenge needs to be taken into account in the development of knowledge management systems (KMS). Also, organisations interested in implementing KMS need to realise that it is not possible to replace a human with a system while keeping the organisational context unchanged. In considering knowledge management consultation systems, Connell et al. posit that an expert (person or system) and a client (user of expertise) are components of a larger system and exist only in relation to each other.

A common challenge is that when employees leave an organisation, it is difficult for both parties to determine what valuable information the employee has, who will benefit from transferred knowledge, and what type of knowledge it is. In terms of codifying knowledge (Ruggles, 1997), a possible approach is to determine what types of knowledge are useful to recapture into the organisation. Process knowledge and factual knowledge are more easily defined but of lesser value to the business. However, catalogue knowledge (knowing where to find knowledge) and cultural knowledge (the knowledge about how to achieve results in the organisation culturally and politically) may consist of high value tacit knowledge that can be codified and made available to other groups. There are also other methods of ascertaining what an employee knows and what might be of interest to others, such as the use of concept maps as a means of modelling knowledge in a diagrammatic way (Gaines \& Shaw, undated).

Failed attempts to transfer knowledge can often, in practice, be attributed to the lack of motivation or the initiatives being based on the wrong motivational drivers. However, contrary to this view, Szulanski's (1996) quantitative study of 22 best practice transfers in eight companies led her to conclude that major barriers to successful knowledge transfer manifest as knowledge-related factors. One of these factors is causal ambiguity: 
when the reasons for a success or failure of a transfer are unknown, there is a possibility that a portion of the knowledge is highly tacit. Another factors is that the unproven nature of the knowledge being transferred may inhibit success.

Knowledge transfer may also fail due to the recipient being reluctant to accept the new knowledge for reasons such as the "not invented here" (NIH) syndrome (Husted \& Michailova, 2002). The possibility also exists that, lacking the life experience of the donor, the recipient may fail to understand the importance or significance of the knowledge being offered. The knowledge recipient may lack absorptive capacity, so that they are unable to assimilate or apply the new knowledge successfully.

Alternatively, they may lack retentive capacity and not be able to institutionalise the use of the acquired knowledge. Retentive capacity is defined as "the ability to recognise the value of the new knowledge, assimilate it and apply it to commercial means" (Cohen \& Levinthal, 1990). The sheer workload implications of the transfer process itself may be too onerous. An arduous or difficult relationship between the knowledge source and recipient, or the organisation, may also contribute to failures in knowledge transfer. The result is that the new knowledge never becomes part of the organisation routine or part of the organisational knowledge stocks.

Szulanski's (1996) concept of "internal stickiness" conveys the difficulty of transferring knowledge within an organisation. The difficulty may be reflected in the cost of the transfer, or be defined as problems the recipient couldn't handle routinely, such as the "eventfulness" of the transfer. There are different problems at different stages of the transfer (Szulanski, 1996, 2000).

Resolving such issues develops the learning capacity of organisational units, fostering close relationships between them, and enables them to systematically understand and communicate practices. Failures occur not because organisations do not want to retain knowledge, but because they may not know how to approach the process, or because the knowledge holder or recipient are unable or unwilling to allocate the amount of time required, as knowledge transfer is a time-consuming activity (De Long, 2007; Foos, et al., 2006; Hammer, 2002).

\subsubsection{Summary}

In reviewing relevant literature on knowledge retention, it was important to highlight the distinctions between knowledge retention, knowledge transfer and knowledge 
sharing. Some organisational perspectives of knowledge were discussed in light of its criticality as a strategic resource and a source of sustainable competitive advantage. Understanding the characteristics of knowledge, such as the importance of tacit knowledge, may better equip organisations to address the implications for its sharing and retention. Several models for knowledge retention were reviewed and retention approaches addressed, recognising the need to retain older experts' knowledge before they retire. Next, the requirements for successful knowledge transfer were outlined. These span areas such as provision of infrastructure, leadership that promotes a knowledge sharing culture, and the linkage of transfer to some element of appraisal and reward. Finally, literature pertaining to the inhibitors, issues and challenges in knowledge transfer was reviewed.

\subsection{Retaining expertise from older experts}

"Knowledge is fuzzy and closely linked to the people who hold it. Its categories and meanings change frequently...knowledge resists engineering" (Davenport, de Long and Beers, 1998, p. 51). Older people possess different types of expertise, as workers and as mentors, but as discussed earlier, there is not a significant body of literature (apart from the literature on wisdom) that elaborates on the specific nature of their knowledge. In participating in mentoring activities, older people may be motivated by generativity, described as "the expansion of care beyond oneself, toward others, and transferring knowledge and wisdom to younger generations" (Glass et al., 2004; McAdams, St Aubin, \& Logan, 1993). The way in which older people pass on their expert knowledge and the question of what distinguishes an expert are relevant matters to explore, as they enable organisations to identify how knowledge may be retained from internal experts.

\subsubsection{Defining expertise}

The literature on expertise does not provide precise definitions of the terms expert and expertise, hence definitions are implied from studies of experts (B. Huber, 1999). While literature on knowledge management focuses on specific aspects such as knowledge creation, transfer or retrieval, but not all three (Huysmann \& de Wit, 2003), the expert has a role in creating, holding and disseminating knowledge (B. Huber, 1999).

There are a few factors that organisations can take into account in considering how to distinguish an expert in terms of knowledge. Scarcity of the knowledge resource is an important factor. If co-workers recognise an older individual as being either the only 
expert, or one of a small number, on an important subject area, their expertise needs to be captured and made available to others (Ardelt, 2004; Didierjean \& Gobet, 2008; Mata, 2007). Individuals with expertise in handling events that are rare but critical are candidates for knowledge transfer (Hanes, undated; Hylko, 2005). Events such as hurricanes and extensive power outages are examples of rare failures where older experts are able to access knowledge from their past experiences. Experts are noted as being able to learn from the past and having a powerful recall of episodic memories (Didierjean \& Gobet, 2008; Ericsson \& Kintsch, 1995; LaFrance, 1989). The US Electrical Power Research Institute (EPRI)'s Strategic Human Performance Program analysed the types of valuable expertise that should be captured from older experts, by identifying the organisational risks of losing key knowledge.

People who hold expert knowledge, as well as the knowledge itself, are valuable organisational resources (Hammer, 2002; B. Huber, 1999), and often these experts do not realise that they possess unique, valuable knowledge and, for cognitive reasons, are not able to express this knowledge (Hinds \& Pfeffer, 2003; Hylko, 2005). LaFrance (1989) notes that the knowledge held by experts is different from that of novices. Differences include their "underlying schema, goal-orientation, practical focus, categorical chunking, cognitive complexity, automaticity of expert problem solving, and finally, the episodic nature of expert memory" (LaFrance, 1989, p. 6).

The discipline of psychology regards expertise as a personal characteristic, existing at an individual level, and as a relative characteristic. An expert exists only in relation to a lay person: a client, co-worker or manager who needs and seeks their expertise (B. Huber, 1999). Expertise can be defined as the ability to perform with excellence in a specific area, involving intellectual and cognitive effort over a sustained period of time (Ericsson \& Ward, 2007; B. Huber, 1999). An expert demonstrates higher levels of efficiency than a lay person, performing tasks with greater accuracy and effectiveness. They hold subject specific knowledge, such as on methods and procedures, including knowledge of how to deal with problems and new situations. An expert has significant experience in a subject area, and has been through a labour-intensive process of developing specialised knowledge (Krems, as cited in Huber, 2005). Their mental processing is handled in larger chunks of information than can be processed by a nonexpert (Hinds \& Pfeffer, 2003; B. Huber, 1999). 
Sociology adopts a societal perspective on expertise, as a social pattern and an interpersonal characteristic. The work of Hitzler (as referenced in B. Huber 1999), defines experts as people who have built up experience, including through risk-taking, and hold much knowledge in a specific subject area. Experts understand interrelationships, have worldly knowledge, experience unique challenges, and have welldeveloped powers of interpretation. They can locate the knowledge they require, and organise it for a purpose. Experts' capabilities and knowledge cannot be imitated and are all demonstrated within a social context (B. Huber, 1999; M. H. Zack, 1999).

\section{Subject matter expertise}

Older experts hold types of knowledge, skills and insight that are in demand and of value to others (Taylor \& Dryfoos, 1998). Experts are a powerful source of value creation within organisations and have "deep, specialised knowledge of a subject, who are tested, trained, especially by experience" (B. Huber, 1999). However, they may be difficult to identify, as there is a complex distribution of expertise throughout the modern organisation, and experts may not necessarily be labelled as such. Casher \& Lesser (2003) define experts as being holders of subject matter knowledge, possessing field knowledge that can be elicited through story-telling.

Experts rely heavily on their skills and knowledge, rather than on capital assets, and are creative and proficient at solving unusual problems (Hylko, 2005). Kleimann (1996; cited in B. Huber 1999) distinguishes three different types of expert knowledge. First, experts may have specialised and sought-after knowledge in a narrow field. Second, their knowledge can be rare and from an overview perspective, with proficiency in an extensive subject area and the ability to form a synopsis of the entire field. Third, an expert may have general knowledge, operating at the edges of specialist subject areas, thus having a breadth of general knowledge. An expert knows their way around the discipline or field (Tobin, 2004).

Studies with a practical basis recognise expertise as being tacit in nature, consisting of capabilities, knowledge and skills unique to individuals or a specific team, that may represent up to $80 \%$ of business critical knowledge, and be outside the scope of job documentation (EPRI, 2006; Hinds \& Pfeffer, 2003; Lesser, 2006). Experts possess knowledge of longstanding, complex systems whose failure leads to negative economic, operational, safety consequences (Hylko, 2005; IBM Business Consulting Services, 2005). The energy sector has taken a risk perspective in identifying expertise. Initially, 
it has considered the risk of staff not being available for a variety of reasons, including retirement, illness, travel and being on leave. It has then analysed the risks of resultant events when knowledge is not available, for example loss of services, operational failures and injuries or loss of life. Critical incident analysis in the power industry shows that experts often possess non-routine knowledge enabling them to solve difficult problems using actions a less experienced person would not choose (Hylko, 2005).

Subject matter expertise within organisations includes knowledge of work processes and work planning and organisation. Klemp and McClelland's (1986) analysis of managerial expertise identifies a range of key characteristics such as planning and causal thinking, searching for diagnostic information, and the ability to conceptualise and synthesise information. Experts were seen as having a desire for influence, with directive power being important. Self-confidence, the power to collaborate and influence groups, including symbolic influence, were also identified (B. Huber, 1999).

Experts have an important role in an organisational context, where the knowledge base can be complex and distributed throughout the organisational structure. The role of the expert involves making specialised knowledge available to others for executive decision-making processes, and being a conduit for making knowledge available to nonexperts. This contribution of authoritative, objective knowledge serves to legitimise organisational decisions (B. Huber, 1999). Expertise also exists within knowledge professions such as advertising, accountancy, consulting, investment banking and law, and such individuals can be highly educated (Sharma, 1997).

\section{The tacit dimensions of expertise}

Experts hold knowledge beyond explicit documented knowledge. Experience, intuition and older experts' contextual awareness and knowledge of social networks is often tacit (Hylko, 2005; Jackson \& Webster, 2007). With the demands of an increasingly knowledge-based economy, coupled with high staff turnover, organisations need to understand the expertise they possess and act urgently to retain it so they are better equipped to compete successfully in a more demanding environment (BecerraFernandez \& Sabherwal, 2005; Casher \& Lesser, 2003).

The valuable knowledge and skills that experts possess include understanding missioncritical methods and procedures (Lee, Simmons, \& Drueen, 2005) and the organisation's key tools, equipment and artefacts. Experts know about key relationships 
with customers, suppliers and partners, and they serve as connectors within the organisation, for facilitating the exchange of critical information. They also have deeper experience with local conditions in critical geographical areas and the ability to make perceptually based assessments of plant, equipment and systems, for systems engineering and problem-solving (Hylko, 2005). This includes detecting and diagnosing problems and identifying and implementing solutions. In his work on practical intelligence, as a component of his WICS leadership model, Sternberg (2003) perceives tacit knowledge to be part of practical intelligence, "the ability to solve everyday problems by utilising knowledge gained from experience in order to purposefully adapt to, shape and select environments" (p. 388).

The tacit nature of some expertise has implications for knowledge capture and transfer — tacit knowledge may not easily be transferred but lends itself to sharing. Organisations need to capture undocumented business critical knowledge from older workers and various studies describe processes for achieving this (Foos, et al., 2006; Hammer, 2002; Hylko, 2005; IBM Business Consulting Services, 2004, 2005). The tacit nature of expertise and the cognitive and motivational limitations for knowledge transfer, however, make this difficult (Hinds \& Pfeffer, 2003). Organisations therefore need to distinguish between the types of knowledge that it is possible and appropriate to capture and document, and the tacit knowledge that experts possess, that is difficult to transfer and inappropriate to convert to explicit knowledge.

\subsubsection{A wisdom perspective}

In conducting a literature review on the valuable knowledge of older experts, I found that the concept of knowledge may be insufficient to embody some aspects of expertise. In considering the literature on expertise, I became aware of a linkage that exists between expertise and wisdom - specifically that wisdom is a type of expertise. Wisdom concepts encapsulated some features of older experts' knowledge (which were subsequently recognised in some of the findings of the second phase of my study on the knowledge of an older expert in an organisational setting). Therefore, in reviewing aspects of the knowledge of the older expert, a specific type of expertise that needs to be considered is wisdom.

The concept of wisdom is relevant to a review of the knowledge literature for three main reasons. First, in considering knowledge transfer and the types of knowledge that are useful for organisations to retain, the concept of knowledge may not be sufficiently 
broad or meaningful to represent the asset that is of value to organisations. The same may apply to the concept of expertise. Second, some of the literature on wisdom indicates strong links between wisdom and knowledge. For example, specific types of knowledge represent components or characteristics of wisdom (Baltes \& Staudinger, 2000; Hammer, 2002; McKenna \& Rooney, 2005b), or an alternative view is that some types of knowledge are wisdom-related (Kunzmann \& Baltes, 2003). Third, although wisdom is an ancient topic of theoretical study, there have, since the 1980s, been a few empirical studies that have tried to operationalise theories of wisdom (Baltes \& Staudinger, 1993; Ericsson \& Smith, 1991; Grossman et al., 2010; Knight, 1999).

Two recent developments are also pertinent. There is a prominent body of research on the link between wisdom - as a type of expertise - and old age, partly driven by a new emphasis on positive psychology (Ardelt, 2004). Over the last decade, both expertise and wisdom have been the subject of research in an organisational setting, and there have been concerns about knowledge retention and succession planning, with the departure of older workers who are recognised as possessing valuable expertise. (Bierly, Kessler, \& Christensen, 2000; Hammer, 2002; Leonard, 2005; Leonard \& Swap, 2005; McKenna \& Rooney, 2005b; McKenna, Rooney, \& Boal, 2009; Rooney \& McKenna, 2007; Rowley \& Gibbs, 2008).

The study of wisdom has a rich heritage but there is not a generally agreed definition (Ardelt, 2004; Trowbridge, 2005). Sternberg (2003) notes that the main approaches to wisdom are in the nature of philosophical, implicit theories and developmental approaches. Under the philosophical approach there has been a long history of the study of wisdom, starting with Plato as the first to provide in-depth analysis of wisdom with three different senses (Robinson, 1990). These are sophia, which is "to be found in those who seek a contemplative life in search of the truth", phronesis, "the kind of practical wisdom shown by statesmen and legislators", and episteme, which is "found in those who understand things from a scientific point of view".

In the literature, different approaches have been taken in attempting to understand the concept of wisdom, in disciplines such as philosophy and religious studies, cultural anthropology, political science, education and psychology (Baltes \& Staudinger, 2000). Within these disciplines, various views and definitions of wisdom exist. Conceptually, one branch of study has its origins in Eastern philosophy, with the view that wisdom is 
instantiated in wise individuals and their products. The other branch arises from

Western philosophy and represents scientific theory in the narrower sense.

\section{Implicit and explicit theories of wisdom}

Implicit theories of wisdom are based on folk-psychological and common sense approaches and relate to how wisdom is described, and wise people characterised.

Explicit theories focus on behavioural manifestations and expressions of wisdom.

Summarised from Baltes \& Staudinger (2000), Table 2-4 (p.51) describes some conclusions drawn from these theories.

\section{Theory type Conclusions about wisdom:}

Implicit theories - from The concept of wisdom has specific meaning that is widely psychological research shared and understood in its language-based representation, and is distinct from related concepts such as social intelligence, maturity or sagacity

Wisdom involves an exceptional level of human functioning, related to excellence and ideals of human development. Wisdom includes knowledge about the limits of knowledge and uncertainties of the world

Wisdom is associated with a high degree of personal and inter-personal competence, including the ability to listen, evaluate and give advice

Wisdom involves good intentions and is used for the wellbeing of self and others

Implicit theories - from cultural-historical and philosophical analyses of wisdom

\section{Characteristics of wisdom:}

Superior level of knowledge, judgement and advice Addresses difficult questions and strategies about the conduct and meaning of life

Includes knowledge about the limits of knowledge and uncertainties of the world

Includes knowledge with extraordinary scope, depth, measure and balance

Involves perfect synergy of mind and virtue Includes knowledge used for the good of oneself and others Wisdom is difficult to achieve and specify, but is easily recognised when manifested

Explicit theories formal theories of wisdom that are proposed to account for wisdom

\section{Theories:}

Wisdom is a personal characteristic or constellation of personality dispositions

Wisdom is post-formal and dialectal thought

Wisdom is an expert system dealing with the conduct and meaning of life, with the application of tacit knowledge

Table 2-4: Implicit \& explicit theories of wisdom summarised from Baltes \& 
Approaches to wisdom that are based on implicit theories do not provide a

psychologically true definition of wisdom, but an account that is true in terms of people's beliefs (Sternberg, 2003). Relevant to this research study is the view that there is a link between wisdom and successful ageing (Baltes, 1993; Knight, 1999).

\section{Wisdom and fundamental pragmatics}

The work of researchers at the Max Planck Institute (MPI) treats wisdom as a theory on "expert knowledge, judgement and advice about difficult and uncertain matters of life" (Baltes \& Kunzmann, 2004). Baltes \& Staudinger (2000, p. 122) define wisdom as "an expert knowledge system concerning the fundamental pragmatics of life", that is, planning, understanding and managing a good life. In considering how wise judgements are made, they propose that general person factors, expertise-specific factors and facilitative-experiential factors are involved. This framework, the Berlin Wisdom Paradigm, uses five distinct criteria for evaluating responses in an empirical study. The criteria are rich factual knowledge, rich procedural knowledge, lifespan contextualisation (knowledge pertaining to the themes and contexts of life, for example education, family, work and the good of society), relativism of values and life priorities (value-relative knowledge, judgement and advice), and the recognition and management of uncertainty. While the first two factors originate from the study of expertise, the other three relate to cognition and personality.

An important component of the theory is the notion that wisdom-related knowledge accumulates throughout an individual's life span. Baltes \& Staudinger's (2000) research framework is shown in Figure 2-1 (p. 53).

The factors and organising processes depicted in the diagram need to work together with a degree of synergy for wisdom to develop, and the authors envisage constrained but multiple pathways to achieving wisdom. Their perspective is of wisdom as a metaheuristic, an encompassing concept with the objective of achieving excellence of self and others, such as for organisational and societal good. Consistent with this framework is Hammer's (2002) view that wisdom is an attribute or asset of an organisation, and that over time, individuals contribute to this organisational stock which is constantly renewed and updated. Adopting the perspective that wisdom is a collectively-anchored product and that individuals are weak carriers of wisdom (Baltes \& Smith, 1990), Baltes \& Kunzmann (2004) note that wisdom can be considered as bodies of knowledge and as a utopian quality. They, and others such as Birren \& Fisher (1990), posit that because 
wisdom is a God-like quality, humans can only exhibit imperfect models of wisdom. Furthermore, they highlight that if we examine historical figures who are cited as being wise, we have access only to historical constructions of them.

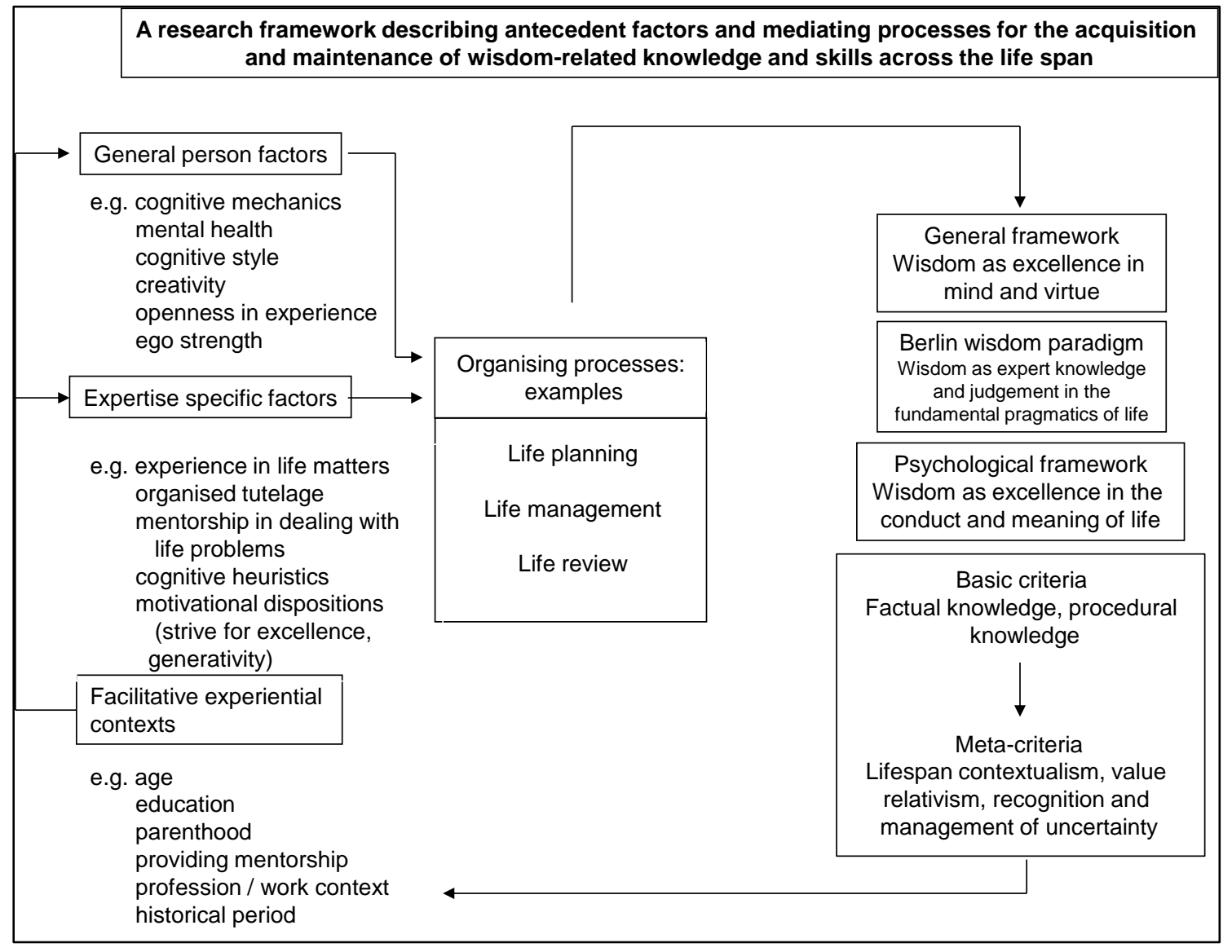

Figure 2-1: Research framework (Baltes \& Staudinger, 2000, p3).

\section{Alternative models of wisdom}

In reviewing the literature on wisdom, some alternative models and perspectives of wisdom were identified.

Ardelt (2004, p. 257) argues that "the term wisdom should be reserved for wise persons rather than expert knowledge" and that the manner in which the MPI group defines, operationalises and measures wisdom in fact centres on measuring expert knowledge in the wisdom domain, rather than focusing on wisdom itself. Baltes and Kunzmann's (2004) response is along the lines that there are two faces of wisdom, and that they study wisdom as a theory of knowledge about human conduct, rather than focusing on the study of wise people. There is a view that wisdom cannot exist independently of individuals (Ardelt, 2000; Labouvie-Vief, 1990) as it is developed and understood at an experiential level. On this basis, literature or cultural artefacts encapsulate theoretical 
knowledge, until a person experiences or realises the inherent wisdom. Accordingly, knowledge is therefore one aspect of wisdom. Ardelt notes Kunzmann \& Baltes' (2003) implication that wisdom is personal, concrete, applied and involved, but that they then proceed to use general hypothetical stories and fictional characters in their measurement of wisdom. Based on the work of Clayton and Birren (1980) and Ardelt (1997, 2003), Ardelt defines and operationalises wisdom as a three-dimensional personality characteristic, as summarised in Table 2-5 (p. 54). She proposes that the cognitive dimension and part of the scope of her reflective dimension resemble the five wisdom criteria which form the basis for the Berlin researchers' model.

\begin{tabular}{|c|c|c|}
\hline Dimension & Definition & Operationalisation \\
\hline Cognitive & $\begin{array}{l}\text { An understanding of life and a } \\
\text { desire to know the truth, that is, } \\
\text { the significance and deeper } \\
\text { meaning of phenomena and } \\
\text { events, particularly with regard } \\
\text { to intrapersonal and } \\
\text { interpersonal matters. } \\
\text { Includes knowledge and } \\
\text { acceptance of the positive and } \\
\text { negative aspects of human } \\
\text { nature, of the inherent limits of } \\
\text { knowledge, and of life's } \\
\text { uncertainties. }\end{array}$ & $\begin{array}{l}\text { Items or ratings should assess: } \\
\text { the ability and willingness to } \\
\text { understand a situation or } \\
\text { phenomenon thoroughly; } \\
\text { knowledge of the positive and } \\
\text { negative aspects of human nature } \\
\text { acknowledgement of ambiguity and } \\
\text { uncertainty of life } \\
\text { the ability to make important } \\
\text { decisions despite life's } \\
\text { unpredictability }\end{array}$ \\
\hline Reflective & $\begin{array}{l}\text { A perception of phenomena and } \\
\text { events from multiple } \\
\text { perspectives. Requires self- } \\
\text { examination, self-awareness and } \\
\text { self-insight }\end{array}$ & $\begin{array}{l}\text { Items or ratings should assess: } \\
\text { the ability and willingness to look at } \\
\text { phenomena and events from } \\
\text { different views } \\
\text { the absence of subjectivity and } \\
\text { projections (i.e. the tendency to } \\
\text { blame circumstances or others for } \\
\text { one's own situation or feelings) }\end{array}$ \\
\hline Affective & $\begin{array}{l}\text { Sympathetic and compassionate } \\
\text { love for others }\end{array}$ & $\begin{array}{l}\text { Items or ratings should assess: } \\
\text { the presence of positive emotions } \\
\text { and behaviour towards others } \\
\text { the absence of indifferent or negative } \\
\text { emotions and behaviour towards } \\
\text { others }\end{array}$ \\
\hline
\end{tabular}

Table 2-5: Wisdom as a three-dimensional personality characteristic (Ardelt, 2004)

Based on her own wisdom studies, Ardelt posits that the above characteristics are necessary but not sufficient for an individual to be regarded as wise. 
Another approach to understanding wisdom involves viewing it as a stage of cognitive development beyond logical reasoning. Descriptions of wisdom from various other studies are summarised in Table 2-6 (p. 55).

\begin{tabular}{|c|c|}
\hline Authors & Descriptions of wisdom \\
\hline Clayton (1975) & $\begin{array}{l}\text { This study scaled terms related to wisdom, such as experienced, } \\
\text { pragmatic, understanding and knowledgeable. }\end{array}$ \\
\hline $\begin{array}{l}\text { Holliday \& } \\
\text { Chandler (1986) }\end{array}$ & $\begin{array}{l}\text { Factors identified as components of wisdom were: exceptional } \\
\text { understanding, judgement and communication skills, general } \\
\text { competence, inter-personal skills and social unobtrusiveness. }\end{array}$ \\
\hline $\begin{array}{l}\text { Sternberg } \\
(1985 b, 1990 c)\end{array}$ & $\begin{array}{l}\text { A study of professors revealed a high correlation between wisdom } \\
\text { and intelligence (average .68). } \\
\text { A study of college students revealed that wisdom consists of } \\
\text { "reasoning ability, sagacity, learning from ideas and environment, } \\
\text { judgement, expeditious use of information and perspicacity". } \\
\text { A study of adults found a strong correlation between wisdom and } \\
\text { intelligence, and a correlation between wisdom and creativity. }\end{array}$ \\
\hline $\begin{array}{l}\text { Sternberg }(2003, \\
\text { p. } 395)\end{array}$ & $\begin{array}{l}\text { "an individual is wise to the extent that he or she uses successful } \\
\text { intelligence, creativity, and experience as moderated by values to } \\
\text { (a) seek to reach a common good, (b) by balancing interpersonal..., } \\
\text { interpersonal..., and extrapersonal ... interests, (c) over the short } \\
\text { and long terms, to (d) adapt to, shape and select environments." }\end{array}$ \\
\hline $\begin{array}{l}\text { Csikszentmihalyi } \\
\text { \& Rathunde } \\
\text { (1990) }\end{array}$ & $\begin{array}{l}\text { Wisdom is seen as: } \\
\text { 1. a cognitive process } \\
\text { - dealing with enduring universal truths } \\
\text { - trying to understand how various aspects of reality are } \\
\text { related } \\
\text { - implying a hierarchical order of truths and related actions } \\
\text { 2. a virtue } \\
\text { - with a balance of practical, technical and emancipatory } \\
\text { interests } \\
\text { - providing a holistic, long-range understanding of actions } \\
\text { and events, so we can overcome the consequences of a } \\
\text { narrower view } \\
\text { 3. a personal good } \\
\text { - that brings us closer to the truth, assists with making sound } \\
\text { value judgements, and has an immediate benefit. Only } \\
\text { through wisdom are other goods of benefit, and the } \\
\text { contemplation of wisdom is intrinsically rewarding. } \\
\text { - as an over-arching concept, Plato notes "All that the soul } \\
\text { attempts or endures, when under the guidance of wisdom, } \\
\text { ends in happiness" (Meno, 88, in Jowett, B. Trans, 1987) }\end{array}$ \\
\hline $\begin{array}{l}\text { Labouvie-Vief } \\
\text { (1990) }\end{array}$ & $\begin{array}{l}\text { "There is some emerging consensus that wisdom refers to a set of } \\
\text { attributes assumed to be correlated with advanced age and not } \\
\text { usually covered under the umbrella of "intelligence." Moral and } \\
\text { spiritual integrity, humility and compassion, or insight into the } \\
\text { paradigmatic, subjective and psychological dimensions of life all } \\
\text { have been associated with the concept of wisdom." (p. 52). }\end{array}$ \\
\hline
\end{tabular}

Table 2-6: Descriptions of wisdom summarised from a sample of literature 
Although most of the research on wisdom has been theoretical, some empirical studies have involved testing the validity of the association of wisdom with intelligence and creativity (Sternberg, 2003), in the context of an organisational leadership model, and testing the hypothesis that older people are judged as being wiser than people in other age groups (Knight, 1999). In considering wisdom as integrated thought, knowledge is seen as developing through two distinct but complementary modes of organising experience and of experiencing reality (Labouvie-Vief, 1990). Robinson (1990) makes a similar point, that wisdom differs from science in that it takes a view from a greater height, and that a decision may need to be made that cannot follow the common rules of procedure. This requires the ability to "see through" such procedures and make a higher level judgement, as wisdom relates to higher states of order and longer range goals (Csikszentmihalyi \& Rathunde, 1990).

\section{Wisdom and age}

Divided views exist as to whether wisdom is a characteristic that is solely associated with old age. There is a general belief in Western society that wisdom develops over time and is thus an attribute of older people (Birren \& Fisher, 1990). In Knight's (1999) study, when participants made judgements about people who possess wisdom and creativity, those judgements depended on the age of the participant, and it was also found that while wisdom may be associated with increasing age, the same cannot be said for creativity. Creativity can be taught, and individuals can choose to develop the capability to be creative (Sternberg, 2003).

Both intellectual and wisdom-related knowledge take time to acquire, and are acquired by relatively few, but where intellectual knowledge may decline with age, wisdomrelated knowledge may grow (Ardelt, 2000). Wisdom has the potential to increase further in old age (Ardelt, 2004). The characteristics required for wisdom to develop include aspects such as openness to a range of experiences, self-reflection and awareness determination and constancy, and these do not decline with the ageing process, since they are personality traits.

Findings from other studies suggest that wisdom-related performance does not degenerate through adulthood, but that in old age it may start to decrease at about 75 years of age, due to cognitive ageing (Baltes \& Staudinger, 2000; Lindenberger \& Baltes, 1997; Schaie, 1996). However, older study participants were better represented in the top $20 \%$ category for wisdom-related performance (Baltes \& Staudinger, 2000). 
A study by Baltes, Staudinger, Maercker \& Smith (1995) found that the performance of older individuals nominated for their wisdom was as good as a group of clinical psychologists when it came to completing wisdom-related tasks. Also, adults up to the age of 80 years performed as well as younger adults. Labouvie-Vief's (1990) empirical study suggests that wisdom appears to peak in middle adulthood, which she defines as being in the fourth or fifth decade, while Baltes \& Staudinger (2000) conclude that "the world record for wisdom is probably held by a person in their sixties". Kunzmann \& Baltes (2003) found that from a developmental perspective, there was a positive correlation between age and wisdom-related knowledge.

Individuals can be seen as weak carriers of wisdom, and there is an interactive minds, or social-collaborative aspect to wisdom (Baltes \& Smith, 1990; Baltes \& Staudinger, 2000; Staudinger \& Baltes, 1996), that results in enhanced wisdom-related performance where individuals collaborate and reflect upon tasks. This is particularly so in the case of older people, as with increasing age, people acquire a knowledge base that is enhanced by interaction and inter-personal consultation with others. There is a change in the balance between acting and reflecting on the consequences of one's actions as people age (Birren \& Fisher, 1990), which means there is a greater tendency to reflect. (Baltes \& Staudinger, 2000) also found that with age, people gain wisdom-related knowledge in the form of proverbs that can be useful in dealing with difficult problems. In proposing his WICS-based leadership skills model, Sternberg (2003) explains that leaders who wish to develop wisdom-related skills need to develop dialogical thinking. This involves making a conscious decision and genuine efforts to understand other people's viewpoints and incorporating them into their own thinking. The model is based on the idea of successful intelligence, synthesising wisdom, intelligence and creativity.

Labouvie-Vief (1990, p70) suggests that the manner in which people solve problems differs depending on their age. While adolescents and younger adults tend to use simple, deductive structures that treat problems as being "unambiguous and not requiring interpretation of the self', the problem-solving style of older adults is more suited to solving less structured problems. In studying mature executives' strategies, Birren (1990) notes their ability to generalise and deal with information in a more abstract manner, to solve a problem. This involves a degree of detachment (Csikszentmihalyi \& Rathunde, 1990) but involves a reflective state or attitude to generate alternatives for problem-solving. "If individuals employ effective decision strategies and their reputation spreads, as they grow older, they will be increasingly sought for advice." 
(Birren \& Fisher, 1990, p. 320). Emergence of wisdom in later life has important implications for adaptation, with regard to coping, defending, understanding self and others, and creative productivity.

\section{Implications for knowledge retention}

An important implication for the retention of wisdom and expert knowledge from older workers is that one cannot assume that an individual is wise or has valuable knowledge by virtue of age alone, or that all knowledge held by older workers is of value (Labouvie-Vief, 1990; Leonard, 2005). Wisdom may be an ideal reached by a few.

In considering the knowledge of some older experts as being a valuable organisational asset, organisations need to recognise that the components that need to be retained extend beyond the more widely recognised aspects like factual, procedural and organisational knowledge. Recent work on processes and procedures for retaining knowledge from older experts refer to the steps of identifying at risk knowledge (Stoutamire, 2006) and those who possess this knowledge (Gross, et al., 2001; Hammer, 2002; Lesser, 2006). Organisations wish to capture wisdom-related knowledge from identified candidates. In Ardelt's (2004) study of individuals regarded as being wise, these individuals were also nominated as such by their peer group. This section outlined many characteristics of wisdom-related knowledge, and capabilities of people who may possess it. Table 2-7 (p. 58) distils and interprets some of the key characteristics of people who may possess wisdom-related knowledge. The capabilities may be operationalised as measures of expertise.

\begin{tabular}{|l|l|}
\hline Wisdom-related characteristics & Capabilities \\
\hline $\begin{array}{l}\text { Possess expert, value-relative knowledge, } \\
\text { judgement and advice about difficult and } \\
\text { uncertain matters }\end{array}$ & Able to recognise and manage uncertainty \\
\hline $\begin{array}{l}\text { Demonstrate an exceptional level of } \\
\text { human functioning, have superior levels of } \\
\text { knowledge, excellence, and a high degree } \\
\text { of personal and interpersonal competence }\end{array}$ & $\begin{array}{l}\text { Able to listen, evaluate and give advice, } \\
\text { able to demonstrate positive intentions } \\
\text { towards the organisation and regard } \\
\text { knowledge transfer as being positive }\end{array}$ \\
\hline $\begin{array}{l}\text { Possess knowledge with extraordinary } \\
\text { scope, depth, measure and balance, and } \\
\text { have synergy of mind and virtue } \\
\text { (knowledge and character) }\end{array}$ & $\begin{array}{l}\text { Have the ability to see beyond procedures } \\
\text { and make higher level judgements with a } \\
\text { strategic focus; able to solve less } \\
\text { structured problems }\end{array}$ \\
\hline
\end{tabular}

Table 2-7: Characteristics and capabilities of individuals possessing wisdomrelated knowledge 


\section{Cooperation and problem-solving}

The problem-solving style of older people who possess wisdom-related knowledge has implications for knowledge retention. Processes and technologies to support knowledge retention must be able to capture this type of knowledge so it is useable. As wisdom also encompasses the ability to act to solve a problem, this lends itself to actively involving older workers in the retention of knowledge and expertise. For example, opportunities to be actively involved may include mentoring, providing practical assistance to ensure that knowledge retention processes work successfully, and that the organisation can use the retained knowledge effectively.

People who are open to experiences, open-minded and creative are thought to have higher levels of wisdom-related knowledge, according to Staudinger, Lopez and Baltes (1997; cited in Kunzman and Baltes, 2003). Wisdom involves balance and reflectivity, and could influence the way in which knowledge is transferred by older people who are seen to be wise. Wisdom is said to involve modulation and complexity, together with a desire to develop potential in oneself and others (Kunzmann \& Baltes, 2003). These authors also found a positive correlation between wisdom-related knowledge and cooperation. This could mean that people with higher levels of wisdom-related knowledge are more likely to be cooperative in transferring their knowledge for the benefit of their organisation. Wisdom-related knowledge includes interpretive knowledge, a commitment to identify and implement solutions to problems, taking a strategic approach and showing a concern for individual as well as collective issues (Ardelt, 2000; Birren \& Fisher, 1990).

In summary, while there is a wealth of information on the study of wisdom, there are many opportunities to learn more about the processes of developing and communicating wisdom (Csikszentmihalyi \& Rathunde, 1990).

\subsubsection{Summary}

The concept of wisdom was explored as a dimension of knowledge. This is appropriate in the context of defining the knowledge that older people possess, while recognising that wisdom is not a universal attribute of older workers. An exploration of the Berlin Wisdom Paradigm as a research framework was compared with alternative models of wisdom. Finally, the implications for knowledge transfer were addressed, with 
discussion of who possesses wisdom within the organisational environment, and the characteristics and capabilities of those purported to possess wisdom.

\subsection{ICT support for knowledge transfer}

\subsubsection{Context for providing ICT support}

Information and communications technology (ICT) support for knowledge transfer needs to be viewed as part of a broader environment for the process of knowledge transfer. Both technical and organisational initiatives, closely aligned, are needed for an infrastructure that supports successful knowledge transfer (M. H. Zack, 1999). BecerraFernandez and Sabherwal (2005) note that knowledge management consists $80 \%$ of organisational and cultural factors and $20 \%$ of technology. Without a knowledgesharing culture in specific work contexts, the use of ICT in itself will not be effective (DeLong, 2004). Nonetheless, much of the literature on knowledge management within organisations is dominated by an ICT perspective (Hinds \& Pfeffer, 2003; Huysmann \& de Wit, 2003; Stenmark, 2001), indicating a strong association between knowledge management and the codification of knowledge, driven partly by the cost-effectiveness of coding, storing and making information accessible (Hansen, et al., 1999).

While ICT should be regarded as having a role in facilitating, supporting and enhancing knowledge transfer initiatives and processes, its existence alone does not promote knowledge transfer (M. H. Zack, 1999). There is scepticism about the role of technology in promoting the sharing of expertise (Hammer, et al., 2004; Hinds \& Pfeffer, 2003). However, the opposite also holds true, in that "the lack of consistency, poor communication and use of antiquated communication tools could contribute to the failure of capturing and disseminating undocumented knowledge" (Hylko, 2005).

\subsubsection{ICT to support knowledge management strategy}

In reviewing the context for ICT support, there are some factors which influence the selection and use of specific technologies and channels to support knowledge transfer. Ideally, the tools that are used to provide support are selected depending on the organisation's business and knowledge management strategies (Hansen, et al., 1999). The knowledge management strategy enables organisations to consider whether they view knowledge as largely residing in computers, or as being held by people. Selecting a codification strategy as the predominant model for representing knowledge is 
appropriate when explicit knowledge needs to be standardised, shared and available for re-use. Organisations who are highly dependent on tacit knowledge, for example whose business models involve delivering customised high-value solutions, would choose a personalisation strategy for knowledge transfer. The selected strategy influences the types of technologies that it would be appropriate to implement, and successful knowledge transfer depends on technologies that are consistent with the strategy. Perspectives of knowledge as residing in computers or people bear some relationship to the view of knowledge as either stocks or flows, with codification being associated with stocks and personalisation associated with flows (Huysmann \& de Wit, 2003).

\subsubsection{ICT to support knowledge transfer objectives and activities}

Instead of consciously choosing a predominant strategy for managing knowledge, organisations have adopted methodologies for identifying experts who possess valuable knowledge and for capturing the explicit knowledge (De Long \& Mann, 2003; Hammer, 2002; Hylko, 2005; IBM Business Consulting Services, 2004, 2005; Lahaie, 2005). The research of Albino, Garavelli and Gorgoglione (2004), introduces human cognitive aspects of communication into the Shannon-Weaver machine-based model of communication. On this basis, they predict that the role of technology in knowledge transfer depends on the objectives for knowledge transfer, the cognitive processes involved, the social context, and whether the knowledge recipient intends to apply the acquired knowledge. There should also be a balance between organisational processes and technology (Albino, Garavelli, \& Gorgolione, 2004) and organisations should not overlook existing knowledge elicitation techniques and software applications that can support knowledge transfer (Hanes, undated; Hylko, 2005).

In considering the types of ICT that can be used to support knowledge transfer, a distinction is made between the different knowledge management activities (Huysmann $\&$ de Wit, 2003). While knowledge retrieval lends itself to reports, databases, and knowledge bases, knowledge transfer and exchange between individuals can be supported via the platform of electronic networks, upon which ICT such as intranets and desktop solutions may be delivered (Gammelgaard \& Ritter, 2005; M. H. Zack, 1999).

Where older experts work away from the office, perhaps because they are transitioning into retirement while being involved in transferring their expertise, high speed internet access to tools and knowledge is crucial. Hewitt (2008) notes that to derive the most benefit from the transfer, the organisation should identify the strategic value of the 
transfer. She also states that technology is one enabler, alongside others such as a knowledge sharing culture, an infrastructure that includes knowledge management services, and some means of evaluating the progress and success of the transfer.

\subsubsection{The three waves of ICT support}

Knowledge management, as practice, has existed for hundreds of years, but it was during the 1990s that executives began to refer to knowledge management in an organisational context. There have been three, non-linear, waves of ICT support for knowledge transfer over this latest era.

\section{ICT to capture explicit knowledge}

The first wave of ICT support involved capturing knowledge that was already explicit, or able to be made explicit. This generation of knowledge management systems facilitated organisations' processes to document explicit knowledge and extend the boundaries of accessibility beyond the individual. At this time, some effort was also focused on converting tacit knowledge to explicit. These systems consist of applications such as databases, electronic document management repositories, content repositories, knowledge bases and associated query tools (Hammer, et al., 2004; Hansen, et al., 1999; Hylko, 2005; Lesser, 2006). Lessons learned may be captured by means of questionbased reasoning software (De Long \& Mann, 2003). Often, these were cost effective tools, in terms of computer network processing capabilities and accessibility, but their value to the business depends on the existing knowledge stores being kept up to date and new, relevant knowledge being added (Crowder, Hughes, \& Hall, 2002; Huysmann $\&$ de Wit, 2003). There are limitations to converting and capturing knowledge, however, as it is not possible or appropriate to capture all of an organisation's expertise. The knowledge base in a domain, for example innovation and design, may be so dynamic that it is not feasible or useful to try to externalise tacit knowledge for capture as explicit knowledge (Leonard \& Sensiper, 1998) before it becomes obsolete.

\section{ICT support for locating expertise}

The second wave of ICT support began with the recognition that solely capturing explicit knowledge does not go far enough to assist knowledge holders with sharing their tacit knowledge, or to assist knowledge seekers in locating and connecting with people who hold expert knowledge. Thus, more recently, attention has turned to how organisational processes and ICT may support, facilitate and enhance the transfer of 
tacit knowledge, without converting it to explicit knowledge, and how ICT can assist with locating these knowledge sources. Tacit knowledge is situated knowledge, being embedded in a context, and has meaning in relation to where and how it is used. In the same way that it is difficult for experts to express their knowledge for cognitive reasons (Hinds \& Pfeffer, 2003), it is also difficult to capture it in a system.

A response to this need for ICT support has been the development of expert locator or recommender systems, which enable users to find experts on particular subject areas, make connections, and build communities of practice (Becerra-Fernandez \& Sabherwal, 2005; Crowder, et al., 2002; Hammer, et al., 2004; Stenmark, 2001). Technology may be an enabler but does not assist in solving the cognitive and motivational problems of knowledge sharing. The value that technology can add in this role is not yet understood (Albino, et al., 2004). In supporting the sharing of tacit knowledge, a different range of ICT may be found. Knowledge centres exist for the purposes of recording personal knowledge and assisting employees to identify existing networks of experts. Intranets and extranets provide access to both documented, explicit knowledge, and also serve as an access point to locator systems for expertise and experts. These delivery mechanisms are useful for professionals, who usually require location-independent access to knowledge, and who tend to be too busy to commit to externalising their knowledge (Huysmann \& de Wit, 2003). Moreover, they are rarely rewarded for knowledge sharing or transfer. Organisation type has some relevance in this discussion, for example, organisations delivering highly customised services prefer to develop their own knowledge. Expert systems were popular in research and in practice; however, it has since been found that they do not stand alone. For example, in the case of Xerox Corporation, the reality was that photocopier technicians, for whom the system was developed, actually solve non-standard problems by locating and collaborating with other technical experts (Hansen, et al., 1999).

\section{Social technologies as ICT support}

The third wave consists of social technologies, which can be described as collaboration tools, tools for aggregating knowledge, and software for supporting communities. Social technologies, in rudimentary form, were first mentioned in a 1945 essay by Vanneveer Bush. In 1968, the head of ARPA, the Advanced Research Project Agency, upon whose research the internet subsequently developed, noted that systems enabling people to communicate and collaborate would enable cooperation (Weiss, 2005). 
With the pervasive nature of the internet, older applications may be more widely delivered via web access or portals, and scattered knowledge domains can be made more transparent to users, aiding the availability of tacit knowledge and intellectual capital beyond traditional organisational boundaries. Depending on the nature of nontechnology knowledge-sharing infrastructures, such as special interest groups (SIG) and communities of practice (COP), the role of ICT may be somewhat subservient, or share a role complementing other forms of exchange. However, internet technology makes available powerful social software, techniques and mechanisms for knowledge collaboration, transfer and exchange. These exist in the form of wikis, blogs, peer-topeer applications such as file-sharing, intelligent agent-based web retrieval systems, automatic content tagging and folksonomies (Weiss, 2005). Such technologies assist with locating specific knowledge, details of knowledge holders, and people who have similar interests as the seeker. These types of software may be regarded as knowledge management systems that are socio-technical in nature (Hasan \& Crawford, 2007). According to Weiser (1993; cited in Meloche, et al., 2009), the easy-to-use and nonintrusive nature of wikis make them a powerful tool for knowledge workers, who experience life through practice and tacit knowledge.

However, knowledge seekers make their own judgements regarding the value and relevance of the content held in social technologies. Characterised by an "architecture of participation" (Gordon, 2006, p26), social technologies also serve as mechanisms for communicating tacit knowledge without externalising it (Automony, 2003; Meloche, Hasan, Willis, Pfaff, \& Qi, 2009; Stenmark, 2001). Jimmy Wales, the inventor of wikipedia, the on-line dictionary, goes a step further in explaining that it "is a project built on the premise of giving away knowledge" (Boisot et al., 2006), arguing that being free (in the sense of no cost and freedom), open and transparent serves to build the trust that is required for successful web communities. Meloche et al. (2009) state that "a working definition of a wiki is an evolving repository where users are encouraged to make additions to this repository by adding new documents or working on existing ones (Pfaff and Hasan, 2006a)" (Meloche, et al., 2009).

Now seen as part of Web 2.0, a second generation of web-based services (Gordon, 2006), wikis have become pervasive since Ward Cunningham implemented the first one to host the Portland Pattern Repository. Phenomenal growth has occurred - wikis have wide use in sectors such as banking, healthcare, pharmaceuticals, (Gordon, 2006) and across the public and private sectors. 
Wikis enable diverse groups to collaborate and strengthen on-line identities, to bring together more diverse types of knowledge than other technologies have allowed until now, and to enable presentation of a more thorough and holistic overview of subject areas. They can open up previously internal business processes to public consultation, as in the case of the US Patent and Trademark Office (Varchaver, 2006), serve as a tool for managing groups and committees, and provide documentation, support, downloads and troubleshooting for groups who need to transfer, share and evolve knowledge.

Comparisons can validly be drawn between the use of wikis "as a simple and inexpensive, but practical, tool that has value for knowledge management" in education (Raman, Ryan, \& Olfman, 2005 p. 311), and in a business environment. Benefits include saving time in capturing and distributing corporate knowledge, having a lower barrier to adoption compared with other technologies, being intuitive to use, and enabling inter- and intra-group collaboration by decentralising the control of communication (Goodnoe, 2006).

If wikis are recognised as the voice of a community, then blogs (weblogs) contain the unedited, spontaneous opinions of individuals (Dearstyne, 2005; The Economist, 2006). Blogs can be described as formatted web journals with frequent, dated entries in reverse chronological order, with capability for others to post unedited comments and opinions in response to the existing content (Brownstein \& Klein, 2006; Dearstyne, 2005; Shaffer, Lackey, \& Bolling, 2006). They provide links to other blogs and web-sites and may be set up to provide RSS feeds of aggregated content to the user's email address or web-site. As for their origins, blogs are seen either as existing from the birth of the world wide web, or as a more recent successor to the personal web pages of the early 1990s (Brownstein \& Klein, 2006; Weiss, 2005). People set up blogs for various purposes. They may be set up as personal blogs, to publish news and discussion as in the case of news service blogs, to provide marketing information, advertising, public relations and customer advice, for business or professional use, or as an organisational internal knowledge sharing mechanism. Examples of internal knowledge sharing are CEO blogs, project managers' blogs for coordinating project activities, and blogs for groups like designers, engineers and other experts (Dearstyne, 2005).

Various features make blogs appropriate and attractive for transferring knowledge. Brownstein and Klein (2006) note that the process of posting, review, discussion and knowledge-building reflects the process for teaching and learning in post-graduate 
science, and corresponds to the manner in which scientists develop concepts, and professionals develop ideas that evolve into best practice. Shaffer et al. (2006) echo these observations in the context of a professional development study group in a nursing faculty. Through ongoing discussion, participants develop subject matter expertise. Small groups can develop ownership through participation, which builds enthusiasm for learning and creativity, as blogs are intuitive to use and sufficiently flexible to meet different learning styles.

The functions of knowledge-sharing and knowledge-building help professionals develop their critical thinking skills. The on-line nature of the channel is suited to busy professionals who need to contribute independently of their physical location, and to give and receive professional and learning support. Relationship-building can be a positive feature of blogs, as companies such as Nokia, Sun Microsystems, Microsoft and General Motors use them to interact more with customers, complementing traditional public relations channels. Information can be spread spontaneously, virally, and it is easy to swarm ideas (Dearstyne, 2005; Kirkpatrick \& Roth, 2005), as demonstrated during the 2004 Asian tsunami and the US election of 2004 (Baker \& Green, 2005), and in instances of consumer dissatisfaction (Kirkpatrick \& Roth, 2005).

Other social media for facilitating knowledge sharing include popular applications such as Facebook, MySpace, LinkedIn, YouTube and Twitter (Kaplan \& Haenlein, 2010). Social networking sites enable users to maintain an on-line identity, present information about themselves and exchange information with other members. Sites like LinkedIn provide a more formal avenue for business people to maintain relationships with their peers and promote their businesses and professional skills. Facebook is also used to promote and serve as a distribution channel for a company's products. New social media applications are appearing rapidly and "allow firms to engage in timely and direct end-consumer contact at relatively low cost and higher levels of efficiency than can be achieved with more traditional communication tools" (Kaplan \& Haenlein, 2010, p. 67).

The micro-blogging application Twitter enables users to post tweets of up to 140 characters. Businesses are increasingly using Twitter as a marketing tool to build a following for their products and services, posting about their sales and promotions, and directing followers to their web sites and other on-line presences such as on Facebook. Twitter also serves as a means of posting queries and receiving quick answers or references for locating further information. 
Social media encourage social networking between people, between businesses and their potential customers and between politicians and their constituents, enabling people to maintain weak ties with little cost and effort (Golbeck, Grimes, \& Rogers, 2010;

Palvia \& Pancaro, 2010). There are age-related differences, however, in the way that Generation Y - digital natives - use social media, compared with those over age 60 (Palvia \& Pancaro, 2010). The different patterns of use in terms of frequency, the purpose for which media are used, and the types of relationships that are maintained may have implications for knowledge sharing between users of different ages.

\subsubsection{Types of information systems that support knowledge transfer}

Table 2-8 (p. 68) summarises the findings of some studies of the types of ICT used to support knowledge retention in a range of organisations. First, where organisations have a codification strategy, knowledge can be captured in repositories and databases and made available as an organisational asset. Second, such systems are used to a lesser degree in organisations that have a personalisation strategy, where there is more emphasis on providing facilities that encourage employees to meet virtually and share knowledge, directories of experts, and software tools for locating knowledge and communities. Collaborative tools enable employees to share knowledge. Last, not all knowledge transfer or sharing activities require technology. For instance, knowledge holders may travel to conferences or be transferred to locations where their knowledge can be shared (Hansen, et al., 1999). Also, mentoring or pairing an older expert with a younger and less experienced employee may not require ICT support, and in certain steps of a knowledge retention process, such as knowledge elicitation, there is more emphasis on methods rather than technology (Hylko, 2005).

\begin{tabular}{|l|l|}
\hline $\begin{array}{l}\text { Organisations } \\
\text { and industries } \\
\text { (author) }\end{array}$ & Description of initiatives \\
\hline $\begin{array}{l}\text { Volvo IT } \\
\text { (Stenmark, 2001) }\end{array}$ & $\begin{array}{l}\text { trialled recommender system for personalised } \\
\text { information delivery from web documents } \\
\text { locator of knowledge and communities, such as } \\
\text { individuals with similar roles, profiles and interests }\end{array}$ \\
\hline $\begin{array}{l}\text { FirstEnergy } \\
\text { (O'Donnell, 2004,p. } \\
\text { 24) }\end{array}$ & $\begin{array}{l}\text { "wisdom transfer" program exists in its early stages, } \\
\text { "pairing an older employee who has endangered skills } \\
\text { with a younger worker", for up to four years. }\end{array}$ \\
\hline $\begin{array}{l}\text { NASA, Kennedy } \\
\text { Space Center } \\
\text { (England \& Herrera, } \\
\text { 2005) }\end{array}$ & $\begin{array}{l}\text { web-based education program to capture and retain } \\
\text { knowledge }\end{array}$ \\
\hline
\end{tabular}




\begin{tabular}{|c|c|}
\hline $\begin{array}{l}\text { Organisations } \\
\text { and industries } \\
\text { (author) }\end{array}$ & Description of initiatives \\
\hline $\begin{array}{l}\text { Andersen } \\
\text { Consulting, Ernst \& } \\
\text { Young (Hansen, } \\
\text { Nohria \& Tierney, } \\
\text { 1999) }\end{array}$ & $\begin{array}{l}\text { To support a codification strategy: } \\
\text { - electronic KM repository for documents and templates } \\
\text { - databases containing best practice, knowledge objects } \\
\text { and other materials }\end{array}$ \\
\hline $\begin{array}{l}\text { Bain, Boston } \\
\text { Consulting Group, } \\
\text { McKinsey }\end{array}$ & $\begin{array}{l}\text { To support a personalisation strategy: } \\
\text { - } \quad \text { videoconferencing facilities, directories of experts, use } \\
\text { of consulting directors within firm } \\
\text { - encourage culture of assisting other consultants, } \\
\text { transfer people with skills between offices } \\
\text { - electronic document systems to lesser degree } \\
\text { - electronic repository listing available components for } \\
\text { PC assembly }\end{array}$ \\
\hline Hewlett Packard & $\begin{array}{l}\text { - person-to-person exchanges, travel, company } \\
\text { conferences for knowledge exchange (personalisation } \\
\text { strategy) }\end{array}$ \\
\hline Access Health & $\begin{array}{l}\text { - knowledge repository of software algorithms of } \\
\text { symptoms for over } 500 \text { illnesses, for phone-based } \\
\text { diagnosis (codification) }\end{array}$ \\
\hline $\begin{array}{l}\text { Memorial Sloan- } \\
\text { Kettering Cancer } \\
\text { Center }\end{array}$ & $\begin{array}{l}\text { manages the collaboration of medical experts, } \\
\text { intensive inter-disciplinary face-to-face collaboration } \\
\text { between researchers and different types of clinicians } \\
\text { (personalisation) }\end{array}$ \\
\hline $\begin{array}{l}\text { WESKEM LLC } \\
\text { (Hylko, 2005) }\end{array}$ & $\begin{array}{l}\text { capturing undocumented knowledge using critical } \\
\text { decision method, simulations, scenarios and concept } \\
\text { mapping for elicitation relating to industrial hazards } \\
\text { knowledge captured in work activity database for } \\
\text { multi-site use }\end{array}$ \\
\hline $\begin{array}{l}\text { NASA } \\
\text { (Lesser, 2006) }\end{array}$ & $\begin{array}{l}\text { - scheme for retired employees to volunteers in } \\
\text { knowledge sharing. } \\
\text { Academy of Program \& Project Leadership (APPL) } \\
\text { Knowledge Sharing Initiative conducts workshops and } \\
\text { forums for knowledge sharing on project management. } \\
\text { Leaders as Teachers and Mentors program has expert } \\
\text { database of current and retired practitioners who are } \\
\text { available for consultation }\end{array}$ \\
\hline $\begin{array}{l}\text { Tennessee Valley } \\
\text { Authority } \\
\text { De Long and Mann } \\
(2003)\end{array}$ & $\begin{array}{l}\text { - use of question-based reasoning software to assist with } \\
\text { making tacit knowledge explicit, store lessons learned } \\
\text { from past significant operational failures } \\
\text { questioned employees about intended dates of } \\
\text { retirement, then developed succession plans to capture } \\
\text { knowledge, introduced phased retirements and } \\
\text { mentoring }\end{array}$ \\
\hline
\end{tabular}

Table 2-8: Examples of knowledge retention initiatives and ICT support forms 


\subsubsection{Summary}

Depending on the types of initiatives that organisations use to address the loss of knowledge when older, knowledgeable workers retire, there are various opportunities for ICT support. This section considered how organisations make decisions on the types of ICT they use to support knowledge transfer initiatives. This was followed by an outline of the three main waves of ICT support for knowledge management and a review of the types of technologies commonly in use over a wide range of organisational environments.

\subsection{Gaps in knowledge addressed by research question}

Some gaps exist in the literature, thus providing the rationale for the research questions.

\subsubsection{Gaps in literature}

There is extensive literature on baby boomers and the fact that within this sector of the workforce resides knowledge that is valuable to organisations. Such knowledge may be lost if action is not taken to identify what types of knowledge are valuable, and who holds this knowledge. The main area of concern within industries and organisations is that the next population cohort is only $75 \%$ of the size of the baby boomers and may not yet have developed and acquired similar levels of expertise. There is a large volume of research on how organisations create, store, retrieve, transfer and apply knowledge.

In searching for literature on infrastructure or processes for successfully retaining expertise from older workers in an organisation context, little specific information is to be found. The literature that does exist is high level and general in nature (England \& Herrera, 2005; Gross, et al., 2001; Hylko, 2005; Lesser, 2006). The literature indicates that retaining knowledge from older experts in organisations is a relatively new area of practitioner-based activity. Therefore, the first research gap is in this topic area.

Likewise, extending the scope of the topic to include how ICT supports knowledge retention from older workers also reveals little academic, non-proprietary knowledge or research. This therefore appears to represent the second research gap.

The research topic "retaining the knowledge of older experts in an organisational context and the role of ICT" corresponds neatly with an apparent gap in academic research and literature and is relevant to a wide range of organisations and industries. Organisations of a sufficient size to have a distribution of age groups represented in 
their workforces are most likely to be exposed to the potential loss of knowledge when older experts retire. Factors contributing to the risk include a heavy reliance on knowledge for successfully conducting core business, key business processes that are poorly documented, and reliance on key personnel for their critical knowledge, their ability to locate knowledge and for access to their professional networks. Organisations whose raison d'etre is to profit from creating, supplying and trading in knowledge, and organisations whose personnel are highly qualified in specialised disciplines in which demand exceeds supply, are also at risk.

\subsubsection{Confirmation of research topic}

\section{Retaining the knowledge of older experts in an organisational context and the role of ICT}

This is the main research topic; in seeking to study this topic, there are some relevant sub-questions that merit consideration. In conducting research in organisations that recognise that valuable knowledge will be lost in the event that older workers become unavailable, mainly through retirement, there is an initial step of clarifying what constitutes valuable knowledge at the particular research site.

Hence the first sub-question is:

What types of knowledge does an organisation risk losing when older experts leave?

I reviewed literature on knowledge, expertise and wisdom, and presented several useful models that serve as potential lenses through which researchers and organisations can view knowledge.

Hansen, Nohria and Tierney's (1999) theory, discussed in Section 2.6.2, is that knowledge transfer processes and the technologies that support them, to be effective, should be consistent with the organisation's predominant strategy for managing knowledge. This strategy should be consistent with its business strategy. A codification strategy for knowledge reflects the stance that knowledge exists as an organisational asset, while a personalisation strategy would support a belief that knowledge is an attribute of the organisation's personnel and sharing needs to be facilitated. The extent to which this theory is relevant in a practical research environment depends, first, on whether the organisation being studied has a knowledge management strategy, and second, on whether the strategy development process included considering how the 
organisation views knowledge. In an organisation where both these factors exist, the theory has relevance for a knowledge transfer process improvement and for implementing appropriate ICT support, the two key components in this research study. Moreover, the organisation is likely to have an existing infrastructure that supports knowledge transfer (M. H. Zack, 1999) and perhaps to regard that infrastructure as being successful to some degree.

Table 2-4 (p. 51), representing Baltes and Staudinger's (2000) summary of implicit and explicit theories of wisdom, also serves as a useful integrative framework for addressing this research sub-question. It draws some conclusions about wisdom sourced from implicit theories from research in psychology, and defines some characteristics of wisdom as presented in cultural-historical and philosophical analyses of wisdom. Both the conclusions and the characteristics are relevant in clarifying the nature of knowledge. These authors also discuss explicit, formal theories of wisdom, two of which may relate to organisational environments. The first theory is that wisdom is a personal characteristic or constellation of personality dispositions; secondly, that wisdom is an expert system dealing with the conduct and meaning of life, with the application of tacit knowledge. Using these theories in an organisational setting would generate informative results, including the extent to which they are useful in confirming practitioners' perspectives of valuable knowledge remains.

Ardelt (2004) posits that knowledge is one aspect of wisdom, and that wisdom has three dimensions: cognitive, reflective and affective. On this basis, Ardelt proposes a framework, as shown in Table 2-5 (p. 54) for defining and operationalising the three dimensions, and notes that the scope of the reflective dimension encompasses the criteria that formed the basis for the Berlin researchers' model, in this case, Baltes et al. While this group used hypothetical stories and fictional characters in measuring wisdom, organisations are more likely to actually identify with Ardelt's operational measures of wisdom. Therefore, these measures would provide a practical framework for interviews and discussions.

As discussed above, Baltes and Staudinger's model is a philosophical and theoretical approach, while Ardelt's framework provides rich opportunities, in this case, for answering the research question through measures that are more specific and relevant to organisational environments. Elements of both models are relevant in addressing the first research sub-question. 
Determining how ICT can support knowledge transfer from older experts in an organisational context presupposes an understanding of how a knowledge transfer process or model actually works, and assumes that it is a process that should be supported by some form of ICT. Discovering answers to these assumptions requires a second sub-question to be addressed:

\section{What processes does an organisation use to retain the knowledge of older experts?}

There is a myriad of academic articles on knowledge transfer processes, knowledge sharing and knowledge flows, and the inherent challenges in any transfer. Kwan and Cheung's (2006) analysis identified 126 papers and 11 books on knowledge transfer, from which their research interest focused on 20 recent empirical studies. This exercise revealed that "few researchers have explicitly suggested a process model for knowledge transfer" (Kwan \& Cheung, 2006 p. 17), although there are many process models for knowledge management, as a higher order activity.

The scope of Hansen's (1999) two-stage process model addresses searching for knowledge and transferring knowledge, and examines the implications of weak and strong ties for the transfer of codified and non-codified knowledge. In designing or improving an existing knowledge transfer process in an organisation, it would be useful to consider the dimensions of Hansen's model, specifically as part of analysing the groups that benefit from accessing the knowledge of older and expert personnel.

Szulanski's (1996) process model for knowledge transfer consists of four stages. Initiation occurs when a gap in knowledge is identified and knowledge is found that addresses this issue. The implementation stage is characterised by actual activities of exchange between the source and the recipient. The third stage is ramp-up, signified by the recipient's initial use of the newly-acquired knowledge. Finally, integration occurs upon the first instance of the new knowledge being used successfully, or once it has become a part of routine operations for the recipient. This model is useful, in that Szulanski outlines the areas of difficulty associated with each stage of the process, and how they may be recognised. Both Hansen's and Szulanski's models are relevant as they relate to intra-organisational knowledge transfer.

The framework developed by Kwan and Cheung (2006) builds upon the previously mentioned models, and integrates findings from more recent empirical research studies. Kwan and Cheung's model splits Szulanski's initiation stage into a motivation stage and 
a matching stage. The motivation stage is the same as Szulanski's initiation stage, and matching occurs when a transfer partner is identified and there is commitment to the transfer. Implementation includes the flow of resources between knowledge source and recipient, and includes the recipient's first use of the transferred knowledge. Retention occurs when the recipient has experienced satisfactory results from using the knowledge. This framework has evolved Szulanski's model, due to the distinct determinants for success at each stage, based on the additional literature analysed. Kwan and Cheung's framework therefore appears to be the most comprehensive of the three models described. In terms of planning knowledge transfer processes within an organisation, it provides specific determinants for success. Szulanski's model is complementary in that it specifies inhibitors in terms of knowledge transfer stickiness.

Finally, having addressed the matter of defining what constitutes valuable knowledge for an organisation, and identifying an appropriate knowledge transfer process or model, the third research sub-question can be posed as:

\section{How can ICT support the knowledge retention process for the identified knowledge source(s) and recipients?}

Summarising the discussion in Section 2.6 of this thesis, the choice of specific technologies to support knowledge transfer, and agreement on how such technologies would be used, depends on a few factors. Adopting a top-down approach, the researcher and organisation could discover the extent to which the knowledge management strategy reflects business objectives. Also, the answer to the first research sub-question about the predominant view of knowledge would inform the selection of supporting technology.

Hylko's research in the US utilities sector notes a preference for using existing tools and systems for two reasons: the importance of capturing knowledge within time constraints as personnel were nearing retirement, and the advantages of using familiar technology so that the focus remains on knowledge transfer rather than technology adoption. Thus, the approach for answering the third research sub-question depended on the circumstances of the particular organisations being studied. 



\section{PART 2: THE RESEARCH TASK}

The second part of the thesis addresses the topics of the research methodology and the research process employed in the study.

First, I provide an overview of my research perspective and approach, and then proceed to a discussion of the nature of action research as my method of inquiry, addressing some of its limitations. Next, I introduce the topic of how quality may be measured in action research. Chapter 3 closes with an explanation of my role as researcher.

An overview of my research process opens Chapter 4, and I discuss the design of my research methodology. I describe the activities and discuss outcomes of the diagnosis, action planning, implementation and evaluation stages. . 


\section{Chapter 3. Research methodology}

\subsection{Overview}

The strategy for my research study was to adopt an interpretive perspective, with the use of action research as the methodology. The research topic lent itself to these particular approaches as, at the time the study began, the topic domain represented a relatively new area for academic research. The topic of knowledge loss from older experts is now however, gaining prominence as a concern for both organisations and practitioners. An action research approach gave me the opportunity to contribute to theory in terms of discovering new knowledge, as well as praxis, in working with an organisation to solve a problem within the research domain.

My role as researcher was primarily as an external practitioner in the fields of business consulting, ICT and project management - experience in business process design also happened to be pertinent in the research setting. This skill set complemented the business domain expertise of the study participants. A collaborative approach was important for action research, with the organisation owning decisions affecting practice, and the researcher being responsible for research-related elements.

The primary sources of data were organisational records, data from interviews and focus groups, and the researcher's journal. The key to successful data analysis is in establishing an effective organising scheme, confirming analysis methods and tools, and maintaining the flexibility that action research demands.

\subsection{The interpretive perspective}

Various classification schemes exist for defining research epistemologies. Chua (1986), as cited in Orlikowski and Baroudi (1991), outlines three research epistemologies: positivist, interpretivist and critical. Positivist researchers assume that reality is objective and can be measured independently of the researcher. Lee (1999) notes that positivism implies that a natural science based approach will be used to guide social science research, and that the positivist "pursues the goal of truth in formal propositions" (p. 29). In critical research, the main goal is seen as being social critique, exposing inequities and conflicts in society. The objective is often to leverage research towards some emancipatory action that enables humans to reach their potential. 
Chua's category of interpretivist research most appropriately describes the underlying philosophy for this qualitative study, noting however that "qualitative" and “interpretive” are not synonyms (Klein \& Myers, 1999; Myers, 2002). Qualitative methods are "acceptable as equal in value to quantitative approaches when used appropriately" (Avison, Lau, Myers, \& Nielsen, 1999) for example, in explaining what happens in organisational contexts.

The interpretivist philosophy in information systems research recognises subjective meanings in the process through which humans construct reality. It seeks and recognises meanings that the study participants attribute to organisational structure and processes, as represented in the way they express their opinions, concerns and views. To collect data and gain knowledge, I gained entry to two organisations to understand their situations and interpret the way that meanings were created and sustained in the setting of the study. As a researcher, I tried to understand the actors' view of their world and their roles, and over the course of the study, learned the language, concepts and experiences of the actors. In interpretive studies, the researcher's own subjectivity, embodied in his or her own values, beliefs and experience, become part of the research situation. I was therefore not neutral, and my investigations were thus shaped by the assumptions I inevitably made, based on my own values and beliefs. Direct interaction with the study participants also meant both my own perceptions and those of the participants underwent change (Walsham, 1995). As is to be expected, part of this change involved influencing one another's perceptions and understanding throughout the research process.

There were specific reasons for adopting an interpretive perspective for the study. First, the nature of the study involved observing human behaviour in transferring knowledge in an organisational environment. I needed to understand the actors in their specific organisational setting in terms of how they perceived the state of their organisation in relation to the research questions. Second, I wanted to understand their views and definitions of valuable knowledge. Third, part of the study included observing how knowledge was retained from an older expert - specifically this involved observation of his behaviour and processes and his associated reasoning. None of these aspects could be viewed in isolation from the characteristics of his setting within the organisation, industry and political situation. Fourth, I believed that a better understanding of the actors and the organisations would build a greater sense of ownership of the study findings and commitment to the introduction of any 
improvements and supporting technology (Cunningham, 2008; Heron \& Reason, 2001). Last, an interpretive approach assumes there is no objective truth and gave flexibility to deal with the organisation's fluid state and its affect on the research process.

\subsection{Choice of qualitative approach}

A researcher's training and experiences influence their worldview, an important factor in the choice of research approach. Where the nature of the problem being studied is such that it requires exploration, due to the fact that little literature exists, then a qualitative approach is appropriate. It is also useful where the researcher needs to focus on the social or organisational context to solve the problem. In particular, a qualitative approach is suitable for the ill-structured, fuzzy nature of organisations (Avison, et al., 1999). Myers (2002) notes that there is a shift in information systems research away from technology and towards organisational issues.

In this research study, the decision to carry out qualitative research was made for three reasons. First, my background has included working in the area of introducing organisational change, through strategy implementation, business process improvement and project management. The impacts of these change initiatives have been monitored using qualitative methods and data, with follow up activities as indicated by the results of monitoring. This requires a flexible approach in implementing change, and an ability to accept ambiguity and deal with unexpected outcomes. Second, the qualitative approach was appropriate to this research due to the dynamic nature of the organisations, in particular in the case of the second organisation and the changes that resulted from the action research cycles.

While there have been studies on the ageing workforce, there is at this stage relatively little information available on how organisations are dealing with issues of knowledge retention due to this phenomenon. Likewise, in the New Zealand context, there is little information on how information systems may support knowledge retention from older workers. Third, my intention was to work closely with two organisations who recognise the potential for knowledge to be lost when older experts retire, meaning they would be participating partly because they have an awareness of the social perspective of the study. This provided the basis for focusing on how the challenge of knowledge retention could be addressed in their organisations. 


\subsection{The nature of action research}

There exist various definitions of action research, and I present some prominent ones in this section. I then discuss its use in information systems and explain my rationale for selecting action research as the methodology for my study.

\subsubsection{Definitions of action research}

Action research can be described as one type of applied social research, with Rapoport (1970) noting that it differs from other types of research due to the researcher's role in implementing actions to solve a problem. "Action research aims to contribute both to the practical concerns of people in an immediate problematic situation and to the goals of social science by joint collaboration within a mutually acceptable ethical framework" (Rapoport, 1970, p. 499). Curle (1949) notes that action research "aims not only to discover facts, but to help in altering certain conditions experienced by the community as unsatisfactory" (as cited in Rapoport, 1970 p. 500). Susman and Evered's (1978) assessment of the merits of action research cites Kurt Lewin's 1946 definition of action research as "a comparative research on the conditions and effects of various forms of social action and research leading to social action"(Susman \& Evered, 1978, p. 586).

Lewin and Curle's broad definitions still hold true today. Susman and Evered (1978) extended Rapoport's definition to include the need to also develop in the client organisation the capability to be self-sufficient in solving similar problems in future. Baskerville and Wood-Harper (1998) agree, noting that the ability to achieve this adds to the validity of action research in information systems.

Hult and Lennung (1980) reviewed descriptions of action research, commenting on their component parts, and subsequently constructing a comprehensive definition, "Action research simultaneously assists in practical problem-solving and expands scientific knowledge, as well as enhances the competencies of the respective actors, being performed collaboratively in an immediate situation using data feedback in a cyclical process aiming at an increased understanding of a given social situation, primarily applicable for the understanding of change processes in social systems and undertaken within a mutually acceptable ethical framework" (Hult \& Lennung, 1980 p. 247).

In considering how action research may be carried out, some researchers describe the action research process as involving an iterative, five step, cyclical process, initiated by 
diagnosing a problem, then planning action to solve the problem, taking action, evaluating the effect of the action, and lastly, reflecting on the learning that has occurred as the result of each cycle (Avison, et al., 1999; Baskerville \& Wood-Harper, 1996; Davison, Martinsons, \& Kock, 2004). Action research differs from other research approaches as the researcher is a change agent in introducing improvements to solve a business problem in a real organisation. The success of an action research project depends on its ability to facilitate successful business change and to generate new theoretical knowledge (Baskerville \& Myers, 2004; Baskerville \& Wood-Harper, 1998; Davison, et al., 2004). An earlier definition of action research comes from Blum (1955), who defines action research as a two-step process. The first, a diagnostic step, involves the researcher analysing the social setting and forming hypotheses. The second, a therapeutic step, involves introducing change and assessing the results (Baskerville \& Wood-Harper, 1998).

Baskerville and Wood-Harper (1998) highlight the difficulty of defining action research, noting that the term refers to "a genre of research methods" (Baskerville \& Wood-Harper, 1998 p. 90) rather than a single method. In highlighting the diversity of action research methods used in information systems, Baskerville \& Myers (2004) also describe Kurt Lewin's (1947) six-step process, dating from the 1940s and consisting of analysis, fact-finding, conceptualisation, planning, implementation of action, and evaluation (Baskerville \& Myers, 2004). Lewin is credited with developing and using the method for the study of social psychology. Jeffery's (2005) description of integrating a process improvement methodology in the context of organisational development draws upon the model of French and Bell (1999), with its seven distinct process steps: preliminary diagnosis, data gathering, data feedback, data exploration, action planning, action implementation, and evaluation and assessment (Jeffery, 2005).

In summary, diverse forms of action research exist - many definitions have evolved. The following definition that is used in this research study: "Action research simultaneously assists in practical problem-solving and expands scientific knowledge, as well as enhances the competencies of the respective actors, being performed collaboratively in an immediate situation using data feedback in a cyclical process aiming at an increased understanding of a given social situation, primarily applicable for the understanding of change processes in social systems and undertaken within a mutually acceptable ethical framework" (Hult \& Lennung, 1980 p. 247). 
Susman and Evered (1978) note that "action research can also be viewed as a cyclical process with five phases: diagnosing, action planning, action taking, evaluating, and specifying learning. The infrastructure within the client system and the action research maintain and regulate some or all of the five phases jointly" (Susman \& Evered, 1978, p. 588). The design of my research follows the cycle as depicted in Figure 3-1 (p. 81).

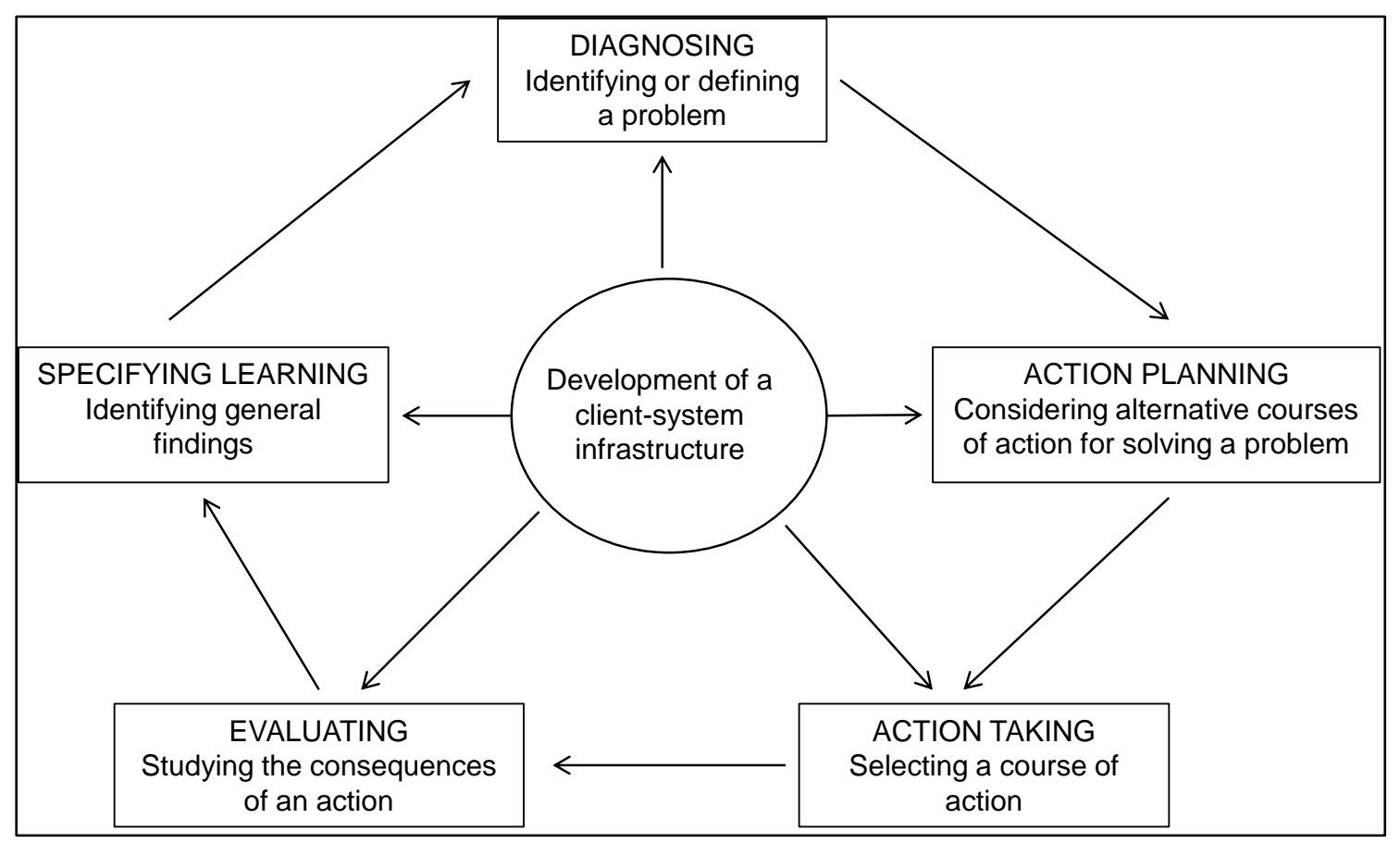

Figure 3-1: The cyclical process of action research (Susman \& Evered, 1978)

The activities at each step of the action research cycle can be summarised as follows:

Diagnostic stage: this stage involves "a collaborative analysis of the social situation by the researcher and the subjects of the research. Hypotheses are formulated concerning the nature of the research domain"(Baskerville \& Pres-Heje, 1999, p. 3). It is important not to separate the problem phenomenon from its environment, as this gives it meaning; a researcher needs to consider the total system holistically, rather than isolated aspects of it (Hult \& Lennung, 1980).

Action planning activity: a collaborative team designs a plan of actions to address the primary problem. The researcher needs to justify, explain and relate the planned actions to the problem (Davison, et al., 2004).

Action taking stage: the changes are implemented, their impacts are observed and the results of the change are noted. During this stage, flexibility needs to be maintained. If 
the action does not succeed in solving the problem, another cycle may be required as planned actions may not always be successful.

Evaluating stage: the researcher and practitioners evaluate the outcomes of the changes and there is a growing understanding of the impact of the changes upon the problem situation. Information gained from the evaluation stage serves to inform subsequent cycles of action research.

Specifying the learning: once the researcher analyses the data, new learning should emerge. If the outcome does not represent an improvement, this may lead to a subsequent iteration of the action research cycle, moving into a diagnosis step. Specifying learning involves reviewing the learning that has taken place for the practitioners in their environment, and includes the learning that has taken place for the researcher in terms of the research question and contribution to theory.

Susman and Evered refer to a client-system infrastructure, and Baskerville and PresHeje refer to a client structure. This context can be regarded as the social system in which the problem being studied has its context and meaning. The client-system infrastructure is described as the infrastructure within which the organisation and the researcher jointly regulate and manage some or all of the five stages of action research.

The researcher-client agreement (RCA) forms part of this infrastructure. As the agreement forms the basis for carrying out action research, it should be agreed and drafted at the outset, and is expected to evolve as the research proceeds. It is a project artefact that is treated as a living document and kept up to date as the project progresses. This is because the events that will occur in each step of the action research cycle can be pre-determined only to a certain degree, and because the action research approach requires some flexibility in response to the changing of the research situation as practitioners and researcher gain more knowledge and clarity as the study proceeds. There must also exist a conceptual framework that underpins the action research study (McKay \& Marshall, 2005) and the practical actions taken to solve the business problem need to be associated with creating, extending, refining and testing theories.

\subsubsection{Action research in information systems}

Baskerville and Wood-Harper (1998) describe the genealogy of action research as having five fragmented streams of development leading to its current use in IS. The 
development streams are: social and organisation science, organisational learning, process consultation, systems science and IS action research.

From an IS researcher and practitioner perspective, four distinct streams have given rise to action research: original or "canonical" action research, management consulting, soft systems methodology and organisational learning. The use of action research as a method in IT has been sufficiently popular, if not pervasive, to enable reviews of IT action research studies, such as those conducted by Orlikowski and Baroudi (1991) and Lau (1997). Lau's review included the identification of criteria that could be applied to measure the quality of action research studies. More recently, MIS Quarterly devoted a special issue to action research in IT, with an editorial that commented on the different action research forms that the exemplars have used (Baskerville \& Myers, 2004).

Avison, Lau, Myers and Nielsen noted that the validity of action research is endorsed by the existence of some key contributions as listed in Table 3-1(p. 83):

\begin{tabular}{|c|c|}
\hline Authors & Contributions to action research \\
\hline $\begin{array}{l}\text { Avison and Wood- } \\
\text { Harper }\end{array}$ & The Multiview development framework \\
\hline Checkland & Soft systems methodology \\
\hline Tavistock Institute & Socio-technical design \\
\hline $\begin{array}{l}\text { Bjerknes, Ehn and } \\
\text { Kyng }\end{array}$ & $\begin{array}{l}\text { Studies on empowering trade unions and strengthening the } \\
\text { position of users in systems development }\end{array}$ \\
\hline Mumford & $\begin{array}{l}\text { ETHICS (effective technical and human implementation of } \\
\text { computer-based systems) participative approach to systems } \\
\text { development }\end{array}$ \\
\hline
\end{tabular}

Table 3-1: Key contributions to action research (Avison, et al., 1999)

Recently, there has been a growth in the action research literature, with journal articles and dedicated issues on action research, extending the earlier literature which was mainly in the form of books. There is now a context for action research in terms of its heritage, and a stronger sense of where it fits as a valid approach. There have been analyses of action research, frameworks have been developed, and there is some ability to measure the quality of action research. For example, Lau's (1999) unifying framework sets out four essential dimensions for action research: a conceptual foundation, study design, research process and role expectations.

Davison, Martinsons and Kock (2004) define principles for measuring rigour and relevance in action research, explaining that they do so in response to the lack of methodological guidance on how to conduct and evaluate action research. Their 
principles are described as: researcher-client agreement, cyclical process model, theory, change through action, and learning through reflection. They specify criteria for meeting each principle. The September 2004 issue of MIS Quarterly is devoted to exemplars of action research which are endorsed as having made contributions to practice and theory, and as demonstrating how the research meets these goals.

In summary, action research is still regarded as being emergent in the IS domain (Avison, et al., 1999) when compared with other research methods.

\subsubsection{The dual imperatives of action research}

Action research study must meet the needs of the participating organisation, for an improvement in a current state or existing process, and be relevant to the organisation. Benbasat and Zmud as cited in Davison, Martinsons and Kock (2004), state that research that is relevant will "focus on concerns of practice [and] provide real value to IS professionals". The topic and the implications of the results should be relevant to the organisation being studied. The research must also meet the researcher's objective of contributing to theory or the body of knowledge in the domain of study. Therefore, the researcher must impose a "clear, mutually agreed theoretical framework on the situation for explicit, general lessons to emerge from the research" (Baskerville, 1999, p. 7)

Baskerville and Wood-Harper (1998) posit that the ideal domain for an action research study is a social setting where the researcher is actively involved, the knowledge obtained can be immediately applied and the research is a typically cyclical process that links theory and practice. Checkland (1991) and Ngwenyama (1991) both view the most important aspects of action research as being the iterative approach for diagnosis, intervention and reflective learning for the participants and researcher alike. Checkland (1981), as cited in Baskerville and Pries-Heje (1991, p 253), states that the criterion by which action research is judged internally is its practical success. This is measured by the participants' willingness to acknowledge that learning has occurred. Ideally, organisational norms are restructured to incorporate the new knowledge gained. The opportunity for integrating learning is in step 5 of the action research cycle, specifying learning, which involves the researcher and practitioners formally reviewing the new knowledge gained from the action taken.

In Figure 3-2 (p. 85), McKay and Marshall (2005) show the dual imperatives of action research. The cycle labelled (a) depicts the problem-solving interest of action research 
and the cycle labelled as (b) depicts the research interest of action research. Both cycles occur at the same time within an action research project. The researcher works with the organisation through each step of the problem solving process. The process may involve more than one iteration if the problem has not been solved following the first set of actions. At the same time, the researcher is also involved in a theoretical process that mirrors the practical problem solving actions.

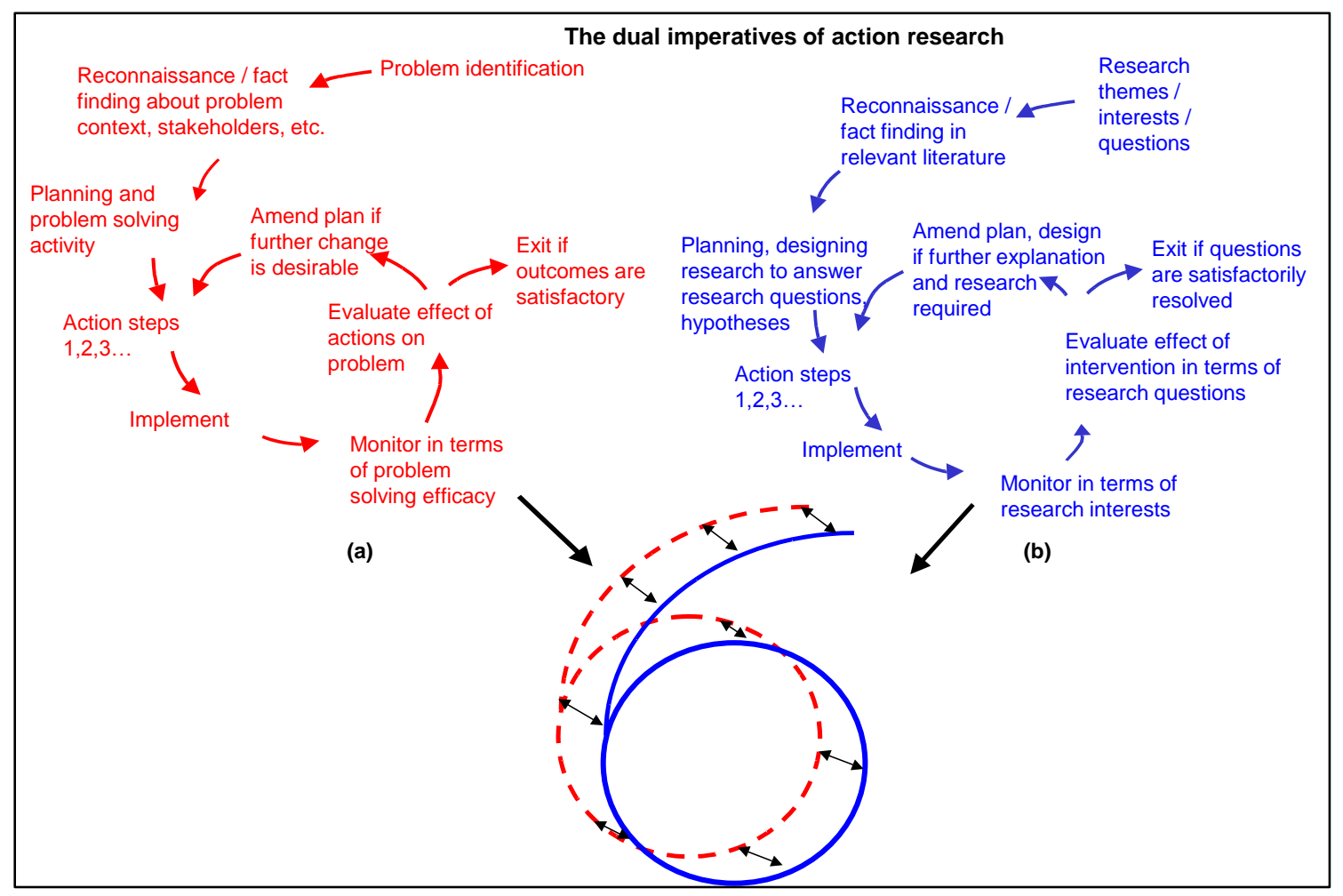

Figure 3-2: Dual imperatives of action research (McKay \& Marshall, 2001, p. 4)

\subsubsection{Rationale for choosing action research}

The action research method produces highly relevant research results "because it is grounded in practical action, aimed at solving an immediate problem situation while carefully informing theory" (Baskerville, 1999, p. 2). I wanted to study the social processes involved in knowledge retention within an organisation, through an intervention to introduce an improvement, and then to observe the impacts of the improvement. In the course of intervening, I became a co-participant of the study, while at the same time observing processes and people, and gathering data that was meaningful to participants and expressed in their own terms and language.

The benefits of conducting action research include the achievement of immediate mutual benefits, collaboration for a better future, and for the researcher, a high degree of participation and the ability to address theory and practice. 
One of the advantages of action research that appealed to me was the immediacy of the benefits for the two participant organisations fairly early in the research process, and for myself as the researcher. For example, I gained an understanding of the social setting as a result of the diagnostic activities, in preparation for introducing an intervention that improved the organisation's current process or current state of knowledge.

Both organisations received a business report setting out the findings from that step of the action research study. This meant that the sponsor and participants learned about their own organisation's perspectives about concepts of valuable knowledge that had emerged. The topic had been of concern to individual managers but they had not got around to discussing it. The participants' confirmation of my findings confirmed that I had understood their concepts and concerns about valuable knowledge. As a result, I derived a better understanding of both organisations' shared meanings on the subject of retaining valuable knowledge.

Action research involves collaborating for a better future, in a way that alternative methods such as case studies and ethnographies do not. Researchers and participants are required to collaborate to achieve improvements in the current state of the unit of analysis. Each party brings its own needs and expertise, practitioner and theoretical, and an interdependence is established and guided by Rapoport's (1970) "mutually ethical framework", including clearly established roles and responsibilities. In my study, the mutually accepted framework took the form of a Terms of Reference document for each participant organisation.

The study resulted in some improvements at different levels. One organisation developed a process for addressing its knowledge retention requirements relatively quickly, as a result of the study. The study participants identified existing, budgeted business initiatives as the vehicles for taking action. The second organisation saw the future in a considerably more positive light, in terms of preventing knowledge loss, once it had taken action to retain knowledge from a specific older expert.

There is a high degree of participation by the researcher in action research, in collaboration with the other parties (Heron \& Reason, 2001; Van der Veen, 2000; Vernooy \& McDougall, 2003; Wadsworth, 1998). Both the organisations in my study had a positive degree of ownership of the change actions and initiatives that they decided to implement. The reality however, is that in implementing change, there were inhibitors like the inability to establish any further change initiatives in one 
organisation, and more immediate concerns about the retirement of the older expert in the short term. In the second organisation, I also was given the role of project manager, so subsequently facilitated the evaluation of its success and collaborated with the organisation to specify learning.

In my role as researcher, I was able to address theory and practice, being actively involved in implementing change and monitoring effectiveness, as well as gathering data for analysis and interpretation. Action research is an appropriate method to "bridge the gap between theory and practice for IS practitioners" (Lau, 1999 p. 5), as it is oriented towards solving practical problems as well as the reflective learning that is required to build new knowledge. Baskerville and Myers (2004) note that action research methods are a means of making IS research more relevant to practice. Action research is "unique in the way it associates research and practice" (Avison, et al., 1999) and each informs the other in a synergistic manner.

As a methodology, action research is already accepted in organisational development and was therefore appropriate for use in the context of my study. Maintaining strong links between practice and theory was important, as I had a practical role in the project, spending time on site, while at the same time I needed to be cognisant of theoretical considerations. For example, I needed to consult the literature to ensure that each step of the action research cycle was carried out in compliance with the methodology. In the course of gathering and analysing data, I was careful to confirm my understanding of emerging themes. Another of my concerns was to ensure that I was sufficiently thorough in my interview techniques to elicit meaningful data.

\subsection{Measuring quality in action research}

Action research is also discussed in relation to a set of principles or characteristics that are present in action research studies. In discussing canonical action research, Davison, Martinsons and Kock (2004) describe five principles. The first principle is that a researcher - client agreement must exist, the client must understand how action research works and what the challenges for the particular organisation might be. The second principle involves the commitment to a cyclical process model, and depending on the circumstances of the intervention, there may be some iterations between stages. The third principle is that there needs to be a theory or theoretical framework for the phenomenon that is being studied. However, there are differing views as to the value of 
a theory at the very beginning of an action research project, but a theory should emerge during the diagnosis stage. The fourth principle is that change is effected through action, with the success of the intervention depends on the researcher and the client agreeing on the appropriate intervention for solving the problem. The last principle is one of learning through reflection - the implications for practice and research should be clearly reported. Davison et al. set out detailed criteria for assessing how well a project may meets each of these principles.

Action research studies must also demonstrate evidence of credibility, validity and trustworthiness. For example, where credibility is concerned, the application of codes of ethics in professional and academic environments is a means of enforcing moral principles in research (Christians, 2000). The literature contains many descriptions of validity and its relevance to qualitative research (Drisko, 1997b; Guba \& Lincoln, 1994; Hammersley, 1990; Janesick, 2000; McKay \& Marshall, 2005), including the view that there is not a process which guarantees validity as an outcome. "Validity is not a commodity that can be purchased with techniques ... Rather, validity is like integrity, character, and quality, to be assessed relative to purposes and circumstances" (Brinberg $\&$ McGrath, 1985, p. 13). There are also various factors that may be taken into account in assessing research in terms of trustworthiness. Drisko (1997) discusses, in the context of social work, a few factors that may be used to evaluate qualitative research. The philosophy and epistemology should be clearly stated, and the methodology used should be consistent with this. The study's objectives and audiences should be evident. Any biases should be declared and addressed in a way that is consistent with the philosophy and objectives of the study. Appropriate ethics should be maintained. Finally, the findings should be consistent with the study objectives and the philosophy adopted (Drisko, 1997a, p. 187).

I assess the research in relation to these factors in Part 4 of this thesis.

\subsection{Role of the researcher}

As discussed in Section 3.2, I adopted an interpretive perspective as a researcher, recognising that reality is subjective, data cannot be separated from the environment from which they are gathered, and acknowledging my own subjective biases. The following description of published interpretivist papers, compared with positivist ones, reflects my position on my study: "interpretive papers provided evidence of a non- 
deterministic perspective, an intent to increase understanding of the phenomena within a specific cultural and contextual setting, and an examination of the phenomena and the setting from the perspective of participants" (Walsham, 1995, p. 384).

\subsubsection{Collaborative}

A collaborative approach recognises that both researchers and members of the target system are important to the research process and the implementation of improvements. However, I was responsible for developing the key aspects of the research process, such as the design of the study. Other major decisions, such as the technology to be introduced and the external parties to be involved in the research, were discussed and agreed with the sponsor of the research. As an external researcher, I had little knowledge of the organisation's constraints - in the case of technology, there were ICT architecture and environmental aspects. In involving external parties, I needed to be sensitive to the nature of existing relationships and their potential impacts on the study.

The nature of the organisation and its current state have an impact on the degree to which collaboration is feasible, and its capacity for introducing improvements in terms of the extent, timing and priority of a change.

\subsubsection{Participative}

A more participative approach enables researchers to recognise that both the researcher and system members have a valuable contribution in the form of the knowledge they bring to the research situation. The researcher brings knowledge of the research process and systems knowledge, and the system members have detailed knowledge of their system, how they view phenomena, that is, how social reality is constructed, and how to achieve results in the organisational setting. Groups also have the ability to solve their own problems, and researchers should not unerestimate their ability to do this (Chisholm \& Elden, 1993; Ellis \& Kiely, 2000; Mumford, 2001).

Taking a participative and collaborative approach allowed me to develop a more holistic view and a deeper and richer understanding, especially of the second organisation in the study. Although an outsider to the organisation and the industry, I was regarded almost as a temporary staff member, given access to desktop software such as electronic mail, and to the computer network almost immediately. These permissions yielded rich data in the form of organisational documents and contextual information, as well as being connected to the knowledge and culture of the organisation. I also had access to 
software applications such as the customer relationship management (CRM) system, which was related to my research, and web site development software. Acceptance as an outsider legitimised to my role and showed the organisation's commitment.

I found that a participatory approach enabled me to gain support for the project from the outset, once the study sponsor had agreed with this style of research. At each stage of the project, I felt in a strong position to negotiate with participants for their contributions - and also suspected that this approach yielded more data than I would otherwise have been able to gather. During my close observations of an older expert at work, which began in my first week on site, I gained valuable and relevant insights into the interfaces between his business process and others in the organisation. There was an immediacy in the way he involved me in his problem-solving processes. I would have missed these opportunities if he had not felt engaged in the research process.

\subsubsection{Researcher skills and competencies}

Action research is a complex process and involves academic and social skills. Mumford (2001) refers to the need for the researcher to find a role that is legitimate to the organisation and to be accepted in that role. For example, the researcher needs to decide on whether they are going to adopt an active or passive role, and this depends on the nature of the project, the researcher's personal skills and their role preference. Specific social skills are required, and the skills of the researcher and the system members are enhanced in the course of carrying out the research. Mumford notes six types of competencies required in action research, in Table 3-2 (p. 90).

\begin{tabular}{|l|l|}
\hline Required competence & Description \\
\hline Knowledge competence & $\begin{array}{l}\text { Ability to learn from experience and add to personal } \\
\text { knowledge }\end{array}$ \\
\hline Resource competence & $\begin{array}{l}\text { Understanding of the kinds of personal skills required: } \\
\text { plan, understand technology and organisational } \\
\text { implications and have social skills to relate to staff }\end{array}$ \\
\hline Psychological competence & $\begin{array}{l}\text { Ability to motivate and encourage groups, maintain } \\
\text { morale and persevere }\end{array}$ \\
\hline Organisational competence & $\begin{array}{l}\text { Ability to think strategically about personal } \\
\text { contribution and how this fits the total situation }\end{array}$ \\
\hline Innovative competence & $\begin{array}{l}\text { Ability to think creatively and approach new and } \\
\text { unexpected problems from different angles }\end{array}$ \\
\hline Ethical competence & $\begin{array}{l}\text { Understanding, willingness to communicate personal } \\
\text { ethical values as relevant to the needs of the project }\end{array}$ \\
\hline
\end{tabular}

Table 3-2: Researcher competencies for action research (Mumford. 2001) 


\subsubsection{Researcher as non-expert}

Classical social science research views members of the organisation as "subjects" of the study, with minimal roles and contributions, with the researcher being in charge (Chisholm \& Elden, 1993; Gustavson, 2008). The Tavistock pioneers of the sociotechnical approach to the study of organisations assumed a research role of expert advisors from outside the organisation (Mumford, 2001) and in their study of coal mines did not involve the miners in analysing problems or identifying solutions.

I did not regard myself as an expert adviser or want to be perceived as such. Although I declared by background as a consultant and thought my problem-solving skills and experience in working with organisations to be an advantage, I was careful not to convey any expertise. My role was as a student researcher and my philosophical stance was that we were embarking on an action research project together and learning jointly from the experience. This perspective was appropriate since both of the study organisations had many reputable scientific and technical experts. Also, I had had no previous experience with either organisation or in the industries involved.

\subsection{Summary}

I adopted an interpretive perspective and a qualitative approach for my study. I used action research as my method of inquiry as there were mutual benefits for both of the participant organisations and for me as the researcher. A high degree of participation was required during the collaboration.

While the action research method addresses both theory and practice, there are some limitations such as a potential lack of control and a lack of methodological rigour. The results have validity within the context of the research and there is a risk that an action research study may be indistinguishable from consulting.

I introduced the issues of credibility, validity and trustworthiness. Finally, I gave an overview of my role as the researcher. 


\section{Chapter 4. Research process}

\subsection{Overview}

Action research is an approach that serves to "bridge the gap between academic research and organisational practice" (Kock \& Corner, 1996, p. 3). These authors state that a research framework should be developed first, and that data collection should then proceed within the context of the framework, which orients the collection of data. The research framework, however, can also restrict data collection and lead to bias in research findings. Another consideration is that the course of an action research intervention may not proceed according to the researcher's plan. The framework therefore needs to be sufficiently flexible so that, as the research progresses, it can accommodate elements of reality such as events at the research site, the researcher's own constraints and the nature of themes emerging from the data. A data collection plan is needed and the researcher must take into account changes to real-world events and balance these with the needs of the plan (Janesick, 2000; Yin, 2003).

Since action research is change-oriented, it necessitates that data are systematically collected at various stages throughout the action research process to track the impacts of the changes that are introduced into the research setting (Elden \& Chisholm, 1993). Interpreting and making sense of the data is at the core of the research process. Action research can include both qualitative and quantitative methods of data collection and analysis. The methods chosen depend on the researcher's background and the nature of the study (Kock \& Corner, 1996). For the purposes of this research, qualitative methods were used for data collection and analysis because I was observing and exploring knowledge retention behaviour within an organisation.

In carrying out a two-phase study, I followed an action research cycle in accordance with Susman and Evered's model as depicted in Section 3.4.1 (p. 79). The design of the research process is explained and discussed in the next five sections, addressing each step of the action research intervention in turn. The action research steps are diagnosis, action planning, action taking, evaluation and specifying learning. I describe the participants and activities involved, including data collection.

Both organisations participated in the diagnosis and action planning stages. One of them then proceeded with an action taking stage, after which it evaluated the results that 
were achieved. The final stage of specifying learning concluded the cycle. Following their participation in the action planning stage, Organisation A's intention was to proceed with an implementation plan. This occurred outside the scope of the research study. The organisation went on to identify three existing organisational mechanisms through which action taking could take place. First, it had recently made a major investment in implementing the first phase of its knowledge management programme and was in the process of planning for a second implementation phase. Second, it had some existing information systems that needed upgrades, and saw specific projects as the vehicle for taking specific knowledge retention actions. For example, as part of the action research action planning stage, a focus group identified two systems which were due to be upgraded. The group agreed that as part of project planning, the project team would specify the elements of expert knowledge that needed to be included in the scope of the upgrades. The final mechanism was the annual corporate planning and budget cycle. The organisation therefore concluded that these mechanisms represented appropriate vehicles for addressing its knowledge retention needs.

\subsection{Diagnosis stage}

The objective of phase 1 of the study was to answer the first research sub-question:

\section{What types of knowledge does an organisation risk losing when older experts leave?}

The diagnosis stage began with preparatory and orientation activities with the aim of confirming two organisations to participate in the study. I completed the diagnosis stage with the first organisation, analysing and documenting its results before proceeding to the diagnosis stage with the second organisation.

\subsubsection{The participant organisations}

The sponsors in both organisations promoted my study and their actions enabled me to carry out the research. They lent their formal support and referred me to the appropriate people in the organisation for establishing my research process. I held initial interviews and discussions with them both as executies, to get a general understanding of their views on knowledge, the organisational stance, and the role of knowledge in their organisations. They were later included in the first set of interviews. The sponsors were also instrumental in reviewing the business reports in which I presented my findings in 
a style suited to the organisation's senior managers as an audience. Both sponsors then assumed ownership for introducing change as a result of the findings.

\section{Organisation A}

Organisation A has a key role in providing policy advice and services, as well as enforcing regulatory requirements. Its work focuses on the development and protection of biological resources in a sustainable manner in the national interest. It has a diverse range of business functions carried out nationwide, a long history of organisational change in business scope and structure, and has responsibilities spanning numerous Acts of Parliament. It is a relatively large organisation by New Zealand standards.

Senior management advised that Organisation A considers itself as a knowledge organisation, with most of its employees being knowledge workers, with scientific expertise across a wide spectrum of disciplines, including economics, trade and the environment. Employees work mainly with information, creating and evolving knowledge in the workplace (Hammer, et al., 2004). The organisation recognises effects such as the ageing workforce and the loss of expertise from the older worker on retirement. The study sponsor pointed out that as well as losing technical expertise, the age of those in senior management roles implied that there may well be an entirely new leadership team in five years' time. Approximately a quarter of Organisation A's employees are over 50 years of age and almost $30 \%$ of all employees have spent more than 10 years in its service. However, it also notes that general workforce mobility and turnover contribute to knowledge loss, and that new employees may enter the organisation bringing expert knowledge, only to take it with them when they leave often in mid-career if no efforts are made to retain it during their employment. Thus, the ageing population and the disproportionate size of the baby boom generation intensify the knowledge loss problem, although it is not the sole contributing factor.

At the time of my engagement with Organisation A, it had recently made significant investments in knowledge management, implementing information systems and promoting change towards embedding a knowledge culture into the organisation and its business processes. The sponsor of the study noted that ideally, an organisation ought to understand the types of knowledge it regards as being valuable, as an initial step of a knowledge management initiative. However, Organisation A saw the study as a timely opportunity to define the meaning of valuable knowledge in an organisational sense, while it was starting a cultural change programme following the ICT implementation. 


\section{BRANZ}

The second of the two organisations studied is BRANZ ${ }^{1}$, an entity with about 100 staff, whose primary business activity centres on construction related research, testing and consultancy, involving a range of scientific disciplines as well as other expertise such as in the architectural and engineering areas. It also has a major role in the development of national codes and standards. It is responsible for subsequently translating and transferring the knowledge it creates from the research arena to the building sector. The Chief Executive explained:

"One of our roles is to ... convert what is a research product into a knowledge product such that the industry can use it. It's that 'research to knowledge' paradigm that's the hard part. You can't just throw the research over the fence, there's a handholding all the time through that process because some of the feedback you get through the industry about how well the knowledge has been picked up and how well it's been applied, actually should feed back into the research programme."

Both organisations see themselves as knowledge organisations, creating and using knowledge as an important resource in their business models (Hammer, et al., 2004). In BRANZ's case, knowledge is regarded as an output of research, forming the basis of products and services that generate some commercial return. Knowledge work spans different domains of expertise — scientific and technical expertise, industry and management expertise, and technology management. The organisation has been in existence for several decades and has demonstrated its ability as an industry and world leader in scientific discovery that contributes to enhancing the built environment. It has developed a global reputation for scientific and technical excellence, and is home to widely published experts in various sciences. The organisation recognises the importance of technology to support knowledge retention and has recently made significant progress in this area through investments in major ICT implementations. However, its people are the important knowledge holders and it is concerned at the loss of knowledge from more senior staff who have decades of expertise and are most likely to retire in the medium term.

\footnotetext{
${ }^{1}$ BRANZ has given its permission to be identified in this study.
} 
"They're top in New Zealand, or world class in their area, so it's their knowledge and their understanding that's very valuable. And it really is the people in the organisation that are valuable."

senior manager of scientific researchers

BRANZ's motivation for participating in the study was that first, the then Chief Executive identified with emerging concerns about the ageing workforce and the potential loss of knowledge from an organisation whose livelihood was founded upon knowledge creation and dissemination. Second, the study sponsor elaborated this concern in noting that in some cases, there is only a single resident expert in a specific technical or scientific knowledge domain. Thus, BRANZ's interest was twofold - to understand the valuable forms of knowledge for the organisation, then to explore the knowledge of an individual and how this might be retained in the organisation. The latter area of interest emerged in the course of discussions with the sponsor during the diagnosis stage.

\subsubsection{Preparation and orientation}

As the first stage of the action research cycle, diagnosis involves identifying and defining the problem that the action research intervention is intended to solve (Susman $\&$ Evered, 1978). For both organisations, the business problem was recognised as being one of knowledge loss when older experts left the organisation. My contact at Organisation A was the Risk, Audit and Assurance Manager, whose concern was that knowledge loss may pose a risk to the business in the next five years, as older experts who were baby boomers left the organisation. Following a discussion with the senior management team, he introduced me to a member of the Executive who would be an appropriate sponsor for the study. At BRANZ, I made initial contact with the Chief Executive, who identified a senior manager responsible for knowledge management as the sponsor for the study. He noted that his organisation had older experts who were already over age 60 and had specialised technical and scientific expertise. This meant that the loss of this knowledge could occur in the next two to five years.

An initial meeting was held in each organisation, during which they confirmed that participation in a short scoping study would be of benefit to them, in terms of discovering more about their organisation's view of valuable knowledge. My principal research supervisor attended these two meetings with me, and he clarified the 
distinction between the practice oriented activities in action research and the research or academic activities I also needed to carry out (McKay \& Marshall, 2005). We noted that there may be tensions and challenges in balancing the two streams of activity.

Part of my preparation for the initial meetings included gathering data in the form of corporate strategy documents and annual reports for the organisations, and I also gleaned other relevant documents from their web sites. This information gave me an insight into each organisation's vision and objectives, business and operating environment, size and structure. I also gained some appreciation of its culture and the role of knowledge in its business objectives. I was then provided with additional contextual information at the initial meetings.

\subsubsection{Diagnosing the problem}

The diagnosis of the knowledge loss problem in each organisation was approached through a series of interviews with a cross-section of staff. I sought the views and opinions of two groups of employees to gain insight into their concepts of valuable knowledge within their organisations. The purpose of each interview was to address the fundamental concepts of knowledge, that is, to discover and define what people mean when they refer to valuable knowledge within their organisations. I was interested in the types of knowledge that the interviewees thought might be lost when older experts leave or retire, where in the organisation such knowledge was located, and what they thought the likelihood and impacts of knowledge loss would be. The interview questions are listed in Section 5.1 .1 (p. 136). An information sheet and a consent form for study participants are included in Appendix A.

Once the interviews were transcribed, participants completed their members' checks, made additions and alterations where relevant, and confirmed the validity of their scripts for use in the study. This enabled me to proceed with data analysis and to draft a business report describing the findings from each set of interviews. The findings of the diagnosis stage relate to the elements of valuable knowledge in the two organisations, and are set out in Section 5.1.

\subsubsection{Stage I data collection process steps}

Data was collected in two stages. In stage 1 of data collection, I followed the steps depicted in Figure 4-1 (p. 98) to discover the two organisations' views on valuable knowledge that would be lost when older workers retire. 


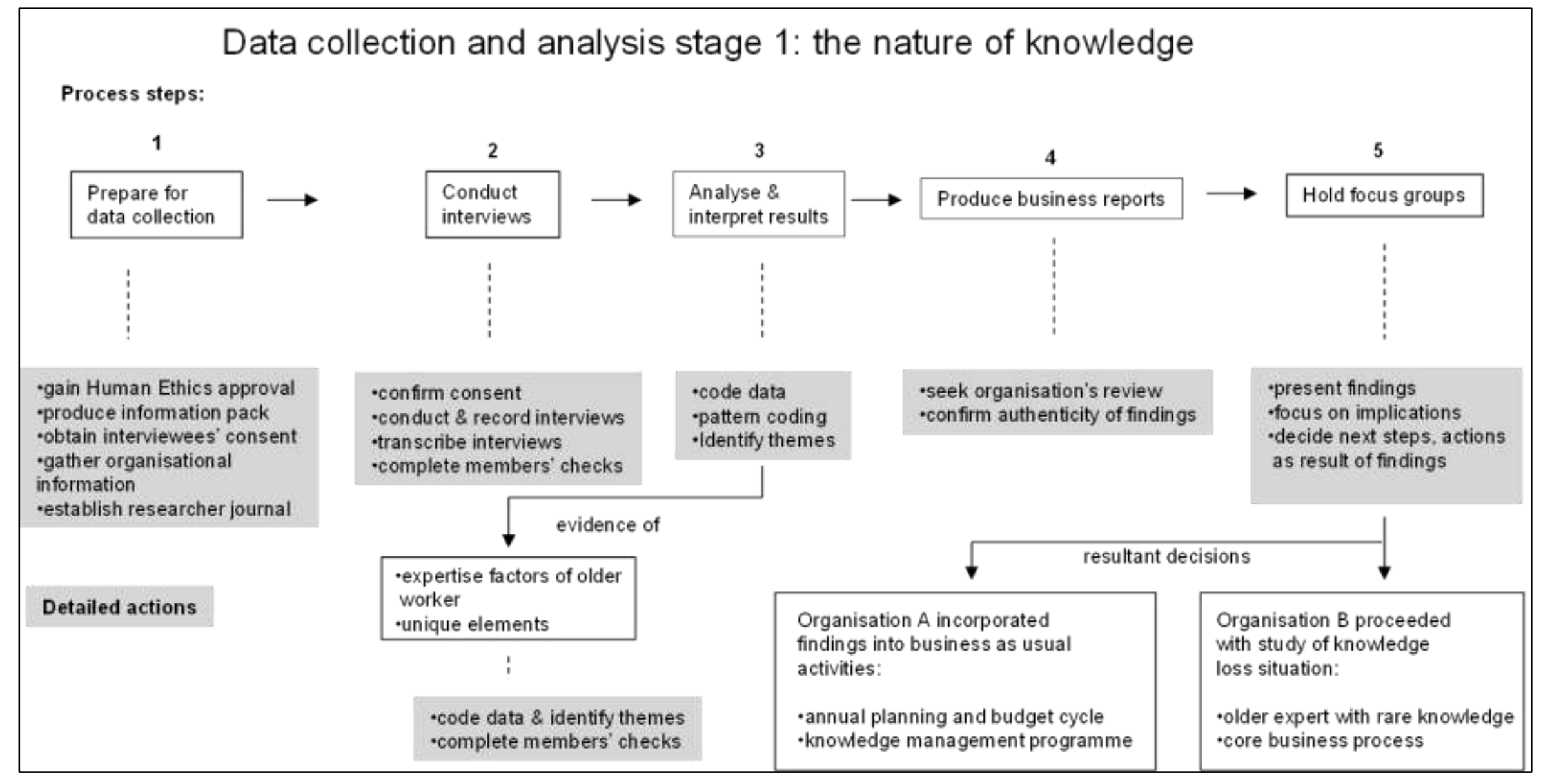

Figure 4-1: Data collection and analysis stage 1 - the nature of knowledge 


\section{The first step of preparation for data collection involved familiarisation with}

organisational information relevant to the study of knowledge concepts. For example, both organisations involved at this stage had been selected due to their perception of themselves as knowledge organisations. I obtained corporate documents and other relevant documentation so I could have contextual knowledge about each organisation and identify how knowledge features in their respective high level business processes.

As soon as academic approvals had been given, a short proposal was written to provide introductory information as the basis for a meeting with each sponsor. An information pack was then produced for interviewees - this included an information sheet, a set of high level interview questions, and a form for interviewees to provide their informed consent (see Appendix A). I conducted face-to-face interviews at this stage, and treated the interviews as interactions with people within the context of their organisation, given that interviewing cannot be a neutral data gathering process (Fontana \& Frey, 2000). Most of these interviewees held senior roles with an interest in knowledge at a managerial and strategic level.

The second step was to record and transcribe the interviews. High level questions were provided to guide the interview and keep within the scope of the topic. Some interviews were narrative in style, while others were structured, as some interviewees considered the questions and made notes in preparation for the interview. The conduct of the interviews followed no particular patterns in terms of order. At Organisation A, the sponsor was the final interviewee, and in addition to his contribution to the topic, lent an overview to the other perspectives. With BRANZ, the sponsor was interviewed first, and in areas where he made overarching comments, he also pointed me in the direction of other interviewees who could be more specific. Given Lincoln and Guba's (1985) advice that researchers must try to consider multiple realities, I also appreciated the sponsor's introductions to another participants with dissimilar views or nuances.

I then gave each participant a copy of their transcript for review and confirmation and they could make any desired corrections, additions and alterations. Some participants added information to clarify or elaborate on their interviews.

In the third step, data were analysed and interpreted. The data collected from each interview was initially coded at a detailed level. Codes were assigned to sentences or sentence fragments where I found statements or ideas that were relevant to each interview question, to describe or interpret the interviewee's comments (Miles \& 
Huberman, 1994). Once I had completed coding all the interviews, I reviewed the codes that I had assigned to each interviewee's answer to an individual question. (The questions are listed in Section 5.1.1, (p. 136). For example, I reviewed all the codes relating to Question 1:

In the context of your organisation and its core business, when you think of "valuable knowledge", what do you mean?

The codes were then rebalanced and evolved into higher level categories or themes. This review led to a better understanding of consistencies and variations across the interviews.

This enabled me to check that where the same or similar ideas had been expressed, I had assigned codes that reflected such similarities or commonalities across the interviews. Completing this step for each question across all the interviews enabled me to better understand the emerging patterns and regularities. This enabled me to assign pattern codes, to bring together more meaningful units of analysis, and to evolve a more parsimonious set of codes. The conceptual framework for the study and the review of literature both implied that there could be a set of high level codes, or themes, which could influence research design. In this case, there were some concepts that served to limit the scope of the research, rather than enforce a set of pre-determined codes. These concepts included the idea that expertise may be associated with certain older individuals; such knowledge may be worth retaining in an organisational setting; and that information and communications technology had some part to play in the retention or transfer of knowledge. A small number of open questions were therefore constructed with such concepts in mind.

A review of the interview transcripts revealed rich, meaningful and detailed information. Initially, each transcript was coded in its entirety at a low level of detail, assigning meaningful descriptors to sentences and sentence fragments, in some cases to the level of summarised ideas that bore varying degrees of relevance to each question.

Once all the interviews had been coded in this way, the data were viewed from a different perspective, which involved examining each interviewee's data in relation to each topic area - which in general terms mapped to the questions. Due to the semistructured style of the interviews and the conversational style of some participants, this meant that data relevant to a particular question were scattered throughout the transcript. 
Through pattern coding techniques (Miles \& Huberman, 1994), a series of higher level patterns and commonalities among the interviews emerged. At the same time, it was clear that, depending on the interviewee's experiences, their role in the organisation and their perspective, a range of not incompatible views existed in some aspects of the domain of study. High level themes or categories were identified as a result of this cross checking step of the analysis, and within each category, a few more detailed concepts, regarded as attributes of each category, were confirmed.

My researcher's journal which was kept from the time the organisations were first approached, was also reviewed at this point (although it was reviewed regularly at other times). The timing of this activity was to ensure that my own impressions, comments and observations did not present undue bias to the content of the actual interviews, that is, the voices of the participants. Fontana \& Frey (2000) note that there needs to be balance in the researcher - interviewee relationship, in terms of control and the emergence of the voices of those who participate in the study.

The fourth step involved producing a business report for each organisation, structured in a way that presented and discussed the findings organised by category. Differences in opinions were summarised, and as the questionnaire provided for participants to make any additional relevant observations and comments, I also included these in a section at the end of the reports. From my point of view, one of the most important aspects of the reports was that they should be verifiable as representing an authentic integration of the findings. Each sponsor in reviewing the report, confirmed that it did reflect a cohesive set of findings, expressed in a way that was recognisable as belonging to and sounding like their respective organisations. One sponsor commented that not only did the organisation described in the report sound like his, but he could identify the source of some unattributed views. The review, acceptance and presentation of the report can be regarded as a higher level members' check.

Lastly, the implications of the findings and the next steps in terms of the organisation's actions to address the findings, formed the agenda for a focus group. The study concluded at Organisation A through a facilitated session focusing on how best to incorporate a series of action points into its usual business activities. Organisation A identified two avenues for addressing the actions, without the additional overhead of starting a new project specifically for this purpose. These avenues included its normal annual planning and budgeting cycle, and an existing knowledge management project 
which had recently been established as the second phase of a significant medium term change programme involving business and information technology process change.

BRANZ took a different approach in that during the study, the sponsor had referred to at least one example of impending knowledge loss that might benefit from further study. This organisation wished to progress with a deeper study of a specific case of potential knowledge loss in the medium term, involving an older expert in the organisation. This situation became the subject of phase 2 of the study.

Thus, this stage of data collection enabled the first research question to be answered:

What types of knowledge does an organisation risk losing when older experts leave?

Findings from phase 1 of the study are presented in Section 5.1 (p. 136).

\subsubsection{Discussion and outcome of diagnosis stage}

McKay \& Marshall include two separate steps in their model of action research: action planning and implementation. The two participant organisations took different approaches following the presentation and discussion of the reports. I facilitated a focus group at Organisation A to discuss the report of findings from the diagnosis stage, and how they would be addressed. Organisation A decided it would take a number of actions as part of its annual strategic planning and budgeting processes and as part of a new ICT project that was scheduled to commence. This set of decisions is recognisable as an intervention activity, as it represents the organisation's mechanism for addressing the study's findings. Organisation A's approach is detailed in Section 4.3.1 (p. 103).

At this point, Organisation A had effectively completed its action planning stage, in action research terms, and also its participation in the study. In closing, this organisation was positive about the findings of the study as it strengthened their knowledge-based perspective. Because Organisation A had at the time of its participation in the study recently completed its annual planning round, they advised that it would take almost two more years for the actions to be fully implemented and for the results to be evident. Therefore, the evaluation of actions fell outside the scope of the study.

The study sponsor at BRANZ had earlier indicated that there may be a couple of areas that could be candidates for investigation with a view to addressing a knowledge-related business issue. The data that I collected and analysed in the diagnosis stage were 
presented in a business report, but also formed input to the action taking stage, during which they were analysed a second time from a different perspective.

\subsection{Action planning stage}

\subsubsection{Organisation A - knowledge management programme}

Based on the findings from the diagnosis stage, Organisation A was most concerned about loss of knowledge related to its business processes and process chains. The study sponsor wished to have further discussions on this topic with the participants I had interviewed, so I presented my findings and facilitated a group discussion. As part of the same meeting, the project manager of Organisation A's knowledge management implementation programme also gave a presentation on the scope of that programme. The discussion of next steps was therefore in the context of this programme and included several topics. The group discussed some desirable approaches for capturing valuable knowledge in the next stage of the programme. It also recognised that it needed to identify specific areas for knowledge retention, and to decide on the methods and mechanisms for ensuring the effective retention of this knowledge.

The purpose of the group discussion was to initiate action planning, and Organisation A saw its knowledge management implementation programme as the vehicle for action taking, in terms of addressing the findings of the study. It was at this point that their role in the study came to an end, with the findings of the study serving as input to the scoping of the next stage of their knowledge management programme of work.

\subsubsection{BRANZ - project initiation}

At the time of the study, this organisation had several older experts who the sponsor thought might retire within the next two to 5 years. The sponsor then confirmed that the technical adviser who was responsible for day-to-day running of the industry helpline would be the focus of the study, as his specialist knowledge was likely to be lost if the organisation did not act. Detailed information on the helpline service is set out in Section 7.1 (p. 178).

The proposal defined a high level scope for a 3-phase project, taking an iterative approach of completing a phase, reviewing and evaluating project progress, then confirming the approach for the next phase once any adjustments had been made. 
In agreeing to the proposal, the project sponsor formed a small project team consisting of: the technical adviser, his manager, a representative from the IT group and a project administrator. This group may be seen as the project's critical reference group, responsible for completing or facilitating project tasks (Wadsworth, 1998). The project team provided invaluable help as I explored and analysed the setting of the helpline, the research domain, as part of the preliminary stages of project initiation. The team also assisted me as the researcher with settling in and familiarisation with the organisation, with the helpline in general, and with the organisation's project processes.

I consequently developed a clearer understanding of the scope of interest for the study in terms of the operation of the helpline. The importance of relationships and the technical adviser's social network also emerged early in discussions. While most of my observations would involve analysing and understanding the adviser's expertise in action, another important dimension was his relationships with other people - experts in the organisation and the customers who used the service. The study also needed to recognise the link between the helpline business process and other processes.

Other suggestions arising from the discussion during the project set-up meeting included the new idea that it might be useful to draft the adviser's job description early in the project, defining the required skills, experience and attributes. This would equip the organisation to recruit an additional adviser as part of the project. The Chief Executive at the time thought that including representatives of different helpline user groups would also be useful because they would have different perspectives and needs from the service. The technical adviser was also open to any general suggestions for improvements that I might identify from an outsider's perspective.

We also acknowledged that at times, there may arise some tension between academic tasks and the organisation's needs which would have to be resolved. At this stage, the sponsor also briefed me on where he saw the project's link to the organisation's knowledge management aspirations at the more strategic level.

\subsubsection{Discussion and outcome of action planning stage}

\section{Organisation A}

Organisation A confirmed that it had benefited from its participation in the diagnosis stage of the study. The findings set our in my report highlighted important and specific concerns about knowledge loss. During the group discussion, the study sponsor noted 
that the knowledge management programme was the organisation's major ICT change initiative over the next two years. First, significant resources, including funding and staff, had been assigned to the programme of work, which was the focus of its efforts. Second, the establishment of another programme or project to address knowledge retention concerns would require additiional resources and potentially compete with the existing knowledge management programme. Last, participants in the group discussion were able to identify where knowledge retention actions could be included and managed within the programme without significant effort. The group also identified other existing processes, such as the annual planning and budget cycle, and other ICT projects, that could include knowledge retention activities.

The outcome of the action planning stage for Organisation A was that activities that would represent action taking, in action research terms, would occur outside the scope of my research.

\section{BRANZ}

Action planning, or project initiation in practitioner terms, was carried out during October 2007. I drafted a short project proposal which I sent to BRANZ, and this is shown as Appendix B. The proposal reflected the practitioner need to solve a business problem, while at the same time was shaped by my own academic interest in action research. This is the research cycle labelled as (b) in Figure 3-2 (p. 85). The project also needed to be achievable within the time frame of my academic study, and it was agreed with my principal supervisor and BRANZ's sponsor that my availability would be for six to nine months, for two to three days each week.

At the initial meeting to set up the project, three key points were identified that demonstrated a balance in addressing the knowledge loss topic. First, the needs of the expert and the service were considered - the sponsor reiterated that the focus was on both the continuation of the helpline service, and on providing options for the technical adviser going forward. Second, the project would identify the skills that were important in the role of technical adviser. Last, the tacit aspects of the expert's actions were of much interest, meaning that observations, shadowing and questioning should reveal the reasons for handling calls in a particular manner. The process of information gathering would also include identifying and discussing incidents that best illustrated what the technical adviser did in his role. 
This last point was reflected in my researcher's journal entry for "Day 1" the first day on site following the initial meeting. I observed the technical adviser answering calls:

\author{
"I am ... being flexible, listening and absorbing information to get a \\ sense of the setting for the service, then will determine what \\ information to gather and how to do this. (The technical adviser) \\ suggested a focus on how and why things are done the way they are."
}

The discussions and agreements relating to the action planning stage were then formalised in a document called the Terms of Reference, a concept that is meaningful to practitioners. In action research terms, it represents an element of the client system infrastructure and may be referred to as the client structure (Baskerville \& Pres-Heje, 1999; Hult \& Lennung, 1980). A copy of the table of contents for BRANZ's Terms of Reference is in Appendix C.

The main outcomes of the action planning stage at BRANZ were the agreement to proceed with the action taking stage, the confirmation of the specific area of business where this would occur, and the development of the formal Terms of Reference.

\title{
4.4 Implementation - action taking stage
}

From my perspective as a researcher, the main focus of the implementation stage was to answer my second and third research sub-questions:

2. What processes does an organisation use to retain the knowledge of older experts?

\section{How can ICT support the knowledge retention process for the identified knowledge source(s) and recipients?}

There were two separate interventions, with action taking occurring in two project phases. The study sponsor was also the sponsor for the project, called the Advisory Services Knowledge Retention Project, which was set up after the action research diagnostic stage. In this role, he attended fortnightly project meetings and promoted action taking in a manner appropriate for BRANZ. He championed the project and worked to motivate staff at a time when work volumes were unusually high and organisational changes were in progress. 


\subsubsection{Phase 1 project}

The action taking steps can be described as constituting all the tasks and activities that formed part of the project. At this stage, I was given the role of project manager. The diagram in Figure 4-2 (p. 107) depicts the initial project plan.

\begin{tabular}{|c|c|c|c|c|c|c|}
\hline Activity & Nov & Dec & Jan & Feb & Mar & Apr \\
\hline 1. Set up project & & & & & & \\
\hline - Develop terms of reference & & & & & & \\
\hline - Confirm project budget & & & & & & \\
\hline - Confirm project resources & & & & & & \\
\hline 2. Define personnel requirements & & & & & & \\
\hline - Gather information & & & & & & \\
\hline - Observe helpline calls & & & & & & \\
\hline - Define knowledge required & & & & & & \\
\hline - Define skills and experience required & & & & & & \\
\hline $\begin{array}{l}\text { 3. Recruit new technical adviser (for } 1 \mathrm{~F} \\
\text { start) }\end{array}$ & & & & & & \\
\hline 4. Train new technical adviser & & & & & & \\
\hline 5. Identify knowledge capture processes & & & & & & \\
\hline - Identify / select knowledge capture p & & & & & & \\
\hline - Use process to capture helpline know & & & & & & \\
\hline - Interview staff, helpline users & & & & & & \\
\hline - $\quad$ Document \& refine process & & & & & & \\
\hline 6. Review Phase 1 and agree next steps & & & & & & \\
\hline
\end{tabular}

Figure 4-2: Helpline knowledge retention project schedule - phase 1

\section{Project execution - phase 1 activities}

Project activities were scheduled to be completed over an elapsed period of six months and consisted of some higher level activities followed by a review of progress as the final activity. First, the project was formally set up with the Terms of Reference being agreed, a project budget being allocated and resources being approved.

Second, the requirements for an additional technical adviser position were defined through information gathering and observing the technical adviser operating the helpline and handling calls. This information enabled me to document the knowledge, skills and experience required for the role in the form of an accountability statement, a position description and for an advertisement to be written and used for recruiting. 
Third, another high level activity centred upon identifying a process to capture helpline knowledge and using it as part of training the new technical adviser. This step was unable to be completed - a new adviser was not appointed in the time frame of the project due to the unavailability of suitable candidates for the role. However, the task of interviewing and capturing users' and experts' views of the helpline was completed. The information from the interviews was written up as a business report and the findings are presented in Chapter 6 (p. 157).

\subsubsection{Discussion and outcome of phase 1 project}

One of the main learning points from the phase 1 implementation was the need to be adaptable, as real life events such as the availability of suitable staff in the employment marketplace are difficult to predict. Another lesson learned was that, in this particular situation, there was little that could have been done to resolve the situation.

By the end of March a suitable candidate for the technical adviser role had not been found, and I drafted a discussion paper setting out some potential options for a project that would be useful to BRANZ as well as fulfilling my research needs. Each option included a description of the input needed from the organisation, and the time frame required for completion. A meeting was held with the sponsor and my principal supervisor, as this represented a milestone decision for the project and a change in orientation for the research element of the action research cycle. Each option was discussed with reference to its feasibility in the time remaining, and usefulness for the organisation in terms of knowledge retention.

The following options were discussed:

1. Complete some analysis on indexing and managing the helpline audio files.

2. Develop a prototype helpline wiki to store notes that technical adviser has written, short documents that scientists have provided, and information that supports his calls.

3. Consider how to adapt what I had found so far (on the knowledge transfer process) to another knowledge domain, for example a principal scientist might be a candidate. 
4. Spend time on working out how to adapt the package to someone else - this might take several months.

5. BRANZ could decide to offer someone the role on a short-term or part-time basis and knowledge transfer could occur.

The result was that the sponsor selected an initiative that was estimated to take six to eight weeks, fitting into the remaining time for the original study. The option selected was to develop a prototype helpline wiki web site to store notes that the technical adviser had written, short documents that scientists had provided, and information that was used as support in the call handling process.

\subsubsection{Phase 2 project}

I developed a project schedule for carrying out this work, described as phase 2 of the action taking step in action research terms, shown in Figure 4-3 (p. 110). While phase 2 was in progress, I also continued with my observations of the technical adviser's problem-solving and knowledge retention processes, and analysed data collected in answering my second and third research sub-questions.

First, the project involved some investigation activities to identify a topic domain for which content could be posted to the web site. The other part of the investigation involved confirmation of the technology aspects of the project. We were able to confirm the feasibility and time frame for the prototype. Second, the environment for the web site needed to be set up, and I needed to learn the software. The third set of activities included testing the site and encouraging the technical adviser to use it and provide feedback. Lastly, the intention was to identify and obtain further content for the site.

\begin{tabular}{|l|l|l|l|l|l|l|l|l|l|}
\hline \multicolumn{1}{|c|}{ Activity } & W1 & W2 & W3 & W4 & W5 & W6 & W7 & W8 & \\
\hline Investigate & \multicolumn{2}{|c|}{} & & & & & & & \\
\hline Identify information to post on web site & & & & & & & & & \\
\hline$\circ$ agree a topic & & & & & & & & & \\
\hline$\bullet \quad$ Identify software \& requirements & & & & & & & & & \\
\hline$\circ$ discuss with IT & & & & & & & & & \\
\hline$\circ$ how to obtain and install & & & & & & & & & \\
\hline$\circ$ how to set up hosting & & & & & & & & \\
\hline$\quad$ scripting and publishing & & & & & & & & & \\
\hline Confirm feasibility, timeframe for prototype & & & & & & & & & \\
\hline
\end{tabular}




\begin{tabular}{|l|l|l|l|l|l|l|l|l|l|}
\hline \multicolumn{1}{|c|}{ Activity } & W1 & W2 & W3 & W4 & W5 & W6 & W7 & W8 & \\
\hline Set up environment & & & & & & & \\
\hline$\bullet \quad$ Install software & & & & & & & & & \\
\hline$\bullet \quad$ Learn how to use it (in progress) & & & & & & & & & \\
\hline$\bullet \quad$ Design the site (in progress) & & & & & & & & & \\
\hline$\bullet \quad$ Set up structure of web site, access & & & & & & & & & \\
\hline Test the site & & & & & & & & & \\
\hline$\bullet \quad$ load some documents & & & & & & & & & \\
\hline$\bullet \quad$ provide demonstration & & & & & & & & & \\
\hline$\bullet \quad$ update feedback & & & & & & & & \\
\hline Publish further documents to site & & & & & & & & & \\
\hline$\bullet \quad$ select useful information & & & & & & & & & \\
\hline$\bullet \quad$ notes & & & & & & & & & \\
\hline Use prototype site & & & & & & & & & \\
\hline Review the concept & & & & & & & \\
\hline$\bullet \quad$ discuss next steps & & & & & & \\
\hline
\end{tabular}

Figure 4-3: Schedule for developing helpline web site prototype

\section{Project execution - phase 2 activities}

The key decision made during the project execution phase was the selection of a subject domain for the site - home insulation. This was an area of great interest to the helpline callers at that time, and many documents had been created.

A series of recordings, reports, notes and other technical documents were collected and collated in preparation for loading to the site once it was developed. The software product the organisation selected was one that was already in use for its other functionality, but at the time, there had been no other live sites built using the product. I was able to obtain a collection of various types of documents for the site over several weeks. The project progressed to the point where I obtained access to the software and was in the process of learning to use it. In structuring the site, I had got to the point of having discussions with the project team on how the topic domain could be structured, before the time allocated for the study came to an end.

\subsubsection{Stage 2 data collection process steps}

The second stage of data collection involved only BRANZ and centred upon the potential loss of knowledge in the event of a specific older expert who might retire in the medium term, for example in the next two to five years. The business context was an industry helpline and the challenge lay first in the fact that he was in sole charge of 
delivering the service, and second, in the belief that the expert's knowledge, experience, background and skills were unique. Although there are other people with a similar technical background, the expert himself had much knowledge that was regarded as being of an embedded nature. There was also the significant matter of his professional and personal reputation, as well as the fact that the service is an inherent part of the organisation's identity and a visible aspect of its industry profile.

During phase 2, data were collected via several methods and forms, including organisational materials - hard copy and electronic, including its internet and intranet site - project papers such as meeting agendas, papers and minutes, interviews and the researcher's notes and journal. There is a high level service description for the helpline and statistical reports of volumes were compiled. Data were made available from the call management module of the organisation's CRM (customer relationship management) system, where call statistics and a content summary were recorded. A smaller volume of call information also existed in the form of electronic mail messages. Recordings of calls initially existed as micro-cassette tapes - later a system enabling them to be recorded as digital files was implemented. The process for data collection and analysis in Stage 2 is depicted in Figure 4-4 (p. 112). 


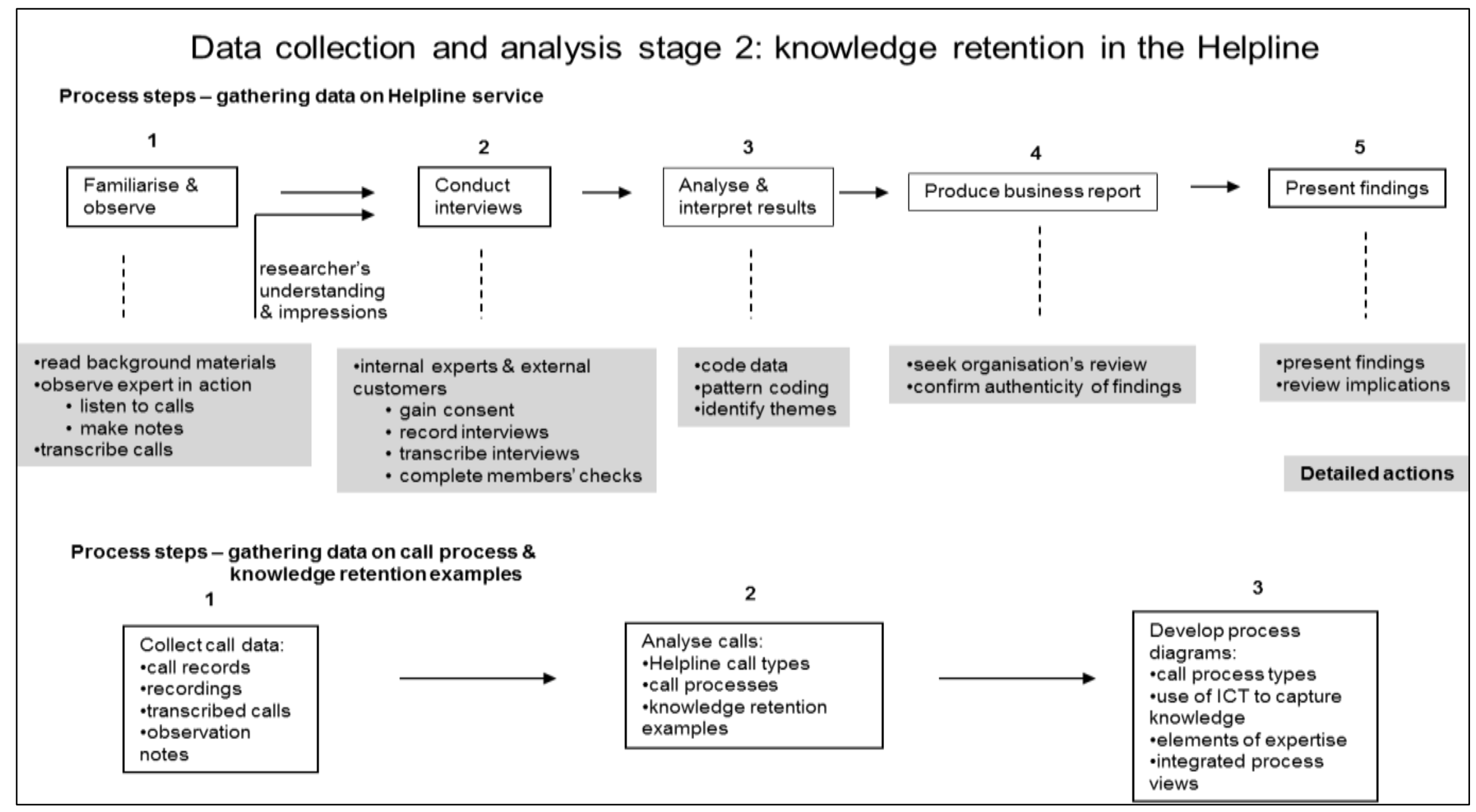

Figure 4-4: Data collection \& analysis stage 2 - knowledge retention in the helpline 


\section{Gathering data on the helpline service}

The first stage of data collection took place by visiting the study organisation, but the second stage was carried out during the time I spent on a placement on site on a parttime basis. Over the first three weeks of the placement, I spent about 10 half days at the helpline, specifically to observe the call handling process and call content, and to understand the materials and other information sources in $u^{2} e^{2}$. Some time was spent to develop an understanding of the types of callers seeking information, and the requirements for involving other experts in the call process. Data collected at this point included materials with content knowledge, for example manuals, trade publications, and extracts of compliance documents. These were studied together with electronic information published at web sites and on the organisation's intranet site. A sample of recordings of unusual, interesting, complex and knowledge-rich calls was transcribed and studied. I also made journal notes during the observation process, and the technical adviser provided clarification of many questions about what I had observed.

The technical adviser was a key participant for the duration of the project. I initially collected a large quantity of data from observing him at work, "shadowing" him at the Helpline over a period of weeks during phase 2 of the study. The observations generated many questions about his problem-solving behaviour and technical expertise, some immediate and others as a result of reviewing my researcher journal. He provided me with much contextual information about the industry including political aspects, relevant historical facts and the motivations behind certain caller behaviours. The adviser was also invaluable in providing me with rich data in the form of call recordings to illustrate the types of knowledge and complexities involved in some of the calls.

The above activities yielded sufficient understanding to proceed to the second step of the data collection process, conducting two sets of interviews on the helpline service. Although there had been regular customer satisfaction surveys completed in the past, this was an opportunity to gather more detailed views and opinions from industry customers, as well as some internal perspectives from people who had key relationships with the helpline. My initial impression was that the internal interviewees were providers of scientific and technical knowledge to the helpline, but the findings revealed a knowledge flow in both directions.

\footnotetext{
${ }^{2}$ Subsequently, I spent time at the helpline as needed, to gather data or confirm aspects of knowledge retention.
} 
The first set of interviews involved internal experts such as scientists and technical experts who provided subject matter expertise to the service. They were part of the technical adviser's social network and some of them had known him for more than a decade. The scope of the questions addressed topics such as the expert's role and the nature and duration of their relationship with the helpline, and the nature of the information flows between them. They were asked their opinions on the most important skills and knowledge that needed to be protected as far as service delivery was concerned. Opinions were sought about the quality of the service, the best features and any opportunities to fine-tune it or make it better, and finally, what sort of feedback they had heard about the service.

The second set of interviews involved external customers of the service, who were asked about their relationship with the adviser, how long they had used the service, how often they made contact, and what they thought of their experiences in using the helpline. They expressed views on the important skills and knowledge that needed to be retained in the service, and they were asked what made the service successful, and whether there might be some aspects that could be improved upon.

\section{The third step involved analysing and interpreting the results of the interviews,} following the completion of a member's check of the interview scripts. Again, the analysis process included detailed coding of the scripts, followed by pattern coding which led to the identification of emerging higher level categories or themes. This process yielded the base information for writing the business report for presentation to BRANZ of the internal and external participants' perspectives of the helpline.

Finally, the findings were presented to the sponsor, the manager responsible for the helpline service, and the technical adviser delivering the service. Findings from these interviews have been included in Section 6.2 (p. 159).

\section{Gathering data on call processes and knowledge retention}

The second process shown in the lower part of the diagram in Figure 4-4 relates to collecting and analysing data on the helpline call process and on examples of knowledge retention. This process occurred alongside the interviews of internal experts and external customers about their experiences with the helpline service.

First, call records were collected from various sources. I collected over 200 records over a month from the call management system. These records included database fields 
such as a record identifier, a code indicating caller type, a textual call summary and response summary, and comments about the action, resolution or outcome of the call. Recordings of knowledge-rich calls in terms of problem-solving processes, call content and unusual problems and queries were transcribed. Some of these examples were highlighted by the technical adviser, while others were identified during my observations of the helpline in action. Observations were also noted in my journal.

Second, the material was analysed to uncover more about the types of actions involved in answering calls, in particular focusing on the actions of the technical adviser, and ascertaining from the call content the overall purpose and result. The analysis also sought to determine whether each call could be shown as belonging to one of a small set of categories. The individual calls were grouped by types of actions, and through a process of review, comparison and regrouping, six distinct types of actions were identified. These consisted of: seeking and using formal documentation; managing scope and signposting; providing detailed technical and practical assistance; providing technical assistance with documents and requirements; advising on compliance, responsibility and reliability; and remedying pre-existing faults and failures — as listed in Table 7-1 (p. 182).

Third, all the data relating to the calls in each category were analysed to determine whether there was a process diagram that could capture all the actions that were taken to answer each call. As a result of this analysis, six logic diagrams of the processes were constructed. The logic diagram of the actions involved in seeking and using formal documentation appears as

Figure 7-4 (p. 183). The other five diagrams are included as Appendix D. Other diagrams in Chapter 7 depict the high level helpline process, and that show how ICT is used at each stage in the process to capture knowledge.

I then analysed the six examples of knowledge retention in the helpline, to understand in more detail where opportunities to retain knowledge occurred and how they were acted upon. In each example, ICT played a role in the process. The examples included retaining knowledge about innovative practices, capturing techniques in use, integrating evolving knowledge, formalising knowledge for replication, extending the use of software, and retaining and grouping related knowledge. The findings on knowledge retention and the use of ICT are set out in Section 7.2. 
Finally, turning to the individual expert, data that I collected also formed input to the analysis of the elements of expertise that were evident in the context of call handling. Each knowledge retention example was analysed to identify the elements of expertise demonstrated at each step of the process. The diagram of expertise elements from the analysis of the first example is shown as Figure 10-3 (p. 254) and the remainder are included in Appendix E.

In closing, stage 2 of data collection and analysis enabled the second and third research questions to be answered:

\section{What processes does an organisation use to retain the knowledge of older experts?}

\section{How can ICT support the knowledge retention process for the identified knowledge source(s) and recipients?}

The outcome of the data analysis stage is the formation of a theory. In particular, it was envisaged that a theory would emerge that would assist with understanding whether the knowledge of older experts is unique, where such elements of expertise may be identified, and how ICT may assist in retaining the knowledge of older workers. This is categorised as a "theory for explaining" (Gregor, 2006, p. 624).

\subsubsection{Discussion and outcome of phase 2 project}

Progress on this part of the project was slower than estimated, for several reasons.

Firstly, the whole study was conducted at a time when the helpline was very busy due to significant changes in the building code which generated a high volume of calls, often complex, as the industry grew familiar with new requirements. This meant the technical adviser was fully occupied with running the helpline and other responsibilities, as well as completing project tasks when time allowed. The result was that some decisions, like the scope of the topic to be included in the prototype, took some time to agree.

In reviewing progress, one of the suggestions was for the technical adviser and the new appointee to continue gathering relevant information and records as part of bringing the new person up to speed. We all knew this would occur over the longer term beyond the end date of the project, and time and effort would be required to focus on this task. A potential issue was also noted, in that there could be more than one correct answer to a question or problem raised in a call. BRANZ needed to give further consideration to how this situation might be handled when posting useable information on the web site. 
As discussed earlier, the priority was to maintain the continuity of the helpline at a busy time, while introducing an additional adviser and getting him to a sufficiently knowledgeable position to run the helpline as well.

\section{Project closure}

In closing the project, it was agreed that the business report on the helpline would be presented to the sponsor, and this was completed shortly after the project ended. Finally, I gave a presentation of my findings at BRANZ at the point where I had documented most of my findings in the first draft of my thesis. It was well received and generated much wide-ranging discussion. One of the main areas of interest was the implications that the findings may have for BRANZ's knowledge management activities overall.

\subsection{Evaluation}

Evaluation is an action research step to study the consequences of an action or intervention (Avison, Baskerville, \& Myers, 2001; McKay \& Marshall, 2005). In this study, the intervention includes the diagnosis, action planning and action taking stages of the action research cycle. Evaluation of the intervention is from two perspectives: the practical view and the research standpoint. This follows McKay and Marshall's (2005) concept of action research having the dual imperatives of problem-solving and research.

\subsubsection{Evaluating the practical intervention}

\section{Diagnosis}

As a result of the practical intervention, that is, the "action" part of action research, the organisations gained several benefits. The diagnosis stage of the action research cycle delivered findings that the participants found informative and valuable, for two reasons. First, they gained an overview of the types of knowledge regarded as being valuable to the organisation, according to a group of selected staff. Neither organisation had addressed this topic previously. Second, the findings of the diagnosis stage were of further use. At Organisation A, they formed input to a focus group that identified existing initiatives where valuable knowledge identified in the report could be retained.

Three themes emerging from the analysis of Organisation A's interviews were presented to the study sponsor as candidate topics for deeper consideration: 
1. Organisational knowledge, memory and continuity. Several participants commented on the importance of having a historical organisational context for understanding the present. Literature notes the concept of organisational continuity as a meaningful approach for introducing change.

2. Business process and process chain knowledge. This may be a relevant theme for Organisation A's current priorities.

3. Subject matter expertise. This may become a pressure point as older, more mature knowledge is gradually lost. A deeper understanding of what types of expertise are required may be of benefit.

The second topic, business process and process chain knowledge, was selected as being the theme of most interest to Organisation A because of the relevance to its priorities at that time. The organisation was restructuring some areas of its business, while at the same time improving and refining its business processes.

In analysing interview data and writing BRANZ's business report, I noticed that one of the recurring themes from the interviews was that the loss of certain older experts was an immediate concern. On several occasions, the sponsor had also made related comments, as a senior manager responsible for a large group of technical and scientific experts. As this subject was confirmed as an important learning point from the study, one of the options suggested in considering the next steps that could be taken was a project to implement a solution to retain the knowledge of an expert who was approaching retirement.

The study sponsor confirmed that for the next phase of the study, BRANZ wanted to focus on such an initiative as it would be of immediate benefit. The sponsor and other executives knew that a few older experts would reduce their working hours or retire from the organisation in the medium term.

\section{Action taking}

The first phase of action taking proceeded well, through the project set up activities such as agreeing the terms of reference, and having a budget and other resources assigned. The project reached a point, however, where some remaining activities in its original scope could not be completed in the time available for the study, as they depended on the appointment of an additional technical adviser. Specifically, it was not possible to train the additional technical adviser, or to identify knowledge capture processes, an activity that required the two technical advisers working together. 
The documentation required for recruitment was completed as a high priority so that the recruitment process could be started before the holiday break in December 2007. It took several attempts before a suitable candidate was selected and joined BRANZ in June 2008, shortly before I was due to leave. At this point, BRANZ's top priority was for the new appointee to get up to speed with the responsibilities of the technical adviser role. This occurred outside the scope of my research.

Materials had been collated for publishing, once an organising scheme was agreed and a web site developed. Although there was some discussion of how the materials would be organised for publication, no agreement had yet been reached, as it was a matter for the technical advisers, who would be the users of the web site. Other matters that needed to be agreed included the responsibilities for editing the materials that had been collected, and who would become responsible for writing content and maintaining the web site once it had been developed and tested, The higher priority at the time of the implementation stage was for the new technical adviser to be trained in the role to the point where he could operate the helpline with little need for support.

Since the web site was not developed in the scope of the study, it was necessary to examine other ways in which knowledge could be retained from the older expert. At this point, I turned my attention to how the technical adviser retained knowledge both through the use of ICT and by other methods. My starting point was to understand the various call processes, and from there I was able to determine how he retained knowledge within his usual processes, and how new methods were introduced when required to retain knowledge.

From the implementation stage, BRANZ gained feedback on the helpline service from internal and external stakeholders. At the same time, data collected at this stage also revealed a clearer picture of the nature of older experts' knowledge. Call processes and knowledge retention processes using ICT were also documented in detail.

\subsubsection{Evaluating the research outcomes}

There are several research outcomes from the action research intervention, and particular aspects of action research have informed the results and contributions of the study. The data gathered from each stage of the research cycle in various ways led to specific findings in Part 3 of the thesis. 


\section{Diagnosis}

The purpose of the diagnosis stage from a research perspective was to answer the first research question about the types of knowledge an organisation risks losing when older experts leave. The analysis of two sets of interviews in two organisations revealed that older experts did possess knowledge that was valuable but not always accessible to colleagues. The analysis resulted in six types of valuable knowledge being identified. These were subject matter expertise and experience; knowledge about relationships and social networks; organisational knowledge; knowledge about business systems and processes; applied knowledge; and governance knowledge. The findings from the diagnosis stage are presented in Chapter 5 (p. 136).

\section{Action planning}

The outcome of the action planning stage was that both organisations recognised the need to take action to prevent knowledge loss. Organisation A chose to carry out its actions within the scope of an existing knowledge management programme and some ICT projects already in progress.

BRANZ's approach was to target the expertise of an individual expert, as the risk of knowledge loss was inherent in the fact that he held a sole charge position. The study sponsor's concern was that valuable unseen knowledge would be lost with the retirement of one person. Data from the action planning stage included the minutes of several meetings with the sponsor, and a research proposal.

\section{Action taking}

Action taking consisted of two separate interventions, with the first one leading to the eventual appointment of an additional technical adviser. The second led to the identification of materials for publication to a proposed new web site, and the introduction of new methods to retain knowledge on the helpline. It was planned to obtain and trial a selected web site software product to support the retention and transfer of knowledge to a newly recruited helpline adviser. The intention was for the two technical advisers to test and use the web site to capture and retain knowledge.

Due to timing and resource issues, however, this was not achieved for three main reasons. First, a suitable additional technical adviser did not become available until about five months after BRANZ began its search. Second, the technical adviser's 
priority was to respond to helpline calls that were increasing in volume and complexity due to the introduction of changes to the building code. Once the new technical adviser was appointed, the priority was to train the new recruit. Third, although I was able to collect existing written materials to be confirmed for publication on the web site, have discussions about structuring the topic domain, and to start learning the software, the time for my placement at BRANZ came to an end.

Although the planned new web site did not eventuate, this does not invalidate the action research action taking stage, since the other parts of the intervention were carried out. These ICT-related interventions to retain important knowledge provided sufficient data to complete the study.

Data was collected in the form of two sets of interviews, with internal and external stakeholders, to gain their feedback on the helpline service. This provided BRANZ with useful information since there were no recent surveys of the service. The data gathered through the interviews, once analysed, revealed some themes about the characteristics of the older expert's knowledge. These results strengthened findings from the interviews held during the diagnosis phase. Six main themes were identified. Older experts have a combination of excellent skills and vast experience; wide networks and relationships; layers of expertise built up over decades; high levels of efficiency and effectiveness; powerful long-term recall; and they are unique as knowledge holders. These themes are described in detail in Chapter 6 (p. 157).

There was insufficient time to implement a new web site in the second phase of action taking, There were, however, action taking steps in the context of dealing with issues that arose in the course of the helpline's business processes. Several types of interventions were carried out involving the use of ICT for knowledge retention and they are discussed in Chapter 7 (p. 187). By analysing data from additional instances of similar interventions, some generic knowledge retention actions were identified, leading to the development of an integrated process view of ICT use for knowledge retention within the business process.

Further analysis of the data gathered during the action taking stage yielded findings on the older expert's knowledge use and retention, including how he deployed existing stored knowledge, and how he updated knowledge to keep it current. The participants and actions involved, and a framework for interpreting his contributions to knowledge retention are discussed in Chapter 8 (p. 209). At this point, I wanted to confirm my 
findings on the nature of an older expert's knowledge, so I analysed all the interview scripts again through the lens of identifying unique characteristics. This yielded about twenty distinct themes that I summarised and asked the initial six interviewees at BRANZ to confirm. Their confirmation enabled me to place a sharper focus on my findings in Chapter 6 (p. 157).

At this stage, however, I also believed that some of the characteristics of expertise that had emerged from data analysis represented a quality beyond expertise and could in fact be characteristics of wisdom. This led me to study potential frameworks that may be relevant for interpreting my findings. I found a research framework for wisdom-related knowledge that I adapted to represent the knowledge framework of an individual expert.. The adaptation of the framework is explained in Chapter 10 (p. 243). I then analysed the knowledge retention processes that the expert had used and identified where elements of expertise had been evident within the steps of each process. This is also discussed in Chapter 10 and the development of an integrated model of expertise and knowledge retention is presented in Figure 10-6 (p. 267).

In summary, an evaluation of the action research intervention from a theoretical perspective led me to the view that although a new web site was not completed in the time frame of the study, interventions were carried out at a business process level and were driven by immediate needs. While the technical adviser was fully occupied with his existing responsibilities of delivering the helpline service, then training a new adviser, this did not preclude him from introducing new ways of using ICT to retain knowledge. His actions were also immediate responses, requiring less time away from his role than participating in a separate project. These interventions contributed valuable findings for the study because of their relevance to the business context.

\subsection{Data collection approach}

The data collection approach was guided by the research methodology and data analysis methods. Semi-structured interviews were appropriate at the early stages. The data from these interviews were coded at a detailed level, then the codes reviewed, with higher level categories assigned. The emergent themes that were revealed were confirmed through members' checks, a review of a business report in each case, and a presentation of findings. The themes formed the topic of group discussions where the findings were presented and validated at a group level in the study organisations. The form and focus 
of the implementation step was determined following the diagnosis stage, where the emergent findings led me to proceed action planning activities in both organisations.

I carried out coding of the data as soon as possible after they were collected, as they informed the next step of action in the organisation (Miles \& Huberman, 1994). This is consistent with the cyclical nature of action research. Likewise, the results of data analysis enabled me to select the methods and procedures for the next round of data collection, leading progressively to answering each of the research sub-questions and enabling me to develop the wisdom-related knowledge framework to represent the knowledge of the older expert, as discussed in Chapter 10 (p. 243). As themes emerged from early data collection, they formed a basis for deeper analysis and a subsequent step of review and confirmation by participants.

Cresswell (1994) notes that there are four data collection types: observations, interviews, documents and audio-visual materials, each with its advantages and limitations. At various stages of my study, I collected data of each type.

\subsubsection{Observations}

I spent a significant amount of time at BRANZ during phase 2 of my study, observing how the helpline operated. The focus of my observations was on the steps involved in handling telephone inquiries and in the retention of knowledge in the helpline as a business process. The primary subject of my observations was the technical adviser, however, at times he collaborated with other experts in delivering advice and solving problems. In these situations, I observed their interactions and noted how their roles and responsibilities interfaced. My role was solely as an observer, rather than having any participatory role in the study (Bogdan \& Biklen, 1992; Merriam, 1988).

Inevitably, there are limitations to observation. I am sure my concentration was variable, and that at times the technical nature of the call content was beyond my understanding. On many occasions, I referred to the call recordings to refresh my memory, and the technical adviser was also patient in explaining technical construction techniques in lay person's terms. To minimise the sense of intrusion that the adviser may have felt, I always positioned myself where he could see me and never spoke during a call. Because of his open, chatty style, a call could open with some personal information being shared, especially if he knew the caller. I was aware that this could be a way of establishing rapport, but decided early in my observations that the social 
preamble to the actual query could not be transcribed or used. This required the exercise of personal judgement.

\subsubsection{Interviews and focus groups}

Researchers need to consider the types of interviews that elicit relevant data and their suitability for the proposed analysis methods. Duffy, Ferguson \& Watson (2004) note many different types of interviews described in literature, and these are listed in Table 4-1 (p. 124). They are not mutually exclusive and describe styles as well as forms.

\begin{tabular}{|l|l|}
\hline Interview types & \multicolumn{2}{l|}{} \\
\hline structured & in-depth \\
\hline semi-structured & partially structured \\
\hline unstructured & informal conversational \\
\hline open & open-ended \\
\hline focused & closed \\
\hline formal & fixed \\
\hline informal & standardised \\
\hline
\end{tabular}

Table 4-1: Interview types (Duffy, Ferguson and Watson, 2004, p. 68)

The study included semi-structured interviews initially, adopting styles that aimed to put the interviewee at ease to best engage with the elicitation process to produce useful information. The way in which participants perceive and make sense of their world is central to qualitative research (Cresswell, 1994). I also took note of Glaser (1992) who strongly advises against stating the research question explicitly in interviews, as this would pre-empt the emergence of data in the analysis phase. Instead, I set the scene for the interview by asking open questions that helped me to understand each participant's role, their general attitude to the study topic and any particular points of concern. Wimpenny \& Gass (2000) note that, in the case of an unstructured interview, the interviewer should still start with a general guide. This goes some way to ensuring that the relevant themes are addressed, as the interviewer is interested in the interviewee's concerns and perspectives. The narrative interviewing technique adopted by Janson (2005) included a set of starting questions only, encouraging interviewees to discuss matters of importance to them as actors in the research situation.

In the case of structured interviews, questions needed to be designed carefully, to ensure that the "appropriate" questions are asked, in terms of theory building, and also to ensure that the required information is drawn out, without being too "directive" of the participants. I therefore framed my questions so that the information gathered assisted 
the study in a general sense and were relevant from a practitioner point of view. The interview structure and follow up process also allowed time and opportunity for interviewees to provide me with any additional information that they saw as being relevant. Likewise, I was also able to approach individual interviewees if I needed them to clarify or elaborate on any aspects of their interviews.

I conducted a group of interviews by telephone when I approached the helpline's industry customers, and the interviews were captured through a recorder linked to the telephone system. As the helpline is a nationwide service, its users are widely dispersed. As it was impractical to travel to single interviews around the country, BRANZ provided me with recording equipment. I prepared for the interviews by calling and booking a time with each participant about ten days before the interview, and sent them an information pack including documents similar to those in Appendix A. That way, I approached each interview having spoken to the participant beforehand.

Given that I could not rely on the visual cues of a face-to-face interview, I focused on preparing for the interview by understanding the interviewee's role and the nature of their relationship with BRANZ. During the interview, I had to listen carefully to the content of their answers, and had to be more aware of speech patterns that provided clues about their attitudes. Examples of these were how an interviewee expressed agreement, indicated they might have more to reveal about a topic, or showed particular interest or satisfaction with an aspect of the helpline service or the technical adviser's expertise. I found it necessary to paraphrase some of the information they gave me, especially where their answer was complex or contained information that was new to me, to ensure that I had understood correctly.

At particular stages of the study where further information was required or a discussion was needed, it was appropriate for me to facilitate a focus group with a few key participants. This method of data gathering can be effective and efficient. For example, a focus group may be held to elaborate on themes that emerge from individual interviews. At the stage of evaluating a change or planning the next steps in a project, I found that a group discussion was appropriate. An example of this was the need to discuss and agree on a project plan for the phase 2 implementation at BRANZ. 


\subsubsection{Documents: records and journal}

\section{Organisational records}

Organisational records may exist in the form of documents, diagrams, plans, archival materials, discussion papers, e-mails, and presentations (Strauss \& Corbin, 1998). Organisation A also provided background information on one of its key projects, a recently implemented knowledge management system that represented the first stage of a larger programme of work. The concepts behind the design of the system shed light on the organisation's concepts of knowledge. This was useful background at the diagnosis stage of the study.

At BRANZ, I had access to many corporate documents, some of which were publicly accessible. During phase 2 of the study, I also collected documents and records relating to all aspects of the business process in which the study was situated. I found that access to organisational documents, especially at the start of the study, was very useful in understanding an organisation's culture, its strategic position, business model and priorities and similar contextual information. Having such background knowledge enabled me to approach the organisations from a more informed position and ask questions about the role of knowledge and to understand where they placed the study in relation to their beliefs and concerns about knowledge.

\section{Researcher's journal}

The researcher's journal is valuable as it enables the researcher to capture thoughts, impressions and concerns that may not be expressed elsewhere, and may not appear immediately meaningful (Fontana \& Frey, 2000). In reviewing the early entries in my journal from my first few weeks on site at Organsiation B, I found a series of seemingly random facts that I had noted because I thought they were relevant at the time. For example, hand drawn diagrams of events during several helpline calls did not fit with my understanding of the technical adviser's initial explanation of the usual process. In discussing several of these calls with him, I found that although there was a high level process for handling calls, I had encountered and mapped several complex queries that happened to have occurred on my first week on site. Within a short time, this led me to identify and categorise call types, resulting in the summary shown in Table 7-1 (p. 182). It was only in reviewing the journal later that I also saw those entries as making more sense and being part of a larger story. As I analysed the technical adviser's knowledge 
in more depth through the lens of "wisdom as a type of expertise", I realised that such exceptions held a deeper significance.

My journal is a repository for my personal learning, but its contents may also lead to action, as discussed. Some of the entries led me to actions such as checking out my impressions and assumptions with the study participants, cross-checking one person's opinion or perspective with another. Periodically, I would review the progress of the study, as a journal is useful for retrospective analysis, or for review away from the research situation. Garnston \& Wellman (1994) describe how their structured journal entries helped them reflect on "what was working", allowed them to return to things that they could not make sense of in the moment, and enabled them to maintain their focus on the key questions of the research.

This leads to discussion of the reflective aspects of journal keeping. Away from the research site, I would note thoughts in the journal and take a few minutes to clarify my understanding. On my third day of observations, I was reflecting upon the distinction between the helpline service being free for industry users, and involving a small charge for members of the public:

"I wonder about the perception of value for money, for those who pay to use the helpline service..."

Several entries later, I had formed a clearer view:

"an example was a 10-minute call costing about $\$ 20$, which gave the potential home buyer sufficient information to reconsider whether she should make an offer on a house with an unusual construction. As a result of the call, she had information on ... where to get professional technical advice, the questions she needs to ask ... confirmation of the areas of definite concern ...(with) construction, that need to be addressed (6 November 2007).”

Reflections captured in journal entries also helped me to make sense of my observations of the helpline. I had two questions in mind when observing actions: what is happening during a call? Why is the technical adviser doing this? My journal was the container for my thoughts and impressions as I made my observations. As I reflected on my notes on an increasing number of calls and read literature on data analysis, I arrived at several methods for presenting data in a way that took account of these questions. My journal 
therefore also had a developmental role, in that I noted impressions, intuitive thoughts, facts and behaviours. The act of recording them enabled me to be sensitive to them later, and this is evidenced in the development of lists, diagrams and models over time. My journal contains wide-ranging lists: the technical adviser's social network for the helpline; aspects of his personal communication style; the boundaries and guiding principles for providing the service; and authoritative documents used on the helpline. Some of these lists became meaningful as they formed the basis of further data gathering, analysis and the development of findings. There were also short lists of points to clarify and tasks to follow up.

My researcher's journal existed in two forms. I kept an electronic document that was updated several times a week, when I had an hour on or off site. At the beginning of the month, I would start a new document for entries over the next month. I also kept a notebook with me whenever I was away from my computer at BRANZ, visiting Organisation A, meeting with my supervisors, or any research-related activity.

In summary, keeping a researcher's journal enabled me to capture my thoughts, reflections and concerns. This enabled me to be more sensitive to the research process, and to recognise developing patterns in data that were significant to my research. Important aspects such as the frameworks I used and some of my findings originate from journal entries.

\subsubsection{Audio-visual materials}

The audio-visual materials I used in the course of the study were in the form of photographs, architectural plans showing construction details, existing audio recordings and software. The technical adviser provided me with interesting and relevant examples of helpline calls from his collection at various times during my observations. On occasions when I questioned him about calls, he would provide me with recordings that illustrated aspects of the call that were of interest to me. I was also given access to the helpline's call management system, from which I extracted significant volumes of data for analysis. The importance of audio-visual materials as data cannot be underestimated in this study. The analysis of this data led to my findings in areas such as call processes, the older expert's knowledge retention processes and the nature of expertise. 


\subsection{Data collection considerations}

I now turn to a discussion of the potential and unseen challenges in data collection in the course of conducting research - and how they were addressed in planning and carrying out the study. Physical challenges may include gaining access to study organisations, and planning and co-ordinating data collection. Issues such as the nature of the data sources, richness of the data and matters of interpretation may also arise.

\subsubsection{Access to organisations}

Gaining access to organisations and to the appropriate people to participate in a research study can be time-consuming and frustrating, and according to Kock and Corner (1996), counters the myth that data collection in action research studies can be completed quickly. These authors recommend being well-prepared with a clear research framework, and specific and realistic goals and deadlines, supported by a data collection plan. First, a researcher - client agreement was developed and negotiated with both organisations soon after they expressed interest in participating in the research. It was written in business terms and referred to as "Terms of Reference". In readiness for initiating the research project, it was also useful in clarifying and managing both parties' expectations, including stating the need to get access to the relevant people. The organisations believed that the study would be mutually beneficial and that the reasonable resources should therefore be allocated.

Second, an information package was prepared for each round of interviews and provided to the sponsor for confirmation before being provided to each participant. This information included an outline of the tasks involved in participation, and an estimate of the amount of time that would be required for interviews, review of transcripts, and providing further information. Attendance of focus groups and meetings were also negotiated in advance. There were, however, two interviewees who were simply too busy to participate, so the sponsor provided access to other suitable participants.

An aspect that facilitated gaining access to the organisations was related to managing the relationship through contact with a senior manager. In Organisation A's case, access was provided by a member of the executive, who reported to the Chief Executive. With BRANZ, the Chief Executive himself endorsed the study and selected one of his direct reports as the study sponsor. The sponsor was, at the time, responsible for oversight of the knowledge management function in the organisation. In the course of a promotion, 
he moved to another business group but continued his sponsorship of the study for continuity reasons. A restructuring of the business later occurred, which saw his responsibilities extended, with oversight of the helpline again.

\subsubsection{Bias in data sources}

In collecting data, there is a possibility of bias inherent in some of the data sources. In action research, it is also important to guard against researcher bias, in placing too much emphasis on observation notes. A strong reliance on the researcher's observation can severely distort findings towards the researcher's personal preferences (Barley, 1989).

Although observation notes and journal entries were an important data source in the study, they supplemented other forms that were free from researcher bias. For example, interview transcripts represented the study participants' views, and documents provided by the organisation in the context of the study represented the organisation's formal views and position on knowledge retention. Having a range of data collection types was an advantage in triangulating results, and provided a more balanced approach that goes some way towards mitigating the risk of bias. The majority of data came from study participants, with my observations being treated as a secondary source. Many of the journal entries and observations were used as checkpoints and reminders to confirm my understanding and impressions of certain aspects of calls. For example, in some calls, much of the conversation was technical and I needed to confirm my understanding of the tenet of the conversation or the overall purpose of the call. Several times when I could gleaned insufficient information to understand the call, the technical adviser advised that this was because it had been a continuation of an earlier inquiry.

Essentially, primary data sources consisted of all data types that were provided by or through the organisation, including external contacts. My observations and the documentation I collected represented secondary data sources. My reports to the organisations embodied my interpretation of data into resultant findings, and were therefore provided to various audiences for review and confirmation.

\subsubsection{Richness of information}

Another area of concern in data collection for action research is the value and richness of the information provided. Yin's (2003) analysis of the strengths and weaknesses of sources of evidence notes that in the case of organisational documents and archival 
material, there may be issues of unavailability due to privacy requirements. Documents may also be known to exist but not be accessible.

This issue did not arise in the course of the study, but a similar challenge did. I found that there was relatively little documentation of the helpline service - this did not inhibit the study, but may have been an indication of where knowledge about the service actually resided. In Section 4.6.3, I discussed my researcher's journal entries and the lists that I built up from my observations. On several occasions when I reviewed some of these lists with the technical adviser, he noted that they represented valuable information that was not documented anywhere. Likewise, when I questioned him about my observations of his behaviour in handling calls, he confirmed that he was using his intuition — the actions I had observed were sub-conscious, elements of tacit knowledge in action. This was consistent with other participants' comments that a lot of knowledge was embedded in this individual.

The main data types for the helpline service were interviews and observations. Most of the documentation relevant to the organisation was readily available and located from a variety of sources. The helpline had much formal reference material about its topic domain of construction knowledge, and this was housed in the same office.

A common issue with information gained from detailed interviews is that "you get what you ask for". In this case, questions were structured carefully to obtain information that is relevant to the topic. However, there was also a need to keep questions at a higher level and open in nature, to elicit participants' views but not to channel or limit their thinking. The questionnaire used in stage 1 of data collection had been included in the formal research proposal submitted to the University's Human Ethics Committee. In the course of each set of interviews, the interview questions were reviewed after the first and second interviews and adjusted slightly where needed.

Following each set of interviews, the process of conducting members' checks enabled interviewees to confirm that the transcript reflected what they had wanted to say, and several took the opportunity to add to their transcript. All of the participants throughout the study were able to be contacted in the event that queries arose at a later date.

\subsubsection{Interpretation of data}

Study participants, in the process of generating new knowledge, have their own frameworks and categories for explaining the world. "The insiders' own cognitive map 
or local theory can be as legitimate and as useful in defining the framework and language for scientific investigation as that of the researcher" (Elden \& Chisholm, 1993, p. 128). It is important that the researcher recognises this legitimacy and reflects it in writing up action research findings (Meyer, 2000).

This is particularly relevant in the research topic of this study. In examining how ICT can support knowledge transfer from older expert workers in an organisational context, participants had their own frameworks for describing the types of knowledge that are valuable to the organisation, and also the types of knowledge that expert workers possess. In my experience, organisations that have a perspective on the concept of organisational knowledge also have some capability for describing their views within the context of a framework. Some examples of concepts that came from BRANZ are the idea of experience being accumulated in layers, and of developing expertise as a long term process (Section 6.2.3); and the idea of related knowledge being seen as blind alleys down which researchers have travelled in their past (Section 6.2.5).

\section{Timing and coordination challenges}

Given the inability to predict the action research process and how data emerges in analysis, as discussed in Section 4.6, three challenges had to be managed.

First, maintaining momentum of the data gathering and analysis steps was important throughout the whole study. It was partly for this reason that I planned the study so that the first step of data collection and analysis could be completed relatively quickly, one organisation at a time. This was for logistical reasons due to geography, and because I prefer face-to-face interviews where feasible. I therefore collected data through individual interviews, completed transcriptions and completed members' checks at Organisation A first. I then analysed and interpreted the data, wrote the business report and presented it to the sponsor. After allowing sufficient time for him to review and sign off the report, I held a focus group meeting at Organisation A, as the final step in its part of the study. The presentation of the report was treated as a milestone, so while Organisation A was reviewing the report, I began data collection at BRANZ, where a similar process was followed.

Second, material changes in data gathering methods may require ethical approval, which can delay the progress of research (Duffy, Ferguson, \& Watson, 2004; 
Wimpenny \& Gass, 2000). I gained ethical approval before starting my research and did not need to make subsequent changes to my data collection approach.

Third, data gathering activities cannot be predicted with absolute certainty, but I planned and prepared for data collection, taking practical steps to facilitate progress. I developed call scripts and checklists to use in approaching candidate organisations and contacting interviewees for the first time. The process of interviewing, transcribing, sending transcripts for review, receiving feedback and completing the members' checks was managed by spreadsheet - this made it easier to track progress. It also helped to give adequate notice of interviews, and to prepare by fine-tuning interview techniques.

\subsection{Summary}

I chose a qualitative approach for the study because it involves an inquiry process to understand an aspect of knowledge retention within an organisation, a natural setting for reporting the views of participants. At the outset of the study, it appeared that relatively little literature existed where the three topic areas intersect: older experts, knowledge retention, and ICT support - there is now an increasing amount of literature both academic and practice-oriented, partly driven by the growing prominence of concerns about knowledge loss in organisations, and about the retirement patterns of the baby boom generation. As it is situated in a relatively new domain of academic research, the study lends itself to a qualitative approach and to theory development. In seeking the meaning that participants give to knowledge, expert behaviour and organisational processes, the study adopts an interpretivist perspective of behaviour and change. An interpretivist stance enables greater interaction with the participant organisation, thus enhancing the opportunity for successfully implementing a change initiative.

As the study aims to increase understanding in a multi-variate social setting, and to assist with practical problem solving, action research is an appropriate method to use. My research was conducted in the setting of an industry helpline, and proceeded through the stages of action research. I carried out a diagnosis stage at two organisations, after which they each completed an action planning stage. Organisation A selected some existing organisational mechanisms such as an ICT programme of work through which to pursue action taking activities. BRANZ proceeded with two phases of action taking. An evaluation was carried out and learning has been specified in the form of my findings from the study. 



\section{PART 3: RESEARCH FINDINGS}

This part of the thesis comprises four chapters setting out the major findings of the study, addressing in turn each part of the research topic:

\section{Retaining the knowledge of older experts in an organisational context and the role of ICT}

The first phase of the study involved two organisations and resulted in the identification of their concepts of valuable knowledge that should be retained. Some consistency in the findings, set out in Chapter 5 (p. 136), was evident. They defined as valuable the knowledge of relationships, organisational knowledge, business system and process knowledge, subject matter expertise, applied knowledge and governance knowledge.

The nature of the valuable knowledge that resides in older workers in BRANZ is addressed in Chapter 6 (p. 157). Valuable knowledge included the unique combinations of skills and experience that older workers enact; knowledge of the organisation and industry; the extensive and enduring professional networks; and the concept of layered expertise. Efficiency and effectiveness also feature prominently in the profile of the expert, as do powerful long-term recall, and the uniqueness of the experts themselves.

I describe BRANZ's helpline, the setting for the study of a specific older expert, in Chapter 7 (p. 175). The helpline service was the subject of the second phase of the study, involving an older expert with knowledge regarded as being valuable to the organisation. Brief details of the service are given, including the high level business process for answering inquiries, and the ICT that support the process.

Next, I review six examples observed at BRANZ that show how ICT is used in the helpline business process, in Section 7.2. These include capturing and sharing knowledge on innovative practice; maintaining knowledge of current building techniques; capturing and integrating evolving knowledge; formalising knowledge for replication; extending the software function; and grouping related knowledge.

The knowledge types identified in the business process are described in Chapter 8. Distinctions are drawn between the use of existing knowledge, updating existing knowledge to reflect change, and knowledge creation. 


\section{Chapter 5. Organisational aspects of valuable knowledge}

\subsection{Concepts of valuable knowledge}

As a foundation for studying the role of ICT in retaining the knowledge of older experts in an organisational context, I wanted to question the participating organisations to understand their concepts of what constituted valuable knowledge that was worthy of retention. I begin with an outline the scope of the study and introduce the high level interview questions. I then discuss each theme that emerged from the findings, revealing each organisation's perspectives of knowledge.

\subsubsection{Scope of phase 1 study}

Phase 1 of the study elicited information on the organisational concepts of knowledge. I did not begin with a clear idea of what organisations understood by the concept of valuable knowledge, and they may not have given much consideration to this matter. Therefore, any assumptions needed to be made explicit to give the study a firmer foundation based on a shared understanding with each organisation, and to avoid confusion that might occur as the study progressed. If assumptions about knowledge could be made explicit, this would also reduce the likelihood of researcher bias.

The interviews with representatives from each of two organisations were based on the following questions:

1. In the context of your organisation and its core business, when you think of "valuable knowledge", what do you mean?

2. What types of valuable knowledge might be lost when older experts retire or leave the organisation?

3. What do you think is the extent of any threat (perceived or real) of losing knowledge?

4. How would the loss of valuable knowledge affect your business objectives, responsibilities and outcomes?

5. Where in the organisation does this knowledge currently reside? 


\subsubsection{Action research diagnosis stage}

The findings in this chapter resulted from Phase 1 of the study, which was completed as an action research diagnosis stage. In this stage, the researcher and the participants of the study jointly analysed the social situation with regard to knowledge in two organisations. The interview questions were based on a holistic view of each organisation, with the purpose of identifying or defining a problem. In both organisations, the diagnosis led to the finding that certain types of knowledge were valuable and were at risk of being lost.

The main data collection method was conducting semi-structured interviews that revealed the interviewees' perspectives. The questions were designed to provide a broad scope for the interviews, which were formal but conversational in style. As the interviewee answered a question, I would take opportunities to ask more targeted questions on particular aspects. This led to specific examples in the context of the organisation and meaningful quotes that form part of the findings.

\subsubsection{Organisational perspectives of knowledge}

The two organisations shared some themes with regard to the concepts of valuable knowledge that emerged from the interviews. This section details the themes and the distinctions that were identified. First, subject matter expertise and experience were at the core of both organisations - the significance of applied scientific knowledge was reflected in both corporate strategies. Second, knowledge about relationships, social networks, social processes and co-ordination were held to be important — rich, productive and highly valued social networks existed to varying degrees of visibility. Third, organisational knowledge was described as being about the institution, its memory and the continuity of the entity — with the implication that loss of individual knowledge could potentially degrade an organisational asset in a way that is not immediately clear. Fourth, knowledge of business systems, processes and value chains was pivotal to both organisations - efficiency and effectiveness of processes underpinned the quality of their respective services and financial models. The fifth concept was applied knowledge, which has been aggregated from data and facts and becomes productive in terms of adding economic value. The last concept, knowledge of governance and the big picture, enabled the organisations to focus on their respective strategic directions, while understanding the reasons for their current success. 


\subsection{Subject matter expertise and experience}

\subsubsection{Organisation A}

A wide range of expertise was found in Organisation A - including strategic, business, operational, economic, scientific, policy and regulatory. Subject matter expertise (topicspecific knowledge) did not consist solely of technical or scientific knowledge, and could be lost from any area of the organisation. Such expertise was characterised by a high reliance being placed on a single individual in some cases, for example where there was only a single expert in a specialist knowledge area in the organisation. Subject matter expertise was tied to the skills, knowledge and experience of individuals, and could be developed through formal qualifications, and on-the-job or experiential training. It could be an attribute of workers of all ages. Organisation A had experts who had joined the organisation with expertise which was then honed and adapted to their role. The expertise could be in specific, well-defined areas such as trade negotiations, where a specific person was targeted especially for the role.

Another type of expert knowledge was in the area of rare knowledge, which one interviewee described as being knowledge that was not used in an everyday context, but essential for a business group to function effectively. An example of this is the processes that needed to be completed on an annual basis, such as business planning reviewing past performance, reviewing the current year, and developing plans for the future. Where a manager had sole responsibility for completing such processes (applying this knowledge) then it could become personal knowledge and be lost if the manager left. On the other hand, such knowledge could be well-documented, due to the need for these processes to be disseminated and for them to be completed in a consistent manner throughout the organisation. One manager commented that the underlying information or data that were collected for business planning and review processes may appear to be important, but were of lesser meaning until they were analysed.

The concept of craftsmanship emerged in Organisation A, where a knowledge worker described it as being related to rare knowledge and skills. Some roles, by their specialist nature, were not seen to be easily supported by a process or a system. Tasks could involve dealing with complexity, handling exceptions, or dealing with cases that in some way deviated from a norm. Thus, an older expert would transfer such knowledge and skills via an apprenticeship model to a less experienced colleague over a longer period of time. Another view that emerged was that so long as the development of ICT 
to support business processes was relatively inefficient, the craftsman mode of learning and building knowledge would still be required. As ICT capabilities were further enhanced, the craftsman and apprenticeship model would be less prevalent.

Organisation A found that specific technical knowledge may be narrow and deep, with a greater risk of loss where there was a high reliance on a key person's individual knowledge. However, there was usually less risk if experts gave sufficient notice of their retirement.Mitigations for knowledge loss included identifying the organisation's needs earlier on, and carrying out succession planning and knowledge transfer activities. Organisation A considered it a management failure not to have a succession plan in place to address retirements, noting that its process worked well.

Managers in Organisation A acknowledged a real risk of losing knowledge, especially technical competence, through high rates of staff turnover. While some knowledge was embedded in the business processes, for example risk mitigation processes, losing people who knew how and when to run the processes meant that this knowledge would be lost. There had been some progress in replacing obsolescent technology, with an electronic document management system (EDMS) and taxonomies being developed for improved classification and easier access to documents. However, personally held knowledge was at risk of being lost, for example where an apprenticeship approach to knowledge transfer had been taken.

\subsubsection{BRANZ}

BRANZ recognised that experience is the product of many years in the industry and its acquisition is not easily accelerated, as the Chief Executive acknowledged:

"this is a science that actually takes years to get right, understand properly and make it work. If you do a fast track 'how to be a scientist in two days or two years' exercise, it doesn't happen. ... So the process of building these layers (of knowledge) can be concertinaed somewhat, but you can't do it in a year, and you can't do without having that (senior) person as a mentor, but rather than taking up to 10 years, you can take 4 or 5 to layer someone up to be adequate, and that means we actually have a nurturing model of knowledge within the organisation - we're prepared to invest in and support the nurturing of that knowledge." 
BRANZ has world-class scientific knowledge and understanding, but noted that integrating such knowledge was not easily performed. Experience was required to integrate knowledge, for example, and apply it to the next piece of work. Subject matter expertise was scarce - due to the relatively small size of the organisation and the nature of its funding, there may be only one expert in some areas. Experts had their own specialty domains of knowledge and maintained strong relationships with others in their specialty areas internationally. Much of their knowledge was scientific, that is, knowledge about components and how relationships between them work. Such knowledge was valuable and formed the input to hypothesis formation, which relied on having all the appropriate inputs to research.

Scientists also possessed stocks of professional knowledge that complement their scientific knowledge, for example knowledge of experiments that work, and specific methods of carrying out experiments and findings which are held tacitly, rather than being published (research by-products). BRANZ saw the chance to address the challenges of capturing such knowledge, accessing it and reformatting it for other uses.

This organisation suggested that a defining characteristic of experts is that they are highly efficient and cost-effective in the way they work - and this experience and knowledge needed to be recreated if it was not captured before experts left. Research progresses over time, and with a reduced number of people with valuable historical knowledge in this area, linkages with the past are becoming weak. Expertise was developed and located through personal relationships and was demonstrated in BRANZ's superior customer service and response times in its advisory services function. This expertise formed the foundation of the organisation's and individuals' reputation in the industry and must be preserved to sustain service continuity to meet the information and education needs of the industry.

BRANZ made a distinction between base knowledge, which was established through education such as a doctorate qualification, and the experience that needed to be built upon this foundation. It was this subsequent practical experience that enabled scientists to accrue applied knowledge, for example, an added layer of learning from designing and conducting experiments, and knowledge consisting of understanding the implications of experiments. In terms of technical advice for members of the building industry and the public helpline for home and building owners, this knowledge needed to be captured and replicated so that the service was less dependent on the knowledge of 
the adviser. The organisation recognised that the individual had developed unique knowledge over time in the role because of his experience and connections. Retaining his knowledge would involve training another person and building an "electronic apprentice" - a concept that arose during a discussion with the older expert on how ICT might be used to capture his undocumented knowledge. Recreating this knowledge would take time, especially the knowledge about people and their roles and projects.

There is some related or contextual knowledge that was valuable and at risk of being lost. First, BRANZ observed that knowledge in scientific domains related to the scientists' main area of focus was of value - scientists often moved to such areas and developed their knowledge further. Peripheral knowledge discovered in one piece of research may represent a blind alley for one scientist, and would therefore not be documented, but may still be relevant to another scientist's work in the future.

"for every 100-page report, there will be unpublished knowledge in drawers and directories, and tacit knowledge in people's heads"

senior manager of scientists, BRANZ

Second, knowledge of what scientists and researchers had been involved in previously could be valuable, as they would possess knowledge and experience in areas other than their current domain of expertise. The fact that their history was not evident presented a challenge to accessing that knowledge. Finally, the sources of facts that were integrated to form knowledge, for example the person who made a discovery, and the location of source documents, reports and research were also regarded as being important.

\subsubsection{Summary}

Both organisations noted that the currency of knowledge often increases its value to an organisation, thus knowledge workers who possess information on the latest developments, such as organisational politics and power structures and their implications for negotiations or policy development, were vital contributors to success. This type of knowledge was too new to be documented, and reflected a changing environment that was not directly relevant to the final form of a policy or a product that was developed. In the scientific domain, large amounts of critical technical (scientific) knowledge may reside in the minds of individuals and there may be little or no formal documentation for a period of time. Thus, tacit knowledge relating to scientific discovery would be lost. 
In summary, subject matter expertise warrants retention especially where the knowledge is rare, or the expert holds a unique role that may not be supported by existing systems. Experts' technical skills and experience and their efficiency and effectiveness have developed over a long period of time and cannot be acquired quickly.

\subsection{Knowledge of relationships and social networks}

\subsubsection{Organisation A}

Organisation A is a relatively large entity by New Zealand standards, with a few distinct business functions. Stakeholder relationships exist at multiple levels, for example between individuals, groups across different primary industry sectors and internationally. Collaboration is important as the organisation is a participant in many work streams across the public and private sectors. Reflecting the importance of relationship management, it has well established processes for consultation, coordinating inter-agency activities, and conveying information about regulatory systems and their implementation. Organisation A noted that rich networks existed across agencies, with virtual teams operating effectively across agency boundaries.

Much of the knowledge about relationships was held by individuals and there were common stakeholders across different business groups. This means that although a lot of the knowledge about relationships was tacit and deep, an employee seldom had a sole relationship with a particular stakeholder. Thus the existence of multiple relationships with stakeholders mitigated the loss of knowledge when an individual employee left. Some employees possessed referential knowledge of relationships, and this ability to locate the right contact or refer someone to the right knowledge source is characteristic of valuable job-related networks. The term "deep smarts" was described in recent research on preserving business wisdom within organisations, as being: “... a potent form of expertise based on first hand life experiences, providing insights drawn from tacit knowledge and shaped by beliefs and forces. Deep smarts are as close as we get to wisdom" (Leonard \& Swap, 2005, p.2).

Knowledge about relationships has some important attributes, including knowledge of the key players and how to facilitate productive relationships with them. Organisation A noted that this was particularly valuable with overseas postings, which were expected to involve intensive relationship-building and result in a wide range of professional contacts. There was a reputational dimension to knowledge, in that an older, and more 
knowledgeable person may often be the front person for co-ordinating work, for example liaising with government ministers to facilitate agreement:

"Anyone can sit down and read the ... Act and go into our archives and get out all the information and all the work that's been done around the industry ... but the thing that's most difficult to track is basically the things to do with human beings being in touch with each other ... It's about people and individuals, their particular views, of the chief executive, chairman, director, or someone in a particular area. Understanding who those people are, what makes them tick, what their issues are, what their networks are, how they interact with others, what views they've got on particular issues, how they are best approached, how to deal with difficult questions. ... and the facts of the matter, the analysis and the advice (that's) given to Ministers, all that stuff-it's the social part of what policy is."

deputy director general

A closely related type of knowledge was knowledge of a contextual and social nature, as opposed to factual knowledge. Contextual knowledge may consist of knowledge that is relevant to performing a particular role in the organisation. It can be described as "knowledge about the knowledge" and resides in the minds of people. For example, if a manager recalled that Organisation A was involved in researching a specific topic in the 1970s, he would know that he needed to locate the relevant information, or find someone who was able to suggest where to look. Several interviewees referred specifically to social processes and the importance of knowing how people in groups interact. Thus, social processes can be viewed as all the interactions between people that are required to achieve a successful business outcome or solve a problem. Knowledge about "how things happen" in terms of people and their perspectives was valuable. Social processes may be complex and were evidenced in Organisation A's business activities, for example policy development, that required consultation and co-ordination across the agricultural, forestry and food sectors. A senior executive noted that knowledge about the social aspects and networks as they relate to business relationships is recognised as being important:

“... the Minister would approach a particular industry group - it's a

lot to do with the power structure that's in that industry group at that 
point in time. For example, what would be the way that we would advise them to approach an issue in a particular industry? The end result will be the same, but the way to get there and the way to do it could be quite dramatically different. Even if the Minister changes, that changes. Ministers have different personalities and different strengths and weaknesses. So (how to facilitate the best way through a process) is a lot more, in my view, of a challenge. All knowledge is valuable, but ... the stuff that's hardest or most difficult to catch or understand, it's just that whole "how" question, you know."

There was significant value in the ability to bring together and co-ordinate people and activities. Coupled with this is the knowledge that enabled people to recognise linkages between various pieces of work, or projects, and manage the boundaries and gaps across various individual initiatives. People who are able to apply this type of knowledge provided cohesion in teams and social processes, noting that teams were no longer limited by the boundaries of the organisation, given that Organisation A's business processes span several other agencies:

\footnotetext{
"It's not a binary thing where one person comes in, they do all the work with this stakeholder and then they leave and leave it to someone else. ... the nature of policy is that you divide the cake up and you work in area $X$, but it always relates to area $Y$ and then area $Z$. So you might be working for example on sustainability policy, well it's got impacts in sector performance, in policy and it might have an impact in international policy - so there's always this triangulation that's going on. So that itself gives depth to the relationship and the way in which you're directing the people and helps cover us when people move on."
}

deputy director general

Effective co-ordination required a positive working style and useful networks, and these people were responsible for creating and maintaining knowledge pathways through their contacts. They had well-developed inter-personal skills and a deep understanding of the nuances at the edges of consultation processes, involving people and how they work together, "management recognized that critical knowledge loss is not simply what the departing employees know about their job tasks, but also who they know and 
collaborate with to get work done on time" (Parise, et al., 2006, p. 31). This capability complemented their separate factual knowledge.

\subsubsection{BRANZ}

At BRANZ, a smaller organisation, a key person could often be the face of the organisation's interactions with the scientific community. Thus, contacts needed to be re-established when a key person leaves. A younger scientist observed:

"what definitely comes to mind is people's knowledge of other people within the field that you have to relate to. Because they've known these people, they've built up relationships, so if my principal supervisor or principal scientist left or didn't come in as all sorts of things can happen, she's built up a rapport with people in other organisations, so she's the face of our interactions with certain companies and I may not even know, so it's very much that personal communication"In BRANZ's scientific community, the effectiveness of social networks relied partly upon people-oriented knowledge about how to use networks in scientific fields. Knowledge of networks was important for identifying who was interested in a scientist's research, and gathering related and peripheral knowledge, to include the appropriate people to contribute to a sound piece of research. Knowledge gained from networks complemented documented knowledge enabling scientists to produce thorough research:

\section{"I think one of the things ... in terms of valuable knowledge is also the networking we have. The people who typically have all this (scientific) knowledge also have the very good networks and that's essential for that sort of stage, so you can pull in people, and the right people, to give the right information at that level to then make sure you have formed a good sound piece of research."}

senior manager of scientific researchers

The ability to network and collaborate with other researchers is an important factor in conducting research and also in building a professional reputation — starting within New Zealand then being internationally recognised as expert. In terms of developing younger scientists' careers, BRANZ recognised that it needed to make sure it retained a sufficient number of experts at the top level of seniority. In this way, less experienced scientists could get exposure at an international level with the current experts and 
establish their own networks. In discussing the need to develop younger scientists' knowledge, a senior manager recalled that:

\author{
"Typically, what's happened in the past is that it's only the experts \\ who've been allowed to travel and the rest of it, and suddenly you see \\ that there's a bit of a dilemma there."
}

\title{
5.3.3 Summary
}

In summary, individuals possessed valuable knowledge about relationships and social networks that enabled inter-organisational collaboration. Referential knowledge was also important in the location of experts with deep knowledge and business wisdom. Contextual knowledge about roles and knowledge of social processes enhanced the ability to co-ordinate people and activities to increase productivity across organisational boundaries. The ability to leverage social networks yielded valuable knowledge that complemented documented knowledge.

\subsection{Organisational knowledge}

Under the category of organisational knowledge, four related concepts emerged: institutional knowledge, organisational memory, organisational continuity, and knowledge for mentoring.

\subsubsection{Organisation A}

First, institutional knowledge was noted as being valuable. Managers at Organisation A explained that this was knowledge of the organisation as a whole, its identity, how it operated, and why it functioned the way it did. Its role and its place in New Zealand history had evolved through major organisational entity changes. Knowledge of its social contacts, processes and its communications promoted a common understanding within the organisation. Experts' institutional knowledge was described as being tacit in nature, which means the knowledge holder is unaware of what they know, and it is not documented or easily expressed; it may have been built up over many years and through a web of relationships (Lahaie, 2005; Lesser, 2006).

Senior managers warned that the social and contextual knowledge stocks of experts may be lost and difficult to replace if demographic changes result in a shortage of knowledge workers in New Zealand, requiring it to participate more aggressively in the global 
competition for workers. With regard to immigration, Organisation A noted that even if non-New Zealanders had some knowledge of an organisation's functions, they would not have institutional knowledge, which was described as the way in which such an organisation operates in the New Zealand context. This concept of having inherent knowledge as a New Zealander is akin to BRANZ's concept of the inherent knowledge of scientists having grown up and matured with the industry. Anyway, losing social and contextual knowledge would mean that new people in roles where this knowledge is critical will have less base knowledge, and require training, an additional overhead.

Second, organisational memory is the part of institutional knowledge that deals with why the organisation functions as it currently does, since an organisation's existence is rarely isolated in the present. Older experts had much more experience and knowledge than younger staff had in this area. While knowledge of Organisation A's processes was important to its business, knowledge of how processes had evolved and the rationale for current processes provided a more sound understanding and reconfirmed the validity of the current organisational state. The rationale for taking a particular path included understanding why things were done in a specific way. A senior manager explained that organisational memory included an understanding of the legislation and instruments involved at various times, and how they linked to systems and processes in the organisation, that is, how such instruments had been implemented.

Third, knowledge about organisational continuity was regarded as being valuable and increasingly rare. Continuity may be described as "the connectedness over time among organisational efforts and a sense or experience of continuity that links the past to the present and the present to the future hopes and ideals" (Fry \& Srivastva, 1992, p2). Experts with this type of knowledge were able to tell the story of the organisation and its history and development, from the point of view of someone who had lived through change. These experts were able to recall both the rationale for change and what the operating environment was like at the time that changes happened. The survival of this knowledge relies on the continuity of personnel or good quality recordings and documentation. For example, there were few individuals remaining who had first-hand experience of the evolution of Organisation A as an entity, its organisational boundaries and business objectives over the last couple of decades. According to Kolb (2003), the concept of organisational continuity is useful in dealing with organisational change in terms of relating the latest change to a series of changes in the past, to demonstrate connectivity and continuity, rather than focusing on change as disconnecting from the 
past. At a lower and more practical level, the knowledge that enables effective handover processes from one knowledge worker to another is valuable. When such knowledge transfers fail, there is potential for error, rework and a failure to maintain the continuity of normal business while a new worker becomes familiar with their role.

The last type of organisational knowledge, mentoring, was important, and there was concern that the knowledge and skills required for effective mentoring would be lost as older experts left. At Organisation A, mentoring involved providing support to younger, less experienced staff in dealing with new activities and learning from difficult situations. Two examples of mentoring were dealing with government ministers as part of the policy development process, and familiarising employees with trade negotiations by pairing up a newer person and a more experienced one. While newer employees had a certain amount of base or technical knowledge, mentoring addressed workplace processes and conventions, in other words, how to get things done in Organisation A, and how the world operates for the purposes of conducting its business.

\subsubsection{BRANZ}

At BRANZ, a type of institutional knowledge that was valuable was the expert knowledge of relationships. This included relationships within the organisation, and how it related to other parties. BRANZ's public face and reputation were at the forefront of these relationships when bidding for research funds. BRANZ's experts knew its funding organisations well, in terms of their specialties and interests, and the individuals and groups to whom it could pitch its proposals to gain funding.

Organisational continuity was seen as continuity of knowledge. First, its commercial business model has efficiency as one of its main drivers. This organisation therefore found that where it could re-use older experts' contextual knowledge such as relevant knowledge of the past, this saved time, effort and replication. Second, older experts also had knowledge of the history of the organisation, and how its key relationships have evolved over time, and this was valuable. It prevented current staff from repeating past errors and it enabled an understanding of successful behaviours in terms of managing relationships with important stakeholders, taking into account the management styles of individuals. Last, BRANZ recognised that it is its experts who can provide the most useful linkages with the past, and external links to the right people and relevant content for the current focus of its research and consultancy commitments. 
Thus, the ability to maintain linkages and learn from the past was important and such expertise needs to be documented. An example of this was the knowledge about BRANZ's markets for its scientific research. The organisation found that management skills were more generic, compared with unique scientific knowledge, and senior management roles were held by skilled managers without industry experience.

\subsubsection{Summary}

In summarising the importance of organisational knowledge, institutional knowledge was important for both organisations, and was described as a holistic understanding of the organisation, its identity and operations. An organisational memory, embedded in individuals, enables an organisation to make sense of its current state of operation, reconfirming its validity. Knowledge of organisational continuity was regarded as becoming rare, but the ability to link the past to the present provided a basis to plan for the future and facilitated organisational change. Knowledge and skills for mentoring were applied at a practical level, with experts pairing up with new employees.

\subsection{Knowledge of business systems and processes}

\subsubsection{Organisation A}

Organisation A regarded knowledge about its business processes and value chains as being valuable, as such sequential patterns existed within all business functions and across multiple business groups, forming a foundation for handling the majority of its business consistently and effectively. Steps in one business process were likely to have interdependencies and intervene in another business group's functions or processes. Thus, cohesion and integration across these processes was important, partly because of the need to present a coherent approach to stakeholder communications and relationships. Expert knowledge was a major requirement in managing areas of risk such as inter-process linkages and exceptions, as with compliance-related events.

There is a threat of losing explicit or documented knowledge, since this was not often as up-to-date or as complete as was desirable to complete a task. It was common for most people, especially knowledge workers, to focus on completing the job as a top priority, rather than keeping documentation, records or systems up to date. Human nature may also be responsible for the focus on action rather than documentation, so that expert knowledge resides in people. Thus, with incomplete documentation, there would always 
be a certain amount of knowledge that cannot be retained or replicated. Some of the knowledge that could be the subject of transfer between teams or organisations appeared to be embedded in individuals and did not lend itself to being shared readily.

Organisation A advised that there was a degree of exposure to the loss of timedependent process knowledge. This threat related to the state of knowledge at a particular time in a process, and the continuity of people dealing with that process. One example was that there were vulnerabilities relating to the currency and complexity of knowledge at various stages of the policy development process. Participants in the process often had different areas of interest and familiarity with the policy being developed, but it could be difficult to find the right person to replace someone leaving at a critical time in the process. The tacit knowledge that experts possess may include sensitivity to current issues, possibly political, which would be difficult to replicate. Thus the continuity of experts was important until such time as a policy, regulation or piece of legislation had passed through the regulatory process and been implemented.

Three elements of process-related knowledge were at risk of being lost. First, there were business rules that needed to be applied, but were not always understood or consistent, due to aspects such as political considerations. Second, the logic or rationale pertaining to processes and their modification over time were often not captured, and were more difficult to transfer than explicit and documented knowledge. Third, processes may evolve to meet a new or changing need, and the details of this may be embedded, so that transferring the explicit knowledge alone was insufficient for understanding.

\title{
5.5.2 BRANZ
}

At BRANZ, the knowledge of systems and processes was important in several ways. First, at a high level, its business process involved knowledge creation through research, followed by dissemination to the industry or the public, leading to a greater understanding and potentially a change in beliefs. Second, in a scientific sense, scientists could build upon knowledge of how a system works, to learn how other systems work, as a scientist explained:

\author{
"I came from a background in materials, rather than in the \\ construction industry, so the word 'fire' is different in terms of the \\ context. It's sort of similar, but I have to start in terms of the building \\ side of things, from scratch. Compartment fires are a larger scale
}


Third, at a deeper level, knowledge of systems and processes was inferred. Examples of this were how research was physically carried out, what technology was used, and what models and sensitivities were taken into account in an experiment. Much of this knowledge did not form part of the published results but resided with experts, thus underlying techniques and technologies would need to be inferred where those who carried out the work were no longer contactable. Such related knowledge needed to be available so that research could be understood in its context, and comparisons with past work could be made. A younger scientist noted the value of being able to connect current research with a historical context:

"if you go and talk to someone, they may be foggy but they might say 'this organisation did something like that back in the 1950s or 1960s' and that's a lead that I would not otherwise have, as I don't have that experience. (It's very much about making) people linkages as well as content linkages, because sometimes there'll be clear linkages for one, but not with the people who did it, then sometimes it's about the people, then it filters down to the content. So being able to attack it from both directions is very, very useful. And then it's just networks of people."

Last, the processes relating to the efficient conduct of scientific research and experiments were also important. Aspects of this included how to make things work at a practical level, how to approach people and who to consult for advice, and how to handle any constraints, on people's time or the availability of equipment. This last type of knowledge was important as it facilitated the smooth operation of the scientific process. At BRANZ, knowledge of processes and a reputation for high quality work were also crucial to attracting funding.

\subsubsection{Summary}

Knowledge of business processes was valuable and often complex, and documented elements of such knowledge may be less current than knowledge held by individuals. Knowledge at intermediate stages of a process may be lost, depending on the continuity of people in that process. Process knowledge was especially important where 
knowledge creation was an inherent part of the strategic business model, and where it could be inferred, as in the scientific research process.

\subsection{Applied knowledge}

At BRANZ, applied knowledge, in particular evolved, refined and perhaps rare knowledge was regarded as being valuable. BRANZ made clear distinctions between the large volume of data and the aggregation of these elements into knowledge:
"we collect vast amounts of data; we aggregate them into facts and then, in a pretty traditional model, after that, those facts we aggregate into knowledge. But as applied scientists, the real value of that knowledge, valuable knowledge, really comes from the application of that knowledge, where it's highly applicable - and that's knowledge. Because of the wealth of data and facts we have here, that knowledge is not commonly available"

senior manager of scientists, BRANZ

Knowledge was valuable to applied scientists and was a rarer resource than data or information. Knowledge was applied to improving the built environment and adding economic value, reflecting BRANZ's key business objectives. Where knowledge led to an early understanding of phenomenon, this could enhance the industry's ability to improve construction methods. The distinction between proven, deeper knowledge and long-held beliefs was also relevant. Beliefs about products and materials and their properties may form the basis of hypotheses, which were then proven or disproved through scientific processes. An example of this was the organisation's research on materials and construction methods in relation to the weather tightness of buildings.

Some of this rare knowledge is under threat of being lost as individuals leave the organisation. An important example of this was seen in BRANZ's advisory service, which provides information to the building sector and the public. The organisation had a single expert with an encyclopaedic knowledge and extensive experience. This was complemented by a solid foundation and wide span of knowledge of construction, and exposure to a wide range of queries. When queries were received that appeared unusual or new to other staff, the adviser was aware that most of these questions had been asked before, and recalled exactly what the answers were. 


\subsection{Governance knowledge}

\subsubsection{Organisation A}

The concept of governance knowledge encompassed Organisation A's many references to high level processes, management structures and aspects of the broader, formal context within which it is required to operate. Organisation A's managers identified governance knowledge as a distinct type of knowledge — recognising, however, that it overlapped with some aspects of organisational knowledge and the knowledge of relationships and social networks. The managers saw governance knowledge as the knowledge of how to report to government, liaise with the organisation's Ministers, develop legislation, and how the executive team discharged its responsibilities.

The knowledge of people with a "big picture", holistic or governance perspective was described as being valuable knowledge for Organisation A. As well as understanding how the organisation functioned internally, executives needed to see the big picture, and understand how the pieces of the organisation "hung together". Knowledge that enhanced Organisation A's ability to meet its strategic objectives and to report efficiently on its performance was also noted as being valuable. This type of knowledge was not widespread in the organisation but was critical in ensuring that the organisation continued to be managed effectively within a wider political, government and economic framework. The overview nature of this knowledge included aspects such as environmental, economic and political factors and trends nationally and globally.

Governance knowledge included familiarity with processes, such as executive, government and Parliamentary processes, budgeting and internal management processes. Experts with this type of knowledge operated effectively in the context of internal politics, without regarding politics as having negative connotations. Such experts understood the dynamics of the senior management group and its internal relationships. Organisation A's senior management team regarded the retention of governance knowledge as being particularly important, since there would be some senior management departures over the medium term. The organisation must maintain its stability through these changes, and more importantly, needed to embed the idea that organisational change and adaptation was the norm rather than the exception.

For Organisation A, managerial expertise consisted of the knowledge required to operate a business group in accordance with its stated goals and objectives. Therefore, 
valuable knowledge was defined as knowledge that enabled informed and succinct decision-making. However, there was another dimension to managerial knowledge that included a manager's tacit knowledge of relationships at a senior management level. This was regarded as knowledge in action, and may be difficult to transfer to others. It was useful in carrying out some sensitive tasks that were associated with the manager's role; the need for discretion and sensitivity may extend beyond organisational boundaries to matters involving external stakeholders.

\subsubsection{BRANZ}

Operating in a commercial environment, BRANZ had a similar concept which it described as "business knowledge", and this term refers to the knowledge required to operate the organisation as a profitable business. A senior manager explained that, for this organisation, there were many elements of business knowledge, some of which were intangible and were described as falling between the cracks as non-explicit knowledge. He gave examples of business knowledge, such as the expertise to put together a research programme and secure funding; knowledge of which building codes and standards would have the most industry influence and thus warrant greater attention; and the back catalogue of "things we tried that didn't work", so the organisation could avoid wasting time on those approaches again.

In a similar vein, this organisation also valued its knowledge of why specific initiatives were unsuccessful in the past, and understanding the rationale for why its current mode of operation is successful. BRANZ emphasised the importance of maintaining experts' focus on its strategic direction, ensuring that its functions and research directions remain aligned with the outputs that the government wanted to buy through its tendering processes. Maintaining its alignment and linkage to the construction industry and the needs of the public were also important, to ensure that its research and resultant knowledge products met the needs of consumers in the areas of industry training, seminars, technical services, advisory services and publications.

An element of business knowledge involved having a longer term view and an ability to anticipate impending problems. BRANZ recognised that to be proactive, knowledge of how external factors influence the organisation and its business was imperative. Foresight was valuable, due to the lead times for solving problems in the industry. An example of this was the efforts of experts in getting recognition that the phenomenon that became known in New Zealand as leaky building syndrome could become a 
nationwide problem. Once the problem had been recognised, it was important for the organisation to articulate the need for funding organisations to invest in further research to understand more about the problem and identify solutions.

The business knowledge that underpins BRANZ's services is critical and a lower level of expertise and personnel than currently exists would be insufficient to support these services and manage business risk. The specific scientific knowledge required to support BRANZ's business is at risk of being lost partly because of its scarcity, as some scientific domains had only a sole expert and the process of knowledge retention requires planning and time.

\subsubsection{Summary}

Valuable governance knowledge includes knowledge about an organisation's relationships with senior external stakeholders, and a holistic perspective of the organisation and its strategic objectives. Managers' governance knowledge included an understanding of external factors influencing the organisation and its profitability.

\subsection{Organisational summary}

\subsubsection{Organisation A}

Subject matter expertise, tied to the knowledge of individual experts, was identified as being valuable to the organisation. Rare knowledge — described as that which is used less frequently but for important activities, knowledge of exceptions falling outside the scope of systems, and deep technical knowledge, were also valuable and at risk of loss. Scientific and business knowledge formed the basis of Organisation A's advice to government - however, the necessity to access professional networks to achieve its objectives was just as important. Knowledge retention initiatives too often focus on what a person knows rather than who they know (Parise, et al., 2006). However, this organisation, due to its size and structure, benefited from the replication of some relationships and ensured that less experienced staff had access to networks.

In the case of organisational knowledge, having continuity with the past provided a context and some rationale for the current way of working and the current state of the organisation. Such knowledge was also important because this organisation had been the subject of significant structural change over several decades. 
The interdependent nature of its business processes and the preference to take action over focusing on documentation meant that documented knowledge was important. It was also crucial to maintain continuity of experts who were both knowledge and politically aware, through the whole policy development and consultation process. Governance knowledge enabled Organisation A to manage its relationships with its Ministers and government effectively.

\subsubsection{BRANZ}

Scientific and technical expertise develops over decades and there is limited opportunity to reduce the time taken to develop layers of experience over a base qualification. However, when older experts were able to provide mentoring over an appropriate time frame before they retired, this lessened the risk of losing knowledge. Effective social networks were important in ensuring an appropriate scope for research projects and approaching the right sources for funding and support. BRANZ saw the importance of arranging for less experienced researchers to be exposed to experts' international networks. In terms of organisational knowledge, continuity with the past was an important factor in understanding business strategies and decisions. The evolution and development of the organisation's relationships with the industry provided an important context for the current relationships.

The organisation's highest level business process was actually a knowledge cycle, involving knowledge creation through research, followed by the conversion of this research into knowledge products that were provided to the industry. Finally, feedback was received as input to the research activity. For researchers, processes for identifying and locating relevant knowledge and conducting good science were core competencies.

Moreover, some of BRANZ's knowledge was rare, highly applied and marketable. For this organisation, governance knowledge meant aligning research outputs with the purchasing agenda of the government and other purchasers, while at the same time contributing significantly to the industry good — transferring knowledge that was useable and led to improvements in construction practices. 


\section{Chapter 6. The valuable knowledge of older experts}

\subsection{Scope of phase 2 study}

During phase 1 of the study to reveal the organisations' concepts of valuable knowledge, I hoped that one of the organisations would identify a specific instance of impending knowledge loss from older experts, for further study. As phase 1 progressed, the sponsor at BRANZ revealed that there were some older experts in various business units of the organisation, and that within his own business group, there was a specific instance of an older worker who possesses expert knowledge that was worthy of study.

The scope of phase 2 of the study was to gain an understanding of this example of expert knowledge, by observing the actions of the expert and by gathering data from customers and peers who had interactions with his business process.

There were three reasons for studying this situation of potential knowledge loss. First, the expert in question held a unique role in that there was no other person with a comparable depth of knowledge in the same subject domain. This presented an opportunity to observe an expert's processes and behaviour, a topic on which there has been recent research (Blessing \& Anderson, 1996; Didierjean \& Gobet, 2008; Ethell \& McMeniman, 2000; Mata, 2007; Pederson \& Liu, 2003; Ruthsatz, Detterman, Griscom, $\&$ Cirullo, 2008). Second, the situation presented a genuine business problem that needed to be solved as the staff member was likely to retire in the short to medium term - his expertise would be lost without some form of intervention. Last, the organisation was aware of the impending loss and the need to mitigate its effects. Thus, the sponsor's level of commitment meant he would be able to support the research, promote the study and encourage people to participate.

At the time the study findings were being drafted, it became clear that it would be difficult for the identity of BRANZ to be represented anonymously in the thesis, due to several factors. The nature of the knowledge that was under threat of being lost, the uniqueness of the expert and his relationships in the industry, and the details of how the business unit operated, could all easily lead to the identification of the organisation and the role involved. After considering these issues, the organisation concluded that it would be fitting, as a research organisation, to be transparent about its role in the study. 
Situated half an hour from the Wellington CBD is the head office of BRANZ, whose role is to provide independent consultancy, testing and research services to building industry customers and advice to the general public. It is an industry organisation, partly funded from a fee that is levied on new construction in New Zealand, and is a scientific organisation at the forefront of its field, with the capability for further business development. Indeed, some of BRANZ's staff are recognised and consulted as world experts in their scientific domain. In this context, the organisation recognises knowledge as a key asset that must be leveraged to meet the goals of its commercial model.

BRANZ conducts research, testing and consulting in various domains relevant to the building and construction industry. It also conducts appraisals of building products and systems. It has experts in the areas of fire and structural engineering, materials research, the built environment and sustainability, and economics. BRANZ has undergone much structural change in the last 3-4 years, and has also recently completed significant ICT implementation projects.

Access to this site was facilitated through its then Chief Executive, who was cognisant of the workforce issue involving the impending loss of expert knowledge from older workers. The CE recognised the need for the type of action research project proposed, and broached the topic with senior managers, one of whom was confirmed as the project sponsor. The sponsor subsequently identified a few business contexts in which the research project could yield practical benefits.

\subsubsection{Diagnosis stage of action research}

The findings presented in this chapter are the result of analysing data collected during the diagnosis stage of action research at BRANZ. In the course of conducting interviews with several participants, including managers and technical and scientific staff, I noted that themes were emerging about the specific nature of expertise.

The set of interview questions that formed the starting point for the interviews is listed in 5.1.1 (p. 136). The second question I asked at the interviews was:

\section{What types of valuable knowledge might be lost when older experts retire or leave the organisation?}

This question was followed by the third question, which sought participants' views on the extent of the threat of losing such knowledge. A fourth question asked how the loss of knowledge would affect business objectives, responsibilities and outcomes. 
As a cross-check, a fifth and final question was asked:

\section{Where in the organisation does this (at risk) knowledge currently reside?}

Responses to this final question showed that older experts held much valuable knowledge. Such knowledge could exist in their documents or be tacitly held. Tacit knowledge would also include knowing where to find knowledge or who to approach.

The categories identified during data analysis informed these findings, which were also subsequently reconfirmed as I reviewed the data when similar categories and attributes of expertise emerged during the action taking stage of action research. In this way, subsequent action research activities, such as when the technical adviser introduced a knowledge retention intervention, reinforced findings made during the diagnosis stage.

\subsection{The nature of older workers' expertise at BRANZ}

From BRANZ's participation in phase 1, its organisational perspectives of knowledge were identified, as presented in Chapter 5 (p. 136). Building upon those findings, it is also possible to define its concept of older workers' valuable knowledge. First, not all older workers possess valuable knowledge and not all knowledge that is held by older workers is necessarily valuable. Just because an employee is older, relative to others, it does not follow that he or she possesses knowledge that the organisation would need to retain. Likewise, the focus on studying the knowledge of an older expert does not mean that younger workers do not also possess valuable knowledge - they fall outside the scope of the study.

Second, this study involving the value of older workers' expertise is from the perspective of positive psychology and successful aging, which is well represented in the literature (Casher \& Lesser, 2003; Didierjean \& Gobet, 2008; Mata, 2007).

Third, the study found a combination of factors that led to certain older employees being regarded by fellow scientists and by management as experts, and as such, possessing valuable knowledge that needs to be retained by BRANZ.

Finally, a large component of valuable knowledge at BRANZ was thought to be tacit in nature, and apparent only when it was seen to be converted to explicit knowledge in the course of being externalised and shared. For example, more experienced scientists collaborate with younger protégés in the laboratory environment, which represents a 
space for knowledge sharing. In the process of observing and asking an expert, younger scientists gain tacit knowledge and this transfer of knowledge is also enhanced by the closeness of the working relationship.

Therefore, the findings at BRANZ indicate that it is not solely the factor of the knowledge holder's age that determines whether or not his or her knowledge is valuable to the organisation. Rather, there are several factors that, in combination, lead to the conclusion that older experts possess and use their knowledge in a way that is different from the manner in which younger workers operate, recognising that one of the defining characteristics of expertise is that it exists in relation to non-experts who seek and use knowledge. In BRANZ's context, non-experts includes scientists and technicians, managers, staff who interpret, publish and disseminate scientific knowledge, a wide range of industry users, and the public.

The factors that define the nature of older workers' expertise at BRANZ are presented in the following sections. These findings relate to scientific and technical experts.

\subsubsection{Unique combination of excellent skills and vast experience}

At the highest level, BRANZ's business model involves two activities: the conduct of scientific research and the conversion of the research outputs to knowledge products that are disseminated to the construction industry and the general public. BRANZ's reputation depends predominantly upon the quality and credentials of its scientific and technical experts.

Part of the role of such experts is to lead major research projects, which are either funded by the industry or won through competitive tenders issued by funding agencies. Within the organisation, the highest level of seniority is the position of principal scientist, followed by the position of senior scientist. Advanced qualifications and substantial experience are pre-requisites for leadership or a senior role in a major research project. The long learning processes involved and the acquisition of the required level of experience takes decades, therefore someone in such a role has a reputation as an expert and tends to be older.

As some of the major research projects such as those involving weather tightness and household energy use can run for periods of five to ten years, experts have gone down many paths in the course of their research and know the way around their scientific 
domain. As such, experts in this organisation who have completed such projects tend to be older workers, that is, predominantly over 50 years of age:

\begin{abstract}
"It is actually a long thinking process that involves trials and tribulations of doing different things, going down blind alleys as you said, or uncovering a different understanding of the data you require, and taking a different pathway because you've spent that time thinking and mulling it over. It may be that the longer you do that, the better you get at it, and if you've tested yourself as a scientist over 40 years, trying different hypotheses and knowing different ways and means of testing those, then perhaps that is the way it is, that you just can't acquire something overnight."
\end{abstract}

Chief Executive's observation of older experts

The expertise of older staff consists of a unique combination of knowledge, skills and experience. It can be argued that such expertise is unique to older experts in BRANZ's environment. There is also a direct correlation between expertise and seniority, so that principal scientists exhibit a higher level of expertise than senior scientists. As the Chief Executive observed of a principal scientist:

"It's a function of expertise and time, together, that creates such a level of uniqueness, and his recall of what has and hasn't been done before. There's the institutional knowledge type of expertise as well. A lot of that knowledge is tacit, so while he may not be aware that he has it, he'll be able to recall it very quickly ... When we talked to our Canadian equivalent, they said that the stuff that (he) is doing is unique in the world. The way he has managed to put it together the way he has is world class, not seen elsewhere. So if other experts are saying that it's unique and pretty 'out there' then we can't but agree."

Another function of older experts is that with long experience in the organisation and the industry, they are able to leverage knowledge and recognise patterns from the past to solve current problems or plan for the future in a way that younger scientists cannot accomplish without leadership. As well as recalling and applying their knowledge of previous events to the current situation, experts also make links between their current 
activity and events in their episodic memory. A principal scientist commented that in terms of what New Zealand wants to achieve in its investment in science:

"Taking a backwards look at where we've succeeded, I think, would be enormously useful in plotting a course for the future - that's quite a tricky thing to do."

Therefore, recalling and reflecting on past actions equips experts in planning for the future. BRANZ's experts are instrumental in identifying emerging issues that it should start researching to be prepared for when the industry becomes aware of them, so that they lead the field in terms of emerging knowledge that can be applied in the industry. A senior manager involved in developing BRANZ's five year research programme noted the importance of looking ahead:

\footnotetext{
"Part of the research programme planning is that if you know that it's going to take five years to come up with the answer to a question, and that question hasn't been asked yet, then you really need to be moving on it right away."
}

Both the above examples reference experts' interpretive powers and an awareness of the relevance of the outside world, specifically where its interests are likely to lie as an audience for BRANZ's research.

The necessity of anticipating the future was also recognised as part of BRANZ's planning activity. One of the most valuable assets in the organisation was the technical adviser's knowledge of construction in terms of the questions he was asked on a daily basis. Not only was he a knowledge holder but he was able to advise about current trends in the industry and in the public arena, with such trends often being an indicator of where the next major problem might arise.

\subsubsection{Wide networks, long standing relationships - reputations}

As scientific and technical expertise grows, so an expert's networks grow and extend internationally. Relationships are built up over decades and add to an expert's reputation. The description of an expert is attributed by the expert's peers. An individual attracts recognition from the public, the industry, regulatory bodies, and other researchers in the international domain. BRANZ's experts have solid reputations in a range of subject domains such as economics, air quality, weather tightness and fire. 
While experts may document their interactions with other experts and maintain contact details via ICT, much of the knowledge about relationships and networks is personal, tacit and not easily shared, although experts act as connectors within the organisation. A manager of scientific experts observed that the principal scientists often have deeper access to other organisations, beyond knowing individual experts, to having knowledge of organisational structures and groups and their respective domains of expertise, as a result of the knowledge that has been built up over a long time and cannot be replicated:
"The pure research knowledge that walks out of the organisation when people retire is damned annoying but it's actually the complexity of inter-organisational relationships and individual relationships that is more important because, at the end of the day, business is about people, and that's the stuff you lose that's very hard to document."

senior manager of scientific and technical experts

From the point of view of younger scientists, the biggest loss with older experts retiring over the next few years would be the knowledge related to their respective specialty areas in terms of the networks of people and their experience, as well as the actual scientific knowledge content. Younger scientists have not had time to develop their own networks and needed to extend them beyond the contacts they had made in their fields during their time at university. Relationships between organisations are also important and with the retirement of older experts from BRANZ, some knowledge of organisational politics and their development is likely to be lost. The context, history and complexity of inter-organisational relationships are important to developing a good understanding of the industry and stakeholders. These factors are valuable in activities such as collaborating on research and securing funding for projects. Although the structural characteristics of interpersonal networks have been studied, experts' networks are also a rich source of actionable knowledge: that which enables the knowledge seeker to make progress in the shorter term, such as in a project context. At BRANZ, scientific and technical experts derive rich knowledge from their networks, with some relationships being longstanding. A more detailed discussion on the role of actionable knowledge in the BRANZ helpline can be found in Section 8.2.

Another way in which older experts' knowledge is unique is reflected in the reputations of BRANZ's principal and senior scientists. Such reputations are an element of 
BRANZ's identity as a leading research organisation in the building and construction sector - therefore in this environment, reputation equates to superior knowledge:

The knowledge that these (experts) have, is what people see as BRANZ. If you talk to people in the industry about BRANZ, it's about the knowledge that we have, and so if we lose that, we lose who we are, in the industry."

senior manager of a team of scientists

A principal scientist noted the link between reputation and research funding:

"You need to get to the point where you have people with the reputation, with a hundred peer reviewed papers in the literature and the international reputation that goes with it, because that's what you need to attract funding - so you almost don't get off the starting block without that."

The success of the research process itself depends on the reputations and the predominant role that older experts play in fronting bids for funding of substantial projects. An important objective in relationship building is the need for experts to promote their work so it is known to funding agencies. At the highest level, the ability to conduct scientific research depends on attracting funding through successful bidding processes. The ability to be effective in winning funding is a capability that the organisation needs to nurture. Securing funding means that BRANZ is able to employ new researchers and manage their acquisition of skills. This, in turn, makes it possible to conduct science and create new knowledge, the first step of its business process.

Research outputs are converted to knowledge products for dissemination and sale, representing an important part of BRANZ's intellectual property and contributing ongoing revenue. The education programme involves the regular delivery of high quality technical knowledge in a series of courses to professional practitioners, and this relies on the knowledge of experts who are at the top of their respective fields. The nature of the knowledge is often complex, embodied in formal documents and requires practitioners to adapt to change to comply with regulatory requirements. Some parts of the industry tend to be slower to change, or more resistant to change than others, therefore it is important to communicate new requirements clearly and to be able to discuss the justifications for them. 


\subsubsection{The layering of expertise over decades}

The knowledge of how to physically conduct scientific research projects in a specialist domain is developed over the course of a long career. At BRANZ, there is the concept of a scientific or technical qualification, such as a masters degree or doctorate, being a basic qualification upon which researchers build layers of experience and knowledge, resulting in expertise.

Associated with this concept is a similar idea of the expert's written knowledge in the form of publications and other documentation forming the basic knowledge about a subject. Additional, valuable layers of knowledge are then found through locating the expert to access the related undocumented knowledge. Familiarisation with a project typically involves reading through published literature and the senior scientists' reports initially, then if the expert is still in the organisation, speaking to them with that background knowledge.

Older experts play a key role in the learning of younger graduates in the early stages of research, providing mentoring help, often over long periods of time:

"I'm talking about the ... expert, he's probably 8-10 years off retirement and we've employed a PhD student. The new person is working on his own project but definitely being strongly overseen by the expert, and then eventually, hopefully they'll integrate a lot more of their work, so by the time (the expert's) retirement comes, the student will be ready to step up."

scientist and manager

Experience has to be lived through, as it accumulates over an elapsed period of time and cannot be compressed into a significantly shorter duration. Such a process may take decades, to a point where principal scientists have unique knowledge that forms the foundation of BRANZ's ability to conduct scientific research to a high quality. The knowledge is specialised and BRANZ is unlikely to have access to it in the same way, once the experts have left, or to be able to replicate the project if it needed to. A younger scientist with two years' experience in her research domain noted that:

"the frustrating bit is that experience is a duration thing; you can't be exposed to enough things (in a short time) to get a good grasp of all 
the areas that you really need to be the package researcher that can do the project management, the budgeting, proposals and the actual technical research".

The layering of expertise also happens in terms of the technical research. In reviewing the qualifications and backgrounds of older experts, it was found that they would have graduated with a chemistry, physics or engineering degree which was regarded as their base discipline. Subsequently and over several decades, they have developed their knowledge, experience and expertise in specialist areas relevant to the building and construction industry — some examples are weather tightness, air quality, fire, materials and corrosion. Their knowledge becomes progressively deeper and more specialised, developed through a labour-intensive process. An older expert recalled that at the time he studied at university, degrees in building science as such did not yet exist. It was not until he began his career that he moved towards a specialist area relating to building systems, in this case the components that make up a building, and how those components behave in terms of moisture and precipitation.

Another layer of experience and expertise relates to the challenges facing scientists in terms of how research projects are managed. Senior and principal scientists are often also project managers, due to their greater experience and therefore efficiency at this activity. There is a delicate balance among three important factors. First, the process of conducting research often has an unknown and unpredictable time frame although there are expectations involved. Second, the funding allocated for the research and the availability of further funding are also important. Finally, research that yields meaningful findings for the purchasers and the industry is a priority reflected in BRANZ's business model. Therefore, time, cost and quality are as important as the conduct of technical research itself:

“you can't even predict how many questions you're going to have to ask, or what form that solution may take. All you can predict is the amount of time that you've got available to spend on it, maybe 10 hours a day to solve the problem"

senior research manager 


\subsubsection{High levels of efficiency and effectiveness}

Expertise is characterised by efficiency and effectiveness. Older experts can be very efficient, locating research material over decades, whereas a newer or younger person is less likely to know such material exists. However, younger generations may be more proficient with research tools and technology. Experts also possess peripheral knowledge in relation to research domains over several decades. In the course of developing their research career, they may have completed research in several different areas. One example of an expert having referential knowledge is a principal scientist who a manager described as having the ability to find any piece of BRANZ intellectual property that had been lodged in the library over the last 30 years.

Previous research and its associated valuable but undocumented by products are very important at BRANZ and much knowledge of this is unique to older scientists, sometimes due to the development path of their expertise. BRANZ has been in the business of research since 1969 and there are a few people who have been with the organisation since the early days. Part of the knowledge that is lost when older experts retire, is the knowledge of what has gone before:

\section{“We've already struck this a number of times: when I'm doing research on such-and-such, where do I find the answer? 'well, so-in- so was working on that five years ago, or 10 years ago'. It was a by- product of a research paper that was never documented."}

general manager

This leads to the point that the uniqueness of older experts' knowledge is due in part to the breadth of their roles. Their roles have been shaped according to the individual and their particular skills, in such a way that no one else can perform the role in the same way. Thus, effectiveness is evident in the configuration of the role. For example, a manager with a scientific background would manage a team of scientists differently from a manager with a business background. In either case, it is not possible to bridge the gap completely as there is a danger that attempting to achieve this would lead to too many people being required, leading to inefficiency.

The more senior scientists at BRANZ are also able to become familiar with a topic and start work on an assignment more quickly than their junior colleagues. For instance, a principal scientist explained: 


\begin{abstract}
"It's just that I can start and do a project immediately, whereas someone new might have to read and get up to speed over a period of a few years. It actually takes that long in this organisation to get new graduates up to being really useful, it takes years and years."
\end{abstract}

This was confirmed by their manager, who noted that part of the efficiency was due to the expert's experience and research skills. The time and effort that can be saved by including an expert on technical discussions in other areas of the business can be significant. An engineering expert was included in a telephone conference to discuss a complex roof truss design with some staff from a territorial authority as a precursor to the building consents process. In applying his own expertise to the discussion and answering some engineering questions, he also gleaned very valuable knowledge about the increasing complexity in truss designs in a real, practical context. This knowledge enables him to contribute to the review of the related building standard.

As well as efficiency and effectiveness, there is value in the immediacy of expert knowledge. A principal scientist showed confidence in collaborating and influencing groups, which are among the attributes of expertise, as he described how time savings result from using experts in the building codes and standards development processes:
"now I can go into a codes and standards committee and be asked a question about vapour permeability of building wraps and how that relates to moisture management in walls, and I can answer it in 10 minutes. If you've got a new person from BRANZ, well they'd need to come back to BRANZ and do three months of research to find the answer to the question ... you want the expertise right there and then, and that happens all the time in the building industry. There are problems that come at us all the time."

With the BRANZ helpline, it can be argued that only an expert can deliver the service to the required standard of efficiency because of the breadth of knowledge required, as well as the technical precision. The fact that a professional may be on a building site at the time he or she needs to ask a technical question, means that the expert needs to be able to locate and provide a correct and appropriate answer. Moreover, the service specification for the helpline states that it is a short advice enquiry (SAE) service and that calls are limited to 10-15 minutes duration - although longer calls relate to the nature or complexity of the situation. 


\subsubsection{The power of long-term recall}

The findings at BRANZ reinforce that one of the unique factors of older workers' knowledge and expertise is their ability to recall a wide range of knowledge over decades. With the experiences they have lived through, they have powerful memories of individual events and patterns, leading to the identification of industry trends or specific developments signalling the emergence of a technical problem.

An example of complexity involves the way in which experts recalled the factors and developments that led to the identification that there existed a weather tightness problem in the case of buildings constructed to a certain design from the mid-1980s in New Zealand. The experts' recall included factors such as the beliefs of the industry and the public as to how and why claddings were weather tight, changes in the building code and standards allowing the use of untreated timber, and the increasing popularity of monolithic cladding. Coupled with such factors was the growing realisation that the individual failures of materials to keep moisture out of relatively new buildings actually represented a trend. BRANZ responded by establishing a separate area of research into weather tightness, leading to the development of world class research and experts.

Experts' recall is also valuable in the case of the underlying embedded, tacit knowledge. The scientists at BRANZ made a distinction between published and codified knowledge and the type of knowledge they referred to as the by-products of research, meaning the aspects of their research which are not addressed in published reports and papers: processes they used, their rationale for conducting the research the way they have, and the methodologies employed. The general manager of a large number of experts noted:

"When people go on in their career in research, they keep spinning into side areas and developing that. Knowledge not only gets deeper and deeper, but it gets broader and broader as well. So if we lose someone like (a principal scientist), there's a whole lot of peripheral knowledge that he has, blind alleys he's gone down where he's bumped into information and knowledge that's locked away that probably there was no need to document."

Another senior manager described the value in being able to recall the back catalogue of all the things scientists tried that didn't work, and why, and the things that they were successful with, and maybe why they are not doing them now. Experts have in their 
long term memories chunks of information which, when matched with a current set of objects or objects in short-term memory, are triggered by a link and can be recalled. For example, a colleague's question or comment may trigger the memory of a larger, relevant unit of knowledge such as a document or case.

The helpline is an area where the ability to quickly recall events and decisions is valuable - the technical adviser's vast long-term memory was evident in observations of the helpline in action. In describing the technical adviser's speed in accessing his memory while talking to callers, the research sponsor explained that:

"even the most difficult and odd questions, he's often struck before, so he has this encyclopaedic knowledge of where he's been before."

Both the situation where scientific and technical experts share knowledge with less experienced peers including protégés, and the situation where the helpline technical adviser is discussing technical and construction details with callers, much tacit knowledge is made visible. Collaborative activities such as observing and asking questions of an expert, and working in a close professional relationship not only facilitate the transfer of tacit knowledge, but make it useable to the recipient.

\subsubsection{Experts as unique knowledge holders}

Finally, some of BRANZ's experts are unique, in the true sense of the word - as knowledge holders, they are as valuable as the knowledge they possess. Apart from being unique in the organisation or industry, some of the scientists, such as the weather tightness expert, could well be unique in the world, as explained in Section 6.2.1.

BRANZ is not the sole organisation to provide research in the construction industry, but its research outputs serve the industry from which it receives a significant proportion of its revenue. Because of the size and scale of the organisation, its establishment for scientific and technical experts is small in relation to many of New Zealand's other research organisations. For this reason, there may only be one scientific or technical expert in a specialist research topic at any one time. Therefore, one can argue that such an expert's combination of knowledge, skills and experience is unique. Being a sole expert or a scarce knowledge resource also contributes to his or her uniqueness.

A manager of scientific experts warned that certain areas of knowledge are known to be at risk. On the loss of a single expert: 
"If they just left, there are actually some services that we could no longer offer potentially, that we wouldn't have the people, and the risk would be too high (in Science and Engineering) to let a person with lesser skills actually do that job, because they wouldn't know it well enough to solve the problem accurately and come up with the right answer."

There are several scientists immediately below his level of seniority who either have or are developing niche areas of expertise. Their manager noted that in the world of research, scientists want to develop their own specialised sub-domain of expertise, so having a small number of specialised experts becomes systemic. Therefore BRANZ needs to recognise and manage the resultant knowledge impacts, since such knowledge is deep and honed through years of experience. However, principal scientists do have a greater level of expertise, so the effects of losing their knowledge are more pronounced. Organisations also need to retain the knowledge of those experts who have dealt with rare but critical events. In the New Zealand construction context, weather tightness is a critical phenomenon, with the resultant failures as yet not fully resolved. For an engineering expert, another opportunity for acquiring potentially new knowledge arose early in the study:

"when we had the Gisborne earthquake for example just before Christmas (2007), my feeling was that it would be very useful to contact the local authority and try to ascertain whether we would learn anything by going to visit and seeing the aftermath. ... I spoke to (the advisory services manager) and one way or another he put me in touch with someone who works at the Gisborne City Council who proved to be very helpful. We went up there for a day and a half."

The manner in which knowledge has developed in a specific scientific domain in the New Zealand context may be regarded as unique, or at least rare, according to the Chief Executive; thus the expert as knowledge holder could be regarded as being rare:

“Weather tightness, in the way it's eventuated in New Zealand and in the way houses are built here compared to overseas, and our climate patterns, almost makes it a rarity. However, the science underpinning it - what happens to timber when it gets wet? where does water go once it's in a house envelope? what happens to it? - all those things 
are probably known by other scientists all around the world. But (as

to) how those things come together in a New Zealand context, the combination of factors might be that rarity."

Turning to the dissemination of scientific, technical and regulatory knowledge to the outside world, the technical adviser mans a unique service to the industry and the public. While there exist other building related help services, they do not offer deep, technical advice on the range of topics that BRANZ's helpline covers. The vast majority of calls are received from building practitioners - including architects, different types of designers, builders, trades people and sub-contractors, and territorial and other regulatory authorities. The technical adviser brings to the role his significant experience, skills and knowledge, and both BRANZ and its customers regard him as unique because of his specific combination of skills and industry experience.

Although it may be argued that the helpline could be operated by two, lesser skilled, younger people, much knowledge associated with the older expert would be lost, to the extent that the service itself would change substantially to adapt to the change. In the course of recruiting an additional technical adviser during the course of this study, BRANZ appointed another person who would be regarded as an older expert, also with significant experience and skills in the industry - an important factor being the balance between practical experience as a builder and a solid operating knowledge of the code and standards upon which the technical advice dispensed in the helpline is based.

The outcome of the recruitment process raised the question of whether the helpline service, as it is currently configured as a sole position, lends itself predominantly to an adviser with significant skills, and theoretical and practical industry experience implying therefore, that it is most effectively delivered by an older expert. Thus, if such experts were not available in future, the service may need to be reconfigured and delivered by several people with complementary skills and knowledge.

An important observation emerged near the end of the interviews with BRANZ staff, with the realisation that the older experts have first-hand knowledge that younger staff will never possess, and that is that they experienced significant events and problems in the industry as they unfolded. No doubt there will be new challenges, developments and crises, through which a next generation of experts will develop valuable experience. However, the uniqueness of older experts means that while much of their knowledge 
will be retained in the organisation, the immediacy of their experiences and the first hand recall of events will not be replaced.

Finally, the idea of experts serving the industry and growing their knowledge with the industry is captured in a reflection from the Chief Executive:

"it's that depth of expertise through time that is the core differentiator. They've matured their understanding of the industry at the same time that the industry's been maturing its own understanding of things like weather tightness, leaky buildings and air quality... someone coming up and starting afresh has missed out on a lot of that experience"

\subsubsection{Summary}

The study identified a few factors which define the nature of older workers' expertise at BRANZ. The unique combination of skills and experience that takes decades to develop means that these experts are predominantly older workers. It was found that experts commonly began their careers with a formal qualification which the scientific community regards as a basic requirement, upon which is built successive layers of skills, knowledge and experience. Some of that knowledge and experience itself is directly linked with specific events and developments in the New Zealand building industry during an era of technical challenges and discovery in some scientific domains.

As experts develop their skills, they also build professional networks extending through the scientific community and the construction industry, both locally and globally. Longstanding relationships with other experts and organisations involve social or personal dimensions unique to the individual that cannot therefore be replicated by other individuals. Coupled with scientific or technical research over decades is the development of experts' world class professional reputations, in turn enhancing BRANZ's reputation as a credible research institution publishing authoritative advice.

As older people with extensive experience, experts have powerful capabilities of recall, based on their personal knowledge of events, developments and trends. Such recall includes peripheral knowledge, unpublished and undocumented knowledge comprising the by-products of research, and tacit knowledge they do not realise they possess and therefore cannot articulate until a question or problem triggers the memory. Another characteristic of experts is the efficiency and effectiveness that underpins the way they 
carry out their work. They can quickly locate knowledge produced over a long period of time, get up to speed with a project significantly more quickly than younger staff, and can use knowledge gleaned from one activity such as hearing about new designs out in the industry, to applying it in other contexts such as contributing to standards development meetings.

Finally, BRANZ's experts are unique individuals because they may be the only one with specialist knowledge in a field, they may have a combination of skills and experience that is unique to the individual, or they may have lived through a unique set of events or phenomena that are unlikely to be repeated. 


\section{Chapter 7. An older expert in action: the helpline service}

My findings on an older worker's expertise, in the setting of the BRANZ helpline, are set out in this chapter. First, there is a description of the helpline as a business process that answers queries and provides information that callers can use to make decisions or locate relevant agencies (Closs, Johnstone, Zeigler, Newell, \& Parker-Jones, 2004; Cowan \& Haslam, 2008; Ransom et al., 2006; Resnick, Ugaz, Burford, \& Carrigan, 2008). The business process involves the delivery of an advisory service to construction industry practitioners and members of the public.

Second, the actions involved in answering helpline calls are explained, with a description of the six main types of call actions identified during data analysis.

Finally, I explain how the organisation's existing ICT supports these processes and facilitates the sharing of knowledge with its customers.

\subsection{The helpline service}

BRANZ's helpline has been running for more than a decade and is an example of a service that was established for the purposes of providing advice to construction industry practitioners and members of the general public. Industry helpline services provide dual benefits in the form of advice to practitioners, with resultant benefits for their clients. This is reflected in a description of a similar service in the health industry, "the provision of a national help-line service is a cost-effective way of providing a dedicated, expert resource to support healthcare professionals in resolving their dilemmas and promoting good practice" (Cowan \& Haslam, 2008, p. 325). The reason for BRANZ's existence is to invest in research and disseminate knowledge for the good of the industry, and the helpline is a channel for delivering advice in this context.

Photos of the physical layout of the helpline are shown as Figure 7-1 (p. 176) and Figure 7-2 (p. 176). 


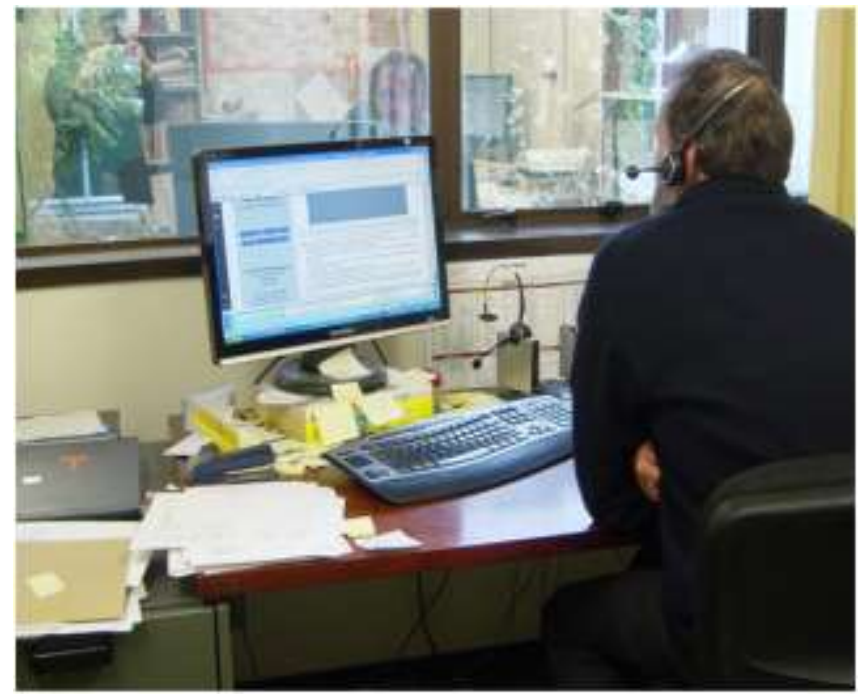

The inquiries that it addresses range from being quick and simple, through to deeply technical and complex. The helpline is unique in the country because it is the only one of its type in the industry, in terms of the depth of technical knowledge required. Moreover, at the time of the study, it was manned largely by a single expert - the technical adviser - applying a significant level of practical building knowledge and experience.

Figure 7-1: The new adviser at work on the helpline

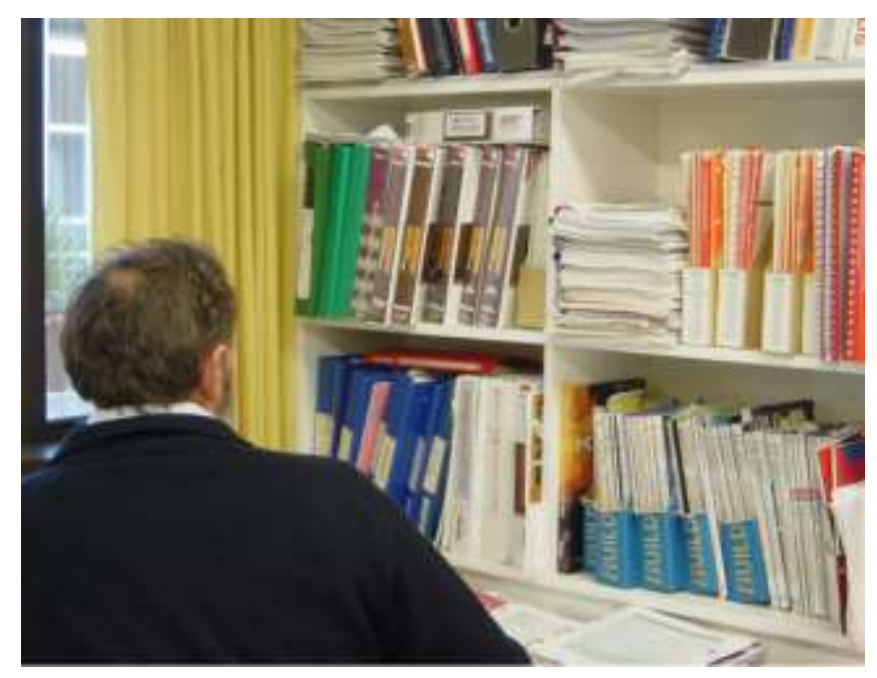

The service runs during business hours and was designed to provide short answers to queries received via telephone. The range of queries extends from simple requests for information or documentation, through to matters such as the discussion of technical or complex aspects of construction, and methods of compliance with regulatory requirements.

\section{Figure 7-2: Sample of helpline resource material}

A weather tightness adviser, in discussing his interactions with the retiring technical adviser noted the value of the adviser's advice on approved documents in the industry:

"In my previous role in building control in local government, there were a lot of (Building) Code interpretations that we would talk through with (the technical adviser), the likes of bracing requirements, all kinds of technical aspects, anything that's related to the interpretation of the Building Code or Acceptable Solutions. There were a whole range of things where we'd tap into (his) vast knowledge of the industry." 
An expert's vast knowledge base and the ability to access it may be significant factors in the nature of expertise (Gobet, 2000). Both the organisation and its customers regard him as unique due to the specific combination of skills and temperament, which are important attributes for providing information and referrals to different types of callers (Ransom, et al., 2006). The same interviewee noted that:

"I'd say that a lot of contact he has with lay people is when they're in a highly stressed situation, like our customers are when they're going through a claim process. They've usually got a very technical problem that they're trying to resolve, that they don't understand ... a lot of what they hear, they don't like, so it's important when you've got a person like (the technical adviser) who can put himself in the homeowner's shoes, ... getting a good understanding of where they stand."

The technical adviser has a set of rare skills and experience and an adaptable manner, as described in Section 6.2.1 (p. 160), and is seen by the service's users as being the face of BRANZ, someone who represents the organisation in a professional manner, is approachable, efficient and able to direct inquiries to other areas of the organisation as appropriate. Therefore the helpline also tends to serve as a provider of sign posts to other business groups, where specialised technical and scientific knowledge resides. The advantages of a single service point for enquiries include the fact that experts who provide advice can stay informed, BRANZ avoids duplicating its advice, and the helpline statistics can be reviewed for an idea of its performance (Kaptein, 2002).

There also exists a reciprocal flow of knowledge, where the caller shares new information with the organisation in contacting with the helpline. Examples of valuable information gleaned in this manner include details of emerging trends in the industry, common problems that members of the public may be experiencing with products, and difficulties and challenges practitioners may face with interpreting or complying with regulatory requirements.

\subsubsection{Action taking stage of action research}

The findings presented in this Chapter are the results of the action taking stage of the action research cycle. Activities in this stage included the planned implementation of a new web site. However, although this was unable to be completed due to timing and 
prioritisation issues, several other interventions were introduced which used ICT for knowledge retention. For example, I suggested that the helpline should move from using tapes to digital recordings which could be archived, and once the software was installed and tested, the technical adviser was able to link the digital recording to the call record whenever the call content needed to be retained. Other examples of interventions include capturing and publishing knowledge on home insulation and using ICT for planning call responses. These interventions were planned and implemented over a number of weeks during the study, were of immediate use, and became embedded into the helpline business processes. I discuss these interventions in detail in Section 7.2 (p. 187), and summarise them in Table 7-2 (p. 189).

I collected data from a wide variety of sources including material from interviews with internal and external stakeholders of the helpline, documentation of the helpline service and the technical adviser's examples of complex and unusual problems that had been solved. Because I was present at each intervention, I was able to observe, take notes of the meetings and collaborations, and start documenting the processes that were being used to retain knowledge. My observations yielded detailed information about the technical adviser's actions in retaining knowledge. I was also given access to the customer relationship management system where call records were kept. My researcher's journal held notes, queries and records of discussions with the technical adviser and his manager. I was able to observe helpline activities, and was invited to meetings the technical adviser organised to collaborate with technical and scientific staff on problem-solving and where interventions were planned, so that knowledge could be retained more effectively. This would make it easier to reuse knowledge in subsequent calls and to provide consistency in giving advice and solving problems.

\subsubsection{Answering helpline calls}

The findings presented in this section and the next, 7.1 .3 (p. 181) relate to the business process of problem diagnosis and resolution. They are separate from my findings in relation to the use of ICT, which are presented in Section 7.2 (p. 187). At the highest level, the activities of the helpline involve answering calls, listening to requests or problems and either providing some suggestions and solutions, or directing the inquirer to an appropriate party if the query falls outside the adviser's knowledge domain. This high level process, together with an indication of some typical detailed actions that occur within each step, are depicted in Figure 7-3 (p. 180). 
All of the data I collected about the process of resolving helpline calls fitted into this high level process. First, the adviser determines whether the inquiry falls within the scope of the service, then asks "discovery questions" (Ransom, et al., 2006, p. 15) to gain an understanding of the issues. Good listening skills are critical from the beginning of the call, to determine the nature of the problem (Emmison \& Danby, 2007) and the subsequent course of action. Second, a decision is made as to the resources that are required to answer the inquiry or solve the problem - references exist in the form of paper or electronic documentation and the knowledge of technical experts may be needed. Third, the advice is formulated and there are a variety of responses depending on the type of inquiry. The adviser may provide assistance in the form of information (e.g. documents and verbal advice), explanations, directions or referral to another person or organisation. Finally, the call is closed after checking that the caller understands what action to take next, and part of closing the call includes updating the knowledge base with any relevant new information and creating a record of the call.

The vast majority of helpline calls are closed at the end of the call, with no residual or follow-up actions required of the technical adviser, unlike other helplines where the call itself forms the initial steps of a longer problem-solving process (Closs, et al., 2004; Emmison \& Danby, 2007; Resnick, et al., 2008). Feedback from customers indicated that the expert is efficient, effective and conscientious in handling calls and resolving queries. These attributes are known to be characteristics of experts, as discussed in Section 6.2.4 (p. 167). Moreover, the resolution of a problem for a caller may result in BRANZ's technical adviser or other experts identifying opportunities for improvements, outside the scope of the call. Examples of such opportunities, which may involve high level or process-related changes, are presented in Section 7.2 (p. 187). 


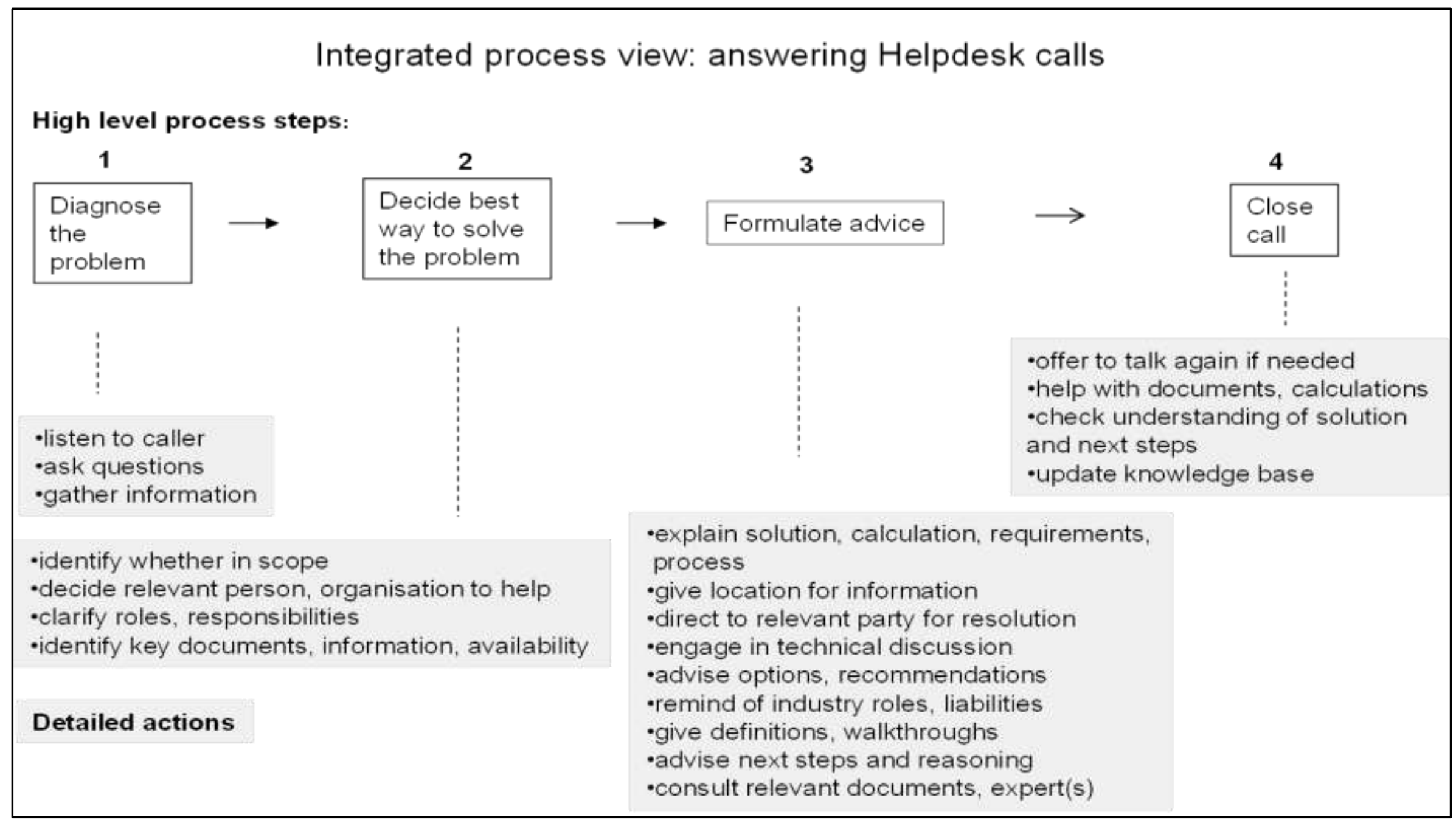

\section{Figure 7-3: High level helpline process}




\subsubsection{Lower level helpline actions}

Information about helpline calls came from several sources. The data sets that were analysed to identify the major call types included the notes I made during observations of calls, the transcribed recordings of information-rich discussion type calls and an extract of 200 records from BRANZ's call management system. These records were of calls received during a month. More detailed information on the data that were collected can be found in this document under Section 3.2: Research methodology.

The helpline process steps depend upon the type of problem or query received. For example, similar steps may be found in a description of KPN Telecom's security and integrity helpdesk (Kaptein, 2002). The first step, called intake, involves discussion, gaining insight into the problem and explaining procedures for resolving it. Secondly, the registration step involves recording call details in the system. The third step of referral results in the appropriate officer being identified to act upon the request or problem (Cowan \& Haslam, 2008). Finally, there is a follow-up step, where the helpdesk worker subsequently phones the caller to confirm that he or she made contact with the appropriate officer. An area of research that analyses the content of conversations yields several studies of opening sequences in helpline calls, revealing that such sequences differ according to the type of help involved. In the case of a national children's helpline where the objective is to empower callers to solve a problem, rather than providing them with solutions, studies of the opening sequences of calls show slight variances in the steps followed (Emmison \& Danby, 2007). The problem diagnosis step in Figure 7-3 (p. 180) includes identifying the problem and distinguishing between this and the reason for the call.

Once I had collected most of the data on the helpline and call handling, I proceeded with a detailed analysis of each call, paying particular attention to what was happening during the call and the process that was taking place to solve the problem. When I had completed the analysis, I tried to determine whether the calls could be grouped into types of actions. I found that BRANZ helpline calls were resolved via six types of actions under the high level helpline process described in Section 7.1.2. The distinct action types are shown in Table 7-1 (p. 182). The detailed call analysis logic diagram for the first action in the above table, seeking and using formal documentation, is depicted in Figure 7-4 (p. 183). The remaining five corresponding diagrams are included as Appendix D. 


\begin{tabular}{|c|c|c|}
\hline & Action type & Process steps identified \\
\hline 1 & $\begin{array}{l}\text { Seeking and using } \\
\text { formal } \\
\text { documentation }\end{array}$ & $\begin{array}{l}\text { - listen to caller, ask questions, understand } \\
\text { nature of the problem } \\
\text { - decide best way to solve the problem } \\
\text { - formulate clear answer; explain solution, } \\
\text { calculation, requirements or process } \\
\text { - explain how to locate authoritative } \\
\text { documentation } \\
\text { - offer any further help if required and close the } \\
\text { call }\end{array}$ \\
\hline 2 & $\begin{array}{l}\text { Managing scope and } \\
\text { signposting }\end{array}$ & $\begin{array}{l}\text { - listen to caller to understand problem } \\
\text { - determine appropriate person or organisation } \\
\text { to assist } \\
\text { - direct caller to appropriate party for } \\
\text { resolution }\end{array}$ \\
\hline 3 & $\begin{array}{l}\text { Providing detailed } \\
\text { technical and } \\
\text { practical assistance }\end{array}$ & $\begin{array}{l}\text { - determine caller's background and level of } \\
\text { - } \text { discuss / address range of technical questions } \\
\text { - } \text { advise alternatives and any recommendations } \\
\text { - reiterate industry roles and responsibilities } \\
\text { - direct caller to any relevant information } \\
\text { sources }\end{array}$ \\
\hline 4 & $\begin{array}{l}\text { Providing technical } \\
\text { assistance with } \\
\text { documents and } \\
\text { requirements }\end{array}$ & $\begin{array}{l}\text { - set scope for providing factual information } \\
\text { and advice } \\
\text { - identify relevant documents, relationships and } \\
\text { availability } \\
\text { - provide technical information, walkthroughs, } \\
\text { definitions and processes } \\
\text { - provide signposting and offer subsequent } \\
\text { advice if required }\end{array}$ \\
\hline 5 & $\begin{array}{l}\text { Advising on } \\
\text { compliance, } \\
\text { responsibility and } \\
\text { reliability }\end{array}$ & $\begin{array}{l}\text { - listen to caller, gather information and } \\
\text { understand the parties involved } \\
\text { - } \text { pinpoint source(s) of the problem } \\
\text { - clarify roles, responsibilities and liabilities } \\
\text { - advise appropriate actions and explain } \\
\text { reasoning }\end{array}$ \\
\hline 6 & $\begin{array}{l}\text { Remedying pre- } \\
\text { existing faults and } \\
\text { failures }\end{array}$ & $\begin{array}{l}\text { - listen to and question the caller to understand } \\
\text { the problem } \\
\text { diagnose the fault or failure and identify } \\
\text { possible causes } \\
\text { consult appropriate sections of Code or } \\
\text { Standard for remedial action, consulting } \\
\text { experts if required } \\
\text { - advise actions for remedying the fault or } \\
\text { failure }\end{array}$ \\
\hline
\end{tabular}

Table 7-1: Lower level helpline actions and process steps. 


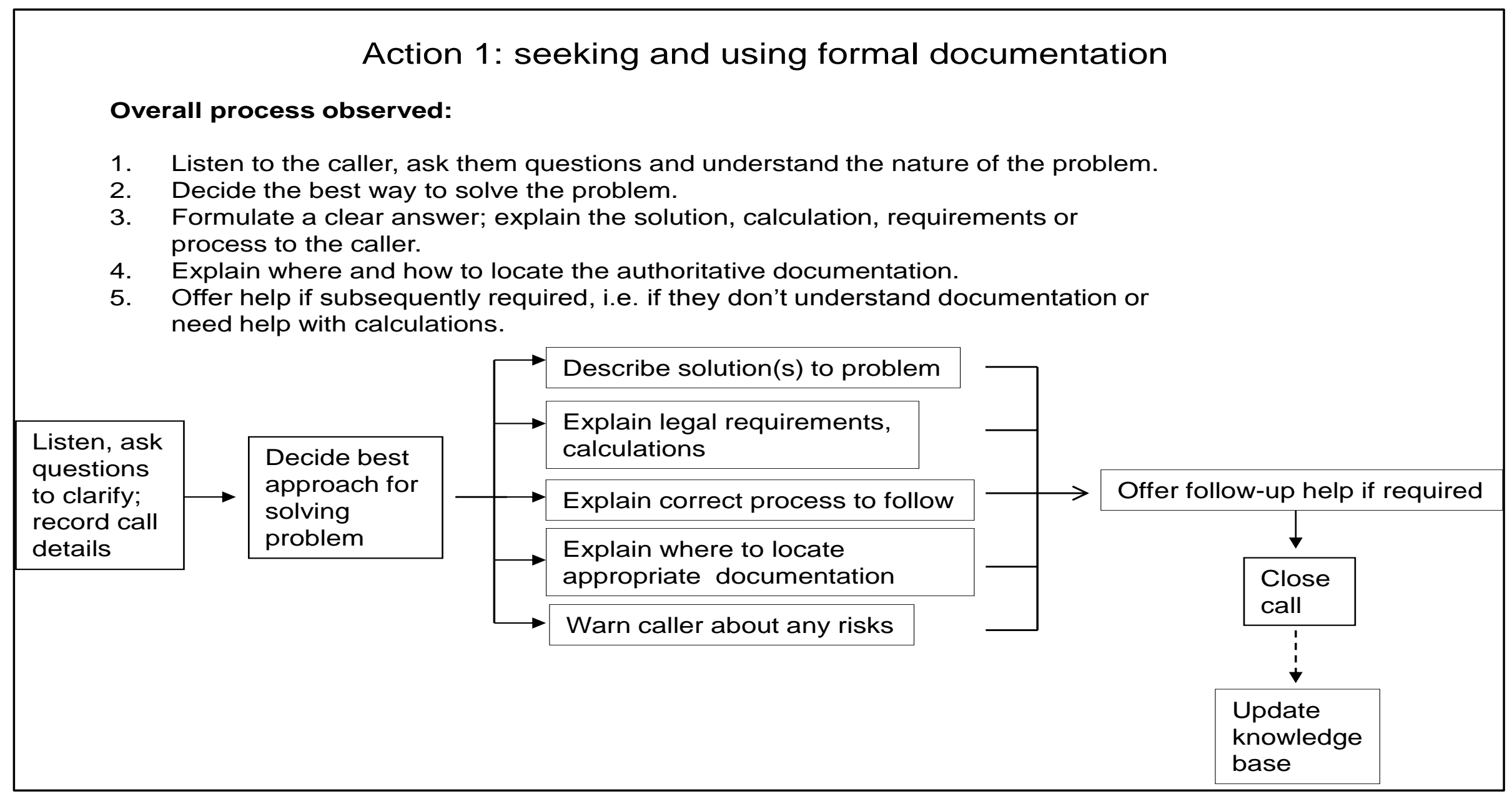

Figure 7-4: Call analysis logic diagram: seeking and using formal documentation 


\subsubsection{Existing ICT support for helpline calls}

Information and communication technologies are employed in several ways in the course of operating the helpline as a business function and the technical adviser uses and relies upon these resources on a daily basis. The main technologies supporting the helpline are the call management system, electronic mail, voice recording, an intranet, web sites and network directories.

Call management system. Call records are created and maintained in the call management system, which includes a function for querying and producing reports on call statistics. The call management software exists as a part of the organisation's customer management software. The adviser creates a record for each call before, during or after the call takes place - the record may be accessed and updated during the call and closed once the call has been completed. The call management software also includes functionality for workflow monitoring, so that inquiries can be sent to the technical expert for action where appropriate and the status of the inquiry can be tracked (Arant-Kaspar, Carter, Desai, Byrd, \& Hahn, 2007). In terms of managing information about the helpline business process, the call management system is one of the central ICT support systems, having been developed to replace a paper-based forms system. Its implementation has resulted in significant operational efficiencies, as is often the case (Stonehouse, Pemberton, \& Barber, 2001). As discussed in Sections 7.2.6 and 7.2.7, some later efficiencies from the software are unintended and innovative in nature. Where callers had left a message indicating the nature of their inquiry, the call record was used innovatively for call planning and preparation, rather than recording the details of calls after the event, as intended.

Electronic mail. There are two ways in which electronic mail (email) is used in the helpline process. First, queries are received predominantly by telephone, however, when the adviser is away from the helpline, a digital recording of a caller's message may be attached to an email and forwarded through the email system. Second, the adviser makes extensive use of email to collaborate with technical experts within the organisation and the industry to gather information in answer to queries, or to identify the appropriate knowledgeable expert to provide an answer.

Voice recording. At the time of the study, calls were being recorded on micro-cassette audio tapes, with the tape set being re-used (taped over) every few weeks. Although this may be considered to be out-dated technology, its replacement had not been considered 
due to the focus on high call activity and the fact that recordings were seldom retrieved. Thus, unless a call needed to be transcribed for a particular reason for example being a controversial topic or being of interest to others, it would not be retained as a permanent record. Section 7.2.7 describes the improvements that were subsequently made with regard to this technology.

Intranet. The organisation's intranet is a major repository of information, providing both the knowledge content for directly answering inquiries and solving problems, and access to directories for locating experts and resources. An example of a directory is the staff database listing expertise-related information so that the adviser can locate individuals with different levels and types of expertise within a specific scientific or technical area.

Web sites. In the helpline business process, web sites are an important source of information and the adviser often refers to the organisation's own web site as well as those of other organisations in the construction industry and central or local government sectors.

Network directories. Much useful information is stored on BRANZ's own IT network within work group related directories. Documents may exist as stable information sources, or as work in progress. For example, a document may be drafted to capture aspects of an ongoing discussion topic such as home insulation, and be useful to access as a discussion evolves.

The use of these supporting technologies varies, with an application such as call management being used systematically in each call, while others may be used intermittently at various stages of a call, or not at all. The use of these technologies depends on the nature of each call in terms of factors such as the complexity or uniqueness of the query. An example of how ICT support helpline activities in relation to the high level call answering process depicted in Figure 7-3 (p. 180) is shown in Figure 7-5 (p. 186). 


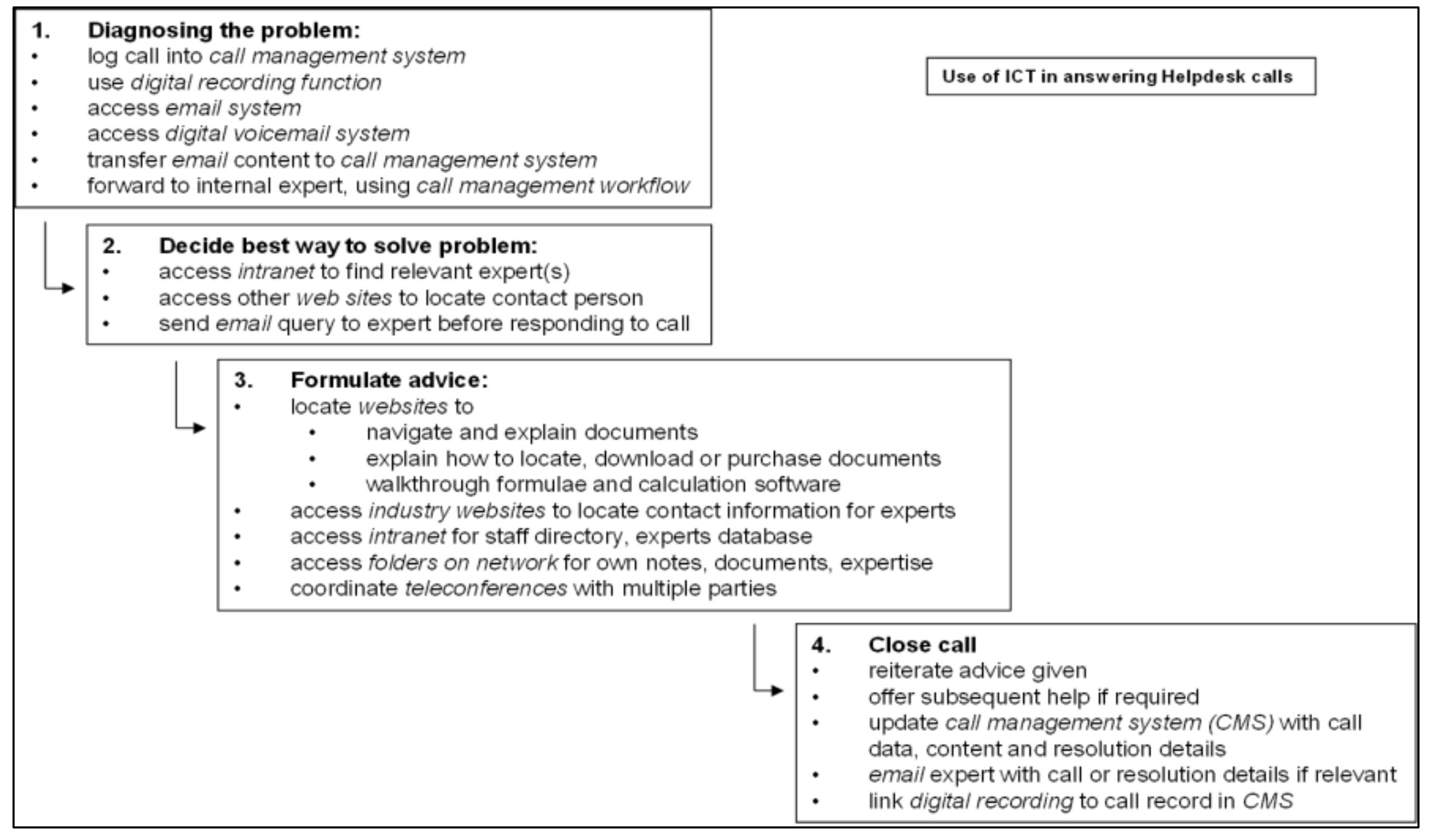

Figure 7-5: Use of ICT in answering helpline calls 


\subsection{Retaining knowledge through the use of ICT}

This section describes how ICT has a role in the helpline function in retaining knowledge, by taking some examples that were identified in the course of observing the technical adviser in action. These examples each represent an instance of a typical pattern where the adviser is using ICT first to access stored knowledge that already exists in the organisation; second, to refresh or extend existing knowledge in the organisation; and third to capture and retain completely new knowledge gleaned from the external environment through the exchange with callers.

Each example demonstrates how knowledge is captured and retained, often for further development, to improve the existing helpline business process, or for subsequent dissemination or inclusion in a consultative process. Such subsequent activities will occur outside the scope of the helpline activity and beyond the scope and time frame of the study. A brief description of the examples is summarised in Table 7-2 (p. 189). In each case, I found that the technical adviser adopted various roles in the retention of knowledge. As knowledge creator, he identified and captured knowledge that was new to the organisation. He facilitated the use of knowledge in other business processes such as updating standards, and grouped related knowledge so it could be more easily retrieved for future use. In a knowledge dissemination role, the technical adviser ensured that new knowledge was shared with a wider audience and was accessible during a telephone conversation with a caller seeking help. The knowledge captured and shared during the call was subsequently written up as an article for publication. In the form of a journal article, it would remain available to other staff and eventually be archived. In the knowledge co-ordination role, the technical adviser liaised with experts to collate and organise knowledge in a more useable form in the business process. A summary of how ICT was used to retain knowledge in each example is shown in Figure 7-12 (p. 208). 


\begin{tabular}{|c|c|c|c|c|}
\hline & $\begin{array}{l}\text { Example or } \\
\text { observation } \\
\text { of } \\
\text { knowledge } \\
\text { retention }\end{array}$ & $\begin{array}{l}\text { Description and purpose of } \\
\text { knowledge retention }\end{array}$ & $\begin{array}{l}\text { Role of technical adviser } \\
\text { identified in study }\end{array}$ & Use of ICT in retaining knowledge \\
\hline 1 & $\begin{array}{l}\text { Stop ends to } \\
\text { window head } \\
\text { flashings }\end{array}$ & $\begin{array}{l}\text { Capturing new, innovative } \\
\text { knowledge on an alternative } \\
\text { method of window cavity } \\
\text { preparation }\end{array}$ & $\begin{array}{l}\text { Knowledge creator in the } \\
\text { sense that he identified } \\
\text { knowledge that was new to } \\
\text { BRANZ }\end{array}$ & $\begin{array}{l}\text { - drawings provided by caller are } \\
\text { retained in a publications database } \\
\text { - call record created } \\
\text { - future intention to publish article } \\
\text { electronically }\end{array}$ \\
\hline 2 & $\begin{array}{l}\text { Ensuring } \\
\text { compliance of } \\
\text { architectural } \\
\text { roof design }\end{array}$ & $\begin{array}{l}\text { Knowledge facilitation: capturing } \\
\text { and retaining knowledge about a } \\
\text { current technique as input to a } \\
\text { future revision of a building } \\
\text { standard }\end{array}$ & $\begin{array}{l}\text { Knowledge facilitator in } \\
\text { ensuring that knowledge was } \\
\text { provided for use in an } \\
\text { important industry process }\end{array}$ & $\begin{array}{l}\text { - drawings retained in repository for } \\
\text { standards-related information } \\
\text { - } \quad \text { subsequent inclusion in revised } \\
\text { standard } \\
\text { - details of caller noted in call record for } \\
\text { future liaison }\end{array}$ \\
\hline 3 & $\begin{array}{l}\text { Capturing and } \\
\text { publishing } \mathrm{H} 1 \\
\text { (insulation) } \\
\text { knowledge }\end{array}$ & $\begin{array}{l}\text { Integrating and widely } \\
\text { disseminating new knowledge } \\
\text { about requirements and } \\
\text { compliance in relation to a newly } \\
\text { implemented section of the } \\
\text { Building Code }\end{array}$ & $\begin{array}{l}\text { Knowledge disseminator in } \\
\text { making new knowledge } \\
\text { widely available. Facilitator } \\
\text { of business process } \\
\text { improvement, so callers can } \\
\text { be informed before using the } \\
\text { helpline }\end{array}$ & $\begin{array}{l}\text { supporting information on } \mathrm{H} 1 \text {, } \\
\text { including calculations, is formalised } \\
\text { and published on the web site and url } \\
\text { publicised } \\
\text { subsequently, web pages updated with } \\
\text { additional information } \\
\text { provision of calculation software on } \\
\text { web site }\end{array}$ \\
\hline 4 & $\begin{array}{l}\text { Formalising } \\
\text { new knowledge } \\
\text { on insulation }\end{array}$ & $\begin{array}{l}\text { Retaining new knowledge in a } \\
\text { replicable format so members of } \\
\text { the public can make informed } \\
\text { decisions on insulation product } \\
\text { types }\end{array}$ & $\begin{array}{l}\text { Knowledge co-ordinator in } \\
\text { liaising with technical staff to } \\
\text { formulate document to ensure } \\
\text { consistency of advice }\end{array}$ & $\begin{array}{l}\text { checklist is drafted, formalised and } \\
\text { reviewed before being retained in the } \\
\text { helpline repository } \\
\text { - refer to checklist in future calls }\end{array}$ \\
\hline
\end{tabular}




\begin{tabular}{|l|l|l|l|l|}
\hline & $\begin{array}{l}\text { Example or } \\
\text { observation } \\
\text { of } \\
\text { knowledge } \\
\text { retention }\end{array}$ & $\begin{array}{l}\text { Description and purpose of } \\
\text { knowledge retention }\end{array}$ & $\begin{array}{l}\text { Role of technical adviser } \\
\text { identified in study }\end{array}$ & Use of ICT in retaining knowledge \\
\hline 5 & Call planning & $\begin{array}{l}\text { Use software innovatively to } \\
\text { organise a call, ensure caller gets } \\
\text { full information and capture } \\
\text { specific advice given }\end{array}$ & $\begin{array}{l}\text { Knowledge co-ordinator in } \\
\text { organising knowledge to } \\
\text { make the call process more } \\
\text { efficient }\end{array}$ & $\begin{array}{l}\text { - } \\
\text { call management system updated with } \\
\text { call details } \\
\text { add topics for discussion during call } \\
\text { use call record including topics to } \\
\text { complete call }\end{array}$ \\
\hline 6 & $\begin{array}{l}\text { Linking digital } \\
\text { recordings to } \\
\text { call record }\end{array}$ & $\begin{array}{l}\text { Group related information so that } \\
\text { it is easily retrieved for future } \\
\text { reference, and enable knowledge } \\
\text { sharing with experts }\end{array}$ & $\begin{array}{l}\text { Knowledge facilitator and } \\
\text { dissemination in providing } \\
\text { knowledge in a useable } \\
\text { format to others }\end{array}$ & $\begin{array}{l}\text { - } \\
\text { digital recording } \\
\text { open call record and link digital } \\
\text { recording } \\
\text { intention to include flag on call } \\
\text { summary screen to indicate presence } \\
\text { of digital recording }\end{array}$ \\
\hline
\end{tabular}

Table 7-2: Examples of using ICT for knowledge retention on the helpline 


\subsubsection{Capturing and retaining new knowledge on innovative practice}

The helpline service is not solely a provider of advice. This section describes how knowledge is created in the course of answering inquiries or solving problems. The significance of this example of knowledge retention lies in the fact that the older expert had the knowledge and experience to recognise instances of innovative practice that a younger, less experienced person may not have. The older expert also recognised the need to retain this knowledge. In the following example, knowledge is created during a discussion clarifying a caller's interpretation of a photograph.

BRANZ is a practice-focused organisation. Its high level objective is to carry out research that informs practice and has practical application - the use of research outputs thus leads to a better built environment. The organisation's role includes educating and informing members of the construction industry. As part of this activity, the organisation identifies technical topics of interest and publishes articles with the purpose of generating discussion and promoting knowledge sharing on such topics.

This first example of knowledge retention involves the initial step of knowledge creation (Riege \& Zulpo, 2007; Roth, 2003) that results from recognising that there is an innovative practice in use in the construction industry. In this case, BRANZ had published an article and photographs on the methods of detailing of stop ends to window head flashings to ensure weather tightness. In the opinion of the caller and the technical adviser, the practice is credible and more effective that some other methods.

The helpline received a call from a builder to discuss the article and check his understanding. The builder described a different method he had recently used in several residential buildings, and in the course of the call, both agreed that the new method had great merit in terms of the weather tightness of the design. The adviser was able to call upon his own extensive construction experience to make this judgement, even though he had not encountered the described implementation method before. The adviser recognised that this new method had validity and value as knowledge to be shared more widely in the industry. This was partly due to the fact that the design had gained approval from the local authority as complying with the Building Code:

"We've had it accepted, the funny thing is we've had it looked at by a couple of building inspectors and they say well, this is not normally what happens. But I say, it's on our plan, been approved by someone 
else, and you know it works. Then I've had another building inspector turn up - we're now building another 3 houses on the same site as the original 3 - and I've said before we start, I'm going to tell you how we're going to do these, ... Anyway, I'm happy to provide (the design), it's an easy detail to show; there's no stop end, it's neat and tidy, you don't have to end up seeing a lot of your head flashings if you get your weatherboards at exactly the right height."

builder explaining details of an innovative design adopted

In summary, what was observed was a process of knowledge construction (Lu \& Jeng, 2006), with the negotiation of meaning between two people with detailed construction knowledge. Also, in observing this call, I noted that the adviser established rapport with the caller through a confirmatory process, recognising him as a fellow practitioner through his knowledge and contacts, and the ability to identify with the callers' experiences with building inspectors. The technical adviser's knowledge of people in different parts of the industry and on occasion of particular building sites is an example of the strength of his networks, as discussed in Section 6.2.2 (p. 162).

The end result was that the adviser arranged for the design to be provided to BRANZ, and for an example to be photographed, with this information being retained in the publications area of the organisation's network, which serves as the repository for writers and publishing, to form content for an article in a subsequent edition. In summary, the new knowledge from a credible source was worthy of being retained and disseminated more widely. Figure 7-6 (p. 192) shows the process of capturing and sharing new knowledge, including the steps where the use of ICT is involved. 


\section{Using ICT for knowledge retention: (1) stop ends to window head flashings}

\section{Process steps:}

1

Builder queries
published
designs, photos
of window cavity
construction

2

$\longrightarrow$\begin{tabular}{l|} 
Helpdesk operator \\
and caller discuss \\
workability of \\
method under \\
some conditions
\end{tabular}

3

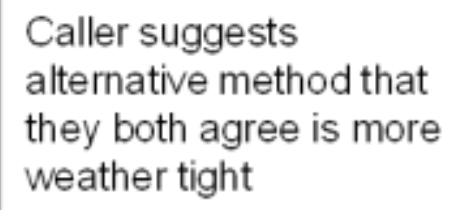

Subsequent

article is

published
4

Caller agrees to get designer to provide his design drawings for future edition of publication

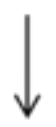

5

Drawings are retained in publications knowledge base

Figure 7-6: Capturing and sharing new knowledge 


\subsubsection{Retaining and maintaining knowledge of current techniques}

BRANZ values opportunities to keep up to date with the industry and refresh its knowledge about evolving practices and trends. This section outlines how a group discussion about the extent to which a proposed design would comply with the Building Code resulted in BRANZ acquiring new knowledge about the increasing complexity roof designs being developed. The example illustrates how complex inquiries can lead to both parties gaining new knowledge.

A large component of BRANZ's activities involves scientific and technical research. The organisation recognises that while research informs practice, research activities also benefit from knowledge of actual construction methods currently employed by practitioners. This is one of the reasons for the strong link between the organisation and its community, in this case a wide range of industry practitioners including architects, designers, engineers and builders. BRANZ's own knowledge stocks need to be kept current and staff must maintain their awareness of techniques currently in use in the industry. BRANZ is also one of a group of entities that are involved as major participants in reviewing and updating the Building Code and construction related Standards. Such regulatory mechanisms have a review and update cycle to ensure that structures are built in a way that is of appropriate quality and are fit for purpose. As input to this process, reviewers also need to be aware of factors such as trends and methods in the areas of design, engineering and construction. Supplementing research knowledge with practical knowledge about the methods in use is another example of how experts build layers of expertise over time, as discussed in Section 6.2.3 (p. 165).

The helpline, therefore, is a conduit for information flowing into BRANZ and available to its experts on such methods as they emerge, evolve or are being taken up in the wider industry. Moreover, the technical adviser in this sense may be described as a knowledge facilitator (Stonehouse, et al., 2001; Thornton \& McCracken, 2005), supporting knowledge creation and retention. The latter authors' study of knowledge facilitation in a scientific environment describes some knowledge specialist roles as part of a knowledge facilitation framework. In the scope of such roles are activities to facilitate learning by helping clients search for information, supporting an organisational learning framework and facilitating knowledge sharing. This literature mentions aspects of the technical adviser's role that were observed, including analysing documents, sharing 
knowledge of key people and industry groups, and helping people to network and learn when they approach the helpline.

\subsubsection{Complex inquiries}

Although the helpline service is defined as providing answers or solutions to short inquiries, some inquiries are complex. This is particularly so at the time of major regulatory change as at the time of the on-site data collection phase of the study. In the observation of this second example, a representative from a territorial authority had called about what he saw as a complex roof design in a multiple tenancy construction. He sent the adviser preliminary architectural drawings he had received that would eventually form part of a building consent application. BRANZ's engineering experts studied these before the technical adviser facilitated a teleconference for the experts and several staff from the authority. When there are complex and unusual factors, involving third parties in answering a call promotes efficient communication as well as efficiency (Ransom, et al., 2006). A key point was the engineer's comment at the start of the meeting that the plan was a prime example of how designs are becoming more complex. Increasing complexity may not be evident until a real example surfaces, for example when a practitioner inquires. He noted that parties to the review and update of the Code and Standards must be made aware of the increasing complexity and that the regulatory mechanisms must be cognisant of these types of constructions.

This example also demonstrates the bi-directional flow of information. In resolving callers' problems, the technical adviser also gleans interesting, useful relevant and therefore valuable knowledge on industry practices and attitudes. Moreover, the knowledge is re-used and shared in a few ways, not just retained solely for use in the organisation. In this case, BRANZ requested a copy of the upcoming roof truss plans, for retention in the area of its network that serves as the repository of standards-related material. Knowledge about architectural and engineering complexity, as demonstrated in this design, would be relevant to the Code and Standards review process. This is an example of organisational learning which is also extended to the industry. The adviser, as knowledge facilitator, may be seen as "the key player on knowledge creation and dissemination ... and connects many different players in a planned, step-wise knowledge-facilitating process, focusing on the horizontal sharing of knowledge ..." (Roth, 2003, p. 33). Figure 7-7 (p. 195) depicts the process of maintaining knowledge of current techniques and the steps where ICT is used at present. 


\section{Using ICT for knowledge retention: (2) compliance of architectural roof design}

\section{Process steps:}

1

Territorial authority queries a complex truss design's

compliance with NZS

3604 , and faxes

drawings for discussion
2

$\longrightarrow \begin{aligned} & \text { Helpdesk operator co- } \\ & \text { ordinates audio } \\ & \text { conference with building } \\ & \text { inspector, consents staff } \\ & \text { and engineer (internal } \\ & \text { expert) }\end{aligned}$

3

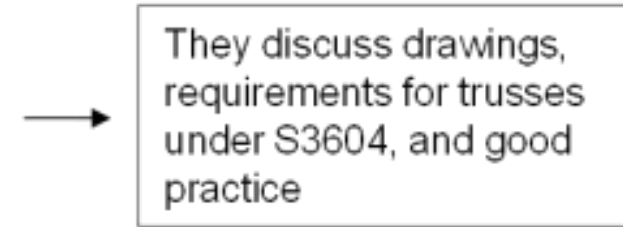

6
4

Confirm need for revision of $\$ 3604$ to recognise techniques in use today - engineer requests copy of truss plans when ready

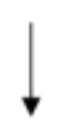

5

Org $B$ retains drawings in repository for standards-related information

Figure 7-7: Maintaining knowledge of current techniques 


\subsubsection{Integrating evolving knowledge for dissemination}

This section describes the process of absorbing and integrating new information in a short time so that it can be disseminated to the industry. This consisted of a learning process and an improvement in the overall business process.

The nature of standards development and implementation is such that although there is wide consultation as part of the process, the industry in general experiences a learning curve upon the introduction of such regulatory changes. The helpline experiences an increase in requests for assistance - explanations, interpretation of new clauses and requirements, and practical advice on how to calculate, design and gain consent for construction projects. Accompanying the introduction of new rules is the need to build understanding in terms of helpline knowledge. In this example, the changes relate to Section $\mathrm{H} 1$ of the Building Code, which addresses the topic of insulation. The changes are regarded as complex, with varying dates of introduction on climate zones, and several calculation methods dependent on a range of variables.

\section{The learning process}

First, in the background, learning occurs at a personal level as the adviser studies the new rules in detail, in a knowledge building exercise that enables him to gain a sufficiently reliable level of knowledge to assist callers. Part of the learning process includes cross-referencing the new requirements with existing related documentation and taking notes to assist his understanding. This process can take several months, but the new knowledge needs to be used while helpline calls about the changes are taken:

\footnotetext{
"All through the industry it's the same when people have a problem in that they want an immediate answer and this is what the helpline does well. That's the way the industry works, especially when people are on building sites. So the day-to-day issues are important and the helpline serves as a mechanism for dealing with such queries efficiently."
}

construction industry official

These comments illustrate that the immediacy of a telephone conversation is preferable to accessing information from a web site, as the caller can discuss such new knowledge, focus on specific aspects and confirm their understanding, rather than being left to make their own interpretation (Cowan \& Haslam, 2008). 
Second, as the adviser explains changes and walks through examples, documents and calculations with callers, learning is reinforced through these clarification actions which are iterative in nature. In the course of discussion, further knowledge developed that is in fact new to the caller and the adviser. This process bridges the gap between theoretically understanding a new rule and being able to use it in a practical sense, for example through explaining a calculation to someone with no understanding of its mechanics or purpose.

Last, part of evolving new knowledge involves dealing with questions that require some effort to answer, as understanding is still evolving, for example in the area of complex calculations. Thus, there were cases where the adviser needed to refer to an expert before continuing with the helpline call. In one of these cases, it was observed that in querying a calculation with an expert, the adviser identified an error in the formula which was quickly corrected.

As knowledge evolves and is re-used at the same time, it may need to be standardised for ease of reference for a wider audience. In this case, the helpline received numerous inquiries about the changes, with the high volume of calls and the increasing time taken to answer calls causing concern. The major concern was the need to maintain overall service levels of the helpline, while allowing for the adviser to continue the learning process and to ensure accuracy of the advice given. It became clear that information needed to be available to callers in a standard form that they could easily access. The insulation experts produced an information sheet which the helpline used as a reference document, alongside the adviser's notes and marked up copies of the formal documents - the Code and relevant Standard - and his own notes. The information sheet was also published to the organisation's web site as quickly as possible, with the url being widely publicised in seminars and publications.

\section{Process improvement}

Publication of the changes to the web site was the result of two factors. Initially, from his experience, the technical adviser noted that the increasing numbers of calls, the complexity of some of them, and his time and effort required to answer them effectively was unsustainable. Secondly, by accessing statistics from the call management system, he was able to quantify his concerns and the need to take some additional action for knowledge dissemination. This may be described as an example of the "conversion of technology-generated information into knowledge" (Stonehouse, et al., 2001, p. 116), 
to disseminate important new knowledge via a mass communication channel, supplementing the traditional one-to-one helpline process.

Callers with inquiries about insulation were asked to go to the web site and locate the information sheet, so that there would be a common basis from which to start a conversation. Once they had done this, the discussion proceeded more smoothly due to both the caller and the adviser having the same information in front of them. Improvements were made to the information on the web site after it had been in use for several weeks. Publishing these changes to the web site enabled callers to access and keep a copy of definitive written information and lessened the probability of misunderstanding complex material, as well as reducing workload, and in many cases call duration, at the helpline. Publishing definitive information to the web site also helped in closing the gap in understanding that is said to be an inhibiting factor in the transfer of knowledge (Cohen \& Levinthal, 1990). Better still, if callers had read the web content in advance their inquiry, this gave them some prior knowledge upon which they could build further understanding (Lane \& Lubatkin, 1998).

The steps that were observed in the process of integrating evolving knowledge for dissemination are depicted in Figure 7-8 (p. 199). 


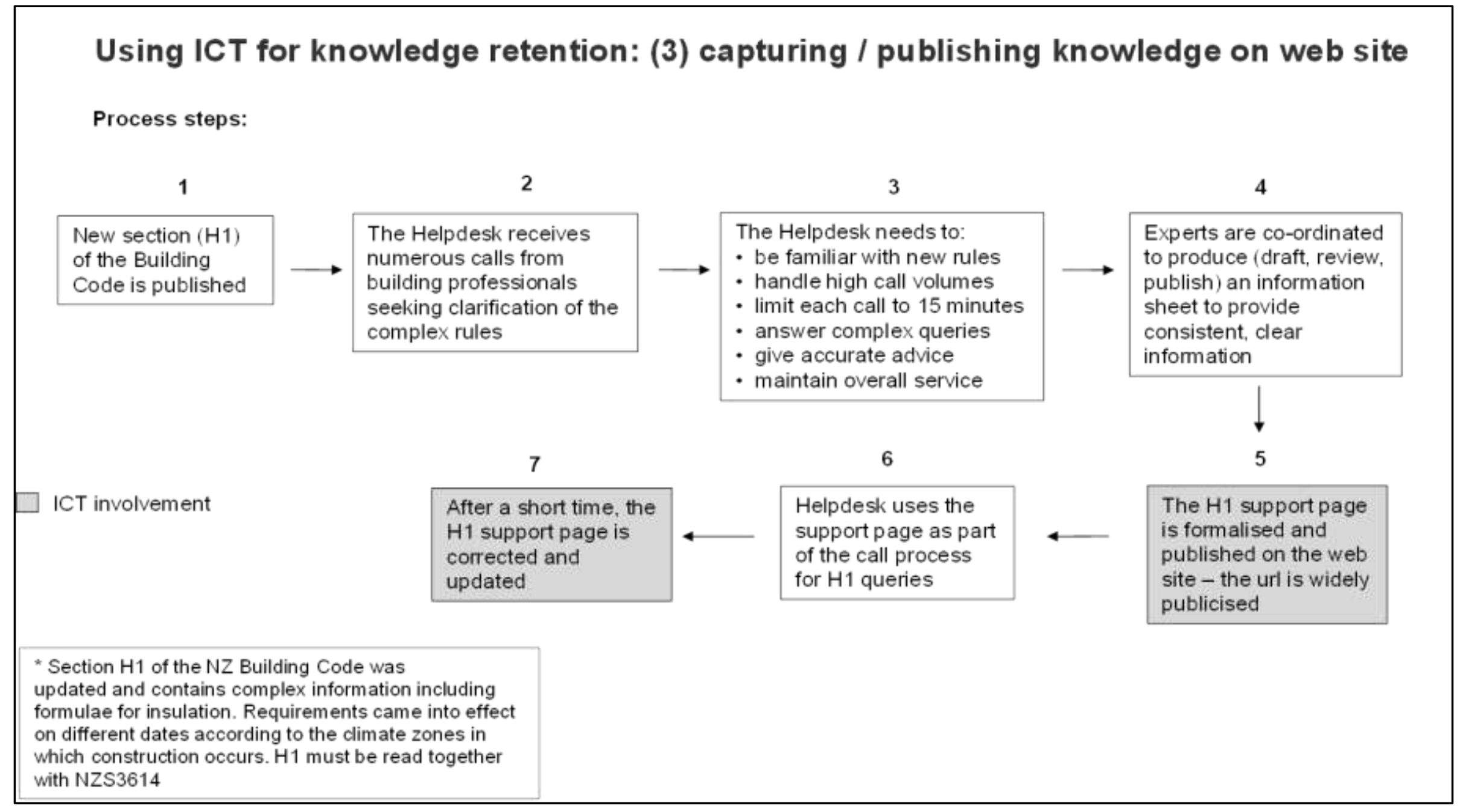

Figure 7-8: Capturing and integrating evolving knowledge 


\subsubsection{Formalising knowledge for replication}

Consumer concerns are often brought to the helpline, for example where callers want to buy certain building products, but do not understand how they perform. The following example shows how the technical adviser used ICT to retain knowledge so he could address consumer concerns in a consistent manner. BRANZ is not authorised to make recommendations on named products and there are risks and liabilities in exceeding this scope. The adviser noted that the number of inquiries about an advertised product type was increasing quickly. However, little was known about its long-term performance. The product was being widely marketed, home owners wanted guidance on whether they should use it, and it was important to provide correct information consistently, without crossing the boundaries for giving advice.

The technical adviser recognised that in answering these inquiries, several important topics should be discussed so that consumers could seek their own information before making a decision. He consulted different technical specialists, compiling a checklist of points to address in the course of a call about this product. Items included questions that a potential buyer should ask product vendors. The checklist was used and evolved over a few weeks, and was stored in the helpline's repository with other documentation used to support the business process. In this case, personally held knowledge that did not exist in the organisation as an artefact was made explicit and collated to formalise an agreed knowledge resource on a specific topic. ICT was used in the collaboration process and for the management of the compiled knowledge that resulted from addressing this problem, but that previously had not existed in an integrated form.

Early in each call, the adviser's challenge is to ascertain the caller's level of knowledge, or absorptive capacity (Cohen \& Levinthal, 1990; Roth, 2003). He must determine how much the caller already knows about the topic, before he can understand the inquiry and form an approach to solve the problem. Generally, on any day of my observations, he switched many times between directly conveying deep technical information to practitioners in one call, and translating technical detail for a home owner in the next call. As most calls about insulation products were from home owners, the checklist served as a single place to cover the important aspects of the topic. The adviser could also give technical details if the caller had a deeper understanding. Figure 7-9 (p. 201) shows the process for formalising this knowledge. 


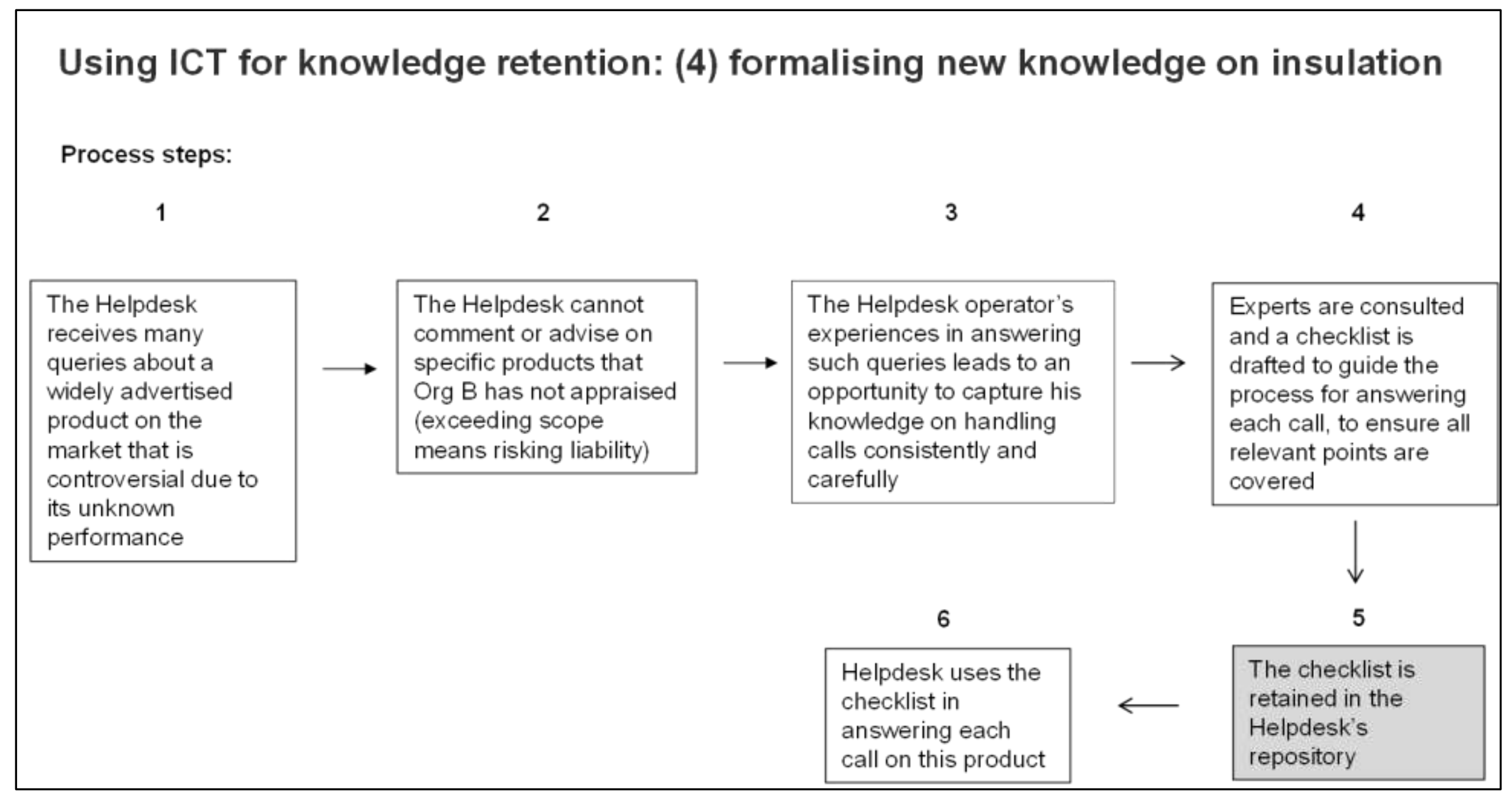

Figure 7-9: Formalising knowledge for replication 


\subsubsection{Extending the use of software function}

Various information and communication technologies, as described in Section 7.1.4 (p. 184), have been implemented over the last few years to support the helpline business process. The call management system is an example of an application that is the subject of innovative, unplanned use post-implementation (Stonehouse, et al., 2001). The technical adviser has adapted his use of the software to be more efficient, and for a smoother flow of discussion during a call.

The situation in this fifth example was observed following the adviser's absence from the helpline, which often happens when the adviser attends meetings as part of his broader responsibilities and no coverage was available for the position. During such absences, the answer phone is left on, callers leave messages and the adviser attends to the accumulated calls on his return. Usually, the adviser answers calls and thinks on his feet, locating documents and thinking about his responses while listening. He may enter details into the call management system during and after the call. If he has summary details of the caller's inquiry, he can plan his call in advance.

At a time when a higher volume of messages was experienced, the adviser listened to each message while entering the call details into the call management system. He was able to enter useful details of each question the caller had, as well as brief notes on the answer he would give. He also assembled the relevant documents and located the written sources he would use. After entering details for all the messages, he would leave the call record window (in the call management software) open for each call. With each call, he was therefore able to work his way through the points he had listed and complete the call, updating any further information as he progressed, to finally close the record and move on to making the next call.

This impromptu but innovative use of the software also allowed for a group of calls on a related topic to be planned and completed sequentially. The time spent planning each call would have been saved in having a logical idea and visual list of what was expected to be covered. This was a direct use of ICT for an improvement to a process that is repeated many times during the day, and is therefore of major benefit to managing the flow of work while handling absences. Figure 7-10 (p. 203) shows how ICT was used to organise responses to call messages. 


\section{Using ICT for knowledge retention: (5) call planning}

Process steps:

1

When the Helpdesk

is busy, callers leave

messages
2

The Helpdesk operator

listens to the messages

when the line is not busy
3

The Helpdesk operator enters all details into the call management system
Topics that he needs to cover in the call are entered into the record in order to plan the call

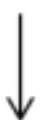

6

The call record is updated and saved at the end of the

call
5

With the call record open, the Helpdesk operator phones the caller back

Figure 7-10: Extending use of software for knowledge retention 


\subsubsection{Retaining and grouping related knowledge}

The final example relates to an upgrade in recording technology and an opportunity that was taken to link digital recordings to the existing call management software function mentioned in Section 7.2.6 (p. 202). At the beginning of the study, all helpline calls were recorded onto micro-cassette tapes. These tapes served as a temporary record only, as the collection of tapes was recycled every three or four weeks. In the event that a call was considered to be controversial, the particular tape would be kept for longer. In some cases, the call might be sent away to be transcribed. Therefore, there was usually no permanent record of the actual calls.

The research was conducted during a period of regulatory change and there were several factors that led to an opportunity to retain helpline knowledge through a simple improvement that may lead to further benefits for the organisation in the longer term. The first factor was that it was a time of significant changes to a section of the Building Code, with the new provisions, requirements, calculations and formulae being fairly complex. As outlined above, staff needed to become familiar with much new information. There was pressure on technical staff to support the helpline, and the technical adviser needed to be able to understand and explain the new rules to a range of audiences. Homeowners would require summary or high level information while practitioners would require a deeper level of understanding and discussion. The volume of calls was also increasing from week to week. Furthermore, the technical adviser noted that the process of his familiarisation and learning and the process of answering calls were interlinked and iterative, and commented that he thought others would also learn from listening to the recordings.

Elsewhere in the organisation, work was being directed towards the implementation of an electronic archive. In the initial improvement, the tape recorder was replaced with new hardware and software purchased for the helpline, and this was set up to enable all calls to be retained as digital recordings and archived in a designated repository on the network. This made the recordings available to other staff, providing they had the appropriate network access rights. Coupled with this was the need to enable a second person to hear calls independently, rather than via a speaker phone. A second headset was used in several ways, and I was able to listen in on calls initially. Later, with the appointment of a second adviser to the helpline, this capability was used for training purposes. From time to time, the technical adviser would involve an expert in answering 
a call — the wireless headsets enabled both people to move about the room to locate hard copy publications, while the caller could hear the conversation clearly.

Second, as the recordings were in digital form, they could now be linked to the appropriate call record in the existing call management system whenever the technical adviser noted that the call would be of interest for any reason. During the observations, he often encountered instances of calls that were of interest in terms of the questions asked, the nature of the topic, or their suitability for training other staff. There might be other reasons for accessing a call at a later date, for example because it could potentially be controversial in a dispute between parties to a project, or it may require some research before the caller's question could be answered.

Third, a couple of planned improvements had been noted near the end of the study. In each case where a digital recording was linked to a call record, the adviser had requested a software change so there would be a flag shown on the summary screen of the record to indicate that a recording was attached. The call management system was accessible only to designated users of the software function, that is, helpline staff. This would limit the ability to share new knowledge with staff in other areas of the organisation. The adviser was aware that other staff such as technical experts could be given access to view records and listen to recordings where they are linked to the call record - and intended to make a request for this functionality to be extended to others. The overall process of how these knowledge retention improvements occurred is depicted in Figure 7-11 (p. 206). 


\section{Using ICT for knowledge retention: (6) linking digital recordings}

Process steps:

1

The Helpdesk has a need to quickly

retrieve recordings of specific calls *
2

The Helpdesk moves from tape recordings to a new system for recording all calls using digital technology
When appropriate, the

Helpdesk operator links

the digital recording to the call record as an

attachment
3

A flag is to be included

on the summary

display of the call

record to indicate when

an attached recording

exists

pdesk
is able to
the digital
ghen

* Calls may be of interest for a number of reasons

e.g. interesting, ongoing topics, complex, require

follow-up, potential to be controversial, or for

training purposes 


\subsubsection{Summary: integrated view}

In reviewing the way in which ICT has been involved in retaining knowledge in each of the six examples observed above, there are some actions that are identified as being common to all of the individual examples. Five generic actions can be described as follows. First, the adviser identifies a need to provide knowledge. Through experience, he is able to quickly decide how to apply his knowledge, for example providing information, clarifying details, holding a detailed discussion on a specific topic, or commenting on a type of product. Second, he may also need to co-ordinate other staff if required in addition to assembling the electronic and paper-based information. Third, he then conducts the discussion. Fourth, there is advice on a solution to the problem and agreement on what steps should next be taken by the caller and often by the adviser. Last of all, once the conversation is completed, the adviser takes some actions to retain the relevant knowledge from the call. An integrated view of the above actions is shown together with the detailed actions and examples, in Figure 7-12 (p. 208).

The five generic actions involved in the knowledge retention process are set out across the top of the diagram. Beneath each action, that is, each step of the process, are the detailed actions and examples, some of which involve the use of ICT. 


\section{Integrated process view: using ICT for knowledge retention}

\section{High level process steps:}

\begin{tabular}{l}
$\begin{array}{l}\text { Identify a need to } \\
\text { provide } \\
\text { knowledge }\end{array}$ \\
\hline
\end{tabular}

- request for

knowledge

- calls seeking

clarification

- discuss with callers

- product knowledge

- retrieve call records

Detailed actions and examples

Actions and examples using ICT

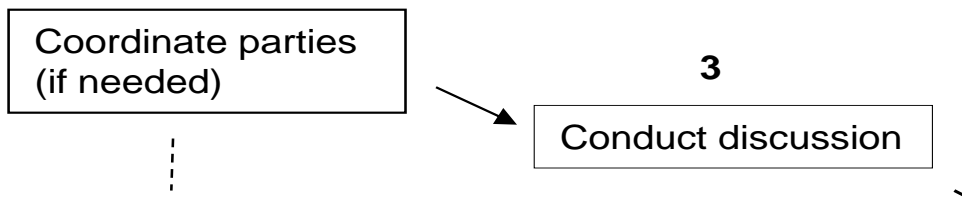

- involve appropriate experts

- provide background information

- co-ordinate audio conference

- facilitate various parties

- discuss standards, options

processes and best practice

obtain drawings and documents

- develop information sheet

- develop checklist with expert input

- use software in innovative ways

- add features to existing

software
5

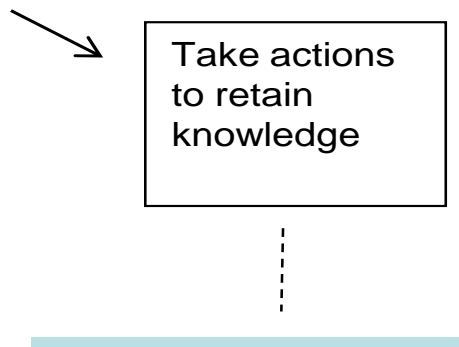

- retain knowledge for input to updating standards

- drawings retained in repository

- publications to web site

- update software to guide calls

Figure 7-12: Integrated process view: using ICT for knowledge retention 


\section{Chapter 8. An older expert's knowledge use and retention}

Having discussed how knowledge was retained with the use of ICT (Chapter 7), I now present findings that focus on knowledge retention activities in the helpline. This discussion of knowledge retention activities addresses the part of the research question that is concerned with the organisational context. It is therefore focused on processes, such as the helpline processes, and the actions of the expert and his collaborators.

First, I address knowledge retention actions in relation to some stages of the knowledge life cycle I discussed in 2.3.1 (p. 24). Following the analysis of the technical adviser's actions as described in Chapter 7 (p. 175), it was found that he used and retained knowledge in ways that can be explained from the perspective of this life cycle.

Second, I present my findings on how valuable knowledge, sourced from the content of calls and the business process, is retained in the organisation at a practical level. Several examples are provided from data collected during my observations.

Last, I place examples of knowledge retention in the context of Berends' (2005) framework for knowledge sharing that I introduced in Section 2.3.4 (p. 31) of the literature review. This framework is applicable to knowledge retention, as its focus on the contributions or effects of knowledge sharing on work practices is directly relevant to knowledge retention. Also, in the context of the study, the purpose of retaining knowledge is ultimately to share it with an industry.

These findings emerged from the action taking stage of action research. Data were collected from inteviews with internal and external stakeholders of the helpline, documentation relating to the helpline and call content, my researcher's journal and observations of helpline calls. The data were analysed from the perspective of the technical adviser's actions in retaining knowledge.

\subsection{Deploying existing knowledge}

The technical adviser used and retained knowledge in several ways. First, he retrieved and used existing knowledge during the call process. This consists of the existing stock 
of knowledge acquired from documented formats or from other sources such as experts and practitioners, and his own tacit knowledge and judgement.

Second, as an older expert who has spent some decades in the industry, he recognised that some forms of existing knowledge needed to be refined and updated in the course of his work, for the use of others. Updating existing knowledge is important in this business context, because the helpline is responsible for distributing accurate information, some of which is technical and evolving. Current knowledge is especially important in an industry with strict, quantitative compliance requirements.

Third, he recorded new or updated knowledge into various information systems, as discussed in Chapter 7.

Fourth, he requested and arranged for colleagues to publish knowledge in various ways, using distribution channels such as trade journals and the web site.

Last, he presented knowledge in ways that made it understandable to different types of callers, ranging from members of the public to building professionals.

He therefore played an active part in knowledge retention for the benefit of the organisation, its clients and the construction industry.

The actions involved in knowledge retention reflect elements of Zack's (1999a) knowledge life cycle, as described in 2.3 .1 (p. 24). The life cycle consists of five stages. First, knowledge acquisition refers to knowledge being created or acquired from a source. Second, knowledge refinement, involves indexing, sorting, abstracting, standardising or re-categorising knowledge for reuse. Third, storage and retrieval refer to the act of entering knowledge into a repository. Fourth, knowledge distribution, refers to the mechanisms for making knowledge content accessible. Fifth and last of all, knowledge presentation refers to selecting, arranging and integrating knowledge.

The technical adviser deals with stored knowledge, as he locates, retrieves and enacts it when he gives advice in the course of answering calls and solving problems. Over time and through daily use, the adviser has built up his expertise, including the awareness that certain types of knowledge are stored, and where to locate them, either within or external to the organisation. Knowledge may comprise text, photographs and drawings in hard copy publications or in electronic form. It may be shared in these forms - an example is where the caller and adviser locate a copy of the regulations and discuss the 
meaning of a section. Alternatively, the adviser may have a copy of the document and refer to it, but the knowledge is mostly shared verbally, while answering a caller's query or solving their problem. The adviser's expertise is demonstrated both in terms of locating knowledge and presenting it in a way that is intelligible to the caller.

The organisation uses its web site as a distribution channel to publish information quickly when required. As described in Section 7.2.4, supporting information about a regulatory change can be drafted, comments collaborated, and the information agreed and published so that it quickly becomes available to anyone with access to a browser. This means that in the course of this process to distribute and present knowledge, experts' technical knowledge is also retained in the organisation as knowledge products that are also available to the public. This process, in effect, turns individual experts' tacit knowledge into explicit, collaborated knowledge for wider industry and public use.

\subsubsection{Knowledge acquisition and retention}

The technical adviser uses existing knowledge that has been acquired and retained in a variety of ways, and a sample of these is summarised in Table 8-1 (p. 212), which lists the form in which knowledge has been acquired, and describes how knowledge retention occurred. The technical adviser participates in several of these processes as a subject matter expert. As an older expert who has been in the industry for a few decades, he has much knowledge that emerges in the course of his participation in these knowledge retention processes.

As an older expert, the technical adviser has over time, accumulated experience of technical subjects that practitioners and members of the public repeatedly find difficult to understand. He is also a subject matter expert on a range of construction, regulatory and contractual subjects. A related area of expertise associated with an older expert who has experienced changes in the industry is the ability to recall and understand the history of changes and the logic behind aspects such as different versions of regulations. During my observations of the technical adviser at work, I recorded several examples of his expertise during discussions with building professionals on matters such as the relative effectiveness of construction rules at particular points in the past. He spoke from his position as a practitioner who had constructed buildings under different rules, as an expert in practical matters. He also explained that building regulations reflect, to some degree, the knowledge that is available to the industry at a particular time - and that as the industry's knowledge of science and construction improves over time, 
regulations are updated to reflect improved understanding. Moreover, he has expertise as a knowledge co-ordinator in sourcing information for a range of audiences, including other internal experts in several knowledge domains.

\begin{tabular}{|c|c|}
\hline Form & Acquisition and retention \\
\hline $\begin{array}{l}\text { Article-photos, } \\
\text { illustrations }\end{array}$ & $\begin{array}{l}\text { The organisation has an editorial team, including subject matter } \\
\text { experts, for its own major publications. This team identifies } \\
\text { topics of interest to the industry. The technical adviser has } \\
\text { input to this process, due to his experience with the types of } \\
\text { inquiries received. The organisation uses technical writers to } \\
\text { produce the articles, with technical staff being involved in the } \\
\text { review process. Publications are stored as hard copies and the } \\
\text { helpline has recent copies, with back copies in its library. }\end{array}$ \\
\hline Product appraisals & $\begin{array}{l}\text { Appraisal documentation is published on the organisation's } \\
\text { web site and may be retrieved by the technical adviser and any } \\
\text { web site visitor. These documents are an output of the } \\
\text { appraisals process managed by a specific business unit. }\end{array}$ \\
\hline Checklists and transcripts & $\begin{array}{l}\text { Checklists are compiled by summarising or distilling } \\
\text { information which experts have provided to the adviser in the } \\
\text { course of answering an inquiry. They are refined through } \\
\text { discussions, then drafting and peer review by colleagues, } \\
\text { before being used on the helpline. Checklists are retained by } \\
\text { the helpline, but could be published in future, for example if } \\
\text { there is increased demand for such knowledge. Transcripts are } \\
\text { similarly developed and cover situations where experts think it } \\
\text { is important to provide a standard paragraph which can be used } \\
\text { consistently wherever a particular inquiry arises. }\end{array}$ \\
\hline $\begin{array}{l}\text { Publications, for example } \\
\text { NZ Standards }\end{array}$ & $\begin{array}{l}\text { The organisation has input to industry publications such as } \\
\text { regulations, the Building Code and NZ Standards that apply to } \\
\text { the building industry. This input is part of a controlled process } \\
\text { involving industry consultation and collaboration. These } \\
\text { publications are a primary knowledge source for the helpline } \\
\text { and its knowledge of specific technical topics can be both } \\
\text { detailed and thorough. The technical adviser also participates in } \\
\text { the process of standards development as a subject matter } \\
\text { expert. This is an example of knowledge presentation. }\end{array}$ \\
\hline Call records & $\begin{array}{l}\text { Call details are acquired during the call and the record is } \\
\text { completed as soon as the call is closed. They are stored in the } \\
\text { call management system and can be retrieved via a topic code } \\
\text { among other attributes. }\end{array}$ \\
\hline Web site content & $\begin{array}{l}\text { This knowledge is created through analysing the questions and } \\
\text { answers addressed over a period of time, for example on the } \\
\text { topic of the new insulation rules contained in Section H1 of the } \\
\text { Building Code. In this case, the technical adviser suggested } \\
\text { developing the support page, when it was found that } \\
\text { information needed to be published quickly, using the web site } \\
\text { as a distribution channel, and made available to large numbers } \\
\text { of people in the industry in a short time. Refer to Figure } 7-8 \text { on } \\
\text { page } 199 \text { for a description of the process. }\end{array}$ \\
\hline
\end{tabular}

Table 8-1: How existing knowledge was captured and retained 


\subsubsection{Application of existing knowledge}

The technical adviser demonstrated various types of skills and experience in applying existing knowledge in its various forms. The actions that I observed fell into three main types: locating and referencing, discussing, and assessing. Another type of action was identified in the course of observing the helpline calls and this relates to the adviser's abilities in using his social networks, an example of personally held knowledge being applied to complete work. As an older expert, he had built an extensive professional and social network over decades, and accessed the network for a wide range of queries.

First, while listening to the caller and asking questions, he determines which publications he needs to reference during the call, locates the hard copy manuals and opens the electronic documents such as web pages and any existing call record. Such actions happen very quickly and appear to be an example of tacit knowledge. Multiple versions of technical manuals are often required when he explains the nature of the changed rules. An added level of complexity exists in the cross-referencing between different documents, for example the Building Code and the related Standard. Thus, the adviser is proficient in making linkages between different knowledge sources. Other reference material may include other organisations' web sites or industry contacts lists. In the latter case, he draws upon his own referential knowledge, meaning he is an expert at locating directories or people who may be able to point him to the right direction for the information needed to answer a query. He demonstrated a powerful recall for names of people and organisations. His actions also reflected his expertise in keeping within the boundaries of his role, and making a clear distinction between giving advice and directing someone towards the proper authority for clarification. He explained that such experience and skills were built up over a long time, and that he had also developed an acute awareness of the liabilities that could arise when unauthorised advice was given.

Second, during the call, the adviser applies existing knowledge in discussions, which can be detailed in the case of industry inquiries. He was observed discussing photographs, interpreting details of construction, critiquing technical details provided by the caller, cross-referencing multiple documents and explaining the relationship between their provisions. This included citing definitions and discussing their meaning and application to the caller. Recalling recent and related cases and topics, the adviser is also able to describe them from his memory and explain his experience of similar situations to the caller. As an older expert, he was able to discuss the sequence and 
rationale for various changes in a section of the Code or Standard, from his own memory and from his experience and background in the industry — whereas a younger and less experienced adviser would not have the same extent of recall or immediacy in terms of answering a call in a single session. Because of his personal history with regulatory changes, the technical adviser demonstrated the ability to identify and quickly summarise the most important changes and what actions the caller should take:

\footnotetext{
“we're looking for a non-solid construction in zone 1. You're looking for a formula there for climate zone 1, use the formula and fill in the holes. That's how simple it will be."
}

technical adviser summarising an insulation calculation

Third, there is a type of action that involves deeper and more complex processing of information, also based on the adviser's own knowledge and using his ability to recall it quickly. This includes actions such as critiquing published information and assessing the clarity of its meaning and intention as applied to the caller's situation. In a few cases that were observed, he concluded that while the intent of a rule was clear, its wording was not, therefore its application would result in an unusual and unintended result for the particular builder or architect. In such cases, he would explain this situation and agree to research it further and contact the caller again, or would refer the caller to another expert for detailed technical advice - since in the case of new rules, it would take some time for precedents to emerge.

As an older expert, he demonstrated a deeper understanding of how to address complexity than a younger and less experienced adviser would. Apart from knowing when to pause and co-ordinate further expert knowledge to solve a problem, he used some other wise approaches such as cross-checking his advice with several different experts, trying to ascertain how widespread a problem was in different areas of the country, and checking as to whether some local authorities adopted different approaches from others. In dealing with industry callers, he would also provide the caller with the names of other experts from whom he had sourced his knowledge, and with whom the caller could check his advice. Thus, in his knowledge co-ordination role, described in Table 7-2 (p. 189), he also referred his caller to the source of the knowledge.

Finally, there were numerous examples of using social networks with a view to getting work completed and also to improve efficiency in the overall helpline process. The 
adviser had a clear knowledge of which experts to use to address problems in a particular topic area. He also knew the best methods for getting experts to review documents, and how to collaborate and organise virtual meetings for a targeted discussion on technical matters.

The skills and experience of the adviser were observed across a variety of behaviours, including the ability to apply personal judgement in the case of construction methods, based on his own considerable experience in the building industry. He also recognised that experts from different disciplines may have varying perspectives on a topic. In a discussion on the benefits that callers got from the service, the adviser noted that "it's about a builder talking to a builder" and being able to call and have a discussion about a specific technical detail during the construction process. The adviser is able to recall his own experiences and make judgements on this basis, for example on the relative performance of different constructions. During these conversations, he was observed making distinctions between theory and practice and applying logic in the discussion of the suitability of different methods.

\subsection{Refining and retaining knowledge}

Zack's (1999a) description of the knowledge life cycle includes a stage he calls knowledge refinement, which may be described as taking actions such as sorting, abstracting, standardising and recategorising knowledge so it can be reused. Another important aspect of refinement is bringing knowledge up to date, especially in the context of the helpline, as explained in Section 8.1 (p. 209).

The technical adviser identified occasions where existing knowledge needed updating. The necessity to update existing knowledge may occur for several reasons. First, existing knowledge may expire as new provisions, rules or calculations come into effect from a specific date, such as in the case of the new formulae for calculating home insulation requirements. Existing knowledge therefore becomes invalid and needs to be updated, regrouped and re-presented:

"use the formula that we've given you on our web site and completely ignore that second note, because it's already incorporated into the formula which we produced subsequent to you getting the sheet" 
Second, once knowledge is disseminated, discussed and applied in a practical setting, refinement takes place in the form of abstracting, standardising and recategorising. BRANZ is one of the parties that participates in the code and standards development and review process that occurs in the broader industry and regulatory environment. An example of existing knowledge being updated is discussed in Section 7.2.2 (p. 193). In this case, the technical adviser and some of the technical experts held a telephone conference with staff of a territorial authority and learned that, in practice, the Standards are being applied to increasingly complex situations in the real world. Thus, in one respect, the organisation's and the experts' knowledge of roof design was updated as a result of the discussion. In another respect, and over a longer time frame, the Standard and potentially the part of the Building Code pertaining to roof design would be updated to reflect the increasing complexity of actual designs. One of the perspectives of the technical adviser's role is that he acts as a bridge between theory and practice. Also, as an older expert with a more holistic view of the organisation and industry, he was focused both retaining and deploying valuable knowledge for the good of the industry.

Last, existing knowledge may be refined when it is extended and updated if a user sees a new opportunity. This occurred in the case of call planning, an example that involves updating an indexed call record both to manage the call and to provide more meaningful details of the call content or discussion. This is outlined in Section 7.2.6 (p. 202), and can be viewed as using an existing function, in this case call management software, in a new way, extending its application to include the ability to manage a call so that the adviser covers all the questions the caller has asked. He also has the opportunity to better prepare for the call in terms of locating the relevant materials and organising his thinking on the topic. These actions represent the refinement of knowledge.

\subsubsection{Participants in refining knowledge}

In the context of the helpline business function, knowledge is refined through a participative process and there are various parties involved. The adviser has a pivotal role as knowledge facilitator, and this involves several activities resulting in the retention and sharing of knowledge. He was observed to co-ordinate and facilitate the collection, update and presentation of knowledge. At any time, he can access details of which experts are working on drafting explanations, updating documents or taking a closer look at more complex helpline inquiries. He demonstrates a high level of commitment and motivation to achieve this, often commenting that "we are all learning 
together" when it comes to the processes of familiarisation and absorption of new knowledge, such as helping callers understand recently introduced regulations. This relates to the idea of engaging and "thinking with" a person to quickly solve a problem (Cross \& Sproull, 2004). This commitment reflects one of the organisation's main functions of distributing and presenting knowledge to the industry, and the helpline makes a major contribution to this function through the advice it provides. The adviser recognises that the ability to codify the updated knowledge, making it available to the appropriate audience quickly is as important as establishing that the knowledge needs updating:

"I've been pushing ... to get some of this stuff up here (on the web site) before we went on the road with the seminars. My view ... is that it's complicated"

technical adviser directing a caller to newly updated information

This leads to discussion of the other parties and activities involved in the knowledge update and presentation process. Initially, it was observed that the role played by callers, both industry and members of the public, was solely that of an inquirer. However, callers, either individually or as a group, are also barometers of what is happening in the industry. Several calls on a similar topic, from the same geographical region or similar climate area, or from the same professional group may indicate a specific trend or problem is surfacing. A practitioner may have a discussion with colleagues before calling the helpline, presenting updated or new information in this way. The technical adviser also has a nationwide social network of peers throughout the industry who can be useful in confirming a trend, opinion or pattern in the industry. These peers include people such as professionals and trades people, manufacturers, retailers and officials within territorial authorities and central government.

Finally, there is scientific and technical expertise within the organisation and other organisations in the construction industry. Internal experts provide new knowledge or scientific and technical input to knowledge that needs updating, but are also involved in drafting documentation in a way that is technically accurate and understandable to the intended audience. The drafting process, knowledge creation, usually involves more than one expert, for peer review purposes, and the adviser who ensures he can understand and explain the changes. This is part of the organisation's usual editorial process. External experts are consulted on wording, intended meaning, application, 
logic and clarification of changes, especially when such changes originate from their organisations. There are therefore multiple parties involved in the process of refining knowledge, involving the tasks of abstracting, updating, standardising and recategorising knowledge. This knowledge is then stored electronically or in printed form in BRANZ's systems and repositories. Knowledge distribution mechanisms include channels such as the web site, the helpline, the BRANZ book store and a range of print publications.

\subsubsection{Actions in refining knowledge}

Observations during the data collection activity led to the identification of actions that were involved in updating existing knowledge. This section describes how the technical adviser as the older expert and protagonist, proceeded through distinct steps in dealing with existing knowledge that needed to be refined for retention and reuse. The steps are retrieving knowledge; understanding new knowledge; liaising with experts to refine knowledge; retaining knowledge; presenting knowledge; and distributing knowledge.

The older expert's actions in refining knowledge are depicted in Figure 8-1 (p. 219), which depicts the six steps described. In the first step, while the technical adviser greets the caller and finds out whether they are a member of the public or a practitioner, he identifies and retrieves the knowledge resources that he is likely to need and assembles them. He may access publications and databases as the call progresses.

In the second step, he needs to understand the additional knowledge. Depending on the type of inquiry, he will discuss the knowledge sources that he consults to solve the problem. With a more detailed inquiry, he often critiques existing knowledge, as an industry practitioner such as an architect or designer may be interested in a specific aspect of technical knowledge. An example of this is the rationale behind certain engineering requirements for a structure. The technical adviser also needs to understand the additional knowledge that a caller contributes to the subject. One observation involved the use of timber in framing for construction. The timber companies had recommendations on how the product could be used, and several territorial authorities had opinions on whether these uses were acceptable in construction, so there was some ongoing discussion in the industry. However, a representative from a retailer also had a relevant perspective on the topic, from the point of view of someone who had also worked in construction. This incident involved telephone discussions and emails with several parties, to clarify different understandings and remedy incorrect, complex and 
confusing information that was circulating the industry. The older expert was able to interpret complex knowledge as well as to understand how that knowledge had developed over the years.

In the third step, as implied above, the technical adviser liaises with experts to refine knowledge. Part of the experts' responsibility is to ensure that knowledge and materials that are distributed are current and accurate.

In the fourth step, the knowledge is retained, usually electronically. At this stage, there may be some contact with the intended audiences to advise that it will be available shortly. Audiences may also be told which distribution channels will be used, for example the knowledge product may be available for free download from the web site.

In the fifth step, activities such as selecting, arranging and integrating are part of knowledge presentation. An example of this is the collation of knowledge from helpline discussions with a building professional who provides supporting diagrams for inclusion in an article that represents a knowledge product.

In the sixth and final step, distribution, the technical adviser completes the knowledge update cycle by ensuring the updated knowledge is available via the appropriate publications. Retained knowledge may also form the input to industry processes, such as the review of building standards.

The older expert's actions in refining knowledge for retention

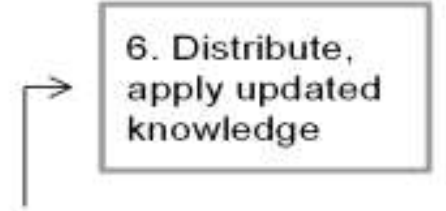

5. Present, integrate knowledge (standards)

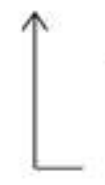

4. Retain (store) knowledge

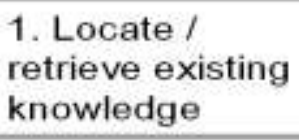

1. Locate /

retrieve existing knowledge

2. Critique, discuss and understand additional knowledge

3. Liaise with experts to refine knowledge

Figure 8-1: The older expert's actions in refining knowledge for retention 
There has been some study of the micro-processes involved in the sharing or transfer of knowledge between source and recipient (Berends, 2005; Cross \& Sproull, 2004). Berends identifies five knowledge-sharing moves, discussed more fully in Section 2.3.4 (p. 31), which are basic meaningful units of knowledge. These consist of descriptions, suggestions, evaluations, questions and actions, some or all of which were observed to occur in the study of the call process.

I observed the technical adviser in a range of situations where he recognised opportunities for knowledge retention. During a call, the adviser would listen to the caller's descriptions of their problem, ask questions to clarify his understanding, and make suggestions as to why something had happened or what the caller should do to remedy the problem. He may also discuss various actions that the caller could take, such as the construction method to use, or the appropriate documentation to consult. The technical adviser quickly compares the contents of the discussion with knowledge held in the organisation and his own knowledge and experience. He may also crossreference it with other forms of related knowledge such as documents, or often his tacit knowledge, and evaluates its usefulness. This occurred in the example of evaluating the relative merits of various ways of installing windows. Underlying such decisions is the knowledge retention challenge that knowledge may not be immediately useful once it is retained, but be useful in future (Berends, 2005; Garud \& Nayyar, 1994).

From his position as an older expert, the adviser was able to distinguish instances where knowledge needed to be retained for future action, but was not of relevance in the short term. He noted that it was his experience and background knowledge that enabled him to make such distinctions. Contrasting with the concept of knowledge retention for future use is Cross \& Sproull's (2004) notion of actionable knowledge, as knowledge that contributes to progress in the resolution of a short-term problem, which is apt for a business process such as the helpline. These authors propose components of actionable knowledge - solutions, referrals, problem reformulation, validation and legitimation (Cross \& Sproull, 2004, p. 449).

In retaining knowledge that arises from a call, the adviser needs to know about the credibility and reliability of the caller's views and opinions and be satisfied that knowledge is well-supported and authoritative. This validation step is important in deciding whether knowledge is relevant and valuable to the organisation, its experts and the industry. Within the scope of the helpline service, all advice must be reliable, 
authoritative and consistent. "High quality advice must be provided ... as it may shape or confirm a course of action that a member has considered or embarked on. The advice must reflect current and accepted good practice, must be legally and professionally robust and be able to withstand challenge" (Cowan \& Haslam, 2008). Legitimation occurs in the case where knowledge has been accepted by another authority. Having identified knowledge that should be retained by the organisation, the next step is for the technical adviser to gather the relevant documentation, such as drawings, written confirmation and copies of correspondence — as knowledge artefacts. The adviser may liaise with other staff in the organisation in the process.

The technical adviser initiated several interventions to physically retain knowledge in the organisation. Table 8-2 (p. 222) lists five events that each triggered an intervention. The purpose of the table is to show that with each event, once the technical adviser recognised an opportunity to retain knowledge, he took certain actions leading to specific results and effects. Each trigger event occurred while answering calls and solving problems on the helpline during the course of the study. In each event, the technical adviser recognised that while he could complete each call without taking any further action, he recognised opportunities to make wider improvements. In doing so, he chose to intervene, liaise with colleagues and retain knowledge in appropriate formats for future use and to improve his call handling process.

In the first example in Table 8-2, a builder called the helpline about how he had fitted a window into a new home. This triggered a discussion, during which the technical adviser noted that the builder's method deviated from usual techniques, but led to a more weather tight construction. The design had also been approved by building inspectors had been used several times. During the call, I observed the technical adviser's actions to retain knowledge, once he had validated the builder's methods, $\mathrm{He}$ answered the builder's queries, providing him with factual and technical advice. This led to the conclusion that the builder's method was innovative and should be shared with the industry. Details of the call were passed to the technical adviser's colleagues, the technical writers, so they could interview the builder, photograph the construction and write an article. They were responsible for knowledge presentation, selecting, arranging and integrating knowledge for publication. As a result of retaining the knowledge and creating a knowledge product in the form of an article, this building technique would reach a wider audience through trade journals and web sites. 


\begin{tabular}{|c|c|c|}
\hline $\begin{array}{l}\text { Description, trigger event and } \\
\text { result }\end{array}$ & Actions to retain knowledge & Results and effects of actions performed \\
\hline $\begin{array}{l}\text { Identified knowledge about stop ends } \\
\text { to window flashings - an innovation } \\
\text { Result: knowledge passed to } \\
\text { appropriate colleagues for action }\end{array}$ & $\begin{array}{l}\text { - } \\
\text { - } \text { and advice } \\
\text { - } \text { plan to write article } \\
\text { - } \quad \text { plan to publish in trade magazine } \\
\text { - } \quad \text { possibly web site }\end{array}$ & $\begin{array}{l}\text { - actions to retain knowledge lead*/ to shared } \\
\text { understanding } \\
\text { knowledge is retained in ICT, and knowledge products } \\
\text { are created for wider audience }\end{array}$ \\
\hline $\begin{array}{l}\text { Identified complex, innovative roof } \\
\text { design } \\
\text { Result: documented knowledge and } \\
\text { contacts noted for future action in } \\
\text { industry process }\end{array}$ & $\begin{array}{l}\text { - } \quad \text { asked for permission to retain drawings } \\
\text { - } \quad \text { request update as plans develop } \\
\text { available } \\
\text { - } \quad \text { maintained link with knowledge source } \\
\text { - noted for future input to standards }\end{array}$ & $\begin{array}{l}\text { - } \text { BRANZ has captured in ICT real examples of innovation } \\
\text { in the industry } \\
\text { - } \text { good practice can be reflected in industry standards } \\
\text { - } \text { relationships are established for future knowledge } \\
\text { retention }\end{array}$ \\
\hline $\begin{array}{l}\text { Discovered function for making } \\
\text { attachments to call record } \\
\text { Result: knowledge embedded in } \\
\text { helpline process immediately; further } \\
\text { action by colleagues }\end{array}$ & $\begin{array}{l}\text { - } \quad \text { tested function for attaching digital } \\
\text { recording to call record } \\
\text { - } \quad \text { advised others who might be interested } \\
\text { - } \quad \text { asked IT Group to update summary screen } \\
\text { to flag existence of recording }\end{array}$ & $\begin{array}{l}\text { - related knowledge is retained together in call } \\
\text { management software } \\
\text { - knowledge is more accessible in system, leading to a } \\
\text { more efficient business process }\end{array}$ \\
\hline $\begin{array}{l}\text { Trend of increasing numbers of calls } \\
\text { about insulation rule changes causes } \\
\text { concern about work flow; accurately } \\
\text { describing calculations } \\
\text { Result: knowledge embedded in } \\
\text { standard form and disseminated } \\
\text { immediately in several cycles }\end{array}$ & $\begin{array}{l}\text { - } \quad \text { had discussions with scientists } \\
\text { - } \text { scientists drafted document explaining } \\
\text { rules and calculations (complemented } \\
\text { seminars) } \\
\text { - } \quad \text { review process completed } \\
\text { - } \quad \text { document published to web site } \\
\text { during call }\end{array}$ & $\begin{array}{l}\text { - } \\
\text { - } \quad \text { available to callers through ICT } \\
\text { co-ordination of experts to create knowledge leads to } \\
\text { shared understanding } \\
\text { - } \quad \text { publication of retained knowledge enables anyone with a } \\
\text { browser to access it directly } \\
\text { - } \\
\text { eventually, call volumes on this topic may decrease }\end{array}$ \\
\hline $\begin{array}{l}\text { Trend of increasing calls about type of } \\
\text { insulation product sparks concern } \\
\text { about consistency and thoroughness of } \\
\text { advice } \\
\text { Result: knowledge embedded in } \\
\text { artefact for use in organisation }\end{array}$ & $\begin{array}{l}\text { - discussed need for a checklist with experts } \\
\text { - } \quad \text { completed review and agreed content } \\
\text { - } \quad \text { document could possibly be published }\end{array}$ & $\begin{array}{l}\text { - experts gain a shared understanding and awareness of } \\
\text { knowledge being created and retained } \\
\text { consistent, reliable and authoritative information retained } \\
\text { in ICT and is available to callers } \\
\text { - it becomes easier to handle this type of call }\end{array}$ \\
\hline
\end{tabular}

Table 8-2: Actions to retain knowledge at BRANZ 


\subsection{Examples of knowledge retention}

During the time I spent observing the technical adviser as an older expert in action, he took action to retain valuable knowledge in several different situations. He recognised many opportunities to retain knowledge in BRANZ, to update other experts and to organise for knowledge to be documented and disseminated to the industry and members of the public. Two types of opportunities were observed.

First, the content of calls was the predominant source of knowledge retention opportunities. This meant that in addition to answering calls and solving problems, the adviser retained valuable knowledge arising from calls that would be useful beyond the boundaries of the call itself.

The second source of knowledge retention opportunities was the helpline business process itself, when viewed as a series of actions required to answer calls and resolve problems. The adviser identified several opportunities to retain knowledge that could also be more readily retrieved in future, directly from the helpline systems.

\subsubsection{Valuable knowledge retained from call content}

Due to his own knowledge and experience in the industry, the technical adviser was able to recognise, sometimes early in the call process, where knowledge was valuable to the organisation and to particular industry groups such as building practitioners. Practitioners' development of enhanced designs or methods of construction sometimes occur in response to changes in the latest version of authoritative documents such as regulations, the Building Code and NZ Standards. Such changes motivate some builders to improve the way they detail and construct a design and BRANZ and other industry bodies need to be aware of the practical implications of codes and standards.

The first example of valuable knowledge about methods is where the adviser identified valuable practical knowledge about construction methods for window flashings, described in Section 7.2.1 (p. 190), being installed in a way that he had never encountered. He immediately recognised it as being innovative, weather tight and effective - sufficiently valuable and valid knowledge that required his further action, to document it for the organisation, and disseminate it to the industry. Here, the adviser is knowledge facilitator, enacting three roles, "as a catalyst, as a coordinator of 
knowledge creation and as one who provides the general direction of knowledge creation" (Roth, 2003, p. 42).

Because of the technical adviser's personal experience as a builder, he was able to look critically at a pair of photographs and discuss them in detail with the caller, who was in the process of installing a window. His age, expertise and experience led to his confidence to have a technical discussion on an article that he had not been involved in publishing. Furthermore, he was able to understand an alternative construction and recognise it as a technically sound design. This warranted the retention of this knowledge as well as a further investigation followed by another article to publicise what he had learned during the call. A less experienced adviser may not have had the level of knowledge to hold such a detailed discussion or judge the alternative design as being significant in terms of knowledge retention and dissemination.

The second example involves the complex architectural roof concept, as described in Section 7.2.2 (p. 193), which several experts in the organisation confirmed as being an innovative design representing valuable knowledge that should be retained. From his own knowledge and experience at the time of the initial call, the adviser recognised that the query was sufficiently unusual and technical in nature to require consultation with the other experts. During the subsequent teleconference, the adviser recognised that this design was far more complex than the whole group had previously seen. On receiving a draft design, an internal expert confirmed its usefulness as input to the review of the related standard. This may be seen as an example of knowledge retention where an opportunity for reuse was immediately identified. Both the knowledge holder (the architect) and the recipient (BRANZ) have an interest in the design concept from a knowledge retention perspective. Specifically, the holder needs validation of his design and the recipient wishes to retain and use the knowledge for organisational awareness and ultimately, industry benefit. This extends the idea that it is important for knowledge sharing and retention to be beneficial to organisational practices, such as problem solving, and learning (Berends, 2005).

As an older expert with a long history in the industry, the technical adviser was able to recognise an opportunity to learn and retain valuable knowledge, sharing it with other experts, but also giving feedback to an innovative design. In terms of the business process, it was an early inquiry about a conceptual design that would in due course have been developed in further detail and submitted directly to a territorial authority for 
approval. It could therefore be argued that a younger and less experienced adviser would have decided that the inquiry was out of scope for the helpline, not recognising it as a knowledge retention opportunity.

Both these examples show that industry practice informs theory. Also, when knowledge is disseminated and design and construction methods promoted, practitioners have the means to increase their skills and experience. Such updated knowledge may also become authoritative, for example the territorial authority gave its consent to the window design and the architectural roof design. This may lead to an improvement in the regulations as the result of a scheduled review. When knowledge of improvements and innovations becomes authoritative, it validates the practices of knowledge retention and sharing more widely around the industry.

My observations of helpline activities over a period of time when rule changes were enacted in relation to home insulation, reveal that knowledge refinement and retention can be a two-step process. The helpline received numerous calls about changes to insulation requirements under Section $\mathrm{H} 1$ of the Building Code, resulting in considerable time being spent solely on this topic. Initially, the technical adviser organised for detailed requirements and calculations to be published to the web site so that callers could access and understand the changes. The initial update to the web site was followed by intensive use, during which many different parties came to terms with the change, learned the practical steps in applying the new conditions, for example adapting to the new calculations and methods, and designing or building the practical solutions. During this stage of "learning together" users became attuned to the implications of the changes.

The technical adviser subsequently became aware that further refinement was needed in several areas, as it became evident that there were clearer or more accurate ways of explaining or conveying the change. An example of this is depicted in Section 7.2.4. This often involves a minor change in wording, leading to greater clarity. In effect, as a people became more conversant with a change, meaning updated knowledge, they found clearer ways of expressing it. Thus, the second instance of updating knowledge may be seen as knowledge refinement. 


\subsubsection{Valuable knowledge retained from helpline process}

On several occasions I observed opportunities for knowledge retention that arose from aspects of the helpline business process itself, rather than from the subject matter contained in the actual calls. There were some instances of knowledge retention resulting in improvements to the helpline, making it a more efficient business process. The following examples show that once action is taken to retain knowledge, it becomes accessible to the technical adviser for reuse, and for other advisers who might operate the helpline, as well as being available to the rest of the organisation when required. Through his experience and attention to accuracy, the technical adviser was also an advocate of representing knowledge in a standardised form so that he both he and the organisation could provide consistent advice. One way of achieving this is to retain knowledge in a publishable form, as a knowledge product that can be accessed quickly. As explained in Section 6.1, BRANZ's highest level business process involves the conversion of knowledge into knowledge products. The concept of knowledge products features prominently in the organisation's perspectives of valuable knowledge - see Sections 5.1 and 5.7.

Soon after the organisation introduced digital recordings of helpline calls, the adviser recalled that there had always been a time-consuming process of transcribing calls, explaining that this was done only in cases where a transcript needed to be kept for future reference or as part of an audit trail. While working with the call record after an interesting and knowledge-rich call one day, he realised that the software for recording call records included a function for linking attachments. The assumption had always been that links would be made to documents; however, the function had never been used since the helpline service is based on the provision of verbal advice. The adviser was able to link a digital recording to the call record. This improvement makes it possible to access the recording at the same time as being able to view the record of the call — taking away the need to transcribe any calls or locate a separate recording.

Finally, the development of the insulation product checklist described in Section 7.2.5 is also an example of knowledge creation. Specifically, the process involved eliciting personally held tacit knowledge from several experts, to form a knowledge artefact that did not previously exist. Participants in the process of creating the artefact also came to a shared understanding and agreement on the contents of the checklist, thus making their knowledge explicit. In the process of contributing to the knowledge product and 
co-ordinating the drafting of the checklist, the technical adviser's original purpose was to ensure he had full information upon which to base his advice. By also ensuring that the knowledge was accessible to others, he reduced the organisation's reliance on his personal knowledge before he was due to leave the organisation. Such knowledge products were later used in the training of his successor.

\subsection{Applications and benefits of retaining knowledge}

Berends' (2005) framework for knowledge sharing was introduced in the literature review and discussed in Section 8.2.2 (p. 218). I explained that in observing the technical adviser's knowledge retention actions, many of Berends' knowledge sharing moves. Moves are meaningful actions in human communication, and Berends defines five of them: descriptions, suggestions, evaluations, questions and actions.

Now I turn to the second part of Berends' framework, as shown in Table 8-3 (p. 229). The purpose of using this framework is to show the contributions and end benefits of knowledge retention in the helpline setting.

At the organisational level, one of BRANZ's responsibilities includes conducting research. It views the output of this research as knowledge which it then has a responsibility to disseminate to the construction industry in a form that is independent and authoritative. The retention process sees the conversion of often theoretical knowledge to practical, actionable knowledge that practitioners can use, for example in design, new construction and renovation projects. It can be argued, therefore, that in BRANZ's case the retention of scientific and technical knowledge is ultimately linked to its dissemination to the industry and the general public. Likewise, the retention of knowledge that improves its business processes leads to efficiency in service delivery.

There is a close relationship between the knowledge retention imperative at BRANZ and the strategic role of knowledge products for the industry. Berends' (2005) framework for knowledge transfer can be adapted for knowledge retention while recognising this important relationship. The framework can be used to show that knowledge retention has benefits for the organisation and contributes to problemsolving in a scientific domain in five ways.

First of all, such knowledge may contribute towards articulating a problem. Second, it may lead to solving a problem. Third, knowledge may have an activating effect in 
prompting others to take action. Fourth, when knowledge is not immediately required in problem-solving but is likely to be used in future, it contributes to the development of background knowledge, an indirect contribution. Last, developing the knowledge of others is also an indirect contribution.

Having observed and analysed knowledge retention in the helpline business process, I found the framework to be a meaningful way of relating the knowledge retention examples to the contribution they make to the organisation, and to define the end benefits for BRANZ as an organisation and as a key participant in the construction industry. I analysed five examples of knowledge retention using the applications, contributions and benefits from Berends. The results are shown in Table 8-3 (p. 229).

If the first example of retained knowledge about current industry practices, for example roof design, is treated as an element of valuable knowledge, then the validation of a complex conceptual roof design contributes to solving an immediate problem for the designer. The discussion of the design involved suggestions, questions, evaluations and led both the designer and the building consents officials to take action. This action would involve steps such as the designer evolving the design further with confidence, and the officials anticipating its submission. The end benefits of retaining this knowledge are threefold. First, the designer and territorial authority and their respective staff, as members of the industry, are better informed. Second, by documenting this knowledge, BRANZ as an organisation increases its physical knowledge asset and its experts have increased their personal knowledge. Third, as mentioned earlier, the retained knowledge may be useful as input to the review of industry standards. Also, the experience of knowledge sharing increased the parties' knowledge of one another, and the agreement to keep in contact also strengthens the links among them for future knowledge sharing and retention.

Further examples of how elements of valuable knowledge may be applied, and the end benefits of knowledge retention for BRANZ in each case, are depicted in . 


\begin{tabular}{|c|c|c|c|c|c|c|c|}
\hline & \multirow{2}{*}{$\begin{array}{l}\text { Elements of valuable } \\
\text { knowledge }\end{array}$} & \multicolumn{5}{|c|}{ Retention application or contribution (Berends, 2005) } & End benefits of retention \\
\hline & & $\begin{array}{l}\text { Contribution to } \\
\text { solution }\end{array}$ & $\begin{array}{l}\text { Articulating the } \\
\text { problem }\end{array}$ & Activating & $\begin{array}{l}\text { Developing } \\
\text { background } \\
\text { knowledge }\end{array}$ & $\begin{array}{l}\text { Developing } \\
\text { knowledge of } \\
\text { others }\end{array}$ & \\
\hline 1 & $\begin{array}{l}\text { Updated knowledge about } \\
\text { industry practices } \\
\text { Example: complex roof design }\end{array}$ & $\mathrm{Y}$ & & $\mathrm{Y}$ & & $\mathrm{Y}$ & $\begin{array}{ll} & \text { Better informed industry } \\
\circ & \text { Increased organisational knowledge stocks } \\
\circ & \text { Increased knowledge of experts }\end{array}$ \\
\hline 2 & $\begin{array}{l}\text { Knowledge about updated home } \\
\text { insulation rules and calculations } \\
\text { Example: changes to Section H1 } \\
\text { of Building Code }\end{array}$ & $\mathrm{Y}$ & $\mathrm{Y}$ & $\mathrm{Y}$ & & $\mathrm{Y}$ & $\begin{array}{ll} & \begin{array}{l}\text { Decreased reliance on older expert's } \\
\text { knowledge }\end{array} \\
\circ & \text { More consistent information given } \\
\circ & \text { Better informed designers, trades } \\
\circ & \text { Better built environments ultimately } \\
\circ & \text { Accessible knowledge via web site }\end{array}$ \\
\hline 3 & $\begin{array}{l}\text { Updated knowledge on innovative } \\
\text { methods } \\
\text { Example: stop ends to window } \\
\text { flashings }\end{array}$ & $\mathrm{Y}$ & & $\mathrm{Y}$ & $\mathrm{Y}$ & & $\begin{array}{ll}\circ & \text { Promotion of discussion in industry } \\
\circ & \text { Publication of innovative ideas and designs } \\
\circ & \text { Increased knowledge of experts and } \\
& \text { organisation (transferred from older expert) }\end{array}$ \\
\hline 4 & $\begin{array}{l}\text { Knowledge about efficiencies and } \\
\text { quality } \\
\text { Example: insulation product } \\
\text { checklist }\end{array}$ & $\mathrm{Y}$ & $\mathrm{Y}$ & & $\mathrm{Y}$ & & $\begin{array}{ll} & \begin{array}{l}\text { Decreased reliance on older expert's } \\
\text { knowledge }\end{array} \\
\circ & \text { More knowledgeable consumers } \\
\circ & \text { Ability to provide consistent and complete } \\
\text { information, documented knowledge }\end{array}$ \\
\hline 5 & $\begin{array}{l}\text { Knowledge about technology } \\
\text { opportunities } \\
\text { Example: linkage of call record } \\
\text { with recordings }\end{array}$ & $\mathrm{Y}$ & & $\mathrm{Y}$ & & & $\begin{array}{ll}\circ & \text { Ability to implement improvements } \\
\circ & \text { Business process efficiency gains } \\
\circ & \text { Greater accessibility to knowledge }\end{array}$ \\
\hline
\end{tabular}

Table 8-3: Contributions of knowledge retention from older expert (adapted from Berends, 2005) 
The technical adviser represents a single instance of an older expert whose knowledge is valuable and at risk of being lost as the prospect of retirement approaches. There are also some experts such as senior scientists and technical specialists in the baby boom age group, or older. Since the challenge of knowledge retention exists at the level of the individual as well as the organisation, the framework lends itself to maintaining focus on this relationship in a transparent manner and would be valuable in planning for knowledge retention from older experts.

\subsection{Summary}

The older expert deploys existing knowledge through his skills in locating relevant knowledge and conveying it in a way that is intelligible to the knowledge seeker. His actions included locating and referencing, discussing and assessing knowledge accessing his extensive social network in the process. He demonstrated a deep knowledge of how to deal with complexity and applied personal judgement based on his experience. The older expert was experienced in identifying opportunities for refining and retaining knowledge that a younger, less experienced person may not have noticed. Once used in a practical setting, such knowledge was refined with other subject matter experts and disseminated to the industry. His actions in retaining knowledge reflected elements of Zack's (1999a) knowledge life cycle.

In observing the expert, I identified specific examples of knowledge retention, evidenced by a set of distinct actions. The applications, contributions and end benefits of knowledge retention for BRANZ were discussed in relation to Berends' (2005) framework. 


\section{PART 4: DISCUSSION \& CONCLUSIONS}

This final part of the thesis begins with a discussion of some limitations and benefits of the research methodology, and explains how matters of credibility, validity and trustworthiness were addressed (Chapter 9).

Based on an interpretation of the results from the study on the knowledge of older experts, a model is presented in Chapter 10 (p. 243)that combines an analysis of expert knowledge demonstrated in the helpline business process, with an adaptation of a model of wisdom.

Many of the factors of expertise from the adapted model were identified in the helpline problem solving and knowledge retention processes, with actions and advice representing instances of knowledge being enacted by an older expert. A summary of results organised in accordance with the elements of the framework is also presented.

An integrated view is developed, showing how the knowledge framework of the older expert is meaningful in the context of the helpline knowledge retention process.

Finally the thesis closes with a discussion of implications, limitations and conclusions of the research in Chapter 11. 


\section{Chapter 9. Action research - limitations and benefits}

Having provided a brief overview of how quality may be measured in action research (Section 3.5, p. 87), I now present a detailed assessment of the research in relation to some perceived limitations of the action research method, and how they were mitigated. I then discuss the credibility, validity and trustworthiness of the study and its findings.

\subsection{Limitations of action research and some mitigations}

Although action research as a method demonstrates strong relevance through the applicability of its results in real-life situations, there is much commentary on the limitations of action research and how they may be addressed (Avison, et al., 2001; Baskerville \& Wood-Harper, 1996; Kock, 2004; McKay \& Marshall, 2005; Rapoport, 1970). Baskerville and Wood-Harper (1996) however, note that some of the limitations are challenges in social science research rather than being specific to action research.

\subsubsection{Lack of control, contingency and subjectivity}

If the researcher lacks control over the research environment, there is a risk of the findings being of a contingent nature and difficult to generalise, and there is a risk of subjectivity and personal bias on the part of the researcher, according to Kock's (2003) discussion of the threats to action research that arose in the course of his study.

First, if the researcher has no previous relationship with the organisation that is the subject of the study, for example, he or she may not be able to collect sufficient data to complete the study, or the intervention may result in organisational efficiency at the expense of the quality of working life. Neither of these issues arose in the course of the study. I was able to gain access, without any difficulty, to both organisations participating in the study, despite not having a previous relationship with either. I believe this was because senior staff I contacted had a genuine interest in the research topic. The interventions that were introduced at BRANZ enabled the helpline to be more efficient during a time of increased workload. Although the implementations required additional effort beyond the technical adviser's usual duties, they led to time savings that enabled him to catch up on his work load over a period of several weeks. 
Second, if the researcher collects data that is too broad and shallow, it may be difficult to isolate specific data that prove effects or theories relating to the research question. This may lead to findings that are contingent in nature and lacking external validity.

Data were collected using a range of methods including conducting semi-structured interviews and focus groups; accessing organisational records and documents; and observing helpline calls, processes and actions. Data from some stages of the study were broad and conceptual in nature, while at other stages, they were detailed and specific. I was also able to discuss my interpretation of the data with the people from whom I had collected them. For example, I discussed with the technical adviser my observations and interpretation of his actions as I documented some of his processes. Another example was the ability to get feedback from individual interviewees on concepts of valuable knowledge that I had distilled from their interviews. This strengthened my findings from two earlier action research iterations. Within the first stage of the study, involving the organisation as the unit of analysis, validity was demonstrated when two datasets from different organisations yielded many common themes.

Finally, subjectivity, or the inability to be impartial (Baskerville \& Wood-Harper, 1996), presents a risk if there is too close a relationship between the researcher and the organisation, resulting in personal bias into the findings. However, Kock (2003) questions the ability to remain a detached researcher while introducing interventions. Personal involvement in the unit of analysis may also lead to subjective interpretations of data. Externalisation bias may also be evident in explaining negative outcomes in action research, meaning the researcher may not recognise his or her own role in a specific negative outcome, thus externalising the cause.

With no previous relationship with either organisation or any of their staff, my role was solely as a researcher. Although I spent several hours at a time in my observations of the helpline, much of this was while the technical adviser was talking with callers and helping them with problem-solving. I had discussions with the technical adviser between calls and these focused on helping me understand my interpretations of call content, which was often technical, and his logic for taking certain steps in problemsolving. I believe this went some way towards reducing subjectivity, although all interpretations of data collected by qualitative methods are influenced, to some degree, by the personal beliefs, experiences and perspectives of the researcher. 
Within the action research methodology lies some remedial mechanisms. Careful attention to the unit of analysis is an antidote to all three threats outlined, especially the contingency threat. Researchers need to be specific about the unit of analysis from the outset of the study, and the more units of analysis are studied in different contexts, the higher the external validity that can be demonstrated. Progressing through a series of coding steps enables a researcher to develop a model or theory that validates high level findings. The coding process also results in an index for referring to intermediate states of data analysis, providing some traceability.

Executing multiple iterations of action research enables the researcher to collect data cumulatively, in different contexts. This has the effect of building upon earlier iterations and strengthening findings in subsequent action research cycles and in wider environments. Completing multiple cycles of action research assists with proving external validity and reducing the threat of uncontrollability. Conducting action research cycles in several organisational contexts reduces the contingency threat.

\subsubsection{Lack of methodological rigour}

Although action research is very relevant due to its focus on solving problems that are meaningful to practitioners, it is criticised for its lack of rigour as a methodology. Rigour may be defined as "the correct use of methods and analyses appropriate for the tasks at hand" (Benbasat, Goldstein, \& Mead, 1987 p. 5). Baskerville and Wood-Harper (1996) note that lack of rigour is a valid criticism of liberal action research, in which researchers focus more on solving the practical problem than extending theoretical knowledge. However, as far as rigorous action research is concerned, researchers can be guided by the very requirements that define action research: "disciplined constructs of cyclical theoretical infrastructure, data collection and evaluation ... a clear cycle of activity; ... a premise; ... a pronounced theory (under test) ... empirical data collection (e.g. diaries)" (Baskerville \& Wood-Harper, 1996, p. 241). Davison, Martinsons and Kock (2004) also note that a degree of rigour is inherent in Susman and Evered's (1978) action research model itself.

\subsubsection{Context bound nature of results}

Because action research is not free of its context, the result of an intervention cannot be isolated from the environment, researcher or methodology (Baskerville \& WoodHarper, 1996) and cannot be replicated exactly in another context. This, however, is the 
nature of the methodology, and because action research studies are carried out in response to a practitioner need, there is an opportunity to develop or discover a theory from the context. These authors note this as a crucial part of action research, and the need to further test and generalise a theory is no less important than with other methods.

\subsubsection{Indistinguishable from consulting-Rapoport's "role dilemma"}

A criticism of action research is that it is indistinguishable from consulting (Avison, et al., 1999; Baskerville \& Wood-Harper, 1996). This view appears to arise from three sources. First, some action research studies have been written up in a manner that places more emphasis on the practical solution of organisational problems and less on the contribution to theory. An imbalanced representation of action aspects and research aspects may lead to criticisms of action but not research being carried out. Second, an observation from the action research literature is that some action researchers are, or have been, consultants. This may lead to a perception of consulting as the focus of the project. Last, some researchers appear to conduct action research within or alongside a paid consulting assignment with the same organisation that is the subject of research. This may lead to perceived and real role confusion. Zuber-Skerritt and Perry (2002) distinguish between collaborative projects occurring in the workplace, and individual thesis work in action research that aims to make a contribution to theory in the researcher's domain of expertise.

This action research study balances the solution of an organisation problem with a contribution to theory, as presented in Chapter 10. Although I have some background in consulting, this is a small proportion of my career experience, and during my research, I was a full-time student with no prior relationship with either organisation.

Baskerville and Wood-Harper (1996) note four responses to the issue of role dilemma. Researchers need to keep more rigorous documentation than consultants, researchers require theoretical justifications compared with consultants' solely empirical focus, consultants are limited in time and budget, and lastly, action research is cyclical compared with the linear consulting process. 


\subsection{Matters of credibility, validity and trustworthiness}

\subsubsection{Credibility}

The research study was outlined in a formal proposal and was approved by Victoria University's Human Ethics Committee as part of the academic requirements. The study design adhered to four common guidelines that Christians (2000) describes.

First, informed consent was gained from each study participant, with the terms and conditions of consent approved by the HEC. Participants contributed voluntarily, and their agreement was based on the full information I provided about the objectives of the study. I distributed an information sheet and consent form to participants at each stage of the research cycle so they could prepare for the interviews - Appendix A.

Second, there was no deception of participants. The objectives and findings of the study were agreed with the sponsors and made available to all participants through the sponsor or researcher. The approach for the study of both organisations was agreed in advance with the sponsor, and any changes required to the approach were discussed and agreed as they emerged. In BRANZ's case, a series of interviews was held with external customers. I realised in planning the research approach that customers may have issues with the organisation or its services. While these would feature in my findings, the organisation would not be able to find out more about the issues or to address them, due to the customer anonymity aspect. The other factor was that alongside my interest in the opinions and perspectives of customers from my research perspective, BRANZ was also curious about customer opinions, partly because it had not recently sought detailed feedback about the business process I was studying. Before each interview, I checked whether the interviewee preferred to remain anonymous to the organisation, or whether he or she would be comfortable with being known. All of the interviewees consented to being named, so I was able to be transparent in reporting my findings to BRANZ.

Third, people's and organisations' privacy and confidentiality must be protected against unwanted exposure, as far as possible. "Despite the signature status of privacy protection, watertight confidentiality has proved to be impossible. Pseudonyms and disguised locations are often recognised by insiders. What researchers consider as innocent is perceived by participants as misleading or even betrayal. What appears neutral on paper is often conflictual in practice" (Christians, 2000, p. 139). Section 6.1 explains how this study addressed the intricacies of attempting to maintain 
confidentiality in the context of an organisation's profile and an individual's profile within the industry in which they operate.

Last, accuracy of data is an important principle in social science research, and the methods used to collect data must also be moral. Data accuracy is instrumental in contributing to the validity of the research findings. In each instance of data gathering, I arranged for interviewees to complete members' checks, or respondent validation (Silverman, 2005) as soon as practicable following transcription. Participants and interviewees were given the opportunity to check and confirm that their contributions had been recorded correctly, and to provide additional information if they wished.

\subsubsection{Validity}

The concept of validity has its origins in quantitative research. While validity may be seen as a positivist concept (Guba \& Lincoln, 1994), it is still a useful concept in qualitative research, although it takes a different form depending on the research method used (Janesick, 2000; Maxwell, 1992; Perakyla, 1997).

Maxwell views validity as demonstrating various types of understanding in the case of qualitative researchers, representing the relationship between an account and the phenomenon being described. He describes five dimensions of validity: descriptive, interpretive, theoretical, generalisability and evaluative.

First, primary descriptive validity refers to the accuracy with which the researcher reports or describes objects, events and behaviours; secondary descriptive validity relates to inferred accounts from other data.

Second, interpretive validity is demonstrated when the researcher has appropriately represented the meaning of the phenomena in relation to the people involved with them. Thus, the researcher has shown understanding not from his own perspective, but from the participants' perspective, including their beliefs and values.

Third, theoretical validity relates to the theoretical construction that the researcher brings to the study or develops during the study, by abstracting the account of the phenomena studied, so that the account becomes an explanation of the phenomena. The theory consists of concepts and categories that the theory uses, and relationships between those concepts. The concepts and categories need to be valid in relation to the phenomena studied. 
Fourth, generalisability is the ability to extend the findings of a study of a particular situation to a different one. Generalisation to a wider population is not generally a characteristic of qualitative research. However, there is an assumption that the theory could be used to explain similar situations. Internal generalisability relates to the validity of the study to others within the same group who were not directly involved in the study. External generalisability is achieved if the findings can be extended to other groups, or instances of the unit of analysis.

Last, evaluative validity relates to the "application of an evaluative framework to the objects of study" (Maxwell, 1992, p. 295). This type of validity may be less important for qualitative researchers, who often do not evaluate the phenomena being studied.

Questions about whether a piece of research is sufficiently authentic, in that it represents some form of reality, whether it its trustworthy and "related to the way others construct their social world" (Guba \& Lincoln, 1994, p. 178) and whether there is sufficient trust to act upon the findings, are highly relevant in the case of this action research study, where action taking is based on diagnostic findings. The merging of research method and interpretation of the results means that both aspects are implicated in the emergence of a truth that can be related to the research context, and is meaningful to the organisations involved. The dual cycles of action research focus the researcher on the research design in a conceptual space that is distinct from executing the research in the real world (McKay \& Marshall, 2005).

Lincoln and Guba (2000) regard validity as authenticity, measured by a set of criteria:

- fairness: achieved through balancing the views and concerns of research participants and other stakeholders

- ontological and educative authenticity: relates to the ability of individual research participants to gain a raised level of awareness as a result of the research, and individuals' increased awareness of those around them in the organisation

- catalytic authenticity: where inquiry results in participants taking action, as happens in action research

- tactical authenticity: where needed, participants are trained to take action

These authors also note that action-taking, in itself, may destabilise objectivity and introduce bias in the results of the research. However, complete objectivity is 
impossible, since the act of knowing is inseparable from the experience and influence of the knower. "As observers and interpreters of the world, we are inextricably part of it; we cannot step outside of our own experience to obtain some observer-independent account of what we experience. Thus it is always possible for there to be different, equally valid accounts from different perspectives" (Maxwell, 1992, p. 283).

Lincoln and Guba's criteria can be met in this study in several ways. One method of achieving fairness was through the presentation of study results. In particular, business reports were subject to review by study participants, and the project sponsor from an overview perspective. The sponsor can be seen as being responsible for confirming balance and fairness to the organisation. Ontological and educative authenticity results in increased levels of awareness about the research topic and about the world around the participants and their organisation. The research covers new ground for the organisation and will reveal new knowledge about the views and behaviour of the organisation and the participants. I believe catalytic authenticity and tactical authenticity are both inherently the result of an action research study. Action-taking is a step in the action research cycle and participants should be able to take action again to implement organisational changes in similar circumstances in future.

Triangulation may be used to reduce misinterpretation of data, and using more than a single means of gathering data (Stake, 2000) may provide the researcher with multiple perceptions to develop consistent meaning to findings. However, as observations and interpretations cannot be totally repeatable, triangulation serves as a cross-check to clarify the meaning of phenomena. The data sources for this study are organisational records, interviews, workshops and the researcher's journal (Section 4.6, p. 122).

According to Hammersley (1990), the two key elements of validity are plausibility and credibility; whether claims in research are believable on the basis of the audience's knowledge, and whether they are credible on the basis of the evidence that the researcher provides. The evidence itself also needs to be credible. However, plausibility and credibility are potentially non-consensual social judgements (Hammersley, 1990; Silverman, 2005; Smith \& Deemer, 2000). Smith and Deemer discuss the problems with setting criteria for judging social and educational enquiry in an age of relativism. They posit that relativism is relevant to any discussion on criteria and moreover is at the core of our human existence, and note Maxwell's (1992) view that validity is relative because understanding is relative. 
In describing the characteristics of quality in qualitative research, Silverman (2005) notes five ways in which researchers can think more critically about data analysis, to produce findings that are more valid. First, greater objectivity may be achieved by trying to refute the initial assumptions about data. However he notes that knowledge is provisional, as further studies may result in different knowledge. Second, the constant comparative method leads researchers to either find more cases to test the validity of a hypothesis, or to ensure that all data are compared. Third, data analysis needs to be comprehensive and include all sources of data. Fourth, deviant cases or data should be included in the analysis until the scheme and rules include all the data analysed. Last, the use of appropriate, accurate and meaningful tabulations leads to increased validity.

CMeasures of quality in action research may be derived from the dimensions of the method: "worthwhile practical purposes, democracy and participation, many ways of knowing, and emergent developmental form" (Heron \& Reason, 2001, p. 187).

\begin{tabular}{|c|c|}
\hline $\begin{array}{l}\text { Characteristic or } \\
\text { quality }\end{array}$ & Elements the researcher needs to consider \\
\hline $\begin{array}{l}\text { Worthwhile } \\
\text { practical purposes }\end{array}$ & $\begin{array}{l}\text { - stating whose reality is being represented } \\
\text { - assisting with forming an effective community of } \\
\text { inquiry among the study participants }\end{array}$ \\
\hline $\begin{array}{l}\text { Democracy and } \\
\text { participation }\end{array}$ & $\begin{array}{l}\text { creating a communicative space (Kemmis, 2001) to } \\
\text { encourage more open dialogue and communication, } \\
\text { which requires time and effort, and may be more } \\
\text { important than solving the action research problem itself } \\
\text { - recognising power and politics; denial of the issue being } \\
\text { studied } \\
\text { managing consensus collusion, where like-minded } \\
\text { participants dominate with one version of reality } \\
\text { managing tensions between role of facilitator and the } \\
\text { community under study }\end{array}$ \\
\hline $\begin{array}{l}\text { Recognising many } \\
\text { ways of knowing }\end{array}$ & $\begin{array}{l}\text { - recognising experiential, presentational, propositional } \\
\text { and practical ways of knowing } \\
\text { - challenging preconceptions } \\
\text { - looking at narratives in a way that is different from the } \\
\text { predominant culture of the group or organisation; } \\
\text { express accounts in new ways } \\
\text { - critiquing existing theories and forging new ones }\end{array}$ \\
\hline $\begin{array}{l}\text { Emergent } \\
\text { developmental } \\
\text { form }\end{array}$ & $\begin{array}{l}\text { - recognising that good action research evolves over time, } \\
\text { thus cannot be closely planned, thus it is acceptable for } \\
\text { results not to be foreseen } \\
\text { recognising that the whole practice of action research is } \\
\text { emergent }\end{array}$ \\
\hline
\end{tabular}

Table 9-1: Characteristics of quality in action research (Reason, 2006) 
The quality and transparency of the action researcher's choices are important, as shown in Table 9-1 (p. 240). Four characteristics or qualities are considered important in action research, and specifies elements that the action researcher needs to consider.

Another perspective centres upon authenticity as a quality of the researcher "authenticity may be framed in terms of being attentive, intelligent, reasonable, and responsible in engaging with the challenges of action research" (Coghlan, 2008, p. 351). Applying such qualities as a researcher enables us to engage with data while being authentic in our action research practice. Coghlan summarises authenticity as consisting of three dimensions: operations, activities and precepts (Table 9-2, p. 241).

\begin{tabular}{|l|l|l|} 
Operations & Activities & $\begin{array}{l}\text { Transcendental } \\
\text { precepts }\end{array}$ \\
\hline Experience & Attending, sensing, imagining & Be attentive \\
\hline Understanding & Inquiring, understanding & Be intelligent \\
\hline Judgement & $\begin{array}{l}\text { Reflecting, weighing evidence, } \\
\text { judging }\end{array}$ & Be reasonable \\
\hline Decision & Deliberating, deciding, acting & Be responsible \\
\hline
\end{tabular}

Table 9-2: Dimensions of authenticity (Coghlan, 2008, p. 360)

\subsubsection{Trustworthiness}

A story is convincing, in the clinical sense, if the study fulfils three criteria, which also appear to be relevant for action research study within organisations. First, the research question needs to be relevant to the participants and the study must answer the question. The relevance of the research questions was confirmed through the process I used to recruit study participants. This involved identifying organisations that might be interested, to proceed with two organisations who wre both sufficiently interested in the topic and were in a position to participate in the research. The research topic builds upon growing concerns about the ageing of the workforce and the loss of knowledge. The scope of the research topic includes knowledge management and ICT, two areas of concern for the organisations I approached.

Second, the researcher needs to recognise that the audience or stakeholder is also a participant in research, and this should be evident in documenting the research. This is addressed in Section 4.2.1 (p. 93). The sponsors of my research in both organisations and other members of the senior management team were participants as well as recipients of the research findings. In presenting my research, I have considered the audiences as my research conclusions are more likely to make sense to readers if they 
can relate the story to their own experiences. For example, the findings on the organisational aspects of valuable knowledge that appear in Chapter 5 were written up in the form of business reports for the two organisations. The research outputs therefore included business reports, structured and presented in a format that was relevant to the organisations involved. This was addressed through language, writing style and presentation formats.

Last, the research should reveal assumptions about the participants' lives and perspectives, for example behavioural, social and cultural. The philosophies, perspectives, culture and attitudes of the organisation and individual participants play an important role in the research. These assumptions began surfacing early in preliminary discussions with the organisations, shedding light on their current state, beliefs and attitudes, and have been taken into account in the presentation of the research.

\subsection{Summary}

The study was conducted using action research methods, which have some limitations that can be mitigated. The absence of prior relationships with either participant organisation did not hinder access to the research sites or inhibit my ability to gather sufficiently detailed data to complete the study. The lack of prior knowledge of either organisation meant that personal bias was minimised, and participants saw me only in the role of researcher. Findings from the study are inevitably context-bound, since data have meaning in the research setting, but were able to be generalised to a theory.

The study's credibility was established by compliance with the university's human ethics requirements, to avoid any deception of participants and to ensure that their privacy entitlements were addressed. I was careful to ensure that, as far as possible, data were accurate and the triangulation of results was completed.

In demonstrating the trustworthiness of the study, I sought participants to whom the study topic was relevant. The stakeholders of the study were also participants, and I reflected this in the documentation, providing the stakeholders with business reports at each stage where I developed findings. Trustworthiness is also evident in the research, as it revealed assumptions and discoveries about participants' behavioural, social and cultural perspectives, which were confirmed by the stakeholders. 


\section{Chapter 10. A wisdom-related knowledge framework}

Phase 2 of my study included observations of an older expert in action within an important business process, the helpline advisory service. I described a series of knowledge retention actions, presenting an integrated view of his knowledge retention process (Chapter 7). I then addressed the older expert's use of knowledge and his actions in updating knowledge for retention in the organisation. His expertise was in the subject matter of calls and the helpline process (Chapter 8).

Following the analysis of data and the resultant findings on a specific instance of expertise - that of the BRANZ technical adviser - I now propose a wisdom-related knowledge framework, based on two components. First, Baltes \& Staudinger's (2000) research framework for wisdom-related knowledge, described in Section 10.2.3, is presented as a relevant candidate framework for interpreting the expertise of older workers. Its concepts can be adapted to represent expertise in the helpline context.

Second, the elements of expertise can be related to the knowledge retention process with the use of ICT, as identified in the helpline, presented in Section 7.2.8 and depicted in Figure 7-12 (p. 208). Thus, my proposed framework incorporates representations of expertise and knowledge retention. Next, I apply the knowledge framework to the expertise of the older expert operating the helpline and present the findings. The study makes some unique contributions in identifying additional examples of expertise factors. The framework is then extended to include these factors (Figure 10-2, p. 251).

Finally, I discuss the occurrence of the expertise factors in the knowledge framework in each step of a high level knowledge retention process that has been generalised from six detailed processes (Section 10.4, p. 266).

\subsection{Baltes \& Staudinger's research framework}

The "research framework describing antecedent factors and mediating processes for the acquisition and maintenance of wisdom-related knowledge and skills across the lifespan" (Baltes \& Staudinger, 2000, p. 3) described in the literature review on wisdom theory, in Section 2.5 .2 (p. 49), is shown as Figure 10-1 (p. 244). I then discuss the framework and its relevance in presenting findings on the expertise of an older expert. 


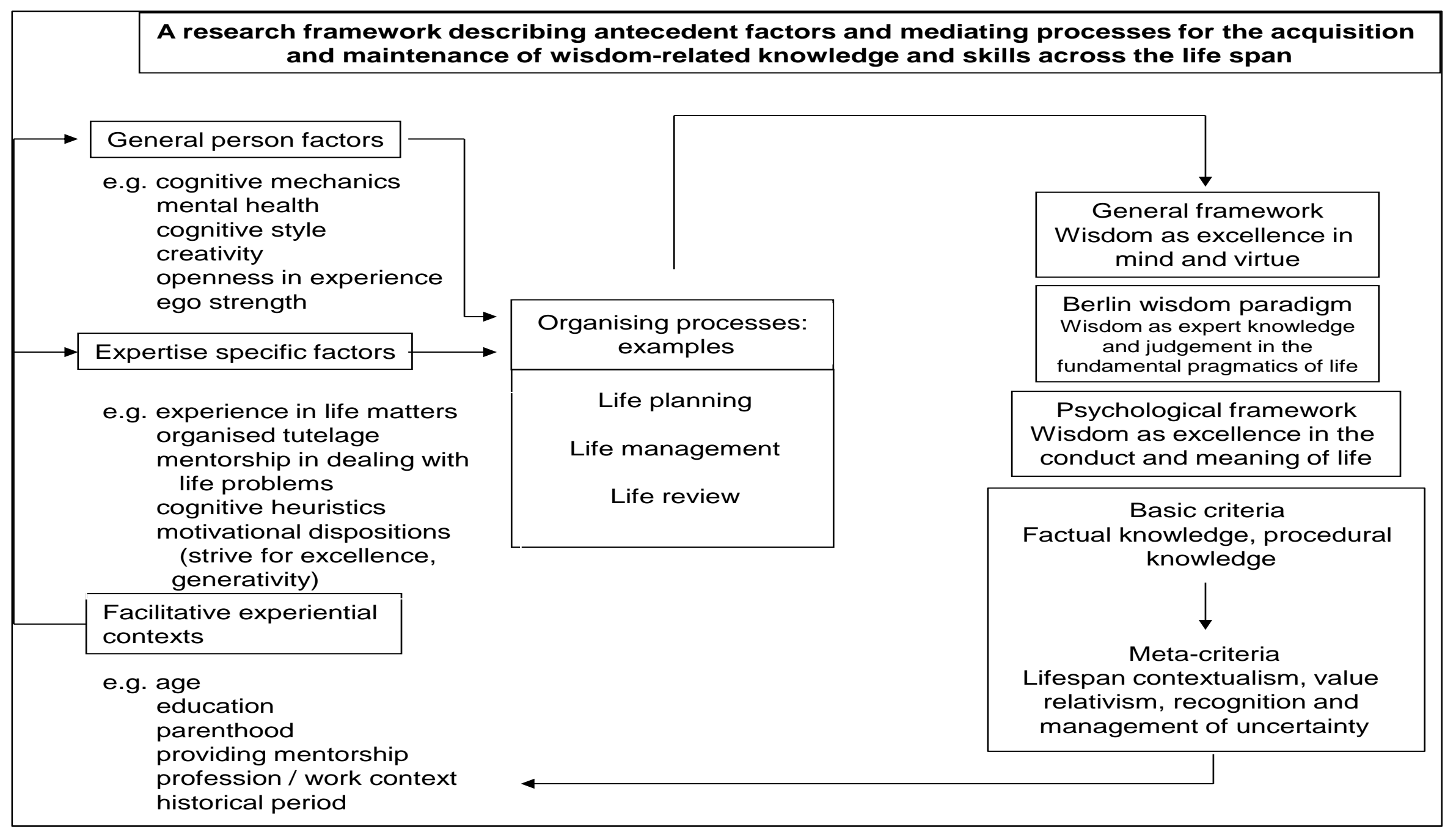

Figure 10-1: Research framework (Baltes \& Staudinger, 2000, p3) 
The framework was developed as a result of Baltes and Staudinger's research on wisdom, including their analysis of implicit and explicit theories of wisdom from their perspective as psychologists. While they acknowledge that it is difficult to operationalise the concept of wisdom, partly because of the diverse inter-disciplinary nature of wisdom studies, they describe the above framework as one way of representing the characteristics of wisdom-related knowledge. Although it shows processes for the acquisition of knowledge and skills, the scope of my study of expertise in the BRANZ helpline is limited to findings based on a snapshot of data at a point in time. Therefore, the subject of acquisition of expert knowledge falls outside the scope of the current study, which is limited to the findings in relation to aspects of expert knowledge that were identified from the data collected.

\subsubsection{Discussion of Baltes and Staudinger's framework}

The right side of Figure 9-1 (p. 244)depicts some qualitative criteria for wisdom as it may appear in individuals or in a society. Factual knowledge and procedural knowledge constitute elements of wisdom-related knowledge, with factual aspects including "variations in developmental processes and outcomes, interpersonal relations, social norms ... and knowledge about the coordination of the well-being of oneself and that of others." (Baltes \& Staudinger, 2000, p. 125). Procedural aspects refer to strategies and approaches for providing advice, handling decisions and conflicts, and having alternative strategies. Sourced from the study of cognition and personality are three meta-criteria. First, lifespan contextualism refers to knowledge about life contexts such as education, work public good and culture — and inter-relationships among these factors. Second, value relativism pertains to an individual's values in relation to those of society, and the ability to recognise and tolerate differences in values. Finally, the ability to recognise and manage uncertainty demonstrates the notion that there are constraints on human capabilities for information processing, understanding reality and knowing what the future holds.

Other concepts represented in this part of the framework include the notion of wisdom as being focused on excellence and linking the mind to virtue, on excellence in the way individuals conduct their lives, and on expert judgement in the pragmatics of life. The authors also note that the concept of personal well-being and common good underpins all the factors, although this may not appear obvious in the framework. This notion of 
common good is highly relevant in the case of expertise discussed in Section 10.3 (p.252)

In the middle part of the figure are the organising processes such as the activities of life planning, management and review, which contribute to the development of the aforementioned wisdom-related skills and knowledge. The organising processes are influenced by an individual's general person factors and expertise specific factors.

The meta-criterion of lifespan contextualisation operates in concert with the general person factors such as intelligence and personality, and the expertise-specific factors on the left side of the framework to influence the development of wisdom-related knowledge and skills. Facilitative experiential contexts such as age and profession influence an individual's experience and their personal factors.

Baltes and Staudinger's framework is informed by several empirical findings from their research that I also found to be relevant to the study of expertise in the BRANZ helpline environment. Wisdom-related knowledge and judgement do not begin to decline once adulthood is reached, and as mentioned in Section 6.2, the presence of wisdom in an individual is not a function of age alone. Wisdom involves the balancing of several types of human functioning, implying "a coordinating configuration of multiple attributes, including knowledge associated with specific life experiences" (Baltes \& Staudinger, 2000, p. 129). Finally, the concept that wisdom is a collectively anchored product and that individuals may be weak carriers of it (Baltes \& Smith, 1990), was supported by research that found that higher levels of wisdom-related performance where problems were solved through social collaboration followed by reflection.

\subsubsection{Appropriateness of framework of wisdom-related knowledge}

Many of the models discussed above are pertinent to the study of various aspects of knowledge retention. However, in analysing the data from the specific study of an older expert, it was found that the nature of the emerging findings lent themselves to representation through a model that would elucidate the nature of the expertise through the lens of age and experience, and give credence to observations of an expert in action in the context of his daily business process. To meet these requirements, the business process needed to be made explicit and a specific wisdom-related framework is more appropriate in capturing the concept of uniqueness through the integration of features of 
the older expert - such as age, effectiveness and the layering of expertise and experience, as described in Section 6.2.

The data exhibit numerous demonstrations and examples of individual expertise and knowledge. Moreover, some elements of wisdom were directly observed in the actions of the expert studied. It can be shown that these actions fall within the scope of the conclusions about wisdom and the characteristics of wisdom that Baltes and Staudinger describe, as addressed in the literature review in Section 2.4 .3 (p. 41) and in the summary contained in Table 2-5 (p. 51).

The development of expertise over time also mirrors the process by which some individuals may develop wisdom with age (Ardelt, 2000, 2004; Knight, 1999), based on the correlation between wisdom and age (Kunzmann \& Baltes, 2003). Baltes and Studinger (2000) provide a framework that forms an appropriate basis for the presentation of findings in respect of this older worker for four reasons.

First, the framework has been structured upon research on "successful lifespan development" (Baltes \& Staudinger, 2000, p. 127), demonstrating a focus on older people as subjects most capable of providing insight into knowledge and behaviour from experiences over a longer lifespan. Their empirical findings on the role of age in wisdom performance indicate that more older than younger people are represented at the highest levels of performance (Staudinger, 1999), with a remark to the effects that the most wise may be in their sixties. Given that the findings from the study at BRANZ involve discoveries about expertise and the actions that demonstrate expertise in an older worker, an approach based on many studies of older people carries much weight and meaning.

Second, part of the richness of the research on wisdom stems from the diversity of disciplines from which it emerges. However, the common thread is that by definition, wisdom is premised upon a focus on excellence and the use of knowledge for individual well-being and common good, from a societal point of view. This is reflected in characteristics of the knowledge loss problem in that as older experts are progressively being lost from the workforce, the effects will have widespread impacts. Other remaining workers must continue delivering equal or better services without their expertise, organisations as employers will be affected, as will industries that rely on that knowledge. At the highest level, BRANZ's business process involves scientific research 
and its conversion into value-laden knowledge products for the industry that partially funds its existence.

Third, the Berlin wisdom paradigm incorporates the Western approach of "wisdom as a theory of expert knowledge, judgement and advice" (Baltes \& Kunzmann, 2004, p. 290) in a specific domain, that of the elemental practical aspects of life (Baltes \& Staudinger, 2000). Thus, wisdom represents a specific type of expertise. Therefore, their framework can suitably be adapted to explain findings on expertise in a different knowledge domain, that of a business process within an organisational context. Baltes and Staudinger note that wisdom is a more general body of knowledge, compared with the fact that much of the research on expertise has centred on factual and procedural knowledge, both of which are actually represented in the framework.

Finally, over the last few decades there has been a resurgence of interest in both wisdom and expertise, coinciding more recently with concern about knowledge loss from the work place due to demographic trends, and ensuing interest in the types of knowledge and expertise that older workers may possess. Furthermore, the Berlin group's research is guided by the principles of positive psychology and positive ageing. This provides a relevant and useful perspective for organisations because it recognises older workers as potentially having valuable knowledge that should be understood and retained. In a similar way in which "wisdom, although difficult to achieve and specify, is easily recognized when manifested" (Baltes \& Staudinger, 2000, p. 123), the components of expertise may not be evident until an expert is observed in action.

\subsection{Adaptation of framework concepts}

Based on the discussion in Section 10.1.2 of the suitability of Baltes \& Staudinger's framework, I explain in this section how it is adapted conceptually and applied in the current study of expertise. The idea that "wisdom is fundamentally a cultural and collective product in which individuals participate" (Baltes \& Staudinger, 2000, p. 127) has similarities with the idea of knowledge and expertise as being organisational assets of which individuals are weak carriers and contributors. Following a discussion of the components of Baltes and Staudinger's framework as shown in Figure 9-1 (p.244, an adapted version is presented in Figure 10-2 (p. 251). 


\subsubsection{Frameworks and criteria}

Baltes and Staudinger's concept of "wisdom as excellence in mind and virtue" has been adapted to encompass the idea of expertise as excellence in mind and virtue, being applied with the motivation towards the common good. Within the study environment, an organisational business process, the idea of good relates primarily to professional and organisational well-being. In this context, the application of tacit knowledge may be observed, in terms of the mind being geared towards virtue (Sternberg, 1998), and therefore the concept of common good is relevant to the context of the study.

The degree to which the psychological concept of "wisdom as excellence in the conduct and meaning of life" is applicable in the context of the study is unclear. In terms of the data gathered, examples of actions or pieces of advice that could be categorised in this way were not obvious, probably due to the business scope and technical context of the service. Likewise, the Berlin wisdom paradigm, "wisdom as expert knowledge and judgement in the fundamental pragmatics of life" may not be supported by the data gathered in the helpline context. It may be regarded as a paradigm relating more towards the existence of wisdom - expertise in terms of knowledge and judgement is represented on the other side of the diagram under "expertise specific factors". These two concepts in the originating framework have thus not been applied.

The basic criteria of factual knowledge and procedural knowledge are themselves dimensions of expertise in any domain, therefore these concepts are directly applicable to the study. The meta-criteria of value relativism and recognition and management of uncertainty are also relevant and meaningful in the study of expertise. Baltes and Staudinger describe value relativism as the recognition and tolerance of differences in others in the interest of the common good. Applied to expertise, an example of this would be the recognition that people in an industry will hold different perspectives depending on their respective roles. The ability to recognise and manage uncertainty is also an attribute of expertise, as shown in Section 10.3. The authors' research involved measuring subjects' performance in the basic criteria and the meta-criteria by getting them to solve life problems. In the context of this qualitative study, I observed the expert in action and sought the opinions of others sought on his expertise in solving technical problems and providing advice. 


\subsubsection{Factors and contexts; organising processes}

In summary, general person factors, expertise specific factors and facilitative experiential contexts can be recognised as conditions relevant to expertise. Some of the examples expressed in Baltes and Staudinger's framework are applicable, and I also propose additional examples that were identified from the data collected.

First, examples of general person factors for expertise include cognitive style, creativity and openness to experience from the framework - as well as personality, judgement, values, confidence and reputation. Second, expertise specific factors include experience in life and professional matters and motivational dispositions such as striving for excellence and generativity. Additional factors include industry experience, knowledge of responsibilities, roles and politics, knowledge of theory and practice and support in problem solving. Finally, facilitative experiential contexts, being those that assist the development of expertise, include age, professional work content, and historical period - together with career background, qualifications, social network and relationships, knowledge transfer and mentoring and knowledge facilitation.

The organising processes of work planning, work management and work review are all directly applicable to the study of the helpline. They are perpetual and organising in nature and can be shown to be present in the expression of expertise.

\subsubsection{Knowledge framework of individual expert}

In adapting Baltes and Staudinger's framework for use in the analysis of expertise in a business process, I took three steps involving the data that I had collected about the technical adviser, to arrive at a resultant framework representing the knowledge of an individual expert, as depicted in Figure 10-2 (p. 251). The examples of factors which represent unique contributions as a result of this study are highlighted by an asterisk in the figure. 


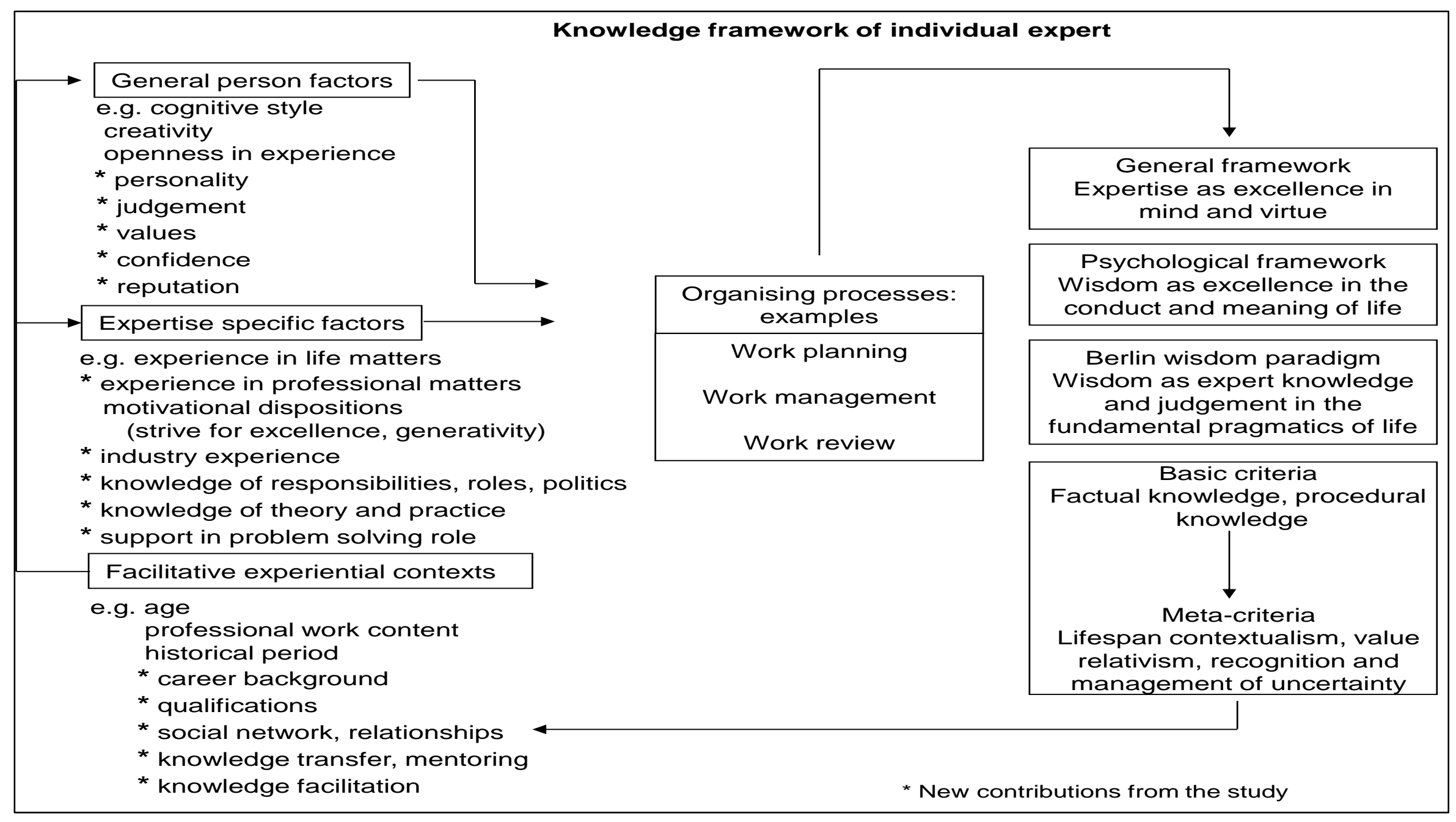

Figure 10-2: Knowledge framework of individual expert (adapted, Baltes \& Staudinger, 2000) 
First, I located all the interviews, transcripts, digital recordings, notes and researcher's journal entries relating to the technical adviser as the older expert. These data provided me with insights into his problem-solving processes, knowledge and skills. The notes I made during my observations reminded me of instances where he had exercised sound judgement, while interview scripts contained many references to his colleagues' recall of his knowledge, for example of building theory and practice.

Second, I analysed the data to identify examples of the factors, such as general person factors and expertise specific factors, shown in Baltes and Staudinger's framework. Some of Baltes and Staudinger's examples do not appear on my resultant framework because I did not identify them in the data.

Third, I analysed the data again to identify additional examples under the categories of general person factors, expertise specific factors and facilitative experiential contexts.

Many additional examples of such factors emerged from the data and these represent a key contribution of the study. Under general person factors, I identified in the data instances of personality, judgement, values, confidence and reputation. In the case of expertise specific factors, I found excellence in professional matters; industry experience; knowledge of responsibilities, roles and industry politics; knowledge of theory and practice; and support in the problem-solving role. Additional examples of facilitative experiential contexts found in the data included career background; qualifications; social network and relationships; knowledge transfer and mentoring; and knowledge facilitation.

Following this analysis, I updated the framework to reflect my findings. This adapted framework therefore includes the factors from Baltes and Staudinger's (2000) framework that I have described as being relevant to the study of the individual older expert, with the additional examples of factors arising from the analysis of data that were collected.

\subsection{Knowledge framework and helpline expertise}

Next, I present my findings on the expertise that was evident in the technical adviser's processes of answering queries and retaining knowledge. The findings are discussed with direct reference to the factors shown in the knowledge framework of the individual 
expert in Figure 10-2. Following the discussions of those findings, I introduce a taxonomy of the older expert's knowledge, that focuses attention on an expert.

Many of the factors of expertise in the framework were found in the study of the helpline problem solving and knowledge retention processes. I reviewed each of the six detailed knowledge retention processes, as set out in Section 7.2 (p. 187). The initial step was to review the data I had collected, and identify the technical adviser's detailed actions at each process step. The actions for the first example of knowledge retention are shown above the dotted line in Figure 10-3 (p. 254). The second step was to identify what elements of expertise he exhibited, according to the factors shown in the knowledge framework (Figure 10-2), as he proceeded through each step of the process. The elements of expertise I found are shown below the dotted line in the same figure.

I then repeated the same two steps with the remaining five knowledge retention processes. The following sections present a summary of results organised in accordance with the elements of the knowledge framework adapted from Baltes and Staudinger (2000). The supporting diagrams showing the results of the individual analyses of expertise in the other five knowledge retention processes are included in Appendix E.

\subsubsection{General person factors}

The technical adviser applied sound judgement in selecting an approach for answering each call. This led to a better result for the caller, with the quality of advice received. As the knowledge was retained, refined and distributed, the industry also benefited. The helpline call came from a caller who was unable to understand some photographs.

An analysis of the call, shown in Figure 10-3 (p. 254), indicates the presence of many general personal factors at process step 2. The technical adviser adopted a more creative approach and this broadened the scope of the conversation in two ways. First, his cognitive style included the ability to quickly recall his related knowledge — with over three decades of building-related experience, he made judgements about the performance of several other methods, including traditional ones, in relation to the requirements of the Building Code, with confidence and authority. Second, the adviser's openness to experience and curiosity about new knowledge led to the caller, a builder, offering his advice about a new method that he had implemented in several residences. Thus, new knowledge was created and shared with the industry. 


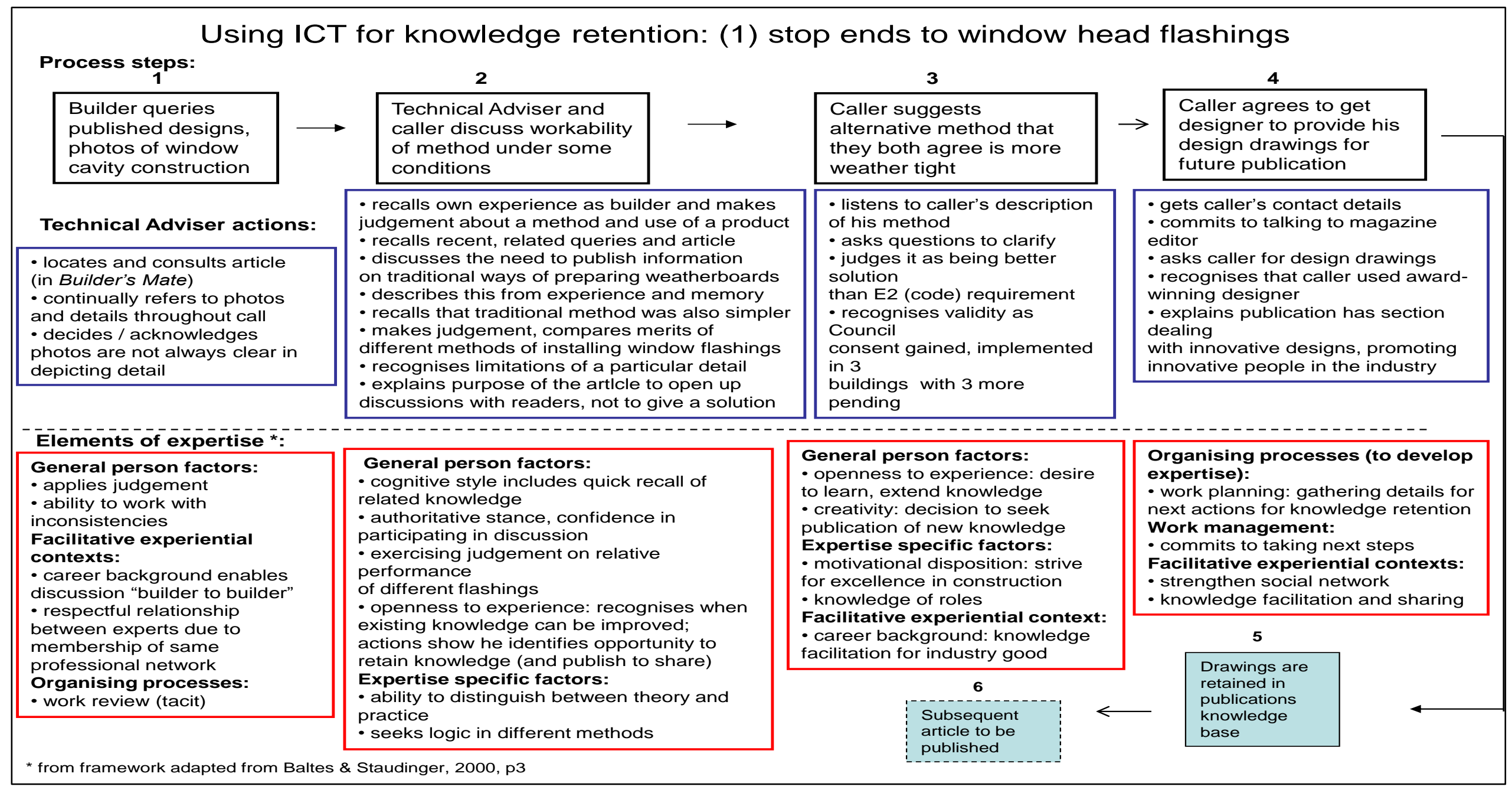

\section{Figure 10-3: Example of general person factors - at process step 2}


The knowledge framework used for the analysis suggests that general person factors are influenced by facilitative experiential contexts. In the study, contextual factors like age, historical period, career background and social networks and relationships contribute to the technical adviser's judgement, confidence and values of accuracy, consistency and fairness. Observations and comments from his peers and customers indicated that he demonstrated values of generativity, where older people contribute knowledge to others (Glass, et al., 2004; McAdams, et al., 1993), and empathy towards people whose problems had placed them at a disadvantage. At the same time, other building professionals identified with his superior knowledge and trusted his advice, as a specialist designer noted:

\section{"I found (the technical adviser) really good because when I talk to} him, he sounds very similar to me. Sometimes you have been doing things over the years that you haven't been taught but you've used your initiative. So you need someone to cross check that with, to make sure you're on the right track, and I find him very good like that.",

The technical adviser had a reputation for giving accurate and authoritative advice, and his cognitive style included skills for concentrated effort to absorb large scale change such as updated regulations. It was crucial that he built up his knowledge in preparation for the implementation of such changes. However, the challenge lay in being able to provide advice while this process was in train. At the time of the study, significant changes were made to Section H1 of the New Zealand Building Code, as explained in Section 7.2.4. He prepared himself for the changes through iterative cycles of learning, clarifying his understanding with technical experts and integrating the new knowledge so he could in turn explain the changes to callers nationwide.

Another example of the importance of cognitive style is in the methods that are used to present knowledge. Since knowledge is conveyed mainly through the use of language (Rooney, undated), and often accompanied by diagrams and drawings in this business context, the framing of language to explain change is also important. The following exchange, as described in Section 7.2.4, is with an architect who needs to understand how to select from several insulation-related calculation methods, so that he can brief his team. During the call, the technical adviser and the architect refer to the process of developing a "patter", the mental script developed for explaining the changes, as they 
discuss details published on the BRANZ web site. This refers to the way in which the changes can most clearly be explained:

"TA: Go to the compliance bit (an area of the web page), 'to start you must have copies of the compliance documents and the standard' (he is reading text from the page and commenting on it). I would have added 'and the BRANZ House Insulation Guide'.

Caller: Yes, I've got that. [from the seminar?] Yes, got that.

TA: Well, read on then, it just cross references there to the other stuff. The schedule ... how do I start? I haven't developed my patter yet for this issue.

Caller: Yes, it's exactly the same problem with me, that's why I've just got to ask you. Well you go with your patter, it's probably easiest.

TA: We'll probably develop one while you sit there. I suppose the first thing would be: what's the percentage glazing?"

The adviser had also learned from his experience in discussing such changes verbally in the past, that callers would understand new information better if they could view a document on line during a discussion. This, in turn, led him to realise that having received numerous calls from the industry, he needed to organise for a document with the key changes, dates and calculations to be published. A published document would complement his verbal advice and minimise the risks of misunderstanding. He recalled several similar major changes in the Building Code in various roles such as construction manager, builder and technical adviser over the last three decades.

Finally, in the examples of Section 7.2.7 where ICT was used for linking digital recordings, general person factors were again evident in the form of the technical adviser's cognitive style for powerful recall. He was able to recall groups of related calls over time that were of significant interest in terms of sharing scientific knowledge, such as the way in which materials behave. Establishing links between related pieces of information in different systems turned it into knowledge that was shared with the materials scientists and other experts, and shared with the industry as published articles.

\subsubsection{Expertise specific factors}

As an older worker, the technical adviser's experience in life and professional matters was prominent in some areas. In the example of retaining and maintaining knowledge of 
current techniques, Section 7.2.2 (p. 193), he firstly recognised that in practice, roof designs were becoming more complex architecturally, and took a professional interest in understanding elements of the design. Second, from his professional building experience, he recognised this discussion as being part of early discussions between the engineers, architects and the territorial authority who would eventually grant consent. This provided the context for the discussion as a learning experience free of the potential tensions of the more advanced stages of the consent process. He was also able to make distinctions between different information sources such as architectural drawings and roof truss engineering drawings, and judgements as to which sets of drawings should be made available to the authorities at different stages of the building consent process, based on his professional knowledge.

The motivation for excellence was demonstrated in his coordination of the teleconference in a way that each party was recognised, their needs and the content of the call carefully facilitated, and the technical adviser benefiting from the new knowledge despite not being an architect or engineer. At the personal level, he recognised new knowledge and was motivated to integrate this. A motivation for excellence can be seen in the understanding of finer details, such as in the discussion of different methods of window construction in Figure 10-3 (p. 254).

Industry experience and the knowledge of roles, responsibilities and politics are closely related in the context of the study. The co-ordination referred to above relies on an understanding of roles and their distinctions, and likewise, many calls involved instances where industry roles and responsibilities had been misunderstood or neglected. For example, a builder has a responsibility to query the architect or designer if they do not understand their design, rather than asking BRANZ how to execute the design. Home owners also benefited from the technical adviser's knowledge of the responsibilities of different parties, and resulting pitfalls with contractual arrangements. Members of the public who had called the helpline for advice learned for example, that an architect who has designed a new home cannot be expected to be the project manager unless he has also been contracted in this role.

The technical adviser came from a rich professional background so his advice was also given weight through his experience of mediation in dispute resolution. He provided reasoning and clarity in his advice so that callers could resolve difficulties before they 
fell into dispute. Above all, he managed his own boundaries for giving advice, recognising the legal constraints that exist.

In the context of the study, one could regard theory as consisting of all the knowledge products commonly used in the construction industry. Examples of knowledge products would be the Building Code and the related New Zealand Standards, and other guidelines and manuals. By contrast, practice relates to the implementation of such standards, specifications and requirements, and is concerned with the methods and actions that professionals need to adopt to comply with the requirements.

The technical adviser's knowledge of theory and practice spanned several decades and knowledge domains. His deep knowledge of building methods enabled him to have meaningful discussions with practising building professionals, who benefited from his experience, some of which was in more traditional techniques still regarded by some practitioners as being reliable. Several builders noted that construction techniques that had been developed more recently may not always produce better quality results than traditional methods. The adviser's ability to distinguish between theory and practice was observed when he was helping builders with interpretations of drawings, and discussing how details could be executed in practice, in logical and sequential steps. Another example of applying theory to practice was seen in the example of formalising new knowledge on insulation, depicted in Section 7.2.5, where the adviser collaborated with scientists to understand theoretical aspects of a specific type of insulation. Then, with their guidance and review, he constructed a checklist of the practical advice that BRANZ could give to home owners who enquired as to the suitability of such products.

The adviser cannot perform his problem-solving role in isolation and draws on various sources for support. This support is largely in the form of specific knowledge, confirmation of understanding, and knowledge sharing. Support may be related to answering a specific enquiry or to a knowledge domain. The technical experts and scientists are valuable to the helpline as knowledge interpreters and their role as part of the technical adviser's social network is just as important. The social dimension of the relationship leads to sharing of their latest research and developments on their various projects - the adviser is updated on theory while the other experts hear about realworld construction practices. 


\subsubsection{Facilitative experiential contexts}

The factors of age, and historical period facilitate the development of expertise in several ways. First, age and historical period, which is the length of time spent in the industry, underlie the technical adviser's expertise. He had developed layers of expertise in the same way that the scientists had, as discussed in Section 6.2.3, but in a different knowledge domain, that of practical construction and all matters related to construction projects. Second, he has lived through his experiences as the industry has developed, and he has first-hand knowledge of building techniques, processes, products and failures has been accumulated over decades. Last, he has the quick recall of events from the episodic memory of an older expert, and can also locate and describe the provisions of rules and standards at a point in time, as required.

In terms of professional work content, career background and qualifications, the adviser was able to relate to building professionals due to their shared background, and is skilled in conducting discussions and coordinating different professionals in solving problems, from a common understanding of technical topics. A respectful relationship exists due to his career background and their membership of the same social and professional networks - the adviser mentioned that there was much shared knowledge enabling a productive discussion when it was a builder-to-builder conversation.

The same sense of having knowledge in common with building practitioners put the technical adviser in a valuable position to facilitate the exchange of knowledge for the good of the profession and the industry. For example, through exposure to builders' issues via the helpline, he was able to understand their needs for further knowledge with specific topics. Thus his input to BRANZ's publications to the industry was invaluable.

Over a career of several decades, the adviser had a very wide and strong social network, often contacting people for their opinions and a sense of industry trends, acknowledging the limits of his own knowledge. The strong network ties therefore facilitated both formal and informal knowledge sharing, which in turn, has the effect of strengthening the network in terms of continuing contact. The informal network was extended when contacts were made with new people, who the adviser found to be staff of people he knew well. Other skills that were demonstrated included knowing which internal and external experts to involve in problem-solving or technical discussions, and how best to engage them. Face-to-face meetings, tele-conferences and electronic mail suited different purposes, depending on experts' location, availability and working methods. 
Finally, consultation skills also facilitate the development of expertise, in terms of gathering together information to formulate cohesive advice. An example of this is the development of the insulation checklist in Section 7.2.5, which provides guidance for consumers lacking the information for making the right decision about insulating their homes. The technical adviser was described as a mentor, in that he helped callers by describing step-by-step approaches for finding information, making decisions or solving problems. To industry users of the helpline, he was also regarded as a mentor. They described a sense of security in knowing they could always telephone him when they wanted to confirm a proposed approach or a building technique.

\subsubsection{General framework}

Examples of expertise in excellence in mind and virtue, based on Baltes and Staudinger's framework, were evident in two examples. The first example arose in the process of formalising new knowledge on insulation, where the concept of common good for the organisation and for home owners was evident. Potentially, consumers could purchase a product without knowing enough about its long term performance, thus potentially exposing occupants to some risks. Thus, the checklist equipped them to ask the right questions, but they were also warned that there may be little information available about a new product's long term performance or degradation.

The second example involved improving a part of the helpline process itself, so that knowledge was more easily retained and shared, in using ICT to link digital recordings of interest to their corresponding record in the call management system. This is of benefit to the organisation, as other experts can access and listen to recordings and be aware of current practices and challenges. Because of his age and experience the technical adviser had experienced many process changes over the years and was proactive in implementing improvements, but his personality was such that he valued efficiency and simple processes that saved time, while making knowledge available to those to whom it is relevant.

\subsubsection{Basic criteria and meta-criteria}

In terms of the basic criteria shown in the knowledge framework, the helpline is founded upon the provision of factual and procedural knowledge. Also, the knowledge needs to be authoritative and reliable, reflecting that BRANZ is a reputable source of 
construction knowledge for the industry. Its advice also needs to be tailored to the requirements of non-technical audiences such as members of the public.

The meta-criteria of value relativism, that is, the recognition and tolerance for different values for a common good, were evident but not problematic in the helpline setting. With different roles and relationships among helpline callers, the adviser was constantly recognising and balancing any competing perspectives. Some calls involved tension between home owners and professionals, while others hinted at problems that had arisen through a lack of awareness of commercial relationships and boundaries.

On a different note, the adviser was seen as meticulous in his handling of details, with a commitment to being consistent in each piece of advice. There were two well-known caller behaviours. One was a pattern where different professionals on the same building site would call the helpline independently for advice, maybe some time apart, due to a simple difference in opinions, but potentially with the prospect of a dispute. The technical adviser was careful to convey the facts and describe a process for resolving the issue in a consistent, non-judgemental manner that would be relevant to both parties.

The second behaviour involved one person contacting the adviser, as well as other BRANZ experts, hoping to receive different advice, from which they could select a version that best served their purpose. This was referred to as "shopping for an answer", another reason for the helpline having two way communications with the BRANZ experts. Therefore, adherence to values of consistency, non-judgement, fairness and fact-based knowledge is critical.

Recognition and management of uncertainty, as one of the meta-criteria for expertise, appear in several situations in the helpline. Firsy, the technical adviser needs to manage uncertainty about the caller's level of knowledge. Observations revealed that some home owners or people in the process of having a home built for them could be very knowledgeable about certain aspects. Conversely, there were instances of builders who admitted they were less knowledgeable because of their young age and lack of experience, or because a particular situation was unfamiliar to them, for example involving a certain product or method of construction.

Second, the technical adviser needs to handle uncertainty about the caller's identity and motives. Callers were not always open about their identity and some were observed to frame enquiries in an unusual manner and be reluctant to elaborate. The adviser 
provided information in good faith even in cases where he may have felt uncomfortable because of the lack of a meaningful context about the caller's identity or their problem.

Third, there could be uncertainty based on the caller's interpretation or perspective of a problem or the symptoms described. For example, it may be hard to understand a home owner's description of the method or technique used by a builder or installer.

Fourth, there can be uncertainty during the call process, as to the reason for the call (Emmison \& Danby, 2007), and what the outcome of a call could be. An apparently minor problem with understanding a construction detail might lead to a valuable discussion and exchange of important additional knowledge (Section 8.2, p. 215).

Finally, the adviser handles uncertainty about factual and procedural knowledge. In receiving a call, it may be difficult to discern the facts when events are being recounted after a problem has occurred. Another example relates to the boundaries of scientific knowledge, and the adviser refers to other experts for the confirmation of facts, for example there are limits to knowledge about how materials behave with certain other materials and in particular climate conditions over time. Therefore some queries relating to these areas of knowledge may not have a definitive answer.

Instances of managing uncertainty about procedural knowledge were observed in several different areas. The ordering of steps in the construction and assembly of building components was an area of uncertainty, with some calls involving discussions on how to remedy steps having been carried out in the wrong order. Industry processes such as the development of standards and codes presented another area of uncertainty, in particular timing aspects and the likely contents of upcoming versions. Another area of uncertainty was observed in helpline calls about the processes, or assumptions underlying the processes, for obtaining building approvals and consents. An example was the inconsistency between two adjoining territorial authorities' rulings in the building consents process.

\subsubsection{Organising processes}

Organising processes are cited as factors for the development and maintenance of wisdom (Baltes \& Staudinger, 2000) and expertise, as shown in this study. Work planning was an essential part of the adviser's role, with daily processes and commitments to call response times. At the time of the study, the helpline was experiencing a significant increase in call volumes; moreover the technical adviser had 
other duties such as membership of technical committees and reviewing technical documents. On a longer horizon, the adviser's work planning included contributing to other organisational processes, managing timing and inputs needed. Process owners also booked his time to ensure his rare knowledge was captured.

Work management is the activity of focusing on immediate tasks. Much of this activity was influenced by the calls received at the helpline. For example, answering complex calls required managing and coordinating other experts, as shown in Figure 10-4 (p. 264). In some cases, a complex query may involve contacting the caller again after several calls to other knowledgeable people. Telephone conference calls were not so common, but served as a rich source of new knowledge when they were held.

At various times, the adviser participated in activities that represent work review, an organising process. He took time out or used quiet periods on the helpline to review recent work, in terms of reviewing call records, and quantifying volumes and types of calls to improve his work approach. Taking a more holistic view resulted in more efficient ways of working, such as developing checklists, publishing materials to the web site so callers could refer to them during calls, and involving other experts in drafting content that could be reused, such as in emails.

Finally, organising processes are required not solely for the development of individual expertise. For the BRANZ helpline, such processes are also important for improving an already proficient service in business terms. Furthermore, they are crucial to knowledge retention and sharing among staff — the subject matter experts and staff such as technical writers, editors, tutors and marketing staff who are responsible for converting research into knowledge products. 


\section{Action 2: scope management, signposting}

\section{Overall process observed:}

1. Listen to the caller to understand the problem.

2. Determine appropriate person / organisation to assist

3. Direct the caller to the appropriate party for resolution.

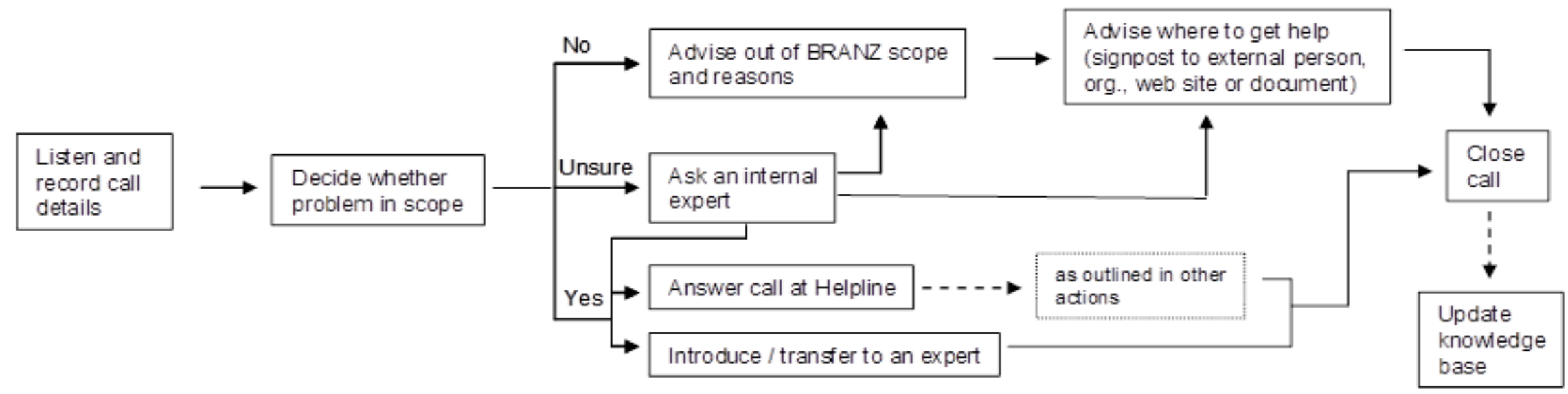

Figure 10-4: Signposting as an example of helpline work management 


\subsubsection{Taxonomy of an older expert's knowledge}

Having discussed the knowledge framework in relation to the helpline process, I now discuss a separate representation of the older expert's knowledge. In analysing data, reviewing transcripts of interviews with the technical adviser's colleagues and helpline stakeholders, and observing the expert in action on the helpline, I wanted a different way of representing his knowledge. Most of the models I had developed were based on processes, both detailed and taken to a summary or abstract level. An observation that emerged in one of the cycles of data analysis, was that the data included many rich descriptions of characteristics and behaviour. These descriptions tend to be at a lower level than the examples given by Baltes and Staudinger.

The descriptions may be represented as a taxonomy, shown in Figure 10-5 (p. 265).

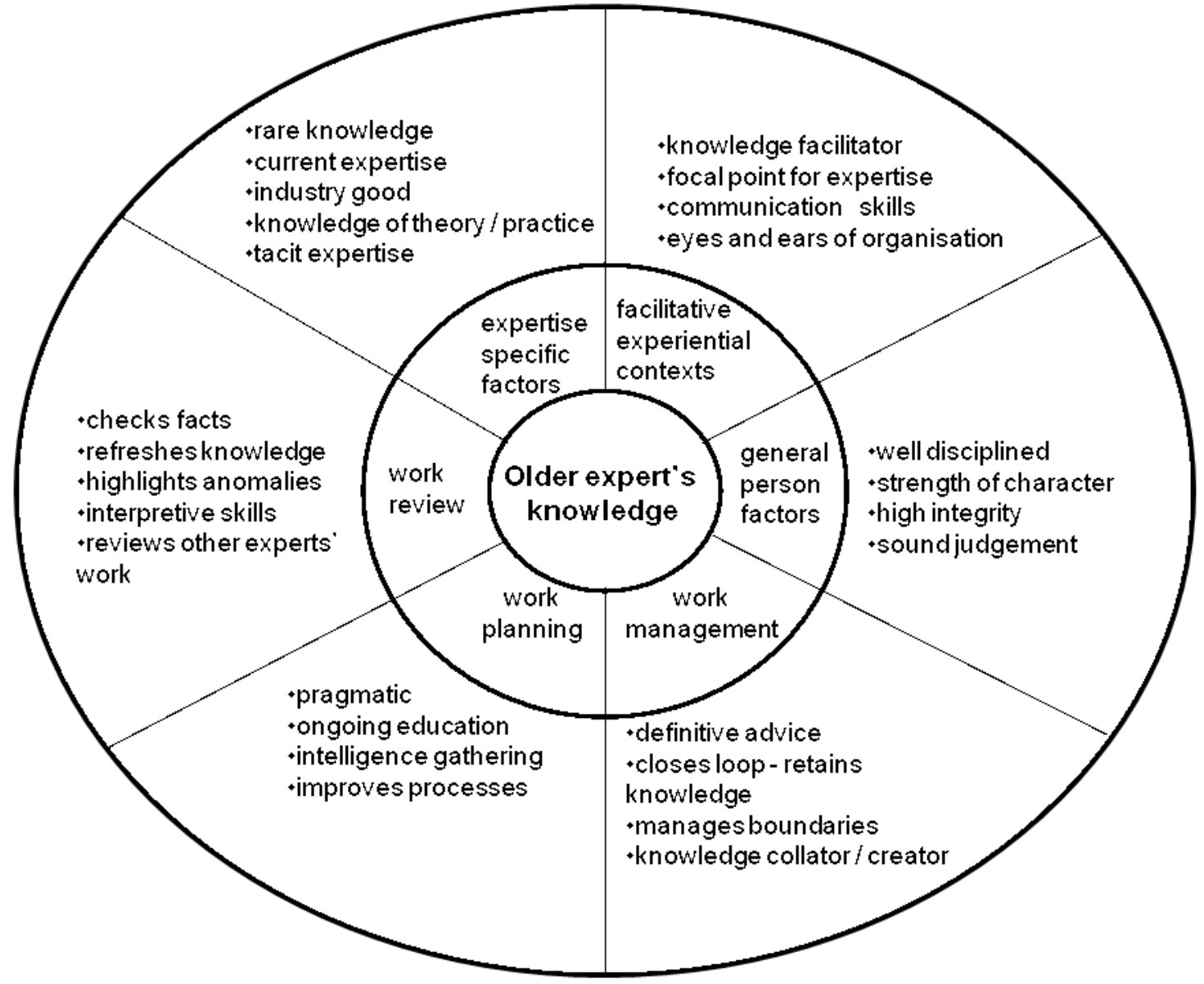

Figure 10-5 Taxonomy of an older expert's knowledge

The purpose of the taxonomy is to provide a different perspective of expertise, based on the individual expert. The taxonomy centres on the older expert's knowledge, and depicts the elements of expertise in the knowledge framework, adapted from Baltes and Staudinger's (2000) framework. These elements are located in the inner part of the 
circle. The characteristics, descriptions or examples of expertise (or expert behaviour) are grouped near the relevant element, at the outer edge of the circle. For example, instances of facilitative experiential contexts included the observations that one of the technical adviser's roles was as a knowledge facilitator. In operating the helpline, he was the focal point for providing expertise to callers. He had communication skills that enabled him to convey advice to a variety of callers, from members of the public seeking general information, to industry professionals wanting to have a technical discussion. He was also described as the eyes and ears of the organisation, as he gleaned information from the outside world through his role, and detected patterns and trends.

\subsection{Integrated model of expertise and knowledge retention}

The findings discussed in Section 10.3 involved the analysis of six detailed knowledge retention processes, to determine which of the elements of the knowledge framework of an individual expert, as shown in Figure 10-2 (p. 251) were evident. I now discuss an integrated model, incorporating a higher level (summary) view of the six processes, and depicting the expertise factors from the knowledge framework. The purpose of the integrated model is to relate the high level knowledge retention process to a more holistic view of the expertise factors that the older expert possessed. These factors include the organising processes and the basic expertise criteria, from the knowledge framework, that were evident.

The integrated model in Figure 10-6 (p. 267) is composed of two parts, with the first part being the high level knowledge retention process of the older expert. The process steps are shaded and are shown across the top part of the figure. The knowledge retention process involves identifying a need to provide knowledge; coordinating the parties needed; conducting discussions as required; agreeing a solution and any actions needed; and taking action to retain knowledge. This process comes from Figure 7-12. The rest of the figure shows elements of expertise from the framework of the individual expert, that were present in Figure 10-2 (p. 251). The elements are placed beneath the step of the process where they were identified. This shows the elements of the knowledge framework present at each step of the knowledge retention process.

Reviewing each step of the process in turn, some patterns can be identified. These are discussed in the five sections following the integrated model. 


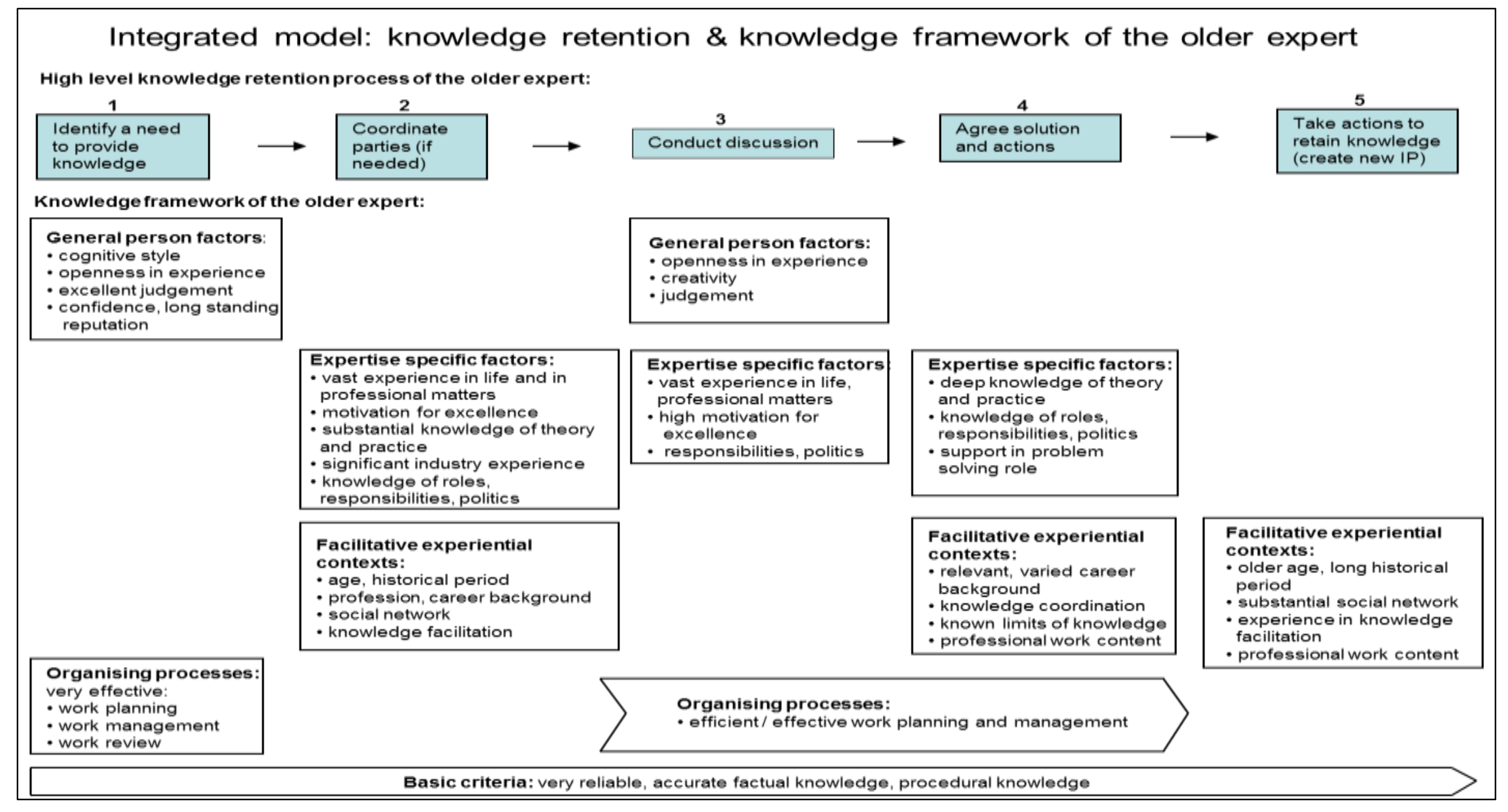

Figure 10-6: Integrated model - knowledge retention and expertise factors 


\subsubsection{Step 1 - identify a need to provide knowledge}

At the first step in Figure 10-6 (p. 267), where the need to provide knowledge is identified, a group of general person factors (cognitive style, openness in experience, excellent judgement, confidence and long standing reputation) was observed as the predominant knowledge factor. The technical adviser's cognitive style for quickly assessing the caller's situation and needs was evident. As an older expert, he was able to make judgements confidently and was open to the possibility that the call was not always a simple problem, but could lead to more complex discussions and opportunities for knowledge retention. He made judgements about the nature of the caller's inquiry based on his technical knowledge, while some judgements about the caller were made on the basis of his knowledge or intuition. For example, he was able to detect when a caller seemed reluctant to provide him with full information. General person factors included the expert's cognitive style, his experience and confidence in his subject matter and in dealing with people. These factors enabled him to glean sufficient information to decide how best to handle the call and what knowledge he could provide.

The adviser's organising processes also became evident from the beginning of the call and he anticipated issues such as whether there would be a quick answer to the inquiry, or whether further actions would need to be organised outside the scope of the call, for example follow up activities, or coordination of other experts' opinions. Work management included actions such as locating documents on-line and in hard copy and locating details for the call. Work review would involve going over the knowledge provided in answering recent inquiries and then initiating action to produce information in standard form for re-use, in the interests of greater efficiency. Knowledge was formatted for re-use in the helpline, but was also disseminated to other experts in the organisation.

In summary, general person factors and orgnisaing processes were important at the beginning of the call when the technical adviser was trying to determine the caller's knowledge needs. The data analysis revealed that Baltes and Staudinger's basic criteria of factual knowledge and procedural knowledge were present at each step of the knowledge retention process. This is represented as a continuous arrow at the lower edge of the combined framework diagram in Figure 10-6 (p. 267). 


\subsubsection{Step 2 - coordinate parties to provide or retain knowledge}

At this step, expertise specific factors were most prominent and the experts who contributed their knowledge were mainly in-house. The older expert's motivation for excellence was demonstrated in two ways. First, where volumes of helpline calls were high, it could be tempting to focus solely on answering each call, rather than taking a more holistic view and starting work in the background that would lead to greater efficiency. Second, the motivation for excellence was also seen in other experts, as they were also busy with their allocated research projects. Despite their commitments, they wanted to provide their knowledge to the helpline to assist callers, and also to document their knowledge or to be involved in publishing BRANZ's knowledge products.

The knowledge of both theory and practice was important, as the technical adviser was often asked to interpret theory in the form of rules, formulae and calculations, in a way that made sense to practitioners. Understanding the logic and rationale behind changes was therefore a pre-requisite to providing authoritative and reliable advice.

The facilitative experiential contexts for expertise included the technical adviser's age, memory of events and historical experience of how to handle change and also of previous versions of rules, calculations and requirements. In the course of coordinating other experts and facilitating the creation of new knowledge products, he also strengthened his own social network and benefited from other experts' deeper understanding of the changes.

Expertise specific factors and facilitative experiential contexts were therefore important in the coordination of other parties to provide knowledge to callers, and to retain knowledge so it could be refined for publication.

\subsubsection{Step 3 - conduct discussions on knowledge retention}

In answering helpline calls the adviser conducted individual discussions with callers, and also facilitated discussions involving experts when new knowledge was being formulated for use on the helpline or for publication. General person factors such as his openness in experience, sense of creativity and careful judgement about who to involve and managing time frames were observed in this step of the knowledge retention process. In this setting, demonstrating creativity could mean taking action outside the scope of the business process to resolve an issue more effectively. Making a choice 
between using a drawing or a photograph to illustrate a construction technique would be an example of applying judgement.

The expertise specific factors included the technical adviser's experience in life and professional matters, for example distinguishing between the appropriateness of different experts for a range of topics, and his knowledge of roles, responsibilities and the organisational or industry politics involved. Above all, there was a common commitment to quality advice - accuracy, clarity and simplicity in conducting discussions, and at the next step of agreeing solutions and actions.

In the conduct of discussions, therefore, general person factors enabled agreement on how to approach knowledge retention, and expertise specific factors ensured that the appropriate experts provided input to discussions. Organising processes were also important in managing the process of discussion.

\subsubsection{Step 4 - agree solution and actions}

At this step, expertise specific factors such as the knowledge of theory and practice and the knowledge of roles and responsibilities were observed. This is to be expected, since the helpline is focused on practical problem solving tasks and on providing information. Knowledge of roles and responsibilities in this context relates mainly to the industry and is a common theme in many inquiries from the industry. For example, when a tradesman describes a problem that has arisen on a construction site, the technical adviser often has to remind him to check the contractual responsibilities involved. The problem solving role is shared with other BRANZ experts where inquiries are specialised, complex or beyond the scope of one person's expertise.

This leads to the recognition of the boundaries of the adviser's own knowledge, a facilitative experiential context. The adviser's knowledge is enhanced by his career background which provides him with skills to absorb new knowledge, and by the knowledge coordination tasks, as he becomes involved in discussions that are relevant and serve to broaden his understanding of other areas of the industry.

In agreeing solutions and actions, the importance of roles and responsibilities were recognised, and the boundaries of knowledge acknowledged. The technical adviser's organising processes enabled him to plan work and organise resources for the final step in the process, taking steps to retain knowledge. 


\subsubsection{Step 5 - take actions to retain knowledge}

These same facilitative experiential contexts are present in the final step of the process, which is to take action to retain knowledge and create new knowledge products for the industry. Age and historical period and the adviser's professional work content mean that he has the appropriate level of understanding as well as a connection with real world practices to play a key role in knowledge retention. His position as one of only two remaining people with practical building experience makes his knowledge a rare asset at BRANZ, coupled with the fact that he has a meticulous approach to reviewing documents for accuracy before publication.

As an older expert who has been at BRANZ for more than a decade, the technical adviser is aware of situations where knowledge from helpline calls may provide useful input to other processes. Examples of this are the publication process and the industry processes for reviewing and updating industry standards and the Building Code.

\subsection{Summary}

Baltes and Staudinger's (2000) framework of factors in the acquisition and maintenance of wisdom related knowledge was selected from several concepts as being the most appropriate for addressing the knowledge framework for an individual expert in the context of the BRANZ helpline service and its related knowledge retention process. It was considered appropriate as it provides a means of understanding the nature of expertise in relation to an older expert's age and experience.

The framework was adapted from the domain of "wisdom-related knowledge and skills across the life span" (Baltes \& Staudinger, 2000, p. 3), and applied to the specific case of an older expert in an organisational context. It was found that most factors in the original framework were adaptable to this business context, including the general person factors, expertise specific factors and facilitative experiential contexts.

Furthermore, the organising processes were also highly relevant in this context, as were the basic criteria and meta-criteria. The principle of wisdom as excellence in mind and virtue was included under expertise specific factors.

The data from six examples of knowledge retention were analysed and found to include many of the factors for the acquisition and maintenance of expertise. Taking a view across all six examples and referencing the process steps to the expertise factors in a 
combined framework of expertise and knowledge retention, I have demonstrated that the technical adviser exhibits many of the factors adapted from Baltes and Staudinger's (2000) framework.

The integrated view indicates that the basic criteria of factual and procedural knowledge extend through the whole knowledge retention process. General person factors were predominantly found when the need to retain knowledge was initially recognised, and when discussions occurred. Expertise specific factors were present in coordination, discussion and in agreeing solutions and actions, in actually formulating knowledge. Facilitative experiential contexts were evident during coordination activities and in agreeing solutions and actions - the steps involving collaboration and in the final step of taking actions to retain knowledge. Finally, the organising processes of work planning, management and review were evident in the initial step of the process, and at the steps of conducting discussions and agreeing solutions and actions for knowledge retention. 


\section{Chapter 11. Implications, limitations and conclusions}

\subsection{Overview}

Following a synposis of the research, I summarise the results of the study in relation to the research questions established at the outset of the study. Several limitations of the research are then noted. I then discuss some implications for research and practice, before drawing some conclusions.

\subsection{Synopsis of the research}

This research was carried out to explore, first, the nature of the knowledge that organisations regard as being valuable and potentially at risk of being lost as older experts retire. Second, the research identified and analysed the processes that a particular older expert in a knowledge organisation used to retain valuable knowledge within the context of a core business process, an industry advisory helpline service. Last, the research examined the role of ICT in retaining an older expert's knowledge.

In reviewing extant literature, I noted in Section 2.7 (p. 69), that the infrastructure and processes for retaining the knowledge of older experts in organisations is a topic appearing in the literature only relatively recently, over the last decade, and mainly from a practitioner perspective (England \& Herrera, 2005; Gross, et al., 2001; Hylko, 2006; Lesser, 2006). I concluded that a research gap therefore exists in this topic domain. Similarly, I found little academic, non-proprietary writing on how ICT supports knowledge retention from older experts — this signified the second research gap.

\subsection{Discussion of results}

The topic of the research was:

Retaining the knowledge of older experts in an organisational context and the role of ICT

I addressed this topic by considering three separate research questions in turn.

1. What types of knowledge does an organisation risk losing when older experts leave? 
Although many organisations focus on knowledge management, they may be less aware of the valuable knowledge that could be lost with the departure of these older experts. In answering the first research question by studying the retention of knowledge from older experts in an organisational context, this study identified several organisational perspectives of valuable knowledge. Some dominant themes emerged from the analysis of the organisations' descriptions of valuable knowledge that was at risk of being lost.

Valuable knowledge included knowledge of relationships and social networks, organisational knowledge, and knowledge of business systems and processes. Subject matter expertise and experience were also found to be valuable, as were applied knowledge and governance knowledge. Findings from this part of the study are presented in Chapter 5 and show the organisations' views of older experts' knowledge.

Following the identification of organisational perspectives of knowledge, I studied an older expert in the context of an important business process, and the nature of his individual expertise emerged from observations and interviews. The expert was described as having a unique combination of skills and experience, a vast network of relationships, and demonstrating high levels of efficiency and effectiveness. The other main themes related to the layering of expertise in terms of its acquisition, the power of the expert's long term recall, and the expert as a unique knowledge holder. These findings also address the first research question and are presented in Chapter 6 (p. 157).

Studying the older expert in action and focusing on the business process within which he operated, enabled me to examine how knowledge retention occurred within this context. Some processes for retaining knowledge involved technology, while others did not. The second and third research questions were therefore answered together:

2. What processes does an organisation use to retain the knowledge of older experts?

\section{How can ICT support the knowledge retention process for the identified} knowledge source(s) and recipients?

While organisations may not have specific processes for retaining older experts' knowledge, I found that the expert who participated in this study had his own processes and techniques for retaining valuable knowledge. Furthermore, he recognised knowledge that was new and valuable to the organisation and the industry, and acted upon those opportunities. Observing the expert in action revealed that while individual 
helpline calls were diverse in nature, they were reducible to six major categories of problems or calls (see Table 7-1 (p. 182) and Figure 7-4 (p. 183)) and that a single high level problem-solving process could be identified. Within this process, he adopted an organised approach to knowledge retention.

In the study, the actions taken reflect the knowledge life cycle (Zack, 1999). Knowledge was acquired or created in the course of solving problems. It was then refined to a standard or abstracted form, and stored in a repositories and databases. In collaboration with others, the expert ensured that the knowledge was distributed, making it accessible. After the knowledge was arranged and integrated, it was presented to various audiences. Within the scope of his role, the expert therefore acted as a conduit for new knowledge entering the organisation, and as a knowledge facilitator and collaborator, involving other staff and experts in knowledge retention and dissemination to the industry.

Turning to the role of ICT in knowledge retention, my observations of the expert in action revealed that ICT played a part at different stages of the knowledge retention process described above. The expert accessed information systems at the knowledge creation stage, to refer to existing publications in web sites, and to create records. $\mathrm{He}$ also updated and refined existing knowledge in the organisation's systems. Different types of ICT were used for the storage and retrieval of knowledge, and these included existing databases, and new archives and repositories. Knowledge was often stored in temporary repositories for further development, aggregation and refinement, activities which required collaboration. ICT were used to create new knowledge products, for example, developing a function for calculating formulae for insulation, for publication on a web site. In summary, the expert used ICT at each step of the knowledge retention process, and the use of ICT was closely integrated with the business process.

Observations of the expert led to the identification of a set of knowledge retention examples involving the use of ICT. Knowledge retention processes included capturing innovative practice, retaining knowledge of current techniques, retaining knowledge on complex inquiries, formalising knowledge for dissemination, and retaining and grouping related knowledge. These processes are presented in Chapter 7 (p. 175).

Although there is a role for ICT to support knowledge retention, it does not necessarily mean that new or significant investments are required - a more parsimonious approach may be necessary — with older workers, the time horizon for action may be short. My observations and analysis revealed that in many instances, existing processes were used 
and slight improvements made. Also, knowledge was retained by involving other experts and business processes, such as the publication process at BRANZ. Changes to the Building Code were documented, reviewed and posted to an existing web site within a few days. In a subsequent update, software was made available for download from the site. In similar fashion, Organisation A decided that it would use an existing knowledge management programme of work and its annual business planning process as the means to address its knowledge loss concerns. The extent to which organisations' existing infrastructure and processes could support knowledge retention is certainly a topic that deserves further investigation.

\subsubsection{Contribution of research}

This research was concerned with the valuable knowledge held by older experts, and how it may be retained in an organisational context. In the analysis of the elements of expertise, it emerged that a model of wisdom was useful and relevant to understanding expert knowledge. The philosophical position I adopted at the outset of the study recognises that wisdom is a type of expertise: "an expert knowledge system concerning the fundamental pragmatics of life" (Baltes \& Staudinger, 2000, p. 122). Holistic or transcendent characteristics of wisdom exist alongside the more practical aspects, known as phronesis (Csikszentmihalyi \& Rathunde, 1990; Labouvie-Vief, 1990; Rowley \& Slack, 2009; Sternberg, 2003).

Baltes and Staudinger's framework represents wisdom as a set of factors, which I have adapted to more closely represent the knowledge framework of an older expert. The study's results demonstrate connections between the expertise (specialist knowledge) of the older expert and elements of wisdom. I have described the adapted conceptualisation as the knowledge framework of an individual expert (see Figure 10-2 (p. 251)). This framework is based on specific factors that emerged from the data I collected and analysed in the course of the study.

The first contribution of the study is, therefore, in the form of an adapted framework, incorporating some new examples of expertise factors. The framework includes new contributions including general person factors, expertise specific factors, and facilitative experiential contexts. The results indicate that expertise includes experience, life skills as well as unique, personally held knoqwledge. The research findings therefore demonstrate a relationship to existing theory on wisdom as a type of expertise. In the context of the study, I observed wisdom elements in the actions and approaches of an 
older expert, alongside his demonstration of other forms of expertise, such as his application of specialised construction knowledge, and technical and scientific knowledge. The co-existence of these forms - deep technical knowledge with elements of wisdom, being of a more holistic or transcendent nature - in the study's findings also show a clear link between age and wisdom in the case of this older expert.

From an analysis of data sourced from hundreds of call records, the study identified a series of knowledge retention processes that were employed by the older expert, as discussed in Section 7.2, enabling his expertise to be retained within the organisation following his retirement. These processes were then summarised to a high level, integrated view of the knowledge retention process (see Section 7.2.8).

The resultant integrated framework therefore extends Baltes and Staudinger's framework in that it combines both expertise and wisdom-related factors. It also links these factors to the older expert's knowledge retention process - at each step of the process, he completed a set of activities, during which different factors were exercised. Thus the view that integrates these two dimensions, as depicted in Figure 10-6 (p. 267), captures the important knowledge retention process in the BRANZ helpline as the research context, and relates it to an adaptation of a prominent and reputable framework whose elements originated from theories of wisdom.

The second contribution of the research, therefore, is in the form of an integrated model, combining the knowledge retention process that was identified, with the elements of expertise and wisdom that were found in the study of the older expert at work in his business process.

The third contribution of this research is in raising the visibility of the older expert as a knowledge holder in an organisational context. The organisation noted that the older expert was a suitable candidate for the study because of his age and expertise, and because he was in a sole charge position. Little was known, however, about the specific nature of his expertise. This study found that wisdom elements were hidden within the fabric of an older worker's experience and specialised knowledge which the organisation saw as being valuable but not easily understood. His role in the helpline service was an appropriate setting for the study, given that wisdom-related characteristics can be expected to be present in an activity such as problem-solving (Ardelt, 2005; Baltes \& Staudinger, 2000; Didierjean \& Gobet, 2008). 
Wisdom is not solely an attribute of education or social background, but may be found in a wide range of environments. This study examined an individual whose peers recognised him as an expert with knowledge that should be understood and retained. The findings are based on organisational documents; observations and interaction with the older expert; and data from interviews with a range of his peers, colleagues, customers and stakeholders in the helpline service. Analysis, cross-checking and triangulation of the data led to a framework that gives greater visibility to the nature of his expertise, including wisdom-related elements.

The fourth contribution of the research is the finding that while ICT may be implemented or used to retain the knowledge of the older expert, the knowledge retention processes included steps involving the use of ICT to facilitate the process, as well as actions that did not involve technology. Steps such as discussing options with colleagues and seeking more detailed scientific or technical advice are examples of important collaborative steps that contributed to problem-solving focus of the helpline (refer to Section 7.1.3 and Appendix D). Knowledge was also retained by transferring it to other individuals, or shared, developed and retained through interaction with other staff without the use of technology.

\subsection{Limitations of the study}

There are some limitations inherent in the study. First, I approached the study with the view that an older expert would have significant experience and technical knowledge that the organisation should retain. Deeper layers of expertise were revealed however, as the study progressed, and a more granular view of the nature of expertise emerged from my analysis. The data I collected and analysed however, are unique to that individual and the findings are therefore not transferable — studying another expert may yield a different set of data.

Second, as more data were analysed, I found that certain elements of expertise could be interpreted as elements of wisdom, and could therefore be located in a "research framework for wisdom-related knowledge and skills" (Baltes \& Staudinger, 2000, p. 3). Another researcher analysing the same data may interpret them differently and be led to a different framework for explaining their findings.

Third, I do not believe that my findings are applicable to younger experts, as the components of their expertise are probably different. Wisdom theorists posit that 
younger people can exhibit wisdom, but the literature is unclear about its characteristics when compared with older people.

\subsection{Implications for research}

The research findings present several implications for future research.

First, the integrated framework draws rich connections between expertise and wisdom, extending the concept of valuable knowledge, through observations and close study of an expert. This presents opportunities for further research into the nature of expertise that organisations may consider to be valuable. While older experts may be visible in their organisations, the nature of their expertise and the presence of wisdom-related characteristics may not be so evident. The framework depicts elements of expertise that are related to a role or a career specialisation. The study also found that there were notable areas within the older expert's problem-solving process where he was observed to apply elements of wisdom alongside his specialist knowledge.

Second, there are opportunities to study the importance of the links between an expert's expertise and the wisdom elements he or she exhibits, as these may also be lost.

Following from this is the question of whether and how wisdom, or characteristics that represent wise behaviour in a specific environment, may be transferred or taught to other staff — including younger ones — or retained in the organisation.

Last, research that leads to a deeper and richer understanding of expertise and wisdom in individuals would be valuable in relation to knowledge organisations and the emerging research on wisdom in organisations and leadership (Hammer, 2002; McKenna \& Rooney, 2005a; McKenna, et al., 2009; Rooney \& McKenna, 2007; Rowley \& Gibbs, 2008). If an important factor in developing wise organisations is the extent to which wise individuals are present in the organisation, then research on how to identify individual holders of expertise and wisdom would be relevant.

The study identified elements of wisdom in the context of a business process involving solving problems and providing authoritative advice. It happened that the expert was an older person. The question arises as to whether particular roles in organisations require, or are better served by, older experts preferably with a degree of wisdom. 


\subsection{Implications for practice}

This research contributes evidence that when organisations lose their older experts, they may also be losing the less visible aspects of their expertise. As shown in Figure 10-6 (p. 267), these may include aspects such as an individual's highly optimised organising processes, for example, in the way they manage their responsibilities; their substantial social networks; or their experience in knowledge facilitation. From a practitioner's perspective, there are opportunities to gain a deeper understanding of such valuable elements of expertise that form the basis for high levels of performance. Added to the hidden nature of expertise, is the potential issue of knowledge loss where an older expert works within a business process that is largely undocumented (Hylko, 2006). This may have impacts at the level of a work group.

The study's findings contribute a taxonomy of an older expert's knowledge, in this case the helpline adviser, as described and depicted in Section 10.3 .7 (p. 265). The taxonomy may be applicable or valuable to managers who wish to understand more about experts and the nature of expertise and its value to the organisation. The factors may have particular meaning in a specific organisational context, for example some organisations may attach greater value to rare or practical knowledge if their core business knowledge is explicit or well documented. Another use for the taxonomy is for workforce planning - an organisation embarking on strategic workforce planning my use it to determine the types of expertise it must retain, and the expertise it should develop for the future.

The study provides us with a greater understanding of the skills and knowledge used in a helpline process for solving problems and giving advice, and how valuable knowledge can be retained. My analysis of the data revealed that expertise was retained in the organisation and in other individuals - illustrating the collaborative nature of knowledge retention activities. In many cases, the knowledge was also repurposed and developed further for dissemination and reuse. Thus, when the expert leaves, his knowledge exists in multiple locations and forms. This was a positive finding since it implies that there are multiple methods of knowledge retention - not a uni-directional flow from the expert to an electronic repository or a new employee. The topic of storytelling fell outside the scope of the study, and the bardic tradition, meaning a preference for oral forms of knowledge transfer, implies that some knowledge should and would not be documented (Thompson \& Walsham, 2004). 
Finally, older people who possess a degree of wisdom are believed to be resourceful in coping with difficulties, conflicts and life problems, and are capable of learning from experiences (Ardelt, 2005; Grossman, et al., 2010). This has significant implications for practice. If older experts have roles that involve dealing with such difficulties, or providing advice to others on such matters, then to what extent can they be effective mentors for younger people, and how might their wisdom-related expertise be retained, transferred or taught to others?

\subsection{Conclusions}

This interpretive action research study addressed the research gap at the confluence of three topic domains. The domains are: the valuable knowledge that may be lost when older experts retire; how knowledge retention processes are used in an organisational setting to mitigate this; and how ICT may support the knowledge retention process. The research topic represents a strategic business problem in the real world. The problem will intensify as more older experts who are members of the baby boom generation, or the preceding one, approach retirement. Therefore, the theoretical necessity of studying knowledge retention arises from the loss of experts from organisations.

Findings on the nature of older experts' expertise are drawn from two scientific organisations. Subsequently, more detailed results on expertise and findings on knowledge retention processes are centred on a single expert in a business process. The study's findings are consistent with existing theory on wisdom as a type of expertise and the study contributes an integrated view that combines a knowledge retention process with the knowledge framework of the older expert. The knowledge framework was adapted from existing theory.

\section{Older experts' expertise}

Organisations need to direct their efforts to better understand the types of knowledge that are important, and assess the level of risk of losing valuable knowledge as older experts leave. Part of the study centred around a particular older worker, whose organisation and colleagues regarded as being a technical expert. He held a sole charge position, had a wide social and professional network, and was considered to be the face of the organisation. Senior management expected he would retire in the next few years, but were unsure of how to address the issue of losing his knowledge. Detailed observations of the older expert led to some important considerations for organisations. 
The nature of expertise includes wisdom-related characteristics that may not be easily identifed without close observation. Consequently, organisations may not be aware of the knowledge that their experts possess, and the combination of personal, expertise and social factors may also not be visible or obvious. These factors, however, are inherent in the way the experts perform their organisational roles.

The study found that expertise also included organising processes, drawn from Baltes $\&$ Staudinger's (2000) research. For the purposes of examining experts in an organisational setting, these processes relate to work planning, work management and work review. It is important for organisations to understand the extent to which such processes are embedded in the way experts carry out their roles. In so doing, they can retain this knowledge if it is valuable.

\section{Knowledge retention}

As organisations identify older experts whose knowledge needs to be retained, they may encounter some existing knowledge retention behaviours unique to the individual, which would cease as experts leave. The research uncovered a close relationship between the business process of operating an industry technical helpline, and the processes the expert used to retain knowledge. Some aspects of the business process involved activities that are relevant to the stages of the knowledge life cycle: acquiring, refining, storing and retrieving, distributing and presenting knowledge.

Organisations need to be aware that apart from possessing, acquiring or creating knowledge, experts also act as knowledge facilitators and co-ordinators, and play key roles in knowledge dissemination. In other words, they are involved in the whole knowledge retention process, using their social skills. Experts often represent a conduit for the acquisition of valuable new knowledge from the outside world, due to their roles and exposure to the industry and markets. In such roles, they also detect trends and patterns impacting the organisation and its business. Such knowledge may be worth preserving.

\section{Use of ICT}

While organisations may focus much effort on strategic ICT implementations for knowledge management, there are time constraints on implementing ICT specifically to target knowledge loss from older generations of workers. The study's findings implied that such investments may not be necessary. 
First, an older expert may already be a proficient and innovative user of ICT, although this may not be obvious. In the roles of knowledge facilitator and co-ordinator, the older expert I studied also tested new software for technical calculations. Second, I found that an older expert may also be a scarce resource in the organisation, especially if they are in a full-time role, as well as being consulted to provide expertise to other projects or initiatives. There is therefore a constraint on the expert's availability.

Organisations need to consider making use of existing ICT where possible, or using technologies that can be implemented quickly, once they have understood how they support experts' knowledge retention processes.

In conclusion, the objective of this study was to extend research in the domain of knowledge retention from older experts. The role of information and communications technologies in supporting knowledge retention was also addressed. The study adds to the literature on expertise and contributes a knowledge framework of an individual expert. The study also found that ICT formed an integral part of the expert's knowledge retention processes, and that elements of expertise were demonstrated in the knowledge retention process and the use of ICT. 

Appendix A: Information sheet and consent form

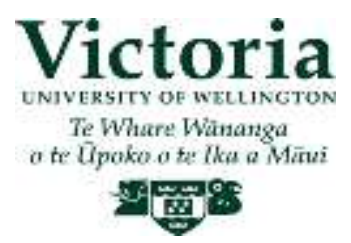

\section{INFORMATION SHEET}

30 September 2009

Dear

\section{BRANZ - the knowledge of older experts}

This information sheet follows my recent email in which I expressed an interest in conducting an interview with you as part of the above research. Before holding any interviews, Victoria University requires that I obtain your written informed consent to participate. This interview forms part of my research contribution towards the course requirements for a $\mathrm{PhD}$ degree in Information Systems.

\section{Purpose of research}

The approach to gathering this information involves conducting a semi-structured interview of about an hour based on a set of questions. There is a possibility that someone other than me will transcribe the interviews, and in this case, they will be required to sign a confidentiality agreement.

The purpose of this study is to explore how ICT can provide support in the transfer of knowledge, where there is a significant gap between workers with knowledge and expertise that are valuable to the organisation, and their less experienced colleagues. Often, people's age or the length of time they have spent in a specific field or organisation are factors that lead to their acquisition of expertise, with a resultant loss of knowledge when these experts become unavailable. In conducting this study, I will be guided by the following question:

How can ICT support knowledge transfer from more experienced workers in an organisational context?

The research provides information to assist with an understanding of how your organisation views knowledge, i.e. the types of knowledge that may be lost when more knowledgeable workers retire. The second area of interest is the processes that the organisation uses, or could use, to transfer this knowledge so it is not lost. Finally, the research seeks to identify how ICT would be used to support the knowledge transfer process.

\section{Approval}

The research has been approved by the School of Information Management Human Ethics Committee. 


\section{Confidentiality}

The interview will be electronically recorded and transcribed (typed). For the purposes of academic research, all the information you provide will be kept confidential to me as the researcher, and my supervisor. You will receive a write-up of your interview for review and feedback, to ensure factual

material has been recorded accurately. Data that is collected, collated and analysed may be published in case studies, academic journals and presented at conferences. If any information or opinions that you provide are attributed to you, your approval will be sought first. Throughout the research, raw data will be kept under password and/or lock protection and destroyed two years after the conclusion of the research.

Please feel free to contact my research supervisor Professor Pak Yoong on 044635878 if you require further information about the study or the informed consent requirement.

You have the right to withdraw from this study at any time up until 30 October 2009, and in the event that you give written advice of such a decision, all data, including recordings, that you have provided will be deleted or destroyed, and will be excluded from the findings of the research.

The consent form is attached. It includes a request for permission to record interviews. If you agree to participate, please complete the form, sign it and return it to me.

Thank you.

Yours sincerely

Carmel Joe

Email: carmel.joe@ vuw.ac.nz 


\section{Victoria \\ Te Whor Würarox \\ ok Dpoko o k ikn a Mant

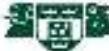

\section{CONSENT TO PARTICIPATE IN RESEARCH}

\section{Project title: BRANZ - the knowledge of older experts}

[Please mark each box with a $\checkmark$ to indicate agreement, then sign and date this form.]

I have been given and have understood an explanation of this research and the confidentiality conditions. I have had an opportunity to ask questions and have them answered to my satisfaction. I understand that the recording of the interview will be erased two years after the end of the research.

I understand that I may withdraw from this project before data collection and analysis is complete, without giving any reason. I can do this by e-mailing Carmel Joe or her supervisor before 30 September 2009, at the e-mail address given below. In the event that I give written advice of such a decision, all data, including recordings, that I have provided will be deleted or destroyed, and will be excluded from the findings of the research.

I understand that the data I provide will not be used for any other purpose or released to others without my written consent.

I would like to receive a summary of the results of this research when it is completed.

I I agree to take part in this research.

I I note that I have the right to withdraw from this study at any time up until 30 September 2009.

Signed:

Name of participant:

Date:

Contact details (optional):

e-mail, phone number or address

Contact details are used only if we need to clarify any information, or to ask you about any further thoughts you may have after the interview.

There is a possibility that someone other than the researcher will transcribe the interviews, and in this case, the transcriber will be required to sign a confidentiality agreement.

For further information on the project or informed consent requirement, please feel free to contact:

Carmel Joe

Supervisor: Associate Professor Pak Yoong
021424132

044635878
Carmel.Joe@vuw.ac.nz,or

Pak.Yoong@vuw.ac.nz 


\section{Appendix B: Project proposal}

\section{Project Proposal: Advisory Services knowledge retention}

\section{Introduction}

This proposal sets out the rationale for BRANZ to initiate a project to address a specific issue facing the Advisory Services 0800 and 0900 helpline services. Much of the knowledge required to provide these services consists of tacit, embedded knowledge that is personally held, complementing the formal documentation that is used. BRANZ recognises that much knowledge is held in the minds of older and very experienced staff, and that such knowledge is at risk of being lost when they leave. It is imperative that BRANZ acts to mitigate the risk of the Helpline services becoming compromised. The two main outcomes of the project would be to effect a smooth transition of the key role to a new staff member, and to implement a suitable technology to support knowledge retention. An important project output is that BRANZ will also have a knowledge retention model that it can apply in other similar situations.

\section{Background}

BRANZ is concerned about the loss of valuable knowledge as staff leave the organisation. We recently participated in a doctoral study that explored views of some personnel on what "knowledge" means in the context of BRANZ's business and in their specific roles. The study identified what constitutes valuable knowledge for the organisation, and what types of knowledge are at risk of being lost due to staff turnover, particularly where older and more experienced workers are concerned. The threat of loss and its business impacts, and the location of knowledge in the BRANZ were also addressed.

The results of the study indicated firstly, that BRANZ risks losing valuable knowledge in the form of subject matter expertise, knowledge of systems and processes, and knowledge of social networks. Secondly, losing some of these types of knowledge would result in depleting the organisational knowledge stocks that are required for the business to function successfully. There would be serious negative impacts on customer service quality, involving the introduction of reputational, commercial and potentially legal risk.

\section{Rationale for the project}

All of the knowledge types mentioned above as being under threat of loss are instrumental in the delivery of the Helpline service to its current high quality standard. The impacts of losing knowledge are significant for the service, which represents "the face of BRANZ" to the industry and to members of the public, and is a crucial component of BRANZ's reputation in the marketplace. The service is a prominent element of the BRANZ brand, historically and in the foreseeable future, and as such needs to be protected and strengthened. It must be made more robust as one of our key knowledge assets. We propose to do this by transferring personally-held knowledge to be retained within the organisation, as far as possible, and to manage a smooth transition of the role of the Helpline advisor to a new person once an appointment is made. The current advisor has also recently taken on responsibilities for editing, following the outsourcing of the technical writing function.

\section{Project approach}

The plan proposes adopting a 3-stage approach to the project to provide strong management control and to establish a clear focus for our efforts. 


\section{Stage 1: Scoping}

In order to scope the project, BRANZ will complete an analysis of the current state of the service to understand the key aspects of the knowledge that needs to be retained, and the appropriate methods for achieving this. The first priority for the project will be how to approach the transfer of knowledge from the Helpline adviser to a new recruit. Requirements will be developed for the project, including:

- people: defining personnel requirements to ensure that the appropriate skills are secured to continue delivering the service to an equal to better standard of customer service. Deliverables would include a position description and a role description for use in recruitment

- processes: identifying processes for capturing and retaining various types of knowledge that are important to the delivery of the Helpline service

- technology: exploring at a high level some technology options available to support and enhance the transfer of this knowledge to a new recruit

- management: agreeing and defining specifically what will be delivered as outputs of the project

- developing a detailed project and resource plan for the subsequent stages implementation and knowledge capture, and defining the project management and governance structures

$\circ$ securing and formalising funding and resources for the project

As a second priority, a report could also be produced that presents software options for managing the Helpline function, if needed. Functionality may include:

- managing the Helpline service (call tracking, analysis and reporting)

- $\quad$ supporting communication with users, and being flexible for the needs of different groups (industry, consultants, territorial local authorities and the public)

- facilitating the re-use of information for calls that are similar in nature

Once stage 1 is complete and the results are reviewed, the scope of the implementation stage will be confirmed and planned in further detail, taking into account BRANZ's project resources.

\section{Stage 2: Implementation}

We currently envisage that the main implementation activities could include the following:

- recruiting the appropriate person for the new role as defined during the scoping stage, complete their induction to BRANZ, start the handover process for the role, involving them in the project from the start of implementation

- $\quad$ starting to document the processes for the Helpline service and how it is delivered, including agreed improvements

- $\quad$ procuring and trialling or prototyping a selected software product that supports the transfer of knowledge to the newly recruited Helpline advisor

- training staff and capturing knowledge on a trial basis as part of testing the prototype

- providing support to BRANZ in trialling software for managing the Helpline function, if relevant, following the report produced in Stage 1

Near the end of Stage 2, the scope of Stage 3 and the resources required would be reviewed and confirmed. 


\section{Stage 3: Knowledge capture}

It is envisaged that knowledge capture would involve BRANZ staff in activities such as:

- continuing with knowledge transfer in the handover to the new recruit

- completing process documentation for the Helpline service and its management

- implementing the new ICT once the pilot or trial is complete, and capturing call information directly into the new system

- making a decision about how to manage historical call information and statistics (whether they may be captured in the new system)

\section{External role}

Our doctoral student, who is an experienced consultant and project manager, plans to be available 2-3 days per week and would act in the role of project manager over a period of 69 months, as part of her research. It is envisaged that this will see the progress of the project through to the start of Stage 3.

Initially, the role is limited to managing the project and working alongside BRANZ staff on a part-time basis to complete Stage 1 of the project as outlined above. Alongside this role, there is another high priority commitment, which is the completion of the academic study that is required for doctoral research purposes. The intention is that at the end of Stage 1, there would be a review and confirmation of arrangements for Stage 2. 


\section{Appendix C: Table of contents for project terms of reference}

Advisory Services Knowledge Retention Project

Terms of Reference

\section{Table of Contents}

1. Introduction

1.1. Background

1.2. Purpose

1.3. Outcomes

1.4. Benefits

1.5. Scope

2. Project approach

2.1. Detailed description

2.1.1. Defining personnel requirements

2.1.2. Identifying processes for capturing knowledge

2.1.3. Review of Stage 1

2.2. Rationale for approach

2.3. Assumptions

2.4. Risks and mitigation strategies

2.5. Milestones

3. Project organisation

3.1. Structure

3.2. Project governance

3.3. Stakeholders

3.4. Project team

3.5. Communications plan

4. Project framework

4.1. Budget

4.2. Timelines

4.3. Critical success factors

5. Appendix A - additional documentation

6. Glossary 



\section{Appendix D: Helpline call actions}

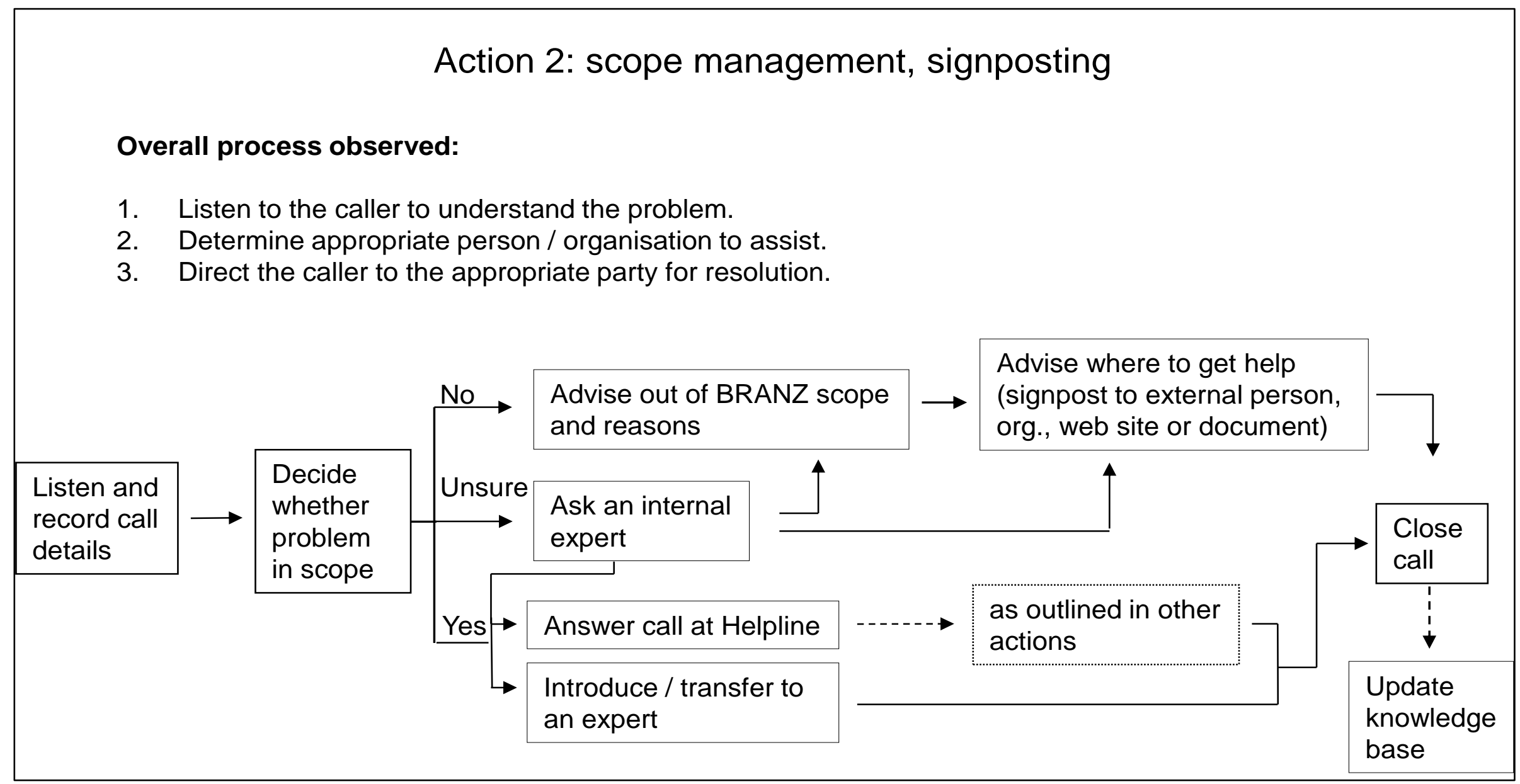




\section{Action 3: provide detailed technical and practical assistance}

\section{Overall process observed:}

1. Determine caller's background and level of knowledge.

2. Discuss / address range of technical questions.

3. Advise alternatives and any recommendations.

4. Reiterate industry roles and responsibilities.

5. Direct caller to any relevant information sources.

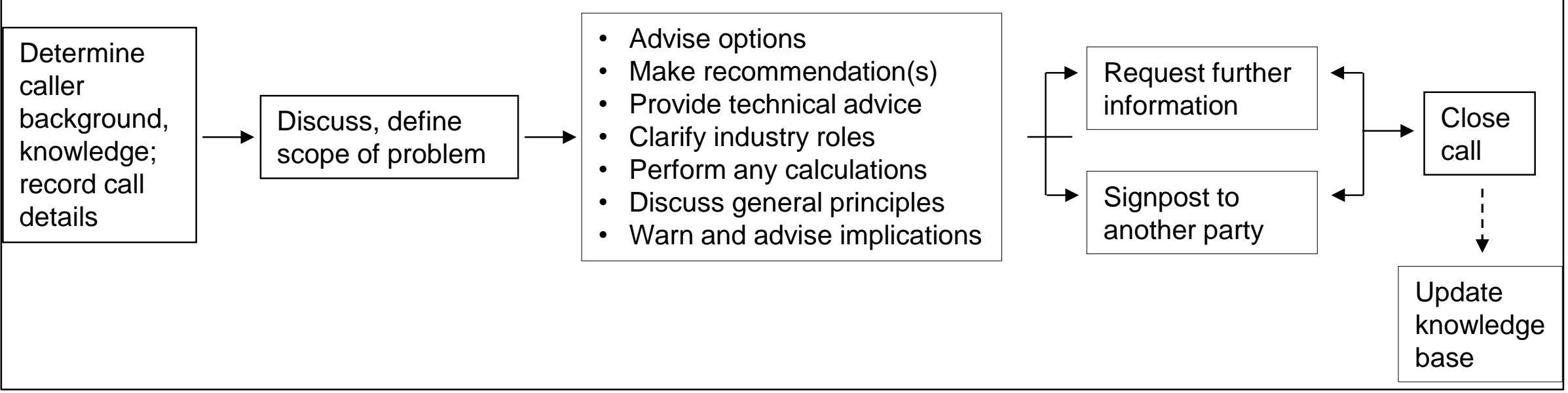




\section{Action 4: technical assistance with documents and requirements}

\section{Overall process observed:}

1. Set scope for providing factual information and advice.

2. Identify relevant documents, relationships and availability.

3. Provide technical information, walkthroughs, definitions and processes.

4. Provide signposting and offer subsequent advice if required.

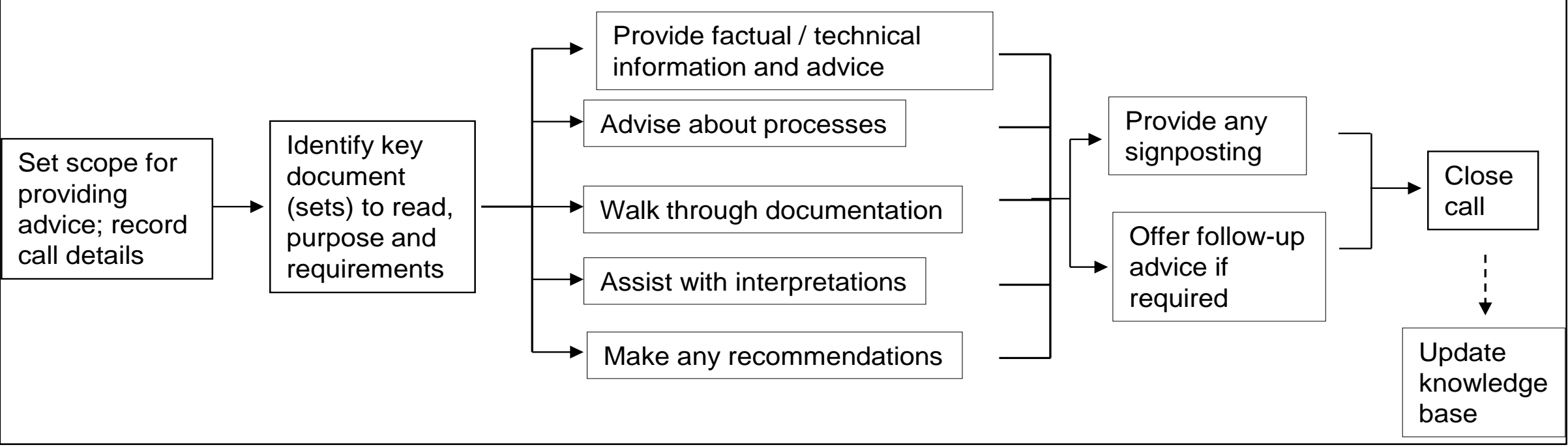




\section{Action 5: advising on compliance, responsibility and reliability}

\section{Overall process observed:}

1. Listen to caller, gather information and understand parties involved.

2. Pinpoint source(s) of the problem.

3. Clarify roles, responsibilities and liabilities.

4. Advise appropriate actions and explain reasoning.

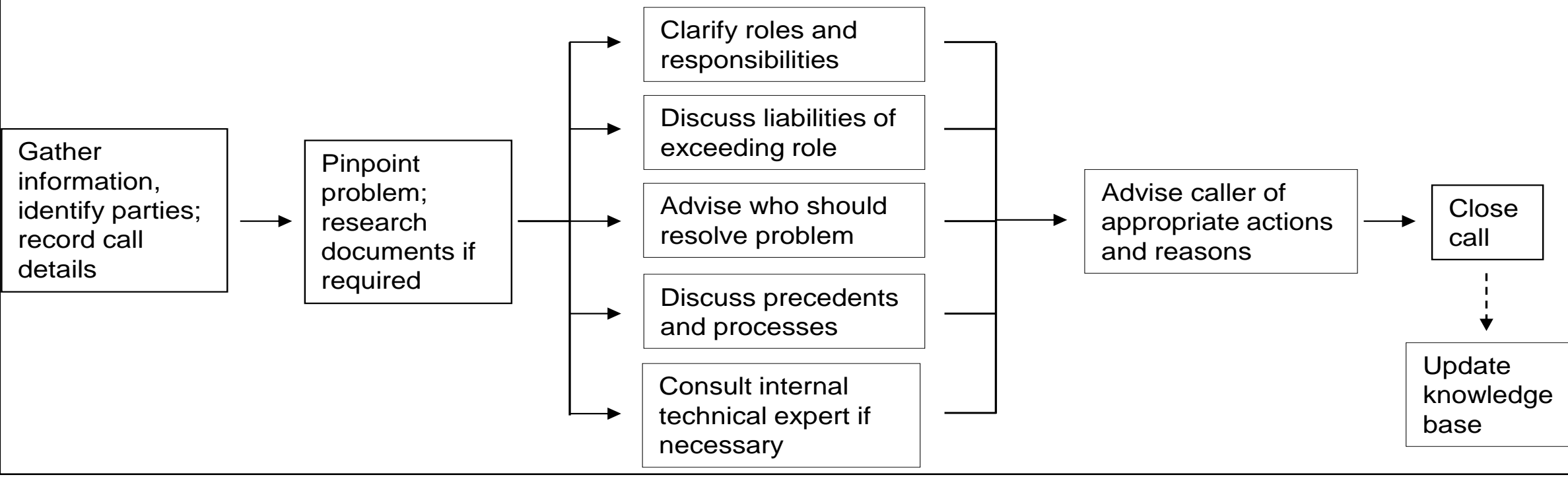




\section{Action 6: remedying existing faults and failures}

\section{Overall process observed:}

1. Listen to and question the caller to understand the problem.

2. Diagnose the fault or failure and identify the possible causes.

3. Consult appropriate sections of Code or Standard for remedial action; consult expert if required.

4. Advise actions for remedying the fault or failure.

Listen to caller, gather details;

record call

details

\section{Make}

$\rightarrow$ (tentative) diagnosis

\section{$\longrightarrow$ Discuss possible causes}

Discuss rules, compliance requirements

\section{$\longrightarrow$ Clarify contractual matters} Consult relevant Code, Standard or expert; complete calculations

Access precedents, own technical knowledge

\section{Advise remedial actions:}

- address responsible party

- get sign offs to protect

against risk

- cite relevant Standard /

Code in resolution

- signpost to expert if

needed

- advise of dispute resolution options

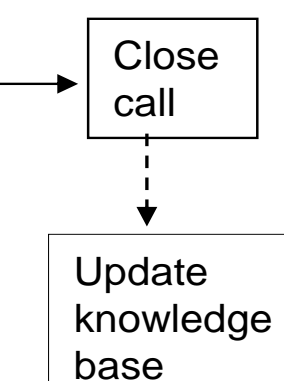

base 


\section{Appendix E: Expertise and using ICT for knowledge retention}

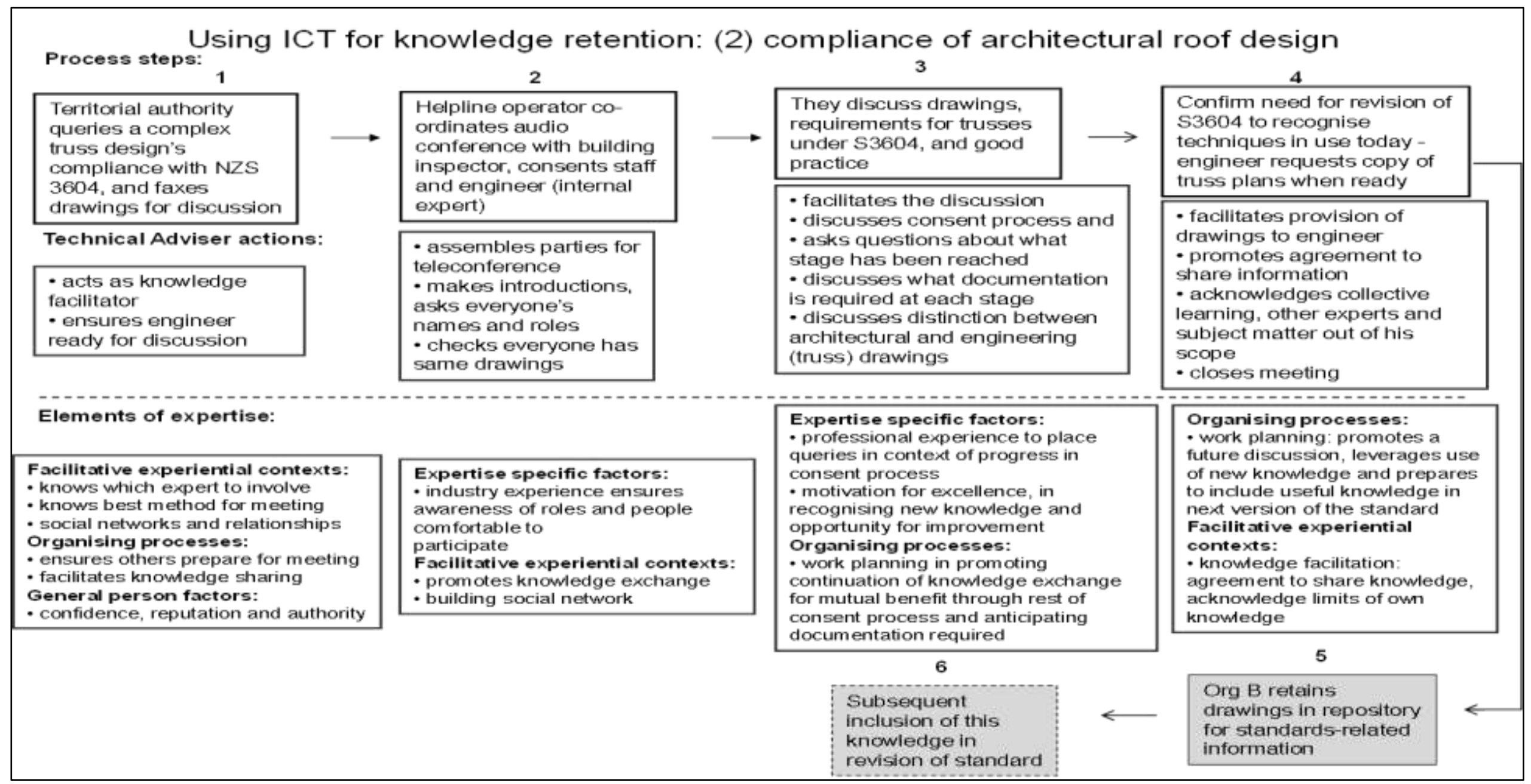




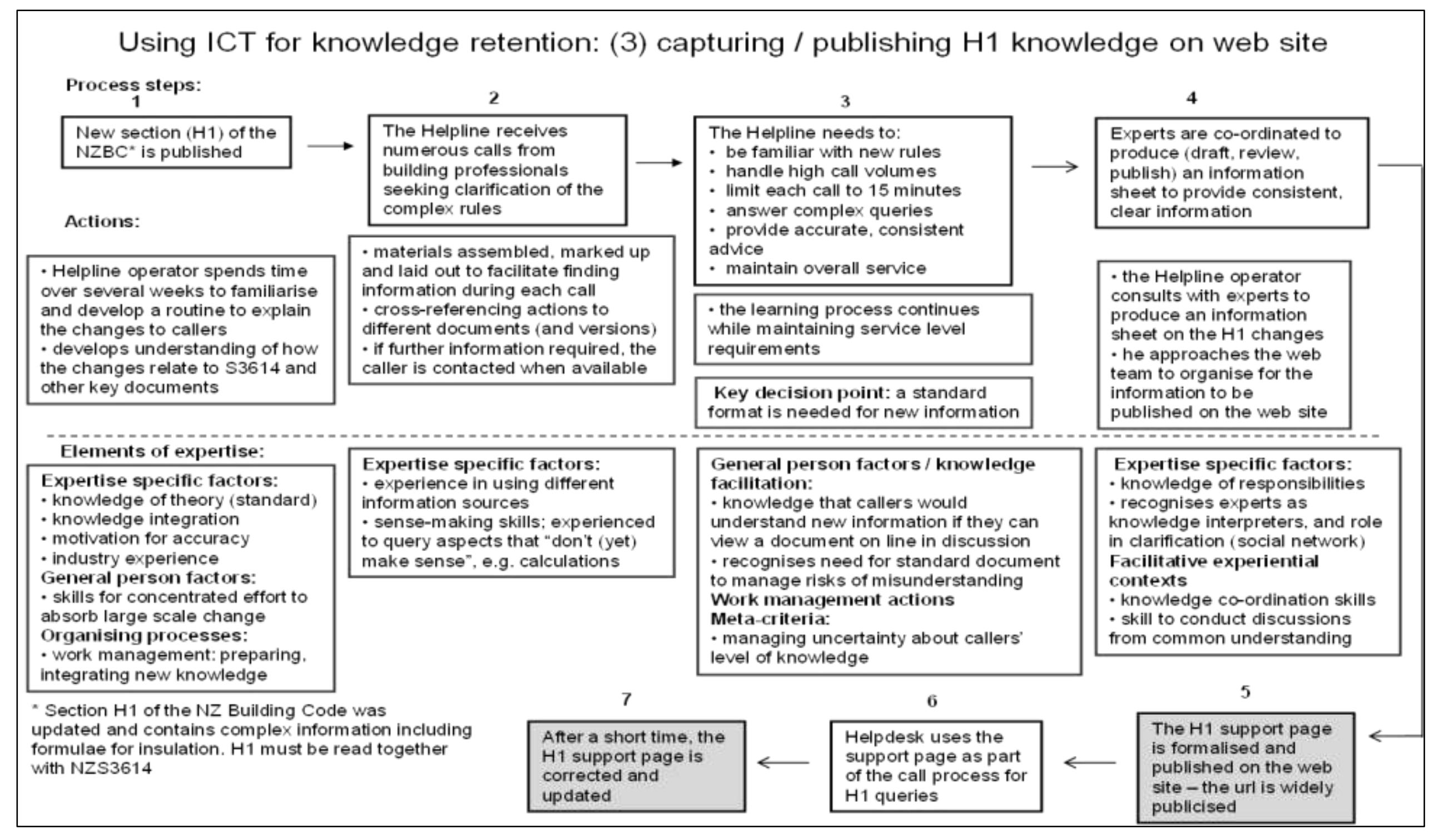




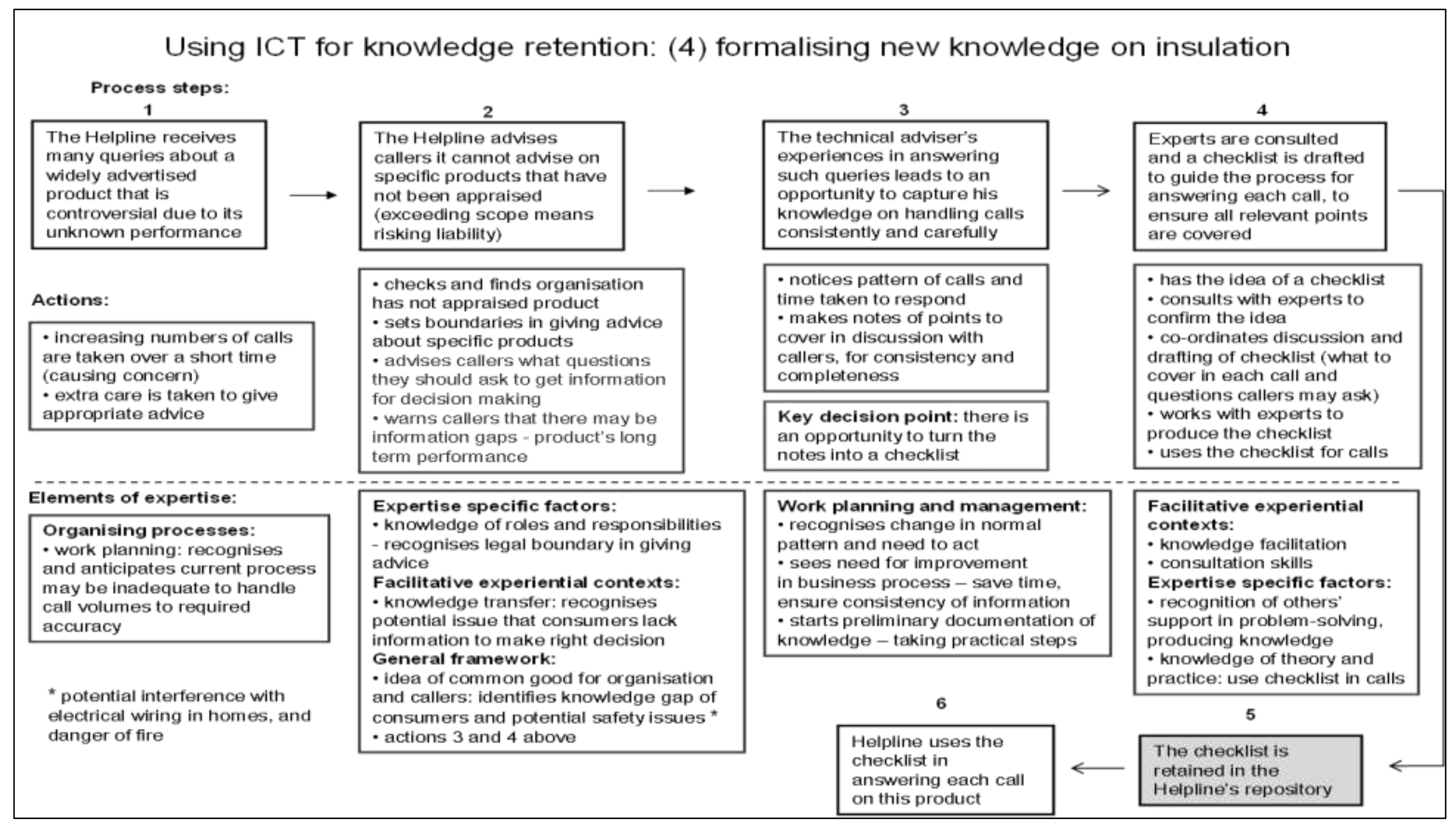




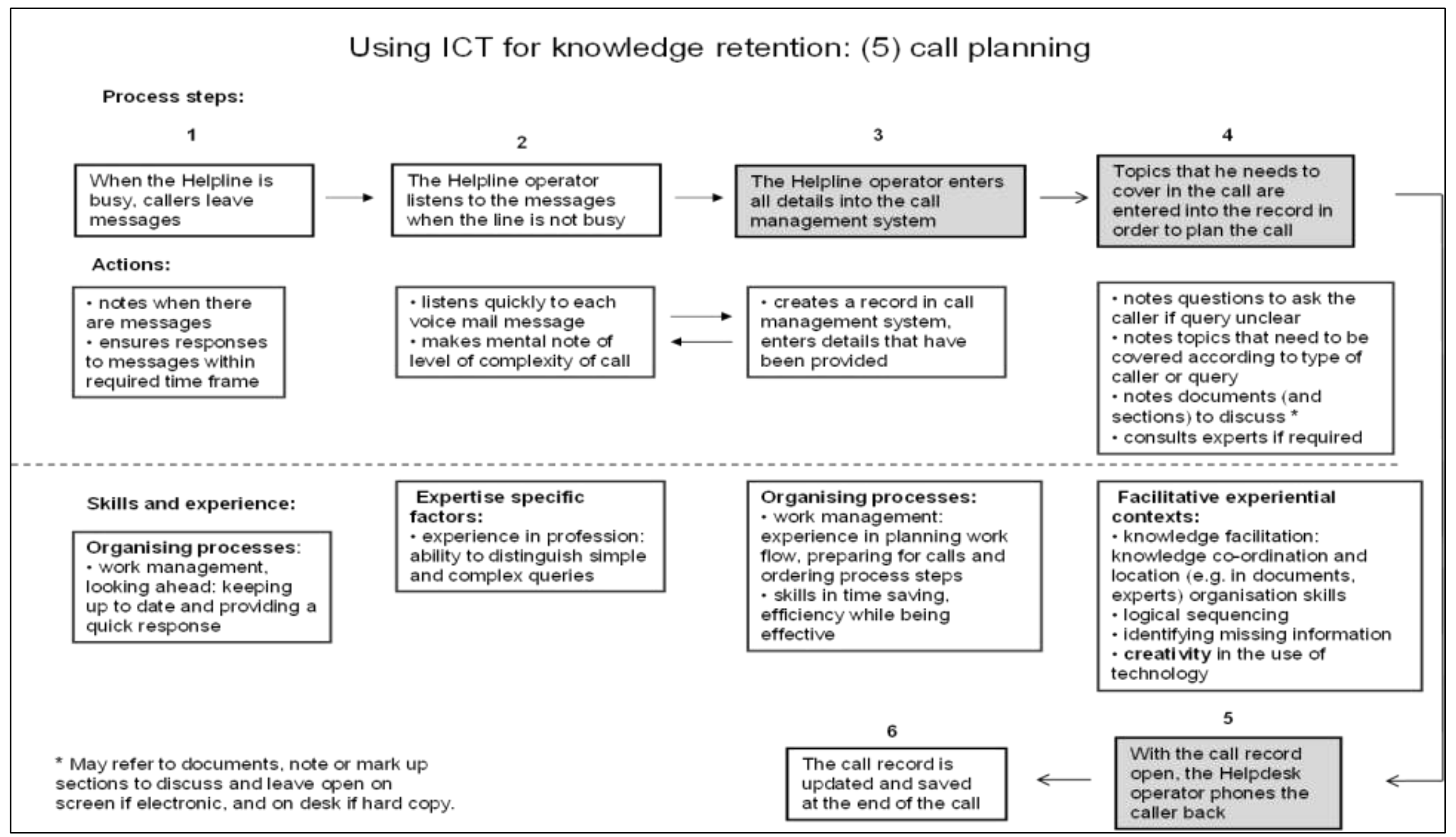




\section{Using ICT for knowledge retention: (6) linking digital recordings}

Process steps:

1

\section{The Helpline has a \\ need to quickly retrieve \\ recordings of specific}

calls *

Actions:

- remembers a call

where a topic of

interest was

discussed
The Helpline moves from

tape recordings to a new

system for recording all

calls using digital

technology

When appropriate, the

Helpline operator links the

digital recording to the call

record as an attachment

- suggests benefits of
digital recordings over
tapes
- participates in trialling
digital recording system

- suggests benefits of

tapes

digital recording system

- identifies recordings that are relevant to attach to cal record

- opens call management

record, clicks on "attach" icon

and selects relevant

recording to link to the record
A flag is to be included

on the summary display

of the call record to

indicate when an

attached recording exists

\section{- scrolls through}

summary screen to locate

relevant call with

recording

- promotes availability of

this feature to other users
Skills and experience:

General person factors:

- cognitive style: skill to recall

details $e . g$. when call occurred

- making connection between

present situation and past

relevant information

General framework:
- recognising common good for
organisation: experience in
identifying new opportunities
for knowledge retention and
sharing
- experience in seeing
business process improvem ent
- simplification, time saving.
better access to recordings

\section{Basic criteria:}

- procedural knowledge: using

technology to quickly link

related information

- retaining related knowledge

where it can be located easily

better access to recordings

* Calls may be of interest for a number of reasons

e.g. interesting, ongoing topics, complex, require

follow-up, potential to be controversial, or for

training purposes

General framework:

- recognising common

good for organisation:

sharing new knowledge

with others (knowledge-

sharing and promotion

skills)

The Helpline operator

is able to access the

digital recording when

required 


\section{BIBLIOGRAPHY}

AARP. (2004). Staying ahead of the curve: employer best practices for mature workers. Washington, D.C.

Abbasi, S. M., Moncef, B., \& Hollman, K. W. (2009). Managing knowledge workers for sustaining competitive advantage. Competition Forum, 7(2), 367-370.

Alavi, M., \& Leidner, D. E. (2001). Review: knowledge management and knowledge management systems: conceptual foundations and research issues. MIS Quarterly, 25(1), 109-136.

Albino, V., Garavelli, A. C., \& Gorgolione, M. (2004). Organisation and technology in knowledge transfer. Benchmarking, 11(6), 584-598.

Albrecht, D. G. (2001). Getting ready for older workers. Workforce.

American Public Power Association. (2003). The aging and retiring work force: new challenges for Public Power. Washington, D.C.: American Public Power Association.

APPA. (2003). The aging and retiring work force: new challenges for Public Power. Washington, D.C: American Public Power Association.

Arant-Kaspar, W., Carter, H., Desai, S., Byrd, J., \& Hahn, D. (2007). ResDesk: an automated solution for course reserves request tracking and process management. Library Hi Tech, 25(2), 197-210.

Ardelt, M. (2000). Intellectual versus wisdom-related knowledge: the case for a different kind of learning in the later years of life. Educational Gerontology, 26, 771-789.

Ardelt, M. (2004). Wisdom as expert knowledge system: a critical review of a contemporary operationization of an ancient concept. Human Development, 47, 257-285.

Ardelt, M. (2005). How wise people cope with crises and obstacles in life. ReVision, 28(1), 7-19.

Argote, L., McEvily, B., \& Reagans, R. (2003). Managing knowledge in organizations: an integrative framework and review of emerging themes. Management Science, $49,571-582$.

Armstrong-Stassen, M., \& Schlosser, F. (2008). Benefits of a supportive development climate for older workers. Journal of Managerial Psychology, 23(4), 419-437.

Ashworth, M. J. (2006). Preserving knowledge legacies: workforce ageing, turnover and human resource issues in the US electric power industry. International Journal of Human Resource Development, 17(9), 1659-1688.

Automony. (2003). Automated management of unstructured content. Retrieved 24 July, 2006, from http://www.autonomy.com 
Avison, D., Baskerville, R., \& Myers, M. (2001). Controlling action research projects. Information Technology \& People, 14(1), 28-45.

Avison, D., Lau, F., Myers, M., \& Nielsen, A. (1999). Action research. Communications of the ACM, 42(1), 94-97.

Baker, S., \& Green, H. (2005). Blogs will change your business. Business Week, May 2, 2005, issue 3931, 56-62.

Baltes, P. B. (1993). The aging mind: potential and limits. The Gerontologist, 33, 580594.

Baltes, P. B., \& Kunzmann, U. (2004). The two faces of wisdom: wisdom as a general theory of knowledge and judgement about excellence in mind and virtue vs. wisdom as everyday realisation in people and products. Human Development, 47(5), 290-299.

Baltes, P. B., \& Smith, J. (1990). Toward a psychology of wisdom and its ontogenesis. In R. J. Sternberg (Ed.), Wisdom: Its nature, origins and development (pp. 87120). New York: Cambridge University Press.

Baltes, P. B., \& Staudinger, U. M. (1993). The search for a psychology of wisdom. Current Directions in Psychological Science, 2, 75-80.

Baltes, P. B., \& Staudinger, U. M. (2000). Wisdom: a metaheuristic (pragmatic) to orchestrate mind and virtue toward excellence. American Psychologist, 55(1), 122-136.

Barley, S. R. (1989). Images of imaging: notes on doing longitudinal field work. Organisational Science, 1(3), 220-247.

Basiulis, K. E. (2009). The new reality of the American workforce: knowledge management as a retention tool. Contract Management, 49(11), 76-85.

Baskerville, R. L. (1999). Investigating information systems and action research. Communications of the Association for Information Systems, 2(10). Retrieved from http://cais.isworld.org/articles/2-19/

Baskerville, R. L., \& Myers, M. D. (2004). Special issue on action research in information systems: making IS research relevant to practice - foreword. MIS Quarterly, 28(3), 329-335.

Baskerville, R. L., \& Pres-Heje, J. (1999). Grounded action research: a method for understanding IT in practice. Accounting, Management and Information Technologies, 1999(9), 1-23.

Baskerville, R. L., \& Wood-Harper, A. T. (1996). A critical perspective on action research as a method for information systems research. Journal of Information Technology, 11(3), 235-246.

Baskerville, R. L., \& Wood-Harper, A. T. (1998). Diversity in information systems action research methods. European Journal of Information Systems, 1998(7), 90-107. 
Becerra-Fernandez, I., \& Sabherwal, R. (2005). Knowledge management at NASAKennedy Space Centre. International Journal of Knowledge and Learning, $1(1 / 2), 159-170$.

Bell, J. (2001). Job market values experience of third-agers: career Crossroads. Journal of Property Management, 2001, 42-46.

Benbasat, I., Goldstein, D. K., \& Mead, M. (1987). The case research strategy in studies of information systems. MIS Quarterly, September 1987.

Berends, H. (2005). Exploring knowledge sharing: moves, problem solving and justification. Knowledge Management Research \& Practice, 2005, 97-105.

Besl, J. R., \& Kale, B. D. (1996). Older workers in the 21st century: active and educated, a case study. Monthly Labour Review, June, 1996, 18-28.

Bierly, P. E., Kessler, E. H., \& Christensen, E. W. (2000). Organisational learning, knowledge and wisdom. Journal of Organisational Change Management, 13(6), 595-618.

Birren, J. E., \& Fisher, L. M. (1990). The elements of wisdom: overview and integration. In R. J. Sternberg (Ed.), Wisdom: its nature, origins and development (pp. 317332). New York: Cambridge University Press.

Blessing, S. B., \& Anderson, J. R. (1996). How people learn to skip steps. Journal of Experimental Psychology: Learning, Memory and Cognition, 22(3), 576-598.

Bockman, S., \& Sirotnik, B. (2008). The aging workforce: an expanded definition. Business Renaissance Quarterly, 3(3), 129-135.

Bogdan, R. C., \& Biklen, S. K. (1992). Qualitative research for education: an introduction to theory and methods. Boston.

Boisot, M., Wales, J., Brindley, L., McAteer, P., Piramal, G., Hagel, J., et al. (2006). How much knowledge should a business give away? European Business Forum, Spring 2006(24), 7-21.

Bolch, M. (2000). The changing face of the workforce. Minneapolis.

Bresnen, M., Edelman, L., Newell, S., \& Swan, J. (2003). Social practices and the management of knowledge in project environments. International Journal of Project Management, 21, 157-166.

Brinberg, D., \& McGrath, J. E. (1985). Validity and the research process. Newbury Park: Sage.

Brown, J. S., \& Duguid, P. (1998). Organising knowledge. Californian Management Review, 40(3), 90-111.

Brownstein, E., \& Klein, R. (2006). Blogs: applications in science education. Journal of College Science Teaching, Academic Research Library, May-Jun 2006 35(6), 18-22. 
Cairns, L. (2009, 15 November). Life is still working for Kiwi pensioners. Sunday Star Times, p. A8.

Calo, T. (2008). Talent management in the era of the aging workforce: The critical role of knowledge transfer. Public Personnel Management, 37(4), 403-416.

Carruthers, F. (2005, 30 September). Older workers fight back. Dominion Post, p. C2.

Casher, A., \& Lesser, E. (2003). Gray matter matters: preserving critical knowledge in the 21 st century.

Challenger, J. A. (2000). 24 trends reshaping the workplace. The Futurist, SeptemberOctober 2000, 35-41.

Chen, C. C., Shang, R., Harris, A., \& Chen, Z. (2007). A structurational analysis of users and management in a knowledge management system project implementation. International Journal of Knowledge Management, 3(4), 18-36.

Chilton, M. A., \& Bloodgood, J. M. (2008). The dimensions of tacit and explicit knowledge: a description and measure. International Journal of Knowledge Management, 4(2), 75-91.

Chisholm, R., \& Elden, M. (1993). Features of emerging action research. British Journal of Management Studies, 9(1), 83-94.

Christians, C. G. (2000). Ethics and politics in qualitative research. In N. K. Denzin \& Y. S. Lincoln (Eds.), Handbook of qualitative research (2nd ed., pp. 133-155). Thousand Oaks: Sage Publications, Inc.

Closs, S. J., Johnstone, D., Zeigler, L., Newell, R. J., \& Parker-Jones, C. H. (2004). Evaluation of RDDirect: an innovative telephone research advisory service. Clinical Governance - an International Journal, 9(2), 101-109.

Coghlan, D. (2008). Authenticity as first person practice. Action Research, 6(3), 351366.

Cohen, W. M., \& Levinthal, D. A. (1990). Absorptive capacity: a new perspective on learning and innovation. Administrative Science Quarterly, 35(1), 128-152.

Connell, C., Klein, J. H., Loebbecke, C., \& Powell, P. (2001). Towards a knowledge management consultation system. Knowledge and Process Management, 8(1), 48-54.

Connell, C., Klein, J. H., \& Powell, P. (2003). It's tacit knowledge but not as we know it: redirecting the search for knowledge. Journal of the Operational Research Society, 2003(54), 140-152.

Connolly, G. (2000). Life begins at 55. Charter, Sydney, 71(2), 72-73.

Cowan, J., \& Haslam, J. (2008). It's good to talk: Telephone help-lines for health professionals can support effective and safe working practices. Clinical Governance - an International Journal, 13(4). 
Cresswell, J. W. (1994). Research design: qualitative and quantitative approaches. Thousand Oaks, California: Sage Publications Inc.

Cross, R., \& Sproull, L. (2004). More than an answer: information relationships for actionable knowledge. Organization Science, 15(4), 446-462.

Crowder, R., Hughes, G., \& Hall, W. (2002). Approaches to locating expertise using corporate knowledge. International Journal of Intelligent Systems in Accounting, Finance \& Management, 11, 185-200.

Csikszentmihalyi, M., \& Rathunde, K. (1990). The psychology of wisdom: an evolutionary interpretation. In R. J. Sternberg (Ed.), Wisdom: Its nature, origins, and development (pp. 13-24). New York: Cambridge University Press.

Cunningham, W. S. (2008). Voices from the field: practitioner reactions to collaborative research initiatives. Action Research, 6(4), 373-390.

Davenport, T. H., \& Prusak, L. (1998). Working Knowledge: how organisations manage what they know. Boston: Harvard Business School Press.

Davey, J. (2007). Maximising the potential of older workers, update to 2007. Wellington: New Zealand Institute for Research on Ageing.

Davey, J. (2008). Workforce ageing - an issue for employers. IPS Working Paper Retrieved 2 April 2010, from http://ips.ac.nz/staff/team/judith_davey.html

Davison, R. M., Martinsons, M. G., \& Kock, N. (2004). Principles of canonical action research. Information Systems Journal, 14, 65-86.

De Long, D. W. (2004). Lost knowledge: confronting the threat of an aging workforce. New York: Oxford University Press.

De Long, D. W. (2007). Searching for the silver bullet: leading edge solutions for leveraging an aging workforce. Retrieved 5 April 2010, from www.lostknowledge.com

De Long, D. W., \& Mann, T. O. (2003). Stemming the brain drain. Outlook Retrieved 12 July, 2006, from www.accenture.com/Outlook

Dearstyne, B. W. (2005). Blogs: the new information revolution? Information Management Journal, 39(5), 38-44.

DeLong, D. W. (2004). Lost knowledge: confronting the threat of an aging workforce. New York: Oxford University Press.

Department of Labour, N. Z. (2007). Older people in work: key trends and patterns 1991-2005. Retrieved 8 April 2010, from http://www.dol.govt.nz/publications/research/older-people/older-people_01.asp

Department of Labour, N. Z. (2009). The working patterns of older workers. From the website of the New Zealand Department of Labour Retrieved 2 April 2010, from http://www.dol.govt.nz/publications/research/working-patterns/index.asp 
Department of Labour, N. Z. (2010). Skillsinsight: future retirement patterns. Skillsinsight Retrieved 22 February 2011, from http://www.dol.govt.nz/services/LMI/tools/skillsinsight/forecastingnarratives/retirement/index.asp\#fig3

Department of Statistics, N. Z. (2003). New Zealand Labour Force Projections 1996(base) - 2051. from www.stats.govt.nz

Didierjean, A., \& Gobet, F. (2008). Sherlock Holmes - an expert's view of expertise. British Journal of Psychology, 2008(99), 109-125.

Drisko, J. W. (1997a). Strengthening qualitative studies and reports: standards to promote academic integrity. Journal of social work education, 33(1), 185-197.

Drisko, J. W. (1997b). Strengthening qualitative studies and reports: standards to promote academic integrity. Journal of Social Work and Education, 33(1), 185197.

Drucker, P. F. (1994). The age of social transformation. The Atlantic Monthly, 274(5), 53-80.

Duffy, K., Ferguson, C., \& Watson, H. (2004). Data collecting in grounded theory some practical issues. Nurse Researcher, 11(4), 67-78.

Dunstan, K., \& Thomson, N. (2006). Demographic Trends. In J. Boston \& J. A. Davey (Eds.), Implications of population ageing: opportunities and risks (pp. 9-50). Wellington, New Zealand: Institute of Policy Studies.

Dychtwald, K., \& Forsberg, S. A. (2001). 'Rehirement' before retirement: baby boomers are at it again. WorldatWork Journal, Fourth Quarter 2001.

Ebrahimi, M., Saives, A.-L., \& Holford, D. (2008). Qualified ageing workers in the knowledge management process of high-tech businesses. Journal of Knowledge Management, 12(2), 124-140.

Elden, M., \& Chisholm, R. F. (1993). Emerging varieties of action research: introduction to the special issue. Human Relations, 46(2).

Ellis, J. H. M., \& Kiely, J. A. (2000). The promise of action inquiry in tackling organisational problems in real time. Retrieved 16 June, 2005, from http://www.scu.edu.au/schools/gcm/ar/ari/p-jellis00.html

Emmison, M., \& Danby, S. (2007). Troubles announcements and reasons for calling: Initial actions on opening sequences in calls to a national children's helpline. Research on Language and Social Interaction, 40(1), 63-87.

England, S., \& Herrera, R. Y. (2005). Conserving government's most valuable resource. Outlook Retrieved 30 June, 2006, from www.accenture.com/Outlook

EPRI. (2006). Capturing and using high-value undocumented knowledge in the nuclear industry: guidelines and methods. Retrieved 30 June, 2006, from http:Iwww.epri.com 
Equal Employment Opportunities Trust. (2008). Valuing experience: a practical guide to recruiting and retaining older workers. Retrieved from www.eeotrust.org.nz/content/docs/toolkits/Valuing\%20experience.pdf.

Ericsson, K. A., \& Kintsch, W. (1995). Long-term working memory. Psychological Review, 102(2), 211-245.

Ericsson, K. A., \& Smith, J. (1991). Toward a general theory of expertise: prospects and Limits: Cambridge University Press.

Ericsson, K. A., \& Ward, P. (2007). Capturing the naturally occurring superior performance of experts in the laboratory: toward a science of expert and exceptional performance. Current Directions in Psychological Science, 16(6), 346-350.

Ethell, R. G., \& McMeniman, M. M. (2000). Unlocking the knowledge in action of an expert practitioner. Journal of Teacher Education, 51(2), 87-101.

Fontana, A., \& Frey, J. H. (2000). The interview: from structured questions to negotiated text. In N. K. Denzin \& Y. S. Lincoln (Eds.), Handbook of qualitative analysis (pp. 645-670). Thousand Oaks, CA: Sage Publications, Inc.

Foos, T., Schum, G., \& Rothenberg, S. (2006). Tacit knowledge transfer and the knowledge disconnect. Journal of Knowledge Management, 10(1), 6-18.

Freeze, R., \& Kulkarni, U. (2008). Validating distinct knowledge assets: a capability perspective. International Journal of Knowledge Management, 4(4), 40-61.

Fry, R., \& Srivastva, S. (1992). Introduction: Continuity and change in organisational life. In R. F. A. S. Srivastva (Ed.), Executive and organsiational continuity: Managing the paradoxes of stability and change. San Francisco: Jossey-Bass.

Gaines, B. R., \& Shaw, M. L. G. (undated). Collaboration through concept maps. Retrieved 6 February, 2005, from http://ksi.cpsc.ucalgary.ca/articles

Gammelgaard, J., \& Ritter, T. (2005). The knowledge retrieval matrix: codification and personification as separate strategies. Journal of Knowledge Management 9(4), 133-143.

Gardyn, R. (2000). Retirement redefined. American Demographics, 22(11), 16-18.

Garud, R., \& Nayyar, P. (1994). Transformative capacity: continual structuring by intertemporal knowledge transfer. Strategic Management Journal, 15(5), 365-385.

Glass, T. A., Freedman, M., Carlson, M. C., Hill, J., Frick, K. D., Ialongo, N., et al. (2004). Experience Corps: design of an intergenerational program to boost social capital and promote the health of an aging society. Journal of Urban Health: Bulletin of the New York Academy of Medicine, 81(1), 94-105.

Gobet, F. (2000). Some shortcomings of long-term working memory. British Journal of Psychology, 2000(91), 551-570. 
Golbeck, J., Grimes, J. M., \& Rogers, A. (2010). Twitter use by the US Congress. Journal of the American Society for Information Science and Technology, 61(8), 1612-1621.

Gongla, P., \& Rizzuto, C. R. (2001). Evolving communities of practice: IBM Global Services experience. IBM Systems Journal, 40(4), 842-862.

Goodnoe, E. (2006). Wiki while you work. InformationWeek, Feb 27, 2006(1078), $52-$ 56.

Goodridge, E., \& McGee, M. K. (2002, September 9, 2002). IT's generation gap. Informationweek.com

Gordon, C. (2006). Wikis - a disruptive innovation. KM World, 15(6), 26.

Gregor, S. (2006). The nature of theory in information systems. MIS Quarterly, 30(2), 611-642.

Gross, M. M., Hanes, L. F., \& Ayres, T. J. (2001, June 4-7). Knowledge documentation problems and efforts in Electric Utilities. Paper presented at the 7th Annual Human Performance/Root cause/Trending Workshop, Baltimore.

Grossman, I., Jinkyung, N., Varnum, M. E. W., Park, D. C., Kitayama, S., \& Nisbett, R. E. (2010). Reasoning about social conflicts improves old age. Proceedings of the National Academy of Sciences of the United States of America 107(16), 72467250. Retrieved from http://www.pnas.org/content/107/16/7246.full?sid=4e27ab94-4bd5-47be-86f8b4f9e242a75f

Grover, V., \& Davenport, T. H. (2001). General perspectives on knowledge management: fostering a research agenda. Journal of Management Information Systems, 18(1), 5-21.

Guba, E. G., \& Lincoln, Y. S. (1994). Competing paradigms in qualitative research. In N. K. D. a. Y. S. Lincoln (Ed.), Handbook of Qualitative Research (pp. 105117). Thousand Oaks: Sage.

Gupta, A., \& Govindarajan, V. (2000). Knowledge flows within multi-national corporations. Strategic Management Journal(21), 473-496.

Gustavson, B. (2008). Action research, practical challenges and the formation of theory. Action Research, 6(4), 421-437.

Hall, K. (2008). Employers will need grey skills. Dominion Post, (27 November 2008). Retrieved from http://www.stuff.co.nz/business/736120

Ham, M. (2009, 14 January). Age also equals maturity and experience. The Dominion Post, p. E10.

Hammer, M. (2002). The getting and keeping of wisdom: inter-generational knowledge transfer in a changing public service. Retrieved 13 April, 2006, from http://www.psc-cfp.gc.ca/research/ 
Hammer, M., Leonard, D., \& Davenport, T. (2004). Why don't we know more about knowledge? MIT Sloan Management Review, Summer 2004. 45(4), 14-18.

Hammersley, M. (1990). Reading ethnographic research: A critical guide. London: Longman.

Hanes, L. F. (undated). Capturing valuable undocumented knowledge. Retrieved 30 June, 2006, from http://www.mtonline.com/articles/0903epri.cfm?pf=1\#boxcopy

Hansen, M. T., Nohria, N., \& Tiernay, T. (1999). What's your strategy for managing knowledge? Harvard Business Review, 77(2), 106-114.

Hasan, H., \& Crawford, K. (2007). Knowledge mobilisation in communities through socio-technical systems. Journal of KMRP, 5(4), 237-248.

Heron, J., \& Reason, P. (2001). The practice of co-operative inquiry: Research 'with' rather than 'on' people. In P. Reason \& H. Bradbury (Eds.), Handbook of action research (pp. 179-188). Thousand Oaks, CA: SAGE.

Hewitt, S. (2008). Defusing the demographic time-bomb. Human Resource Management International Digest, 16(7), 1-4.

Hilsen, A. I., \& Ennals, R. (2005). Age, mobility and knowledge: an action research approach. AI and Society(18), 552-557.

Hilson, G. (2001). Generation gap is big iron's only threat. Computing Canada, 27(7), 1 and 4.

Hinds, P. J., \& Pfeffer, J. (2003). Why organisations don't "know what they know": cognitive and motivational factors affecting the transfer of expertise. In M. S. Ackerman, P. Volkmar \& W. Volkmar (Eds.), Sharing expertise: beyond knowledge management (pp. 27-55). Cambridge, Massachusetts: The MIT Press.

Hirschman, C. (2001). Exit strategies. HR Magazine, December, 2001.

Huber, B. (1999). Experts in organisations: the power of expertise. Plattenstrasse 14, $\mathrm{CH}-8032$ Zurich, Switzerland: University of Zurich.

Huber, G. P. (2001). Transfer of knowledge in knowledge management systems: unexplored issues and suggested studies. European Journal of Information Systems 2001(10), 72-79.

Hult, M., \& Lennung, S. (1980). Towards a definition of action research: a note and bibliography. Journal of Management Studies, 17(May), 241-250.

Husted, K., \& Michailova, S. (2002). Diagnosing and fighting knowledge-sharing hostility. Organisational Dynamics, 31(1), 60-73.

Huysmann, M., \& de Wit, D. (2003). A critical evaluation of knowledge management practices. In M. S. Ackerman, P. Volkmar \& W. Volkmar (Eds.), Sharing expertise: beyond knowledge management (pp. 27-55). Cambridge, Massachusetts: The MIT Press. 
Hylko, J. M. (2005, February 27 - March 3, 2005). Thanks for the memories: a primer on capturing and managing undocumented expert knowledge. Paper presented at the Waste Management Symposium, Tucson, AZ.

Hylko, J. M. (2006). Capturing undocumented knowledge from departing employees. Natural Gas and Electricity, 22(8), 21-26.

IBM Business Consulting Services. (2004). Addressing the challenges of an aging workforce: a human capital perspective for firms operating in Asia Pacific. Somers, NY 10589, USA.

IBM Business Consulting Services. (2005). Addressing the challenges of an aging workforce: a human capital perspective for companies operating in Europe. Somers, NY 10589, USA.

Institute of Policy Studies. (2008). Workforce ageing - an issue for employers. Wellington: Victoria University of Wellington.

Jackson, P., \& Webster, R. (2007). The social reality of business activity: contingent methodology for knowledge elicitation and mapping. International Journal of Knowledge Management, 3(1), 49-65.

Janesick, V. J. (2000). The choreography of qualitative research design. In N. K. Denzin \& Y. S. Lincoln (Eds.), Handbook of qualitative research (pp. 379-398). Thousand Oaks, CA: Sage Publications, Inc.

Jeffery, A. B. (2005). Integrating organisation development and six sigma: six sigma as a process improvement intervention in action research. Organisational Development Journal, 23(4), 20-31.

Joe, C., \& Yoong, P. (2006). Harnessing the expert knowledge of older workers. Journal of Information and Knowledge Management, 5(1), 63-72.

Joyce, A. (2006a, 4 August). Retired and rehired for a second career. The Dominion Post.

Joyce, A. (2006b, 4 August 2006). Retired and rehired for a second career. The Dominion Post,.

Kanfer, R., \& Ackerman, P. L. (2004). Aging, adult development, and work motivation. Academy of Management Review, 29(3), 440-458.

Kaplan, A. M., \& Haenlein, M. (2010). Users of the world, unite! The challenges and opportunities of social media. Business Horizons, 2010(53), 59-68.

Kaptein, M. (2002). Guidelines for the development of an ethics safety net. Journal of Business Ethics, 41(3), 217-234.

Kaye, B., \& Cohen, J. (2008). Safeguarding the intellectual capital of baby boomers. $T+D$, 62(4), 30-33.

Kirkpatrick, D., \& Roth, D. (2005). Why there's no escaping the blog: freewheeling bloggers can boost your product - or destroy it. Fortune, 151(1), 44-48. 
Klein, H. K., \& Myers, M. D. (1999). A set of principles for conducting and evaluating interpretive field studies in information systems. MIS Quarterly, 23(1), 67-88.

Knight, A. J. (1999, June 1999). Age as a factor in judgements of wisdom and creativity. New Zealand Journal of Psychology Retrieved 13 April, 2006, from http://findarticles.com/p/articles/mi_qa3848/is_199906/ai_n8875658/print

Kock, N. F. (2004). The three threats of action research: a discussion of methodological antidotes in the context of an information systems study. Decision Support Systems, 37, 265-286.

Kock, N. F., \& Corner, J. L. (1996). Myths in organisational action research: reflections on a study of computer-supported process redesign groups. from http://tui.mngt.waikato.ac.nz/systems \ned\ned.htm

Kolb, D. G. (2003). Seeking continuity amidst organisational change: a storytelling approach. Journal of Management inquiry, June 2003, 12(2), 180-183.

Kunzmann, U., \& Baltes, P. B. (2003). Wisdom-related knowledge: affective, motivational and interpersonal correlates. Personality and Social Psychology Bulletin, 29(9), 1104-1119.

Kwan, M. M., \& Cheung, P. K. (2006). The knowledge transfer process: from field studies to technology development. Journal of Database Management, 17(1), $16-32$

Labouvie-Vief, G. (1990). Wisdom as integrated thought: historical and developmental perspectives. In R. J. Sternberg (Ed.), Wisdom: Its nature, origins, and development (Vol. 62-83). New York: Cambridge University Press.

LaFrance, M. (1989). The quality of expertise: implications of expert-novice differences for knowledge acquisition. ACM SIGART Bulletin(108), 6-14.

Lahaie, D. (2005). The impact of corporate memory loss: what happens when a senior executive leaves? International Journal of Health Care Quality Assurance, 18(3), 35-47.

Lane, P. J., \& Lubatkin, M. (1998). Relative absorptive capacity and interorganizational learning. Strategic Management Journal, 19(5), 461-478.

Lau, F. (1999). Toward a framework for action research in information systems studies. Information Technology and People, 12(2), 148-175.

Lee, D., Simmons, J., \& Drueen, J. (2005). Knowledge sharing in practice: applied storytelling and knowledge communities at NASA. International Journal of Knowledge and Learning, 1(1/2), 171-180.

Leonard, D. (2005). How to salvage your company's deep smarts. CIO Magazine Retrieved 18 May, 2006, from http://www.cio.com/archive/050105.keynote.html

Leonard, D., \& Sensiper, S. (1998). The role of tacit knowledge in group innovation. California Management Review, 40(3), 112-132. 
Leonard, D., \& Swap, W. (2005). Deep Smarts: How to cultivate and transfer enduring business wisdom. Boston, Massachusetts: Harvard Business School Publishing.

Lesser, E. (2006). The maturing workforce - Managing the crisis before it hits. Retrieved 30 June, 2006, from http://www.learningcircuits.org/2006/January/lesser.htm.

Liebowitz, J. (2004). Bridging the knowledge and skills gap: tapping federal employees. Public Personnel Management, 33(4), 421-447.

Liebowitz, J. (2010). Strategic intelligence, social networking and knowledge retention. Computer, IEEE Computer Society, February(2010), 87-89.

Lindenberger, U., \& Baltes, P. B. (1997). Intellectual functioning in old and very old age: cross-sectional results from the Berlin Aging Study. Psychology and Aging, $12,410-432$.

Lord, R. L., \& Farrington, P. A. (2006). Age-related differences in the motivation of knowledge workers. Engineering Management Journal, 18(3), 20-28.

Lu, L. L., \& Jeng, I. (2006). Knowledge construction in inservice teacher online discourse: impacts of instructor roles and facilitative strategies. Journal of Research on Technology in Education, Winter 2006/2007, 39(2), 183-202.

Mata, R. (2007). Understanding the aging decision maker. Human Development, 2007(50), 359-366.

Maxwell, J. A. (1992). Understanding and validity in qualitative research. Harvard Education Review, 62(3), 279-300.

McAdam, R., Mason, B., \& McCrory, J. (2007). Exploring the dichotomies within the tacit knowledge literature: towards a process of tacit knowing in organizations. Journal of Knowledge Management, 11(2), 43-59.

McAdams, D. P., St Aubin, E. D., \& Logan, R. L. (1993). Generativity among young, mid-life and older adults. Psychology and Aging, 8(2), 221-230.

McKay, J., \& Marshall, P. (2005). Rethinking current conceptualisations of action research. Paper presented at the Proceedings of the 9th Pacific Asia Conference on Information Systems, 2000, Bangkok, Thailand.

McKenna, B., \& Rooney, D. (2005a). Building a knowledge society. Paper presented at the Knowledge Management in Asia Pacific, 28-29 November 2005, Victoria University of Wellington, New Zealand.

McKenna, B., \& Rooney, D. (2005b). Wisdom management: Tensions between theory and practice in practice. Paper presented at the International Conference on Knowledge Management in Asia Pacific.

McKenna, B., Rooney, D., \& Boal, K. B. (2009). Wisdom principles as a metatheoretical basis for evaluating leadership. The Leadership Quarterly, 20(2009), 177-190. 
McPherson, M. (2008). Older workers: employers speak out. Retrieved from http://www.eeotrust.org.nz/research/index.cfm.

Meloche, J. A., Hasan, H., Willis, D., Pfaff, C. C., \& Qi, Y. (2009). Cocreating corporate knowledge with a wiki. International Journal of Knowledge Management, 5(2), 33-50.

Mercer. (2008). Workplace 2012 New Zealand: what does it mean for employers? Wellington.

Merriam, S. B. (1988). Case study research in education: a qualitative approach. San Francisco: Jossey-Bass.

Meyer, J. (2000). Evaluating action research: keynote lecture. Age and ageing - health module, September 2000(29), 8-10.

Miles, M., \& Huberman, A. (1994). Early steps in data analysis. In M. Miles \& A. Huberman (Eds.), Qualitative data analysis: an expanded sourcebook (2nd ed., pp. 50-88). Thousand Oaks, CA: Sage.

Millard, D. E., Tao, F., Doody, K., Woukeu, A., \& Davis, H. C. (2006). The knowledge life cycle for e-learning. Int. J. Cont. Engineering and Lifelong L:earning, $16(1 / 2), 110-121$.

Morrall, A. (2008, 6 October). Older workers vital for economy. Dominion Post, p. C2.

Mumford, E. (2001). Action research: Helping organisations to change. In E. M. Trauth (Ed.), Qualitative research in IS: Issues and Trends (pp. 47-77).

Myers, M. (2002). Overview of qualitative research. Retrieved 20 June, 2006, from http://www.qual.auckland.ac.nz/\#Overview\%20of\%20Qualitative\%20Research. html

New Zealand Treasury. (2002, 16 September ). Population ageing: some economic implications. Paper presented at the NZIRA/Tower Seminar Series, Wellington.

Nonaka, I., \& Konno, N. (1998). The concept of 'Ba': building a foundation for knowledge creation. California Management Review, 40(3), 40-54.

Nonaka, I., \& Toyama, R. (2005). The theory of the knowledge-creating firm: subjectivity, objectivity and synthesis. Industrial and Corporate Change, 14(3), 419-436.

NZ Department of Labour. (2006). Population ageing: where will it take us? From the web site of the New Zealand Department of Labour. Retrieved 11 July, 2006, from www.dol.govt.nz/futureofwork/workforce-ageing.asp

O’Dell, C., \& Grayson, C. J. (1999). Knowledge transfer: discover your value proposition. Strategy \& Leadership, 27(2), 10-15.

Osterloh, M., \& Frey, B. S. (2000). Motivation, knowledge transfer and organisational forms. Organizational Science, 11(5), 538-551. 
Palvia, S. C. J., \& Pancaro, R. (2010). Promises and perils of internet based networking. Journal of Global Information Technology Management, 13(3), 1-9.

Parise, S., Cross, R., \& Davenport, T. H. (2006). Strategies for preventing a knowledgeloss crisis. MIT Sloan Management Review, 47(4), 31-38.

Patton, S. (2006). Beating the boomer brain drain blues. CIO Magazine, 15 January, 2006.

Pederson, S., \& Liu, M. (2003). The transfer of problem-solving skills from a problembased learning environment: the effect of modeling an expert's cognitive processes. Journal of Research on Technology in Education, Winter 2003 35(2), 303-320.

Perakyla, A. (1997). Reliability and validity in research based on tapes and transcripts.

In D. Silverman (Ed.), Qualitative research theory, method and practice.

Thousand Oaks: Sage.

Platt, R. K. (2001). The aging workforce: Angst for organisations, baby boomers. Workspan, 1(1), 26-29.

Polanyi, M. (1967). The tacit dimension. New York: Doubleday Anchor.

Purcell, P. J. (2000). Older workers: employment and retirement trends. Monthly Labour Review, 19-30.

Raman, M., Ryan, T., \& Olfman, L. (2005). Designing knowledge management systems for teaching and learning with wiki technology. Journal of Information Systems Education, 16(3), 311-320.

Ransom, P., Mitchell, J., Kee, N., King-Maxey, M., Brady, M., Wolf, K., et al. (2006). The Pennsylvania Health and Human Services Call Center. Public Manager, 35(2), 9-18.

Rapoport, R. N. (1970). Three dilemmas in action research. Human Relations, 23(6), 499-513.

Rappaport, A. M. (2001). Employer strategies for a changing workforce: phased retirement and other options. Benefits Quarterly, 58-64.

Resnick, T., Ugaz, A., Burford, N., \& Carrigan, E. (2008). E-resources: transforming access services for the digital age. Library Hi Tech, 26(1), 141-156.

Riege, A., \& Zulpo, M. (2007). Knowledge transfer process cycle: Between factory floor and middle management. Australian Journal of Management, Dec 2007, $32(2), 293-314$

Robinson, D. N. (1990). Wisdom through the ages. In R. J. Sternberg (Ed.), Wisdom: Its nature, origins, and development (pp. 13-24). New York: Cambridge University Press.

Robson, W. B. P. (2001). Aging populations and the workforce: Challenges for employers. Winnipeg, Manitoba, Canada: British-North American Committee. 
Rooney, D. (2006). Information architecture for knowledge policy: what knowledge theory suggests. On Lecture, Victoria University of Wellington. Wellington, New Zealand.

Rooney, D. (undated). The Knowledge Economy, Knowledge Policy, Knowledge Management, \& Wisdom Site. Retrieved 19 November 2009, from http://sites.google.com/site/davidrooneyknowledge

Rooney, D., \& McKenna, B. (2007). Wisdom in organizations: whence and whither. Social Epistemology, 21(2), 113-138.

Roth, J. (2003). Enabling knowledge creation: Learning from an R\&D organization. Journal of Knowledge Management, 7(1), 32-48.

Rowley, J., \& Gibbs, P. (2008). From learning organization to practically wise organization. The Learning Organization, 15(5), 356-372.

Rowley, J., \& Slack, F. (2009). Conceptions of wisdom. Journal of Information Science, 35(1), 110-119.

Ruggles, R. (1997). Knowledge tools: using technology to manage knowledge better: Ernst \& Young working paper.

Ruthsatz, J., Detterman, D., Griscom, W. S., \& Cirullo, B. A. (2008). Becoming an expert in the musical domain: it takes more than just practice. Intelligence, 2008(36), 330-338.

Salisbury, D. (2001). No time to snooze: meeting the needs of an aging workforce. WorldatWork Journal, 12-18.

Salisbury, M. (2009). A framework for managing the life cycle of knowledge in organisations. International Journal of Knowledge Management, 5(1), 61-77.

Schaie, K. W. (1996). Adult intellectual development: the Seattle Longitudinal study. New York: Cambridge University Press.

Schetagne, S. (2001). Building bridges across generations in the workplace: a response to aging of the workforce. Retrieved 13 April, 2006, from www.columbiafoundation.ca

Shaffer, S. C., Lackey, S. P., \& Bolling, G. W. (2006). Blogging as a venue for nurse facility development. Nursing Education Perspectives, New York, 27(3), 126129.

Shapinker, M. (2000, April 26). Low unemployment helps the aged. Financial Times

Sharma, A. (1997). Professional as agent: knowledge asymmetry in agency exchange. Academy of Management Review, 22(3), 758-798.

Silverman, D. (2005). Doing qualitative research. London: Sage Publications, Inc.

Slagter, F. (2007). Knowledge management among the older workforce. Journal of Knowledge Management, 11(4), 82-96. 
Smith, J. K., \& Deemer, D. K. (2000). The problem of criteria in the age of relativism. In N. K. Denzin \& Y. S. Lincoln (Eds.), Handbook of Qualitative Analysis (pp. 877-896). Thousand Oaks, CA: Sage Publications, Inc.

Snyder, W. M., Wenger, E., \& Briggs, X. D. (2003). Communities of practice in government: leveraging knowledge and performance. The Public Manager, Winter 2003/2004, 18-21.

Stake, R. E. (2000). Case studies. In N. K. Denzin \& Y. S. Lincoln (Eds.), Handbook of qualitative research (2nd ed., pp. 435-454). Thousand Oaks: Sage Publications, Inc.

Stam, C. D. (2009, 28-29 April). Knowledge and the ageing employee: a research agenda. Paper presented at the Proceedings of the European Conference on Intellectual Capital, INHolland University of Applied Sciences, Haarlem, The Netherlands.

Staudinger, U. M. (1999). Older and wiser? Integrating results on the relationship between age and wisdom-related performance. International Journal of Behavioural Development, 23, 641-664.

Staudinger, U. M., \& Baltes, P. B. (1996). Interactive minds: a facilitative setting for wisdom-related performance. Journal of Personality and Social Psychology, 71, 746-762.

Stenmark, D. (2001). Leveraging tacit organisational knowledge. Journal of Management Information Systems, 17(3), 9-24.

Stephenson, J., \& Scobie, G. M. (2002). The economics of population ageing. Retrieved from http://www.treasury.govt.nz/publications/research-policy/wp/2002/02-05.

Sternberg, R. J. (1998). A balance theory of wisdom. Review of General Psychology, 2, 347-365.

Sternberg, R. J. (2003). WICS: a model of leadership in organisations. Academy of Management Learning and Education, 2(4), 386-401.

Stonehouse, G. H., Pemberton, J. D., \& Barber, C. E. (2001). The role of knowledge facilitators and inhibitors: lessons from airline reservation systems. Long Range Planning, 2001(34), 115-138.

Stoutamire, D. (2006). Documenting institutional knowledge. Public Power MarchApril 2006 Retrieved 25 May 2006, 2006, from www.appanet.org/newsletters.ppmagazinedetail.cfm?pf=1\&ItemNumber=16206 $\&$

Strack, R., Baier, J., \& Fahlander, A. (2008). Managing demographic risk. Harvard Business Review, February (2008), 119-128.

Strauss, A., \& Corbin, J. (1998). Basics of Qualitative Research: techniques and procedures for developing grounded theory. Thousand Oaks: Sage Publications. 
Streb, C. K., Voelpel, S. C., \& Leibold, M. (2008). Managing the aging workforce: status quo and implications for the advancement of theory and practice. European Management Journal, 2008(26), 1-10.

Susman, G. J., \& Evered, R. D. (1978). An assessment of the scientific merits of action research. Administrative Science Quarterly, 23(4), 583-603.

Szulanski, G. (1996). Exploring internal stickiness: impediments to the transfer of best practice within the firm. Strategic Management Journal, 17 Winter Special Issue, $27-43$.

Szulanski, G. (2000). The process of knowledge transfer: a diachronic analysis of stickiness. Organizational Behaviour and Human Decision Processes, 82(1), 927.

Szulanski, G., Cappetta, R., \& Jensen, R. J. (2004). When and how trustworthiness matters: knowledge transfer and the moderating effect of causal ambiguity. Organizational Science, 15(5), 600-613.

Taylor, A. S., \& Dryfoos, J. G. (1998). Creating a safe passage: elder mentors and vulnerable youth. Generations, 22(2), 43-48.

Teece, D. J. (2001). Strategies for managing knowledge assets: the role of firm structure and industrial context. In I. Nonaka \& D. J. Teece (Eds.), Managing Industrial Knowledge: Creation, Transfer and Utilisation (pp. 125-144). London: Sage.

Tempest, S. (2003). Intergenerational learning: a reciprocal knowledge development process that challenges the language of learning. Management Learning, 3(42), 181-200.

The Economist. (2006, 22 April 2006). Survey: the wiki principle. The Economist, p. 10.

The Times. (2010, 6 June). Generation why stop working. Sunday Star Times, p. D12.

Thompson, M. P. A., \& Walsham, G. (2004). Placing knowledge management in context. Journal of Management Studies, 41(5), 725-747.

Thornton, S., \& McCracken, C. (2005). Putting the human touch into knowledge management. VINE: the journal of information systems and knowledge management systems, 2005, 35(3), 149-155.

Tobin, M. J. (2004). Mentoring: seven roles and some specifics. American Journal of Respiratory and Critical Care Medicine, 170(2), 114-117.

Trowbridge, R. H. (2005). The Scientific Approach to Wisdom. Union Institute \& University Cincinnati, Ohio.

Van der Veen, R. (2000). Learning Natural Resource Management. In M. Loevinsohn (Ed.), Deepening the Basis of Rural Resource Management (pp. 15-22). The Hague, Netherlands.

Vernooy, R., \& McDougall, C. (2003). Principles for good practice in participatory research: reflecting on lessons in the field. In E. B. Pound, S. Snapp, C. 
McDougall \& A. Braun (Eds.), Managing Natural Resources for Sustainable Livelihoods: Uniting Science and Participation: Earthscan / IDBC.

Wadsworth, Y. (1998). What is participatory action research? Action Research International, Paper 2, from http://www.scu.edu.au/schools/gcm/ar/ari/pywadsworth98.html

Wah, L. (1999). Making knowledge stick. Management review, 88(5), 24-33.

Walsham, G. (1995). The emergence of interpretivism in IS research. Information Systems Research, 6(4).

Weiss, A. (2005). The power of collective intelligence. Collective Intelligence, 17-23.

Wellner, A. S. (2002). Tapping into a silver mine. HR Magazine, 26-33.

Wiig, K. M. (2001). What future knowledge management users may expect. Journal of Knowledge Management, 3(2), 155-165.

Williams, A. M., Ward, P., Ward, J. D., \& Smeeton, N. J. (2008). Domain specificity, task specificity and expert performance. Research Quarterly for Exercise and Sport, 79(3), 428-433.

Wimpenny, P., \& Gass, J. (2000). Interviewing in phenomenology and grounded theory: is there a difference? Journal of Advanced Nursing, 31(6), 1485-1492.

Yin, R. K. (2003). Case study research: design and methods. Thousand Oaks: Sage.

Zack, M. (1999a). Managing codified knowledge. MIT Sloan Management Review, 40(4), 45-53.

Zack, M. H. (1999). Developing a knowledge strategy. California Management Review, 41(3), 125-145.

Zarraga, C., \& Bonache, J. (2003). Assessing the team environment for knowledge sharing: an empirical analysis. The International Journal of Human Resource Management, 14(7), 1227-1245.

Znidarsic, J., \& Dimovski, V. (2010). Reluctance towards older workers in Slovenia. The International Business \& Economics Research Journal, 9(2), 83-100. 